WSRC-RP--91-1246-Vol . I

DE93 006564

Key Words: PRA

Ground Motion

Earth Sciences

Scismicity

Altenuation

Scismic Risk

Scismic models

Retention: Lifetime

\title{
SEISMIC HAZARD FOR THE SAVANNAH RIVER SITE - A COMPARATIVE EVALUATION OF THE EPRI AND LLNL ASSESSMENTS (U)
}

Author:

H. E. Wingo

Issued: $\quad$ May 20, 1992

Westinghouse Savannah River Company

Savannah River Laboratory

Aiken, SC 29803

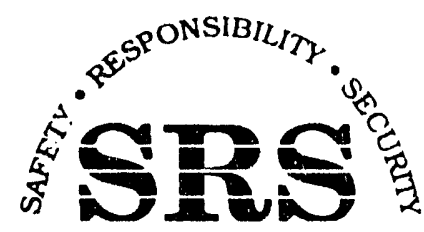

SAVANNAH RIVER SITE

PREPARED FOR THE U.S. DEPARTMENT OF ENERGY UNDER CONTRACT NU. JE-AC09-89SR18035 
Project: $\quad$ PRA

Document: WSRC-RP-91-1246

Title: $\quad$ SEISMIC HAZARD FOR THE SAVANNAH RIVER SITE A COMPARATIVE EVALUATION OF THE EPRI AND LLNL ASSESSMENTS (U)

Approvals:
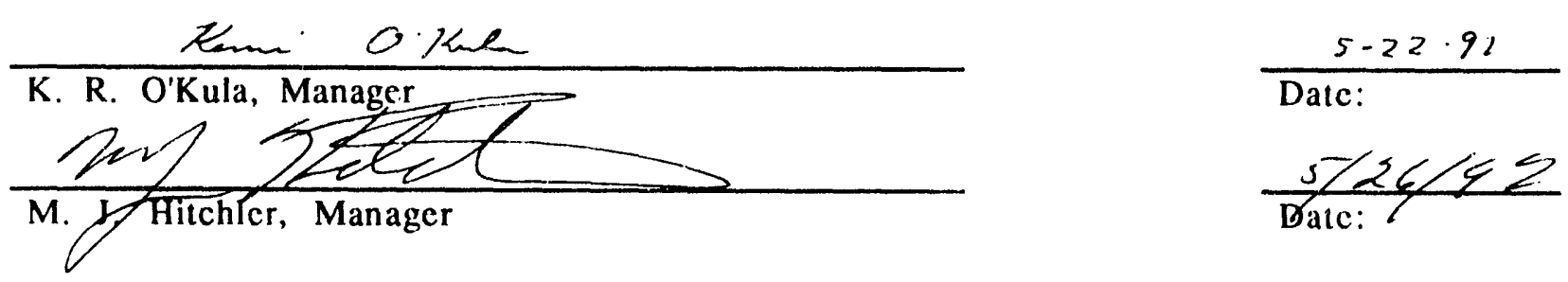


\section{PREFACE}

As part of the seismic probabilistic risk assessments (PRA) being performed for the Savannah River Site (SRS) reactor facilities, input is required on the likelihood that earthquake ground motions may occur. Probabilistic estimates for the SRS seismic hazard were obtained using the results of a Electric Power Research Institute (EPRI) study and a U. S. Nuclear Regulatory Commission (USNRC) sponsored seismic hazard project conducted by Lawrence Livermore National Laboratory (LLNL). In both studies an assessment was made of the likelihood and uncertainty in determining future earthquake ground motions. A comparison of these two sets of hazard results indicated there was a major difference in the estimate of the 0.85 fractile and mean-hazard curves. At the 0.50 fractile or median level, however, the hazard curves are typically within a factor of five or less of each other.

The assessment of seismic risk for the reactors at the SRS used the hazard results produced by the EPRI study because it closely paralleled prior estimates of the site hazard. However, and assessment was performed to consider the impact of the LLNL seismic hazard on the estimated seismic risk. It was determined that using either the EPRI or the LLNL hazard information produced the same conclusions from the perspective of identifying seismic vulnerabilities and assessing the dominant contributors (in a relative sense) to the likelihood of a seismically-induced accident. However, there was a significant difference in the quantification of the coremelt frequency.

This report examines in a uniform manner the EPRI and LLNL seismic hazard estimates for the SRS to identify and understand sources of the differences and to arrive at a composite measure of the likelihood of ground motion at the SRS.

Results of the comparative evaluation indicated that a primary source of the differences between the two studies was the rate of future earthquake occurrences (seismic activity rate) for events of magnitude 5.0 or greater in the vicinity of the SRS. A statistical test was developed to assess whether estimates of the seismic activity rate and ground motion made by the experts in each study were supported by the historic data. The statistical test served as an objective screening tool to evaluate whether the expert predictions of the number of earinguakes that will occur in the future can be 
supported by available iata. Hazard prediciuns: it passed the statistical test were reta $\mathbf{d}$ from both studies in !his manner (note that large uncertainties are still allowed as indicated in the report). No particular group or individual expert was kept or discarded as a unit.

The hazard predictions from the EPRI and LLNL studies that passed the screening evaluation were aggregated to obtain a composite measure of the SRS seismic hazard. This result was generally consistent with previous studies. Consequently it was concluded that the LLNL estimate of the SRS hazard is too high, because of outlier estimates of the seismic activity rate, and that the estimate of the uncertainty in the EPRI study is underestimated.

The composite estimate of the seismic hazard presented in the accompanying document will be used in the seismic PRA for reactors at the SRS. The hazard presented is for a rock site, which is not typical of the $\mathrm{K}$ Reactor. Soils evaluations for the site are currently ongoing and the effect of soils will be incorporated in the hazard when the soils investigation is completed, and is expected to be completed during calendar year 1992. 
Table of Contents

1.0 Introduction ...........................................................

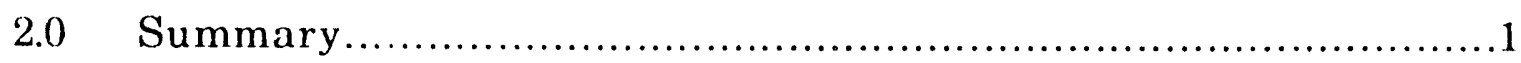

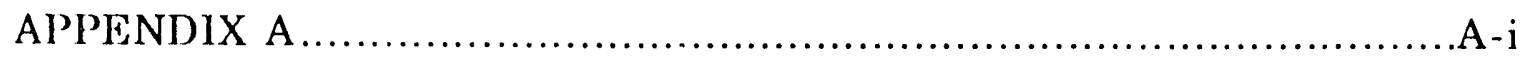




\subsection{INTRODUCTION}

This document records work done by Jack R. Benjamin \& Associates, Inc. under contract \#838585 to develop a seismic hazard relationship for the Savannah River Site to be used in probabilistic risk assessments. Risk assessments previously produced for the P Reactor used a hazard relationship developed for the site using a comprehensive methodology developed by the Electrical Power Research Institute (EPRI). However the Lawrence Livermore National Laboratory (LLNL) has also developed a seismic hazard relationship for the site that predicts a significantly higher hazard, and whose use in seismic probabilistic assessments produces greatly increased estimates of core damage from seismic challenges.

This study was conducted to: 1) develop an understanding of causes for the vast differences between the two comprehensive studies, and 2) using a methodology consistent with the reconciled methods employed in the two studies, develop a single seismic hazard for the Savannah River Site suitable for use in seismic probabilistic risk assessments with emphasis on the $\mathrm{K}$ Reactor.

Results are presented for a rock site which is a-typical because detailed evaluations of soil characteristics at the $\mathrm{K}$ Reactor are still in progress that account for the effects of a soil stablizing grouting program. However when the soils analysis is completed, the effects of soils can be included with this analysis with the addition of a single factor that will decrease slightly the seismic hazard for a rock site.

The analysis is presented in two volumes which are attached as appendixes. Appendix 1 contains the Volume 1 extensive summary, and appendix 2 contains volume 2 (to be added) which is a detailed documentation of the comparative evaluations that were conducted in the development of the SRS seismic hazard.

\subsection{SUMMARY}

The comparative evaluation of the seismic hazard studies identified two major factors that contributed to the differences in the estimate of the probability of exceedance of ground motion at the site. The first factor was the estimate of the seismic activity rate for earthquakes of magnitude 5.0 and greater in the vicinity of the SRS. The mean seismic activity rate values in the two studies differed by approximately a factor of ten and there were a number of extreme estimates of the activity rate in the LLNL study that were inconsistent with the historic record. 
The second contributor to the differences in the SRS seismic hazard was the ground motion models selected by the LLNL ground motion expert 5. These models represent an outlying assessment of attenuation in the Eastern United States that was not assigned any credibility by the other LLNL ground motion experts or the EPRI study. In addition, the technical basis for models selected by this ground motion expert was questionable from the perspective of the data and the numerical procedure used to derive them. Estimates of the probability of exceedance of earthquakes based on the models were not consistent with the historic record at the SRS.

To determine the SRS seismic hazard, the extreme estimates of the seismic activity rate and probability of exceedance of ground motion that were not consistent with the historic record were rejected and the ground motion models selected by LLNL ground motion expert (GME) 5 were not used. The EPRI and the LLNL assessments of seismicity that satisfied the screening evaluation were aggregated with equal weighting applied to each study. Within each study, the same weights were assigned to each earth science team and seismicity expert and to the ground motion models.

A comparison of the resulting mean seismic hazard for SRS (rock) with the EPRI hazard for SRS on generic soils that was previously used for the seismic PRA for $P$ reactor (Savannah River Site PRA of Reactor Operation Level 1-External Events WSRC-RP-89733-Vol I, June, 1990) shows that the SRS hazard (rock) is slightly lower for $\mathrm{g}$ levels up to $0.5 \mathrm{~g}$, and slightly higher for $\mathrm{g}$ levels greater than $0.5 \mathrm{~g}$. Recall that when the $\mathrm{K}$ specific soils are combined with the SRS hazard (rock), the resulting hazard curve will be decreased. 


\title{
SEISMIC HAZARD FOR THE SAVANNAH RIVER SITE
}

\section{A COMPARATIVE EVALUATION OF THE EPRI AND LLNL ASSESSMENTS}

\section{VOLUME 1: SUMMARY}

\author{
Prepared By \\ Martin W. McCann, Jr. \\ Auguste C. Boissonnade \\ Jack R. Benjamin and Associates, Inc. \\ Mountain View, California \\ Prepared for \\ Westinghouse Savannah River Company \\ Aiken, South Carolina
}

March 1992 


\section{EXECUTIVE SUMMARY}

As part of ongoing seismic studies for the reactor facilities at the Savannah River Site (SRS), probabilistic seismic hazard assessments that estimate the probability of occurrence of earthquake ground motion have been performed. The most recent estimates of SRS seismic hazard have been conducted using the results of two comprehensive programs. The first was an effort cond icted by Lawrence Livermore Laboratory (LLNL) as part of the U.S. Nuclear Regulatory Commission (USNRC) funded Seismic Hazard Characterization Project. The second effort, supported by a group of electric utilities in the eastern U.S. (EUS), the Seismicity Owners Group (SOG), was conducted by the Electric Power Research Institute (EPRI). Initial comparison of the two sets of seismic hazard results indicated there were significant differences in the estimated hazard for the SRS.

The difference between the EPRI and LLNL estimates of the seismic hazard at the SRS suggests a wide difference of opinion regarding the probability of exceedance of earthquake ground motions that can be expected at the site. In an effort to provide a stable measure of seismic hazard at the SRS a study was initiated to conduct a detailed exanination of the two sets of results. The purpose of the study was twofold. First, it was felt there must be a clear understanding of the source of the differences between the two studies. Secondly, recognizing the source of the differences, where possible, these should be resolved, and a basis for establishing a single, composite measure of seismic hazard should be developed.

As a starting point for this study, the EPRI and LLNL seismic hazard estimates and supporting input are considered a data resource from which a site-specific measure of the SRS hazard can be derived. Furthermore, no apriori assumption was made as to whether the differences between the two studies represents a 'true' measure of the uncertainty in seismic hazard at the SRS. 
As part of this effort it was considered important to understand the source of the differences in the two studies as a basis to assess whether in fact it represents a true measure of uncertainty or not. If it is a measure of uncertainty, this would be reflected in the final estimate of the SRS seismic hazard. If not, the differences should be resolved where this can be done.

This report is presented in two volumes. Volume 1 provides a summary of the evaluations that were performed and presents the recommended SRS seismic hazard. Volume 2 provides detailed documentation of the comparative evaluations that were conducted and the development of the SRS seismic hazard.

The comparative assessment of the EPRI and LLNL studies demonstrate there is a high level of consistency in terms of methodology, expert inputs and in the seismic hazard estimates for the SRS. As a result, a comparison of the median (50th fractile) hazard curves produced by the two stadies demonstrates an overall level of consistency. However, the hazard estimates begin to diverge in terms of the extreme (more conservative) estimates of seismic hazard. This fact results in large differences in the estimated mean hazard and the $85^{\text {th }}$ fractile levels. In this report, differences in seismic hazard estimates are stated with respect to the mean hazard, unless otherwise noted.

The comparison of the EPRI and LLNL studies indicates there are two, principle sources of the differences. These are the:

- estimated rate of occurrence of earthquakes above magnitude $\left(m_{b}\right)$ 5.0 in the regional vicinity of the SRS, and

- ground motion attenuation models.

Based on the results of the comparative evaluation, two steps were taken to develop the SRS 
seismic hazard. These were,

- examine the EPRI and LLNL ground motion models to identify outlier estimates of ground motion that are not supported by available data, and

- perform a statistical screening assessment to test whether EPRI and LLNL estimates of the seismic-activity rate for events of $m_{\mathrm{b}} \geq 5.0$ and the probability of exceedance of ground motions near the site design basis are supported by available data. Results that are not supportable are rejected from the analysis.

The result of this process, as applied to the EPRI and LLNL studies, are aggregated based on an equal weighting of the two studies to derive the SRS seismic hazard. Figure E-1 shows the final SRS seismic hazard results for peak ground acceleration on rock-site conditions. Figure E-2 shows the SRS uniform-hazard response spectrum (UHS) corresponding to a probability of exceedance of $10^{5}$ per year. The UHS is used as input to the fragility analysis part of the SRS seismic probabilistic risk assessment. Following completion of ongoing geotechnical studies, the effects of soil conditions can be combined with the rock-site hazard curves developed here to determine the final SRS seismic hazard. 


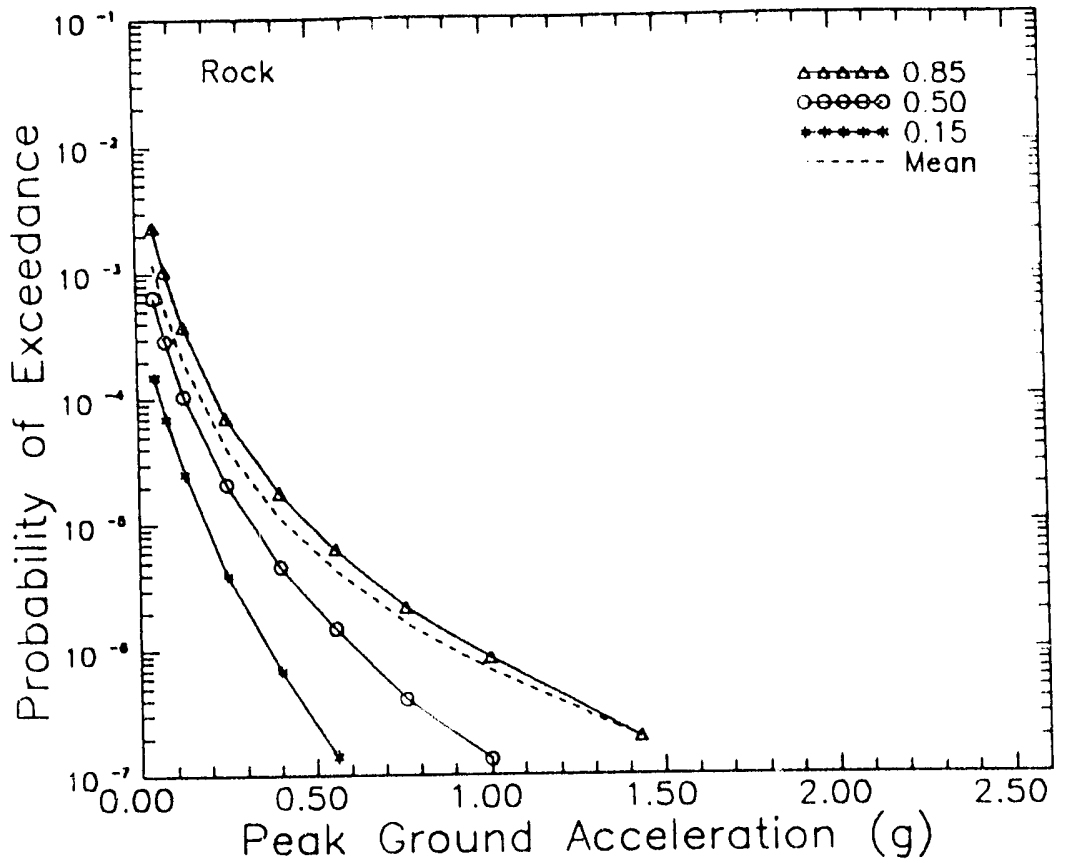

Figure E-1 Final SRS seismic hazard curv for peak ground acceleration and rock-site conditions.

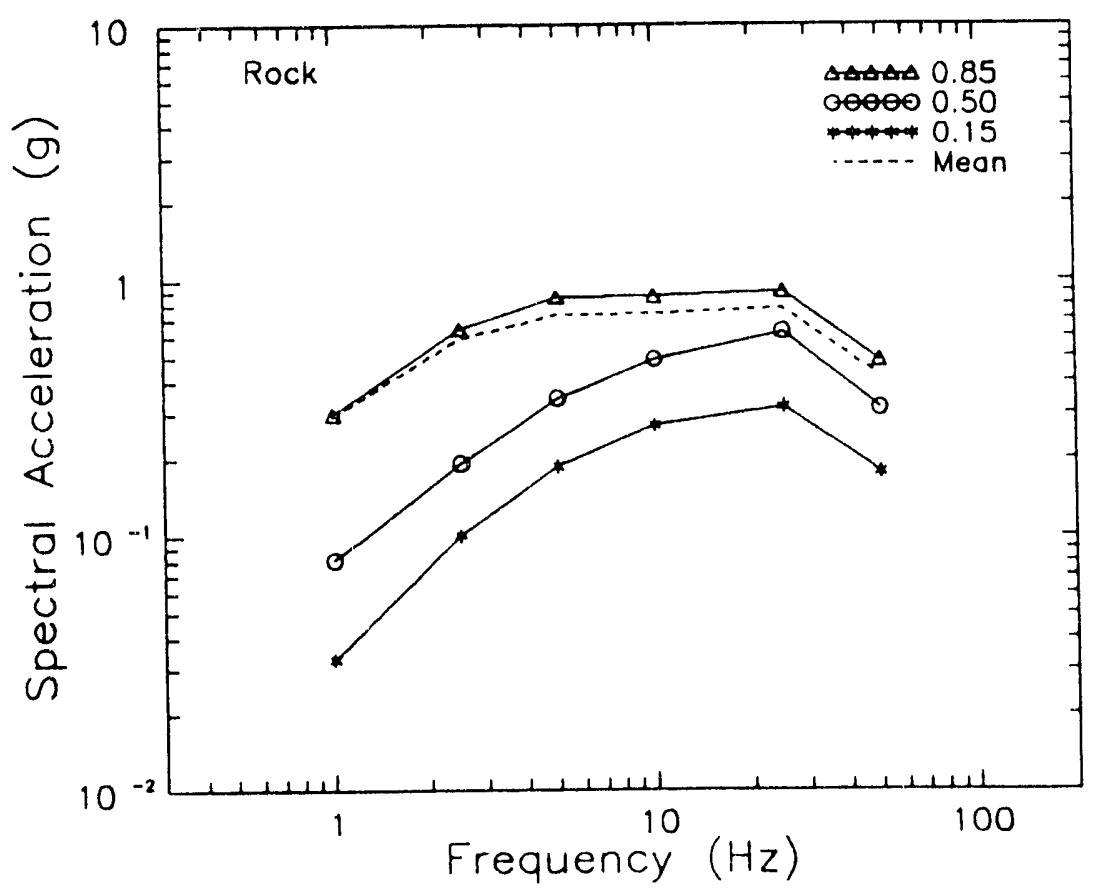

Figure E-2 Final SRS uniform-hazard response spectra for an annual probability of exceedance of $10^{-5}$ for rock-site conditions. 


\section{TABLE OF CON NTS}

EXECUTIVE SUMMARY $\ldots \ldots \ldots \ldots \ldots \ldots$. . . . . . . .

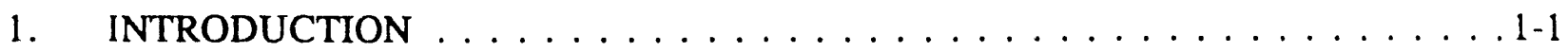

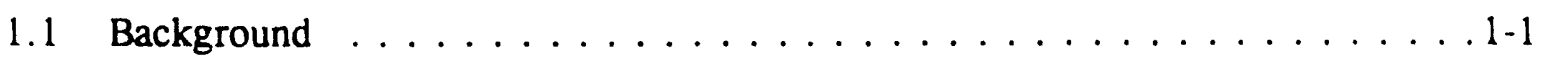

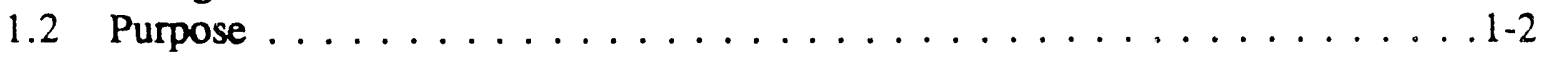

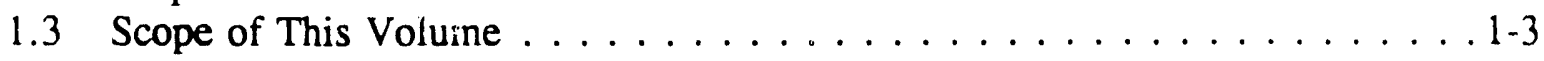

2. SEISMIC HAZARD ANALYSIS OVERVIEW AND COMPARATIVE

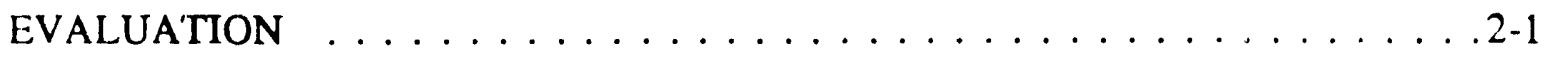

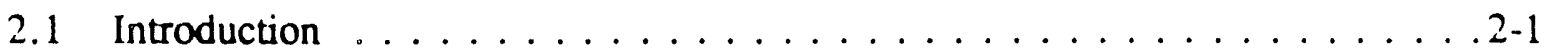

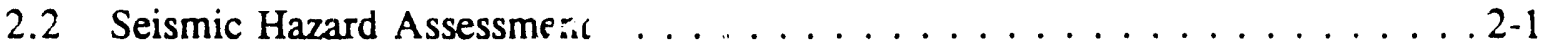

2.3 Uncertainty Assessment . . . . . . . . . . . . . . . 2-3

2.4 Development of the SRS Seismic Hazard . . . . . . . . . . . 2-4

EPRI AND LLNL SEISMIC HAZARD ESTIMATES FOR SRS $\ldots \ldots \ldots \ldots 3-1$

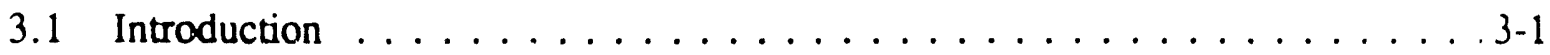

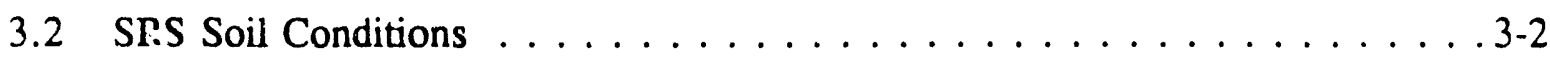

3.3 EPRI and LLNL Seismic Hazard . . . . . . . . . . . . . . . 3-2

3.3.1 LLNL Seismic Hazard Results for SRS - Soil-Site Conditions . . . . 3-3

3.3.2 EPRI Seismic Hazard Results for SRS - Soil-Site Conditions . . . . 3-4

3.3.3 Comparison of the EPRI and LLNL SRS Seismic Hazard Results . . 3-4 Including Soil-Site Conditions

3.4 Base-Case Hazard Results . . . . . . . . . . . . . . . . . . . . . . . . 3-5

3.4.1 LLNL Seismic Hazard Results for SRS - Rock-Site Conditions . . . 3-6

3.4.2 EPRI Seismic Hazard Results for SRS - Rock-Site Conditions . . . 3-7

3.4.3 Comparison of the EPRI and LLNL SRS Seismic Hazard Results . . 3-7 Rock-Site Conditions

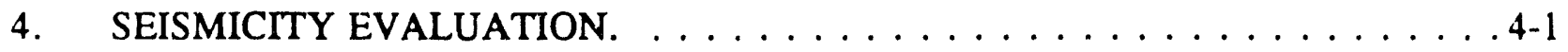

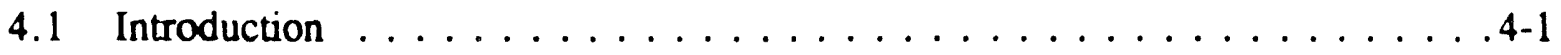

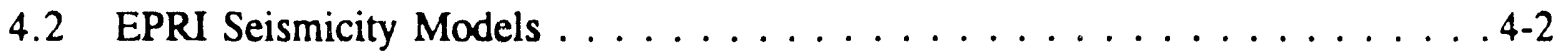

4.2.1 Seismic Source Contribution . . . . . . . . . . . . . 4-2

4.2.2 Seismic-Activity Rate and Magnitude Frequency . . . . . . . 4-3

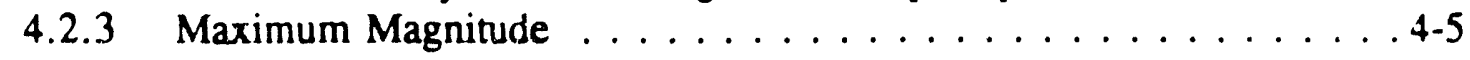




\section{TABLE OF CONTENTS (\%ontinued)}

4.3 LLNL Seismicity Models . . . . . . . . . . . . . . . . . 4-5

4.3.1 Seismic Source Contribution . . . . . . . . . . . . . . . . 4-5

4.3.2 Seismic-Activity Rate and Magnituoc Frequency . . . . . . . . . 4-6

4.3.3 Maximum Magnituce . . . . . . . . . . . . . . . . . . 4-7

4.4 Comparison of EPRI and LLNL Seismicity Models . . . . . . . . . . 4-8

4.4.1 Seismic Sources ... . . . . . . . . . . . . . . . . . 4-8

4.4.2 Comparison of EPRI and LLNL Seismicity Models . . . . . . . . . . 4-8

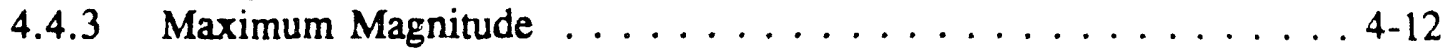

4.5 Summary ......................... . . . . . . . . .

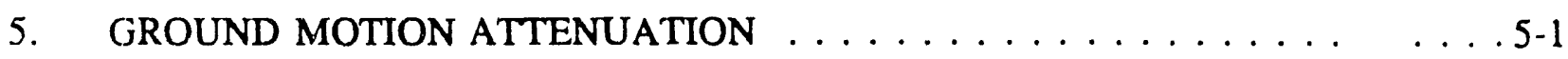

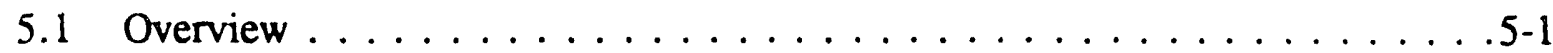

5.2 Ground Motion Modeling in Seismic Hazard Assessments . . . . . . . . . . 5-2

5.3 Modeling Earthquake Ground Motion: EPRI and LLNL . . . . . . . . . . . . 5-5

5.4 EPRI and LLNL Ground Motion Models . . . . . . . . . . . . . . . 5-6

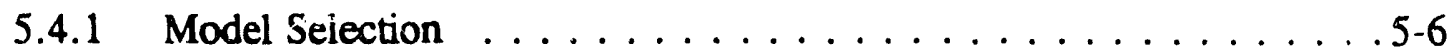

5.4 .2 Comparison With Strong Motion Data . . . . . . . . . . . . 5-8

5.4 .3 Comparative Seismic Hazard Evaluations . . . . . . . . . . . . 5-10

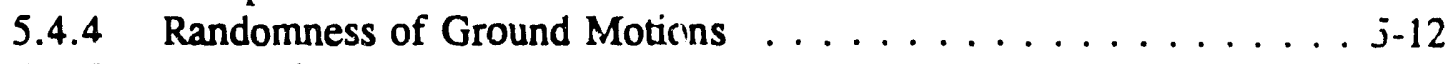

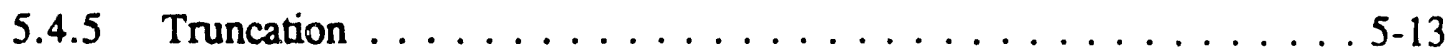

5.5 LLNL Ground Motion Expert 5 Attenuation Models . . . . . . . . . . 5-13

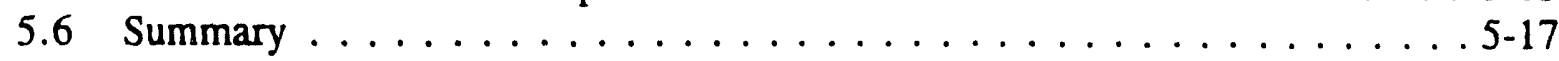

6. SRS SEISMIC HAZARD EVALUATION $\ldots \ldots \ldots \ldots \ldots \ldots \ldots$

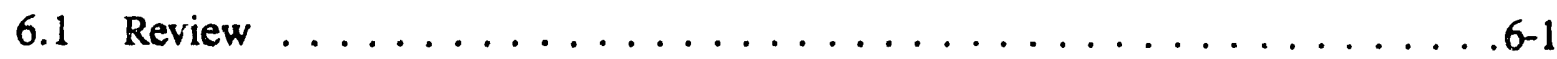

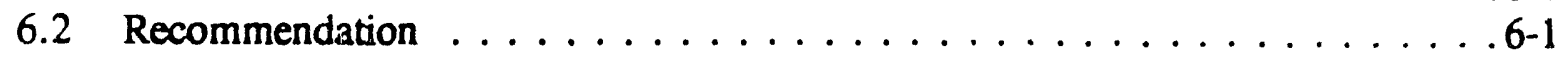

6.3 Screening Analysis - Approach .................. $6-3$

6.4 Seismic-Activity Rate Screen . . . . . . . . . . . . . . . . 6-5

6.5 Evaluation of Historic Seismic Hazard . . . . . . . . . . . . . . . . 6-7

6.6 Final Aggregation $\ldots \ldots \ldots \ldots \ldots \ldots$

7.0 CONCLUSIONS $\ldots \ldots \ldots \ldots \ldots \ldots \ldots \ldots \ldots \ldots \ldots \ldots \ldots \ldots \ldots \ldots$

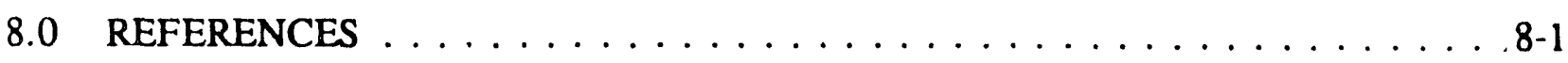




\section{LIST OF TABLES}

Table

Page

3-1 Comparison of EPRI and ILNL (5 GME Case) Seismic Hazard . . . . . . 3-10 Results (Soil-Site Conditions)

3-2 Comparison of EPRI and LLNL (4 GME Case) Seismic Hazard . . . . . . 3-11 Results (Soil-Site Conditions)

3-3 Comparison of EPRI and LLNL (5 GME Case) Seismic Hazard . . . . . 3-12 Results (Rock-Site Conditions)

3-4 Comparison of EPRI and LLNL (4 GME Case) Seismic Hazard . . . . . 3-13 Results (Rock-Site Conditions)

4-1 Contribution (\%) of Seismic Sources for Each EPR: Earth Science . . . . 4-14 Team to the Mean PGA Hazard

4-2 Summary of Earth Science Team Estimate of Seismicity . . . . . . . . 4-15

4.3 Summary of the EPRI Combined EST Results on the Seismic- . . . . . . 4-16 Activity Rate and Earthquake Counts

4-4 EPRI Earth Science Team Maximum Magnitude Estimates for . . . . . . 4-17 the Charleston Seismic Zone

4-5 EPRI Earth Science Team Maximum Magnitude Estimates for . . . . . . 4-18 the SRS Host Seismic Zone

4-6 Contribution (\%) of Seismic Sources for Each LLNL Seismicity _. . . . 4-19 Expert to the Mean PGA Hazard - 5 GME Case

4-7 Contribution (\%) of Seismic Sources for Each LLNL Seismicity _ . . . . 4-22 Expert to the Mean PGA Hazard - 4 GME Case 


\section{LIST OF TABLES}

Table

Page

4-8 Summary of the LLNL Seismicity Expert Estimates of Seismic- . . . . . . 4-24 Activity Rate

4-9 Summary of the LLNL Combined Distribution on the Seismic- . . . . . . 4-25 Activity Rate and the Expected Number of Events

4-10 LLNL Seismicity Expert Maximum Magnitude Estimates for the . . . . . 4-26 Charleston Seismic Zone

4-11 LLNL Seismicity Expert Maximum Magnitude Estimates for the . . . . . 4-27 SRS Host Seismic Zone

4-12 Comparison of EPRI and LLNL Seismic-Activity Rates . . . . . . . . 4-28

4-13 Comparison of EPRI and LLNL Expected Number of Earthquakes . . . . 4-28 in a 200 Year Period

4-14 Comparison of EPRI and LLNL Recurrence Intervals for $m_{b} \geq 5.0 \ldots \ldots$. . 4-29 Events

5-1 EPRI-LLNL Ground Motion Modeling Summary . . . . . . . . . . . 5-19

$5-2 \quad$ EPRI Ground Motion Attenuation Models . . . . . . . . . . . . 5-20

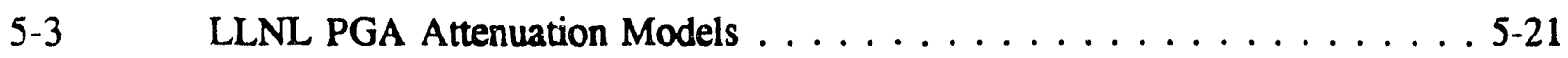

$5-4 \quad$ LLNL PRSV Attenuation Models . . . . . . . . . . . . . 5-22

5-5 Comparison of EPRI and LLNL Ground Motion Models Weights . . . . 5-23

5-6 Results of EPRI and LLNL Seismic Hazard Comparisons . . . . . . . . . 5-24

5-7 LLNL GME Logarithmic Standard Deviation Values . . . . . . . . . 5-25 


\section{LIST OF TABLES (continued)}

Table

$5-8$

Summary of the FGA Seismic Hazard Calculations to Test Sensitivity . . . 5-26 to the Uncertainty in the Logarithmic-Standard Deviation

5-9 Summary of the LLNL Seismic Hazard For PGA of $0.13 \mathrm{~g}$ for the SRS . . . 5-27

6-1 Ground Motion Levels Used in the Screening Assessment . . . . . . . . . . 6-9

$6-2$ 


\section{LIST OF FIGURES}

Figure

Page

2-1 Illustration of the elements of a seismic hazard analysis $\ldots \ldots \ldots$. . . . .

2-2 Logic diagram illustrating the uncertaintits in the seismic hazard . . . . . 2-8 analysis

2-3 Flow Diagram illustrating the scope of the comparative evaluation . . . . 2-9 and development of the SRS seismic hazard

3-1 LLNL PGA seismic hazard curves for the SRS, 5 GME case . . . . . . 3-14

3-2 LLNL PGA seismic hazard curves for the SRS, 4 GME case . . . . . . 3-14

3-3 Comparison of the LLNL 4 GME and 5 GME median and mear. . . . . . 3-15 PGA seismic hazard curves

3-4 LLNL UHS for the SRS for an annual probability of exceedance . . . . . . 3-16 of $10^{5}$ for the $5 \mathrm{GME}$ case

3-5 LLNL UHS for the SRS for an annual probability of exceedance . . . . . 3-16 of $10^{-5}$ for the $4 \mathrm{GME}$ case

3-6 Comparison of the LLNL 4 GME and 5 GME median and mean . . . . . 3-17 UHS for the SRS

3-7 EPRI PGA seismic hazard curves for the SRS . . . . . . . . . 3-18

3-8 EPRI UHS for the SRS for an annual probability of exceedance . . . . . 3-18 of $10^{-5}$

3-9 Comparison of the LLNL 5 GMi case and EPRI median and . . . . . 3-19 mean PGA hazard curves for the SRS

3-10 Comparison of the LLNL 4 GME case and EPRI median and . . . . . 3-19 mean hazard curves for the SRS 


\section{LIST OF FIGURES (continued)}

Figure

Page

3-11 Comparison of the EPRI and LLNL 5 GME median and mean UHS for . . 3-20 the SRS

3-12 Comparison of the EPRI and LLNL 4 GME median and mean UHS for . . 3-20 the SRS

3-13 LLNL PGA seismic hazard curves for rock-site conditions for the SRS, . . 3-21 5 GME case

3-14 LLNL PGA seismic hazard curves for rock-site conditions for the SRS, . . 3-21 4 GME case

3-15 Comparison of the LLNL 4 GME and 5 GME median and mean PGA . . 3-22 seismic hazard curves for rock-site conditions

3-16 LLNL UHS for the SRS for an annual probability of exceedance of $10^{-5} \ldots 3-23$ for the $5 \mathrm{GME}$ case and rock-site conditions

3-17 LLNL UHS for the SRS for an annual proababiklity of exceedance of $10^{-5}$. $3-23$ for the $4 \mathrm{GME}$ case and rock-site conditions

3-18 Comparison of the LLNL 4 GME and 5 GME median and mean UHS for . 3-24 the SRS for rock-site conditions

3-19 EFRI PGA seismic hazard curves for rock-site conditions at the SRS . . . 3-25

3-20 EPRI UHS for the SRS for an annual probability of exceedance of $10^{5} \ldots 3-25$ on rock-site conditions

3-21 Comparison of the LLNL 5 GME case and EPRI meidan and mean PGA . 3-26 hazard curves for rock-site conditions at the SRS

3-22 Comparison of the LLNL 4 GME case and EPRI meidan and mean PGA . 3-26 hazard curves for rock-site conditions at the SRS 


\section{LIST OF FIGURES (continued)}

Figure

3-23 Comparison of the EPRI and LLNL 5 GME median and mean UHS for . . 3-27 the SRS on rock-site conditions

3-24 Comparison of the EPRI and LLNL 4 GME median and mean UHS for . . 3-27 the SRS on rock-site conditions

4-1 Zone around the SRS used to quantify the seismicity expert . . . . . . 4-30 estimates of seismic-activity rate in the regional vicinity of the site

4-2 Cumulative probability distribution function on the seismic-activity $\ldots \ldots$ 4-31 rate $\left(\mathrm{n}_{\mathrm{b}} \geq 5.0\right)$ estimated by the EPRI Earth Science Teains

4-3 Cumulative distribution function on the seismic-activity rate $\ldots \ldots \ldots$ 4-31 $\left(m_{b} \geq 5.0\right)$ for all the EPRI Earth Science Teams

4-4 EPRI frequency of exceedance of earthquakes in the region near . . . . . 4-32 the SRS

4-5 Cumulative probability distribution function on the seismic-activity . . . 4-33 rate $\left(m_{b} \geq 5.0\right)$ for the $L L N L$ seismicity experts

4-6 Cumulative probability distribution function on the seismic-activity rate . . . 4-34 $\left(m_{b} \geq 5.0\right)$ for the LLNL seismicity experts combined for the region near the SRS

4-7 LLNL magnitude frequency distribution for all seismicity experts . . . . . 4-34 for the region near the SRS

4-8 Comparison of the EPRI and LLNL cumulat' 'e probability distribution . . 4-35 functions on the seismic-activity rate for the region near the SRS

4-9 Comparison of the EPRI and LLNL median and mean magnitude frequency curves for the region near the SRS

5-1 Illustration of the elements of the ground motion attenuation model $\ldots . .5-28$ 


\section{LIST OF FIGURES (continued)}

Figure

Page

5-2 Illustration of methods for truncating ground motion . . . . . . . . . . 5-29

5-3 EPRI PGA attenuation relationships for (a) $m_{b}=5.0$, and (b) $\ldots \ldots$. . . . $m_{b}=7.0$

5-4 EPRI ground response spectra for (a) $m_{b}=5.0$ and a distance of $20 \mathrm{~km}, \quad . \quad 5-31$ and (b) $\mathrm{m}_{\mathrm{b}}=7.0$ and a distance of $50 \mathrm{~km}$

5-5 LLNL PGA attenuation relationships for (a) $m_{b}=5.0$, and (b) $\ldots \ldots$ 5-32 $\mathrm{m}_{\mathrm{b}}=7.0$

5-6 EPRI ground response spectra for (a) $m_{b}=5.0$ and a distance of $20 \mathrm{~km}, \quad$. 5-34 and (b) $m_{b}=7.0$ and a distance of $50 \mathrm{~km}$

5-7 Plot of the mean, model-to-data ratio comparing the EPRI ground . . . . 5-36 motion models to EUS strong-motion data recorded at distances

less than $100 \mathrm{~km}$ (a) without and (b) with, Saguenay data

5-8 Plot of the mean, model-to-data ratio comparing the LLNL ground . . . . 5-37 motion models to EUS strong-motion data recorded at distances less than $100 \mathrm{~km}(\mathrm{a})$ without and (b) with, Saguenay data

6-1 Diagram illustrating the procedure to develop SRS seismic hazard . . . . 6-11

6-2 Non-parametric cumulative distribution function on the seismic-activity . . 6-12 rate for the SRS region derived from the historic record

6-3 Comparison of the cumulative distribution function on the historic . . . 6-13 seismic-activity rate and the (a) EPRI and (b) LLNL results

6-4 Comparison of the LLNL original and revised (after screening) . . . . . 6-14 distribution function on the seismic-activity rate

6-5 LLNL revised magnitude-frequency distribution $\ldots \ldots \ldots \ldots$. . . . . . . 


\section{LIST OF FIGURES (continued)}

Figure

Page

6-6 Comparison of the LLNL original and revised median and mean magnitude- 6-16 frequency curves

6-7 Historic cumulative distribution function on the probability of $\ldots \ldots$. . . $\ldots$ 6 exceedance for the Nuttli attenuation model (LLNL model SE1) for $\mathrm{PGA}=0.13 \mathrm{~g}$ for the SRS

6-8 Resulting LLNL $0.15,0.50$ and 0.85 fractile and mean seismic hazard . . 6-18 curves for PGA following the screening evaluation on the seismicactivity rate and probability of exceedance of $0.13 \mathrm{~g}$ PGA (rocksite condition)

6-9 Comparison of the revised LLNL and original 4 and 5 GME case median . 6-19 and mean hazard curves for PGA (rock-site conditions)

6-10 Comparison of the EPRI and the revised LLNL median and mean seismic . 6-20 hazard curves for PGA (rock-site conditions)

6-11 SRS PGA seismic hazard curves rock-site conditions $\ldots \ldots \ldots$. . . . .

6-12 SRS $10^{-5}$ uniform hazard response spectra rock-site conditions $\ldots \ldots$. . . 6-22 


\section{Section 1}

\section{INTRODUCTION}

\section{$1.1 \quad$ Background}

As part of the seismic probabilistic risk assessment (PRA) being performed for the Savannah River Site (SRS) reactors, a probabilistic estimate of the site seismic hazard is required. To assess the seismic hazard the E.I. duPont de Nemours Company (the previous site operator) contracted with Jack R. Benjamin and Associates, Inc. to calculate the hazard based on the Electric Power Research Institute (EPRI)/Seismicity Owners Group (SOG) methodology and data $(1)^{1}$. In addition, duPont contracted with Lawrence Livermore National Laboratory (LLNL) to calculate the SRS seismic hazard based on the methodology and data developed as part of the U.S. Nuclear Regulatory Commission (USNRC) Seismic Hazard Characieñization Project (SHCP) (2). The seismic hazard estimated for the SRS from these studies provide a very different measure of the likelihood of ground motions of engineering interest. Therefore, application of these results in the seismic PRA can produce substantially different results.

The differences in the EPRI and LLNL seismic hazard assessments has important implications in terms of a measure of the seismic risk that would be derived for SRS reactors. While there are a number of differences between the two studies, there are at the same time many similarities. Consequently, it was not apparent and thus not assumed, that the observed variance is a measure of uncertainty in the assessment of seismic hazard.

In an effort to provide a stable measure of seismic hazard and thus seismic risk at the

'Numbers in parenthesis correspond to the references listed in Section 8. 
SRS, the approach was taken that a single estimate of the hazard at the site should be determined. To do this, the EPR' and LLNL hazard results and supporting data were used as the basic input from which a single measure of the SRS hazard was derived. This volume presents the principle results of a comparative evaluation of the EPRI and LLNL seismic hazard studies and development of the SRS seismic hazard.

\subsection{Purpose}

The SRS seismic hazard estimates produced by the EPRI and LLNL studies provide very different assessments of the frequency of earthquake occurrences in the regional vicinity of the site and the probability of exceedance of strong ground motion at or beyond the site seismic design basis. Given the complexity of the hazard assessinent process and the uncertainty associated with each study, the precise reason for the difference in the two hazard estimates is not clear. Furthermore, it is not apparent that the two studies have approached the problem of assessing seismic hazard with the same objectives.

It is the principle purpose of this study to develop a single measure of the seismic hazard at the SRS from the data produced in the EPRI and LLNL studies. As a starting point to satisfy this overall objective, it is important that an understanding of the source of the differences between the two studies be developed. Once the source of the differences are known, an assessment can be made as to whether they can be resolved or whether they in fact provide a composite or total measure of the uncertainty. To satisfy the study objective, the basic steps in the assessment are:

- understand the source of the differences between the EPRI and LLNL studies,

- where it is possible, resolve the source of any differences, and

- aggregate the two studies to determine a single measure of seismic hazard at the SRS. 
Section 2 of this volume provides a sumınary of the scope of the study and the steps that were taken to develop the SRS hazard.

\subsection{Scope of This Volume}

The results of this study are presented in two volumes. This document, Volume 1 , provides a summary of the EPRI and LLNL seismic hazard curves for the SRS, presents the results of the comparative evaluation of the two studies and the procedure that was used to develop the SRS seismic hazard. Volume 2 provides detailed documentation of the study and the results of supporting analyses. 


\section{Section 2}

\section{SEISMIC HAZARD ANALYSIS OVERVIEW AND COMPARATIVE EVALUATION}

\section{$2.1 \quad$ Introduction}

In this section a brief overview of the steps in a seismic hazard assessment is presented. This is followed by a description of the scope of the comparative evaluation of the EPRI and LLNL studies and development of the SRS seismic hazard. This overview will identify the primary elements of the hazard assessment methodology and the steps in the analysis. In addition, a general flow chart of the comparative evaluation is provided.

\subsection{Seismic Hazard Assessment}

The purpose of a seismic hazard assessment is to estimate the probability that specified levels of ground motion may be exceeded at a site. A seismic hazard curve is a display of the probability of exceedance. Due to the uncertainty associated with the understanding of tectonic processes, seismicity and ground motion attenuation in the eastern U.S. (EUS), there is uncertainty in estimating the ground motion hazard at a site. This section provides a brief overview of the elements of probabilistic seismic hazard analysis which is intended to serve as a reference on the primary aspects of the analysis and the focus of the comparative evaluation. A more detailed description can be found in the EPRI and LLNL methodology reports $(1,2)$.

Both the EPRI and LLNL seismic hazard studies used the same fundamental methodology to estimate the likelihood of ground motion at a sice. Figurc 2-1 illustrates the elements of the analysis. The assessment consists of the following basic parts: 
Seismic Sources - geographic regions which are spatial models of tectonic features (i.e., faults) capable of generating earthquakes. The seismic source defines the possible location of earthquakes that may occur in proximity to a site.

Seismicity Parameters - model the temporal rate of earthquake occurrences in a seismic source. The seismicit"' parameters include the a- and b-values of the exponential recurrence model and the maximum magnitude for the seismic source.

Ground Motion Attenuation - a ground motion model estimates the level of shaking that may occur at a site as a function of earthquake magnitude and distance. A model consists of a relationship that estimates the median level of motion as a function of magnitude and distance and a logarithmic-standard deviation that models the randomness (inherent variability) of ground motion.

Hazard Quantification - In the final step in the analysis, the seismic hazard due to a single seismic source is estimated by combining the likelihood of earthquake occurrences (spatial and temporai) with a ground motion model to determine the annual probability that specified levels of motion may be exceeded.

The seismic hazard at a site due to a single seismic source is evaluated according to,

$$
u_{i}(a)=v_{i} \iint P(a \mid m, r) f(m)_{i} f(r)_{i} d m d r
$$

where,

$$
\begin{gathered}
v_{i}(a)=\quad \begin{array}{l}
\text { probability of exceedance of ground motion level a due } \\
\text { to earthquakes that may Jccur in seismic source } \mathrm{i}
\end{array} \\
v_{i}=\quad \begin{array}{l}
\text { seismic-activity rate (SAR) for seismic source } \mathrm{i} \text {, quantifies the annual rate } \\
\text { of occurrence of earthquakes anywhere in the source (of any size), above } \\
\text { the lower-bound magnitude (LBM)) }
\end{array} \\
\mathrm{P}(\mathrm{a} ; \mathrm{m}, \mathrm{r})=\quad \begin{array}{l}
\text { probability of ground motion exceeding a, given an earthquake of } \\
\text { magnitude } \mathrm{m} \text { that occurs a distance } \mathrm{r} \text { from the site }
\end{array}
\end{gathered}
$$




$$
\begin{aligned}
& f(m)_{i}=\begin{array}{l}
\text { probability density function for seismic source } i \text { that defines the relative } \\
\text { likelihood that an earthquake will have magnitude } m \pm \frac{\mathrm{m}}{2}
\end{array} \\
& \mathrm{f}(\mathrm{r})_{\mathrm{i}}=\quad \begin{array}{l}
\text { probability density function for seismic source } i \text { that defines the relative } \\
\text { likelihood that an earthquake will occur a distance } \mathrm{r} \pm \frac{\mathrm{dr}}{2} \text { from the site. }
\end{array}
\end{aligned}
$$

In the vicinity of a site, typically there are a number seismic sources that may contribute to the likelihood of ground motion. The total seismic hazard for the site is denoted,

$$
v(\mathrm{a})=\sum v_{i}(\mathrm{a})
$$

where the sum is performed for all seismic sources that are active near a site.

\subsection{Uncertainty Assessment}

Due to the uncertainty in each part of the seismic hazard analysis, there is uncertainty in the estimate of the probability of exceedance of ground motion. Limited knowledge and understanding of the processes that generate seismic events in the EUS leads to uncertainty as to which tectonic features (e.g., faults) are active. As a result a series of alternative models must be considered to describe the uncertainty in the seismicity assessment for a region. The alternative models include alternative seismic source geometries, combinations of seismic sources that may be simultaneously active near a site and seismicity parameter estimates. Collectively, the alternative estimates of these parameters represent the earth scientist's uncertainty in the spatial (as captured by different seismic source geometries and source combinations) and temporal (as quantified in the alternative estimates of the seismicity parameters) rate of earthquake occurrences in the region around a site.

Uncertainty in ground motion is accounted for by selecting alternative ground motion models that are used to estimate the level of motion as a function of earthquake magnitude 
and distance (see eq. 2-1). In both the EPRI and LLNL studies the uncertainty in modeling gro id motion was expressed in terms of alternative attenuation relationships that define the median level of motion as a function of earthquake magnitude and distance. In the LLNL study alternative estimates of the logarithmic-standard deviation on ground motion was also considered (1).

A probability weight is assigned to each ground motion model which is a measure of the degree-of-belief that a model is the "true" predictor of ground motion.

To estimate the various parameters (e.g., seismic sources, seismicity parameters, etc.) in the hazard analysis, both the EPRI and LLNL studies used groups of experts. In each study, a group of seismicity experts provided input on seismic sources and seismicity parameters and a second group of experts provided input on ground motion. Through the use of groups of experts, the range of professional uncertainty is estimated.

A logic diagram, such as shown in Figure 4-2, can be used to display the sources of uncertainty and their aggregation to estimate the uncertainty in the seismic hazard analysis. Across the top of the logic diagram illustrated in Figure 4-2, the parameters that are modeled in the uncertainty analysis are identified. In the logic tree, alternative values for a parameter are displayed as branches. Corresponding to each branch is a probability weight that quantifies the degree-of-belief in the value a parameter may take. Following a path through the logic tree to its terminus corresponds to a mutually exclusive combination of parameters and a single estimate of the seismic hazard at a site. The relative weight assigned to a single estimate of the seismic hazard at a site is taken as the product of the individual parameter value probabilities. The complete set of branches in the logic tree defines a discrete probability density function and quantifies the uncertainty in the assessment of seismic hazard. In the EPRI study, the logic tree format was used to quantify the uncertainty analysis. In the LLNL study a Monte Carlo simulation approach was used. 


\subsection{Development of the SRS Seismic Hazard}

The purpose of this study is to develop a single measure of the seismic hazard at the SRS which is to be derived from the EPRI and LLNL programs. While the two studies used the same methodology to quantify the probability of ground motion at a site, the process that was followed by each program to develop the analysis input and to assess the uncertainty in individual parameters was different. As such, it is not apparent that the two studies paid the same level of attention to the assessment of uncertainty on the part of the experts or in the aggregation of the hazard results for a group of experts. In light of these questions and the large difference between the two sets of hazard results, no assumption was made as to whether these differences represent a true measure of uncertainty in the assessment of seismic hazard or simply are a measure of differences in approach or objectives of the EPRI and LLNL studies.

Therefore as a first step, this study focuses on understanding which factors contribute to the differences in the two SRS seismic hazard assessments. This is considered an important step to understand whether the differences are resolvable or whether they are a true measure of uncertainty. Figure 2-3 shows a flow diagram of the evaluation process that was followed to examine the two studies and to ultimately develop a single, composite measure of the SRS seismic hazard. The steps in the comparative evaluation that are illustrated in Figure 2-3 are summarized below.

1. Develop SRS Rock Hazard Curves - In both the EPRI and LLNL seismic hazard studies, the SRS was modeled as a deep-soil site. To model the effects of soils, both sets of hazard calculations were performed using generic-soil factors. To estimate the final seismic hazard for the SRS, site-specific soil factors, being developed as part of ongoing geotechnical evaluations will be used. Therefore, with respect to the EPRI and LLNL seismic hazard studies the assessment of the seismic hazard for rock-site conditions will be the basis of comparison.

2. Seismic Hazard Diagnostics - Standard seismic hazard analysis computational routines, particularly those used when uncertainty assessments are performed, provide limited 
information on intermediate results or detailed summaries of the parameters that contribute to each seismic hazard estimate (i.e., each branch of the logic tree in Fig. 22). As a result, a clear picture is not available of the contribution of differen: parameters to the hazard levels that are estimated. In this step, computational tools are developed that provide a capability to evaluate the contribution of individual parameters to the hazard and to compare the two studies.

3. Assess Parameter Contributions - Using the computational tools developed in the second step, a detailed set of results are produced that provide insights to the hazard results and the parameters that contribute to the them.

4. Review Ground Motion Models - In this step an evaluation of the ground motion models used in the EPRI and LLNL studies is performed. The models used in the two studies are compared to available data. The purpose of this assessment is to evaluate the degree to which the ground motion models are consistent with strong ground motion data in the EUS.

5. Comparative Evaluation of Seismicity Models - In this task a comparative assessment is performed of the EPRI and LLNL estimates of earthquake occurrence rates in the vicinity of the SRS. This evaluation concentrates on the estimate of the SAR and the frequency of exceedance of moderate- to large-magnitude earthquakes.

6. Develop Hazard Diagnostic/Screening Tools - In this step screening tools are developed to assess the degree to which extreme seismic hazard estimates in the EPRI and LLNL studies are consistent with available data. These tools will be used to resolve, where possible, those areas of difference between the two studies.

7. Aggregation of the EPRI and LLNL Hazard Results - The final assessment of the SRS seismic hazard will be based on an aggregation of the EPRI and LLNL hazard results that are the output from the previous step. 


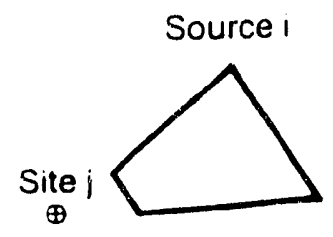

\section{Distribution on distance $f_{D}(d)$ for source 1 , site $j$}

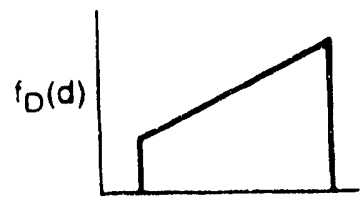

Distance d

Ground motion attenuation $G_{A} l_{\text {m.d }}\left(a^{*}\right)$

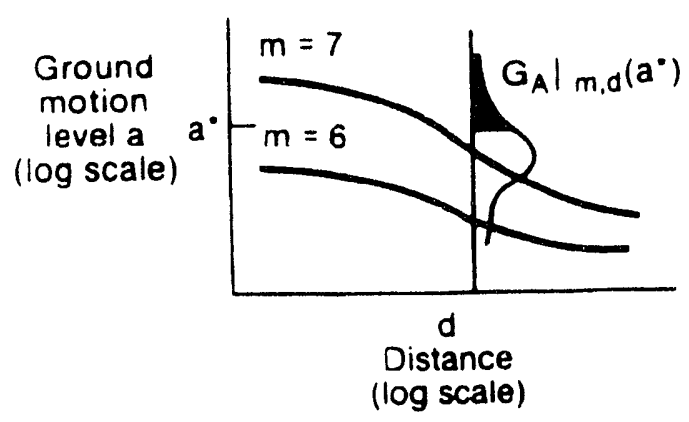

Magnitude distribution, source I $t_{M}(m), \lambda_{1}$

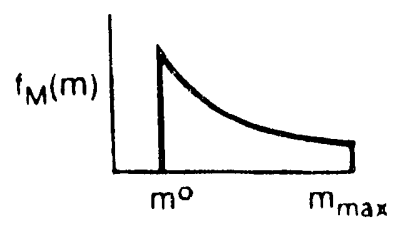

Magnitude $m$

Probability analysis $P\left(A>a^{*}\right.$ in time $t / / t$

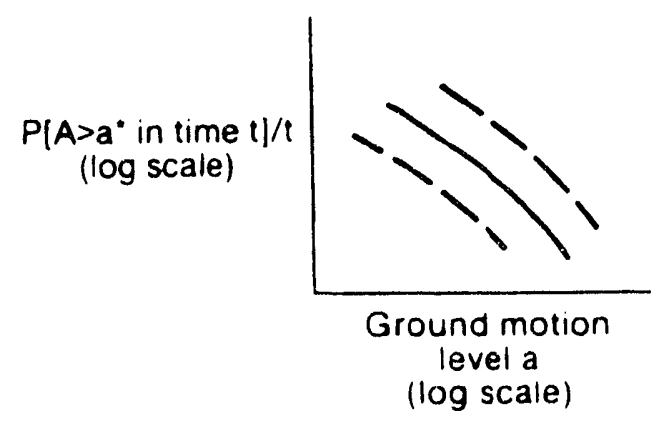

Figure 2-1 Illustration of the elements of a seismic hazard analysis. 


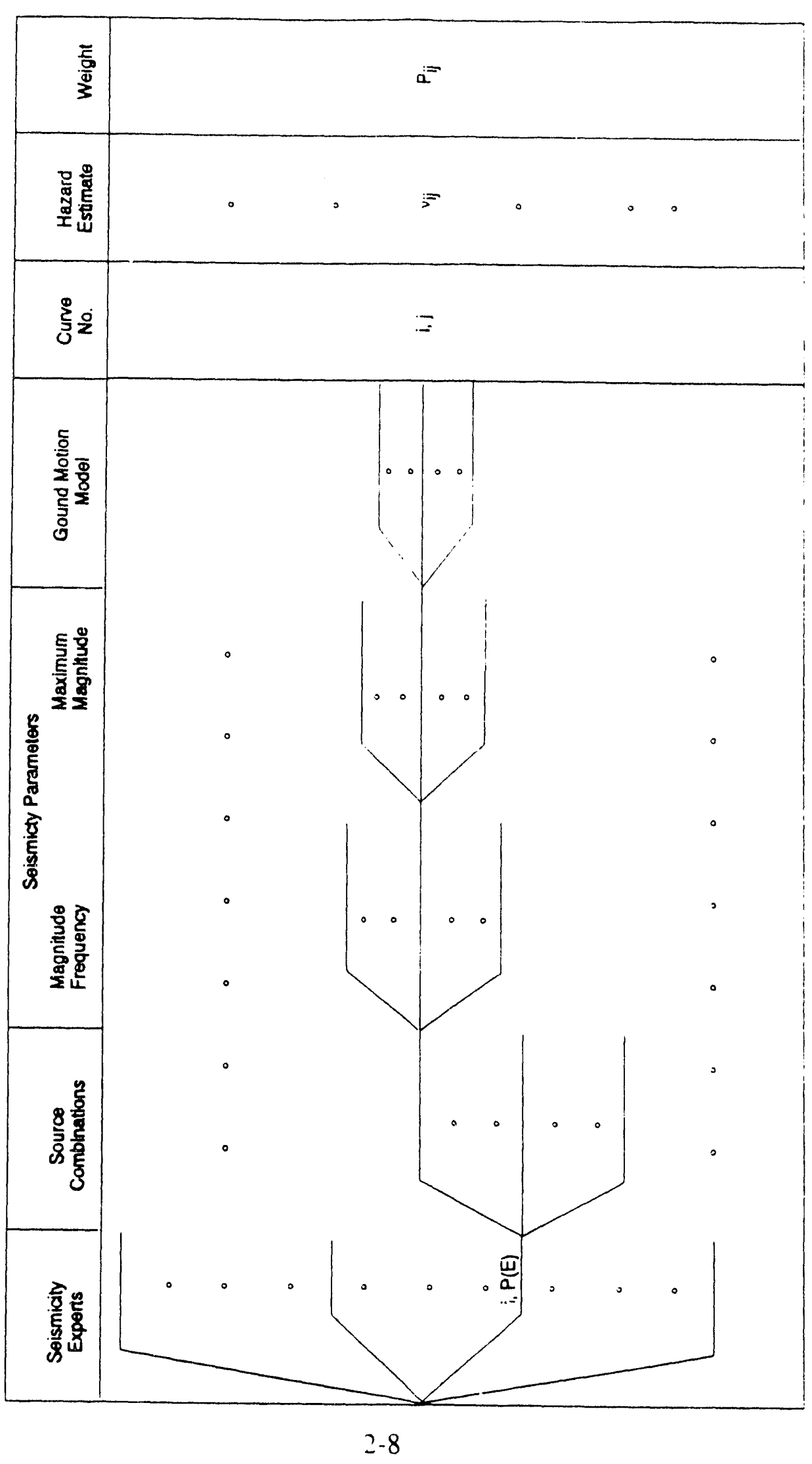

$|53-1140|$

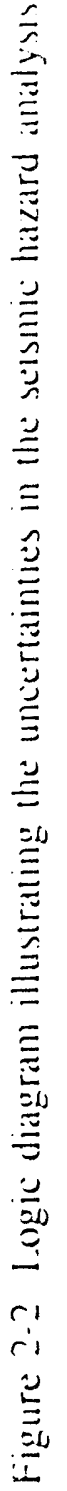




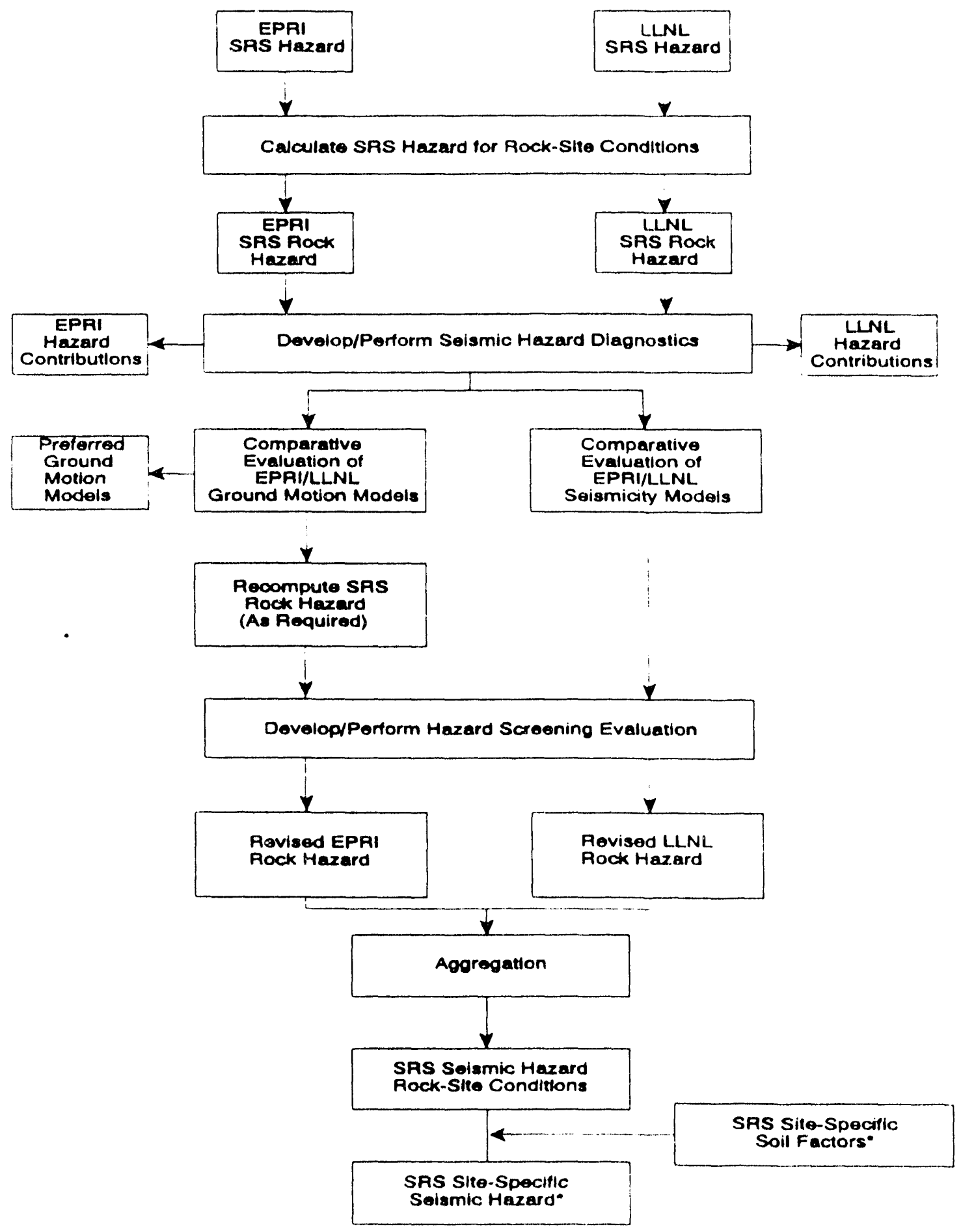

- Not portormed in this study

ligure 2-3 Flow diagram illustrating the scope of the comparative evaluation and development of the SRS seismic hazard. 


\section{Section 3}

\section{EPRI AND LLNL SEISMIC HAZARD ESTIMATES FOR SRS}

\subsection{Introduction}

This section presents the EPRI and LLNL seismic hazard estimates for the SRS and provides an initial summary and comparison of the two studies. The differences in the estimate of the SRS hazard illustrated in this section constitute the starting point for the detailed comparative evaluations that were performed.

The purpose of a seismic hazard analysis is to estimate the annual probability that levels of ground motion may be exceeded at a site. Due to the uncertainty in performing the hazard evaluations, there is a corresponding uncertainty in the estimate of the probability of exceedance of ground motion. Thus, a probability distribution quantifies, at each ground motion level, the uncertainty in the assessment of the probability of exceedance. These results are presented in terms of fractile hazard curves and the mean probability of exceedance.

For purposes of comparing the EPRI and LLNL hazard estimates and in assessing the relative importance of specific parameters to the results, the basis for comparison that is used is the difference or influence a parameter has on the mean seismic hazard. In some cases a comparison of the median hazard level is also used as well. The mean hazard is used as the primary basis for comparison for a number of reasons. First, when the seismic hazard is inpult to the PRA, the mean seismic hazard establishes the estimate of the mean frequency of reactor risk. Secondly, due to the large uncertainty in seismic hazard assessments the mean hazard curve is skewed from the central part of the distribution, toward the upper tail. Consequently, the mean hazard curve incorporates a measure of the uncertainty in the hazard 
analysis.

Comparisons and evaluations are performed primarily by examining the seismic hazard results for peak ground acceleration (PGA). However, the assessment of the SRS seismic hazard includes PGA and spectral acceleration $\left(S_{2}\right)$ at $1.0,2.5,5.0,10.0$ and $25.0 \mathrm{hz}$.

\subsection{SRS Soil Conditions}

In the EPRI and LLNL studies, generic-soil factors were used to convert the seismic hazard estimated for rock-site conditions to the ground motion hazard at the surface of a soil deposit. As part of a geotechnical study being performed at the SRS, site-specific soil response evaluations are being conducted. This study will develop soil factors that can be used to convert seismic hazard estimates derived for rock-site conditions to a site (soil)specific measure of hazard for the SRS. As a result, the final SRS seismic hazard will be site-specific in terms of the effects of soils on estimated surface-ground motions.

Since the soil factors used in the two studies are different, all other factors being equal the assessment of the hazard will differ. In view of the fact that there is no need to use generic-soil factors, a practical starting point for comparison of the EPRI and LLNL studies will be the seismic hazard results for rock-site conditions. A comparison of the hazard results for rock conditions are presented at the conclusion of this section.

\subsection{EPRI and LLINL SRS Seismic Hazard}

This subsection presents the SRS seismic hazard as produced by the EPRI and LLNL studies, which includes the generic assessment of soil effects. This is followed by the results of an initial direct comparison of the two studies. 


\subsubsection{LLNL Seismic Hazard Results for SRS - Soil-Site Conditions}

To estimate the hazard at the SRS using the LLNL methodology, duPont (the SRS operator at the time) contracted with LLNL to perform the calculations. The results are reported in Reference 3. At many sites in the EUS, a single ground motion model selected by one of the LLNL ground motion experts (GME) often contributes substantially to the site hazard. To quantify the impact of this model on the SRS hazard, LLNL produced two sets of hazard results. In the first case the ground motion models provided by all the GMEs were used (5 GME case). The second set of calculations were performed without the input provided by GME 5 (4 GME case).

The seismic hazard is presented in the following format:

- hazard curves for PGA for the $0.15,0.50$ and 0.85 fractiles and the mean $^{1}$, and

- uniform hazard response spectra (UHS) at a specified annual probability of exceedance level for the $0.15,0.50$ and 0.85 fractiles and the mean.

Figures 3-1 and 3-2 show the LLNL PGA seismic hazard curves (including the LLNL soil factors) for the $5 \mathrm{GME}$ and the $4 \mathrm{GME}$ cases, respectively. Figure 3-3 provides a comparison of the median and mean PGA hazard curves for these two cases. A review of the hazard curves indicates the model selected by GME 5, does not contribute substantially to the site hazard. There is little difference in the median at all ground motion levels. The mean-hazard curve for the 5 GME case is generally a factor of 2 (or less) higher than the 4 GME case. This difference is considered small.

${ }^{i}$ The term mean hazard curve as used here corresponds to the LLNL arithmetic mean as described in (2). 
Figure 3-4 shows the LLNL UHS at an annual probability of exceedance of $10^{-5}$ per year for the $5 \mathrm{GME}$ case. The $0.15,0.50$ and 0.85 fractile spectra are shown along with the mean. The UHS have a characteristically broad shape, particularly when considering the mean or 0.85 fractiles. Figure 3-5 shows the LLNL UHS for the $10^{-5}$ annual probability of exceedance for the 4 GME case. Figure 3-6 shows a comparison of the LLNL median and mean UHS for the two cases.

The overall shape of the median and mean UHS are the same in both cases. With respect to the median UHS, the 5 GME case results are approximately 30 percent higher at all frequencies. In terms of the mean UHS, the 5 GME case results are again higher, however the differences vary by frequency. At low frequencies the 5 GME case results are higher by approximately 25 percent or less. Between 2.5 and $10.0 \mathrm{~Hz}$, the 5 GME results are higher by 25 to 50 percent.

\subsubsection{EPRI Seismic Hazard Results for SRS - Soil-Site Conditions}

The EPRI seismic hazard results for PGA are shown in Figure 3-7. Figure 3-8 shows the UHS for the annual probability of exceedance of $10^{-5}$. The results in Figures 3-7 and 3-8 include the EPRI generic-soil factor for deep-soil sites.

\subsubsection{Comparison of the EPRI and LLNL SRS Seismic Hazard Results - Including Soil-Site Conditions}

The EPRI and LLNL estimates of seismic hazard at the SRS produced by these two studies are quite different. Figure 3-9 provides a comparison of the LLNL 5 GME case and the EPRI median and mean PGA hazard curves. A similar comparison is given in Figure 310 for the LLNL 4 GME case. Numerical comparisons for PGA and $S_{1}$ at 1.0, 2.5, 5.0, 10.0 and $25.0 \mathrm{~Hz}$ at selected ground motion levels are provided in Tables 3-1 and 3-2 between the EPRI and the LLNL 5 GME and LLNL 4 GME cases, respectively. Figures 3- 
11 and 3-12 show a comparison of the EPRI and LLNL 5 GME and 4 GME median and mean UHS for the SRS, respectively.

From a PRA applications perspective, differences in the EPRI and LLNL hazard results for PGA levels from $0.25 \mathrm{~g}$ to $0.56 \mathrm{~g}$ are of primary interest. The low end of this range is just above the SRS seismic design basis (PGA $=0.20 \mathrm{~g}$ ), whereas the upper value sets the range of ground motion levels that contribute to seismic risk at the SRS reactors. For spectral acceleration at $5.0 \mathrm{hz}$, which is the parameter used in the SRS seismic risk assessment (4), the range of ground motions of interest is approximately 0.42 to $1.0 \mathrm{~g}$.

The numerical comparisons in Tables 3-1 and 3-2 illustrate the magnitude of the differences between the EPRI and LLNL 5 GME hazard assessments. In general, the median hazard results differ by a factor of 5 or less. In terms of the mean hazard the differences are larger, ranging from about a factor of 17 to over 100. When the EPRI results are compared to the LLNL 4 GME case (see Table 3-2), the median hazard values are in good agreement with a few exceptions. However, differences in the mean-hazard is still large, ranging from a factor 8 to about 79 . (Note, the differences in the two studies is greater at ground motion levels higher than those reported in Tables 3-1 and 3-2.)

\subsection{Base-Case Hazard Results}

Both the EPRI and LLNL hazard studies account for the affect of soils on ground motion through the use of generic-soil factors $(1,2)$. For a given soil category, factors were used that relate the motion at a rock-out crop, to the motion that would occur at the surface of a soil deposit.

As part of the effort to develop a site-specific measure of seismic hazard for the SRS, soil factors will be developed based on an evaluation for the $\mathrm{K}$ Reactor site. Since site- 
specific soil factors will be used to determine the SRS hazard, the hazard results for rock-site conditions, calculated by the authors with the computer code used for reference 2, will serve as the starting point for the subsequent comparative evaluation of the EPRI and LLNL studies presented in this report. The SRS soil factors will then be applied to the final site hazard.

\subsubsection{LLNL Seismic Hazard Results for SRS - Rock-Site Conditions}

Figures 3-13 and 3-14 show the LLNL 5 GME and 4 GME seismic hazard for PGA on rock-site conditions at the SRS, respectively. A comparison of the 5 GME and 4 GME median and mean hazard estimates is given in Figure 3-15. As was the case for the soil-site results (see Fig. 3-3), the median hazard curves are in close agreement. The 5 GME case median hazard is higher by a factor 2 (or less) than the 4 GME median. However, for the rock-site results there is a significant difference in the mean hazard curves. In this case, the 5 GME case mean hazard results are a factor of 10 or more higher than the 4 GME hazard for ground motions greater than $0.50 \mathrm{~g}$. Recall, the mean-hazard curves compared favorably for the soil-site results (see Fig. 3-3). The difference between the rock and soil hazard results is attributed to the following factors,

- for distances greater than about $80 \mathrm{~km}$ the ground motion model selected by LLNL GME 5 is higher than the ground motion estimates made by other models which leads to a higher contribution of the Charleston seismic source to the SRS hazard, and

- GME 5 specified a soil factor of 0.50 which substantially deamplifies the rock motion. This soil factor is significantly different than the soil factors used by the other LLNL experts which predict ground motion amplifications for deep-soil sites. As a result, the rock-outcrop motions estimated by the ground motion model selected by GME 5 are reduced, where as the other experts predict limited amplifications.

This second factor results in hazard estimates produced by the ground motion input for GME 
5, on deep-soil sites, that are not significantly different from other ground motion models (see Fig. 3-3).

Figures 3-16 and 3-17 show the LLNL UHS for rock-site conditions for the SRS and the $5 \mathrm{GME}$ and $4 \mathrm{GME}$ cases, respectively. Figure 3-18 provides a comparison of the 4 GME and 5 GME case results median and mean UHS. As observed in the comparison of the PGA hazard results for rock sites, the 5 GME case mean hazard results are significantly higher than the 4 GME case.

\subsubsection{EPRISeismic Hazard Results for SRS - Rock-Site Conditions}

Figure 3-19 shows the EPRI PGA hazard curve for rock sites. Figure 3-20 shows tis EPRI UHS for an annual probability of exceedance of $10^{-5}$ on rock sites.

\subsubsection{Comparison of the EPRI and LLNL SRS Seismic Hazard Res:-Its - Reck-Site Conditions}

Figures 3-21 and 3-22 compare the EPRI median and mean. PGA hazard with the L.LNL 5 GME and 4 GME results, respectively. Similar com.parisons of the EPRI and LLNL UHS for rock-site conditions are provided in Figures 3-23 and 3-24 for the 5 GME and 4 GME cases, respectively. Tables 3-3 and 3-4 provide a numerical comparison or the LLNL and EPRI median and mean hazard results for rock-site monditions.

For PFA, the EPRI and LLNL 4 GME and 5 GME case median hazard results compare favorably. The largest difference is a factor 2.5 at $0.25 \mathrm{~g}$ for the comparison with the LLNL 5 GME case. With respect to the mean, the LLNL 5 GME results are higher than EPRI by factors of approximately 65 and 144 , at $0.25 \mathrm{~g}$ and $0.56 \mathrm{~g}$, respectively. These differences are approximately a factor of 2 greater than the comparisons made for soil-site conditions (see Table 3-1). The increased variation betwean the two studies is attributed to 
the factors listed in subsection 3.4.1.

In the EPRI comparison with the LLNL 4 GME case, there is about a factor of 10 difference in the two studies. At $0.56 \mathrm{~g}$ this corresponds approximately to a factor of 3.4 decrease in the hazard level. This is attributed to the differences in the EPRI and LLNL soil factors. The EPRI soil factors for PGA predict a deamplification of ground motion beyond $0.20 \mathrm{~g}$, whereas the LLNL soil factor is unity (no deamplification or amplification). As a result, the EPRI hazard results for rock are higher than in the soil case and therefore compare more favorably.

As was the case for PGA, the LLNL 5 GME mean hazard results for $S$, are considerably higher at all frequencies than the EPRI estimates. For the ground motion levels listed in Table 3-3 the differences range from a factor of 50 to over 200 . In addition, these differences are larger by a factor of 2 to about 4 greater than those observed for the soil-site results (see Table 3-1). The LLNL median values in this case are also higher than EPRI. The tifferences vary with frequency and are generally in the range of actor of 3 to 10 .

In comparing the EPRI and LLNL 4 GME hazard results for $S_{\mathbf{a}}$, the median values generally are within 2 of each other. With a few exceptions, the ratio for rock-site results are higher than the corresponding comparison for soil-site conditions (see Table 3-2). In comparing the mean $\mathrm{S}$, hazard curves, the differences are large, ranging from a factor of 7 at $25 \mathrm{~Hz}$ to 118 at $1.0 \mathrm{~Hz}$. In addition, these differences are greater, by about a factor of 2 than the comparisons made for the soil-site results (see Table 3-2), at most frequencies. Since the EPRI soil factors vary as a function of frequency and ground motion level, whereas the LI.NL soil factors are constant with respect to ground motion level, the comparison between rock and soil results is not straight-forward. For example, for $S_{1}$ at $5.0 \mathrm{~Hz}$ and low ground motion levels (less than $0.5 \mathrm{~g}$ ), the EPRI soil factors predict an amplification of 1.3 or greater. However, at larger ground motion levels, a deamplification is predicted. The 
LLNL soil factor predicts a modest (10\%) amplification. As a result, the EPRI and LLNL 4 GME case for rock results for $S_{1}$ of $5.0 \mathrm{~Hz}$ at $1.0 \mathrm{~g}$ are in closer agreement than the soil results by about a factor of 2 . 
Table 3-1

Comparison of EPRI and LLNL (5 GME Case) Seismic Hazard Results (Soil-Site Conditions)

\begin{tabular}{|c|c|c|c|}
\hline \multirow[b]{2}{*}{$\begin{array}{l}\text { Ground Motion } \\
\text { Parameter }\end{array}$} & \multirow[b]{2}{*}{ Level } & Ratio & $\frac{\text { LLNL }}{\text { EPRI }}$ \\
\hline & & Median & Mean \\
\hline PGA (g) & $\begin{array}{l}0.25 \\
0.56\end{array}$ & $\begin{array}{l}3.0 \\
4.5\end{array}$ & $\begin{array}{c}30.15 \\
67.7\end{array}$ \\
\hline $\begin{array}{c}\text { Spectral } \\
\text { Acceleration (g) }\end{array}$ & & & \\
\hline $\begin{array}{c}\text { Frequency }(\mathrm{Hz}) \\
1.0\end{array}$ & $\begin{array}{l}0.19 \\
0.51\end{array}$ & $\begin{array}{l}6.1 \\
5.1\end{array}$ & $\begin{array}{r}51.5 \\
102.2\end{array}$ \\
\hline 2.5 & $\begin{array}{l}0.42 \\
0.74\end{array}$ & $\begin{array}{r}5.0 \\
10.5\end{array}$ & $\begin{array}{l}52.1 \\
106.9\end{array}$ \\
\hline 5.0 & $\begin{array}{l}0.34 \\
1.01\end{array}$ & $\begin{array}{r}2.2 \\
14.5\end{array}$ & $\begin{array}{r}22.7 \\
102.3\end{array}$ \\
\hline 10.0 & $\begin{array}{l}0.29 \\
0.80\end{array}$ & $\begin{array}{l}1.1 \\
3.5\end{array}$ & $\begin{array}{l}16.9 \\
51.8\end{array}$ \\
\hline 25.0 & $\begin{array}{l}0.35 \\
0.67\end{array}$ & $\begin{array}{l}2.6 \\
2.5\end{array}$ & $\begin{array}{l}34.1 \\
36.2\end{array}$ \\
\hline
\end{tabular}


Table 3-2

Comparison of EPRI and LLNL (4 GME Case) Seismic Hazard Results

(Soil-Site Conditions)

\begin{tabular}{|c|c|cc||}
\hline \multirow{2}{*}{$\begin{array}{c}\text { Ground Motion } \\
\text { Parameter }\end{array}$} & & \multicolumn{2}{|c|}{ Ratio $\left(\frac{\text { LLNL }}{\text { EPRI }}\right)$} \\
\cline { 2 - 4 } & Level & Median & Mean \\
\hline PGA (g) & 0.25 & 1.7 & 15.9 \\
& 0.56 & 2.2 & 32.7 \\
Spectral & & & \\
Acceleration (g) & & & \\
Frequency (Hz) & & & \\
1.0 & 0.19 & 2.0 & 40.9 \\
& 0.51 & 1.1 & 56.3 \\
2.5 & 0.42 & 2.0 & 39.2 \\
& 0.74 & 3.8 & 18.8 \\
5.0 & 0.34 & 0.9 & 13.3 \\
& 1.01 & 4.3 & 16.8 \\
10.0 & 0.29 & 0.5 & 16.7 \\
& & 1.2 & 16.2 \\
\hline
\end{tabular}


Table 3-3

Comparison of EPRI and LLNL (5 GME Case) Seismic Hazard Results

(Rock-Site Conditions)

\begin{tabular}{|c|c|c|c|}
\hline \multirow[b]{2}{*}{$\begin{array}{l}\text { Ground Motion } \\
\text { Parameter }\end{array}$} & \multirow[b]{2}{*}{ Level } & Ratio & $\frac{\text { LLNL }}{\text { EPRI }}$ \\
\hline & & Median & Mean \\
\hline PGA (g) & $\begin{array}{l}0.25 \\
0.56\end{array}$ & $\begin{array}{l}2.5 \\
1.8\end{array}$ & $\begin{array}{r}64.7 \\
144.3\end{array}$ \\
\hline $\begin{array}{c}\text { Spectral } \\
\text { Acceleration }(\mathrm{g})\end{array}$ & & & \\
\hline $\begin{array}{c}\text { Frequency }(\mathrm{Hz}) \\
1.0\end{array}$ & $\begin{array}{l}0.19 \\
0.51\end{array}$ & $\begin{array}{l}8.6 \\
4.5\end{array}$ & $\begin{array}{r}141.4 \\
233.0\end{array}$ \\
\hline 2.5 & $\begin{array}{l}0.42 \\
0.74\end{array}$ & $\begin{array}{l}17.2 \\
10.0\end{array}$ & $\begin{array}{l}134.6 \\
198.7\end{array}$ \\
\hline 5.0 & $\begin{array}{l}0.34 \\
1.01\end{array}$ & $\begin{array}{l}8.9 \\
6.8\end{array}$ & $\begin{array}{c}87.6 \\
197.5\end{array}$ \\
\hline 10.0 & $\begin{array}{l}0.29 \\
0.80\end{array}$ & $\begin{array}{l}4.5 \\
3.1\end{array}$ & $\begin{array}{r}59.6 \\
114.5\end{array}$ \\
\hline 25.0 & $\begin{array}{l}0.35 \\
0.67\end{array}$ & $\begin{array}{l}1.9 \\
1.6\end{array}$ & $\begin{array}{l}47.1 \\
56.5\end{array}$ \\
\hline
\end{tabular}


Table 3-4

Comparison of EPRI and LLNL (4 GME Case) Seismic Hazard Results (Rock-Site Conditions)

\begin{tabular}{|c|c|c|c|}
\hline \multirow[b]{2}{*}{$\begin{array}{l}\text { Ground Motion } \\
\text { Parameter }\end{array}$} & \multirow[b]{2}{*}{ Level } & Ratio & $\frac{\text { LLNL }}{\text { EPRI }}$ \\
\hline & & Median & Mean \\
\hline PGA (g) & $\begin{array}{l}0.25 \\
0.56\end{array}$ & $\begin{array}{l}1.3 \\
0.8\end{array}$ & $\begin{array}{r}11.8 \\
9.6\end{array}$ \\
\hline $\begin{array}{c}\text { Spectral } \\
\text { Acceleration (g) }\end{array}$ & & & \\
\hline $\begin{array}{c}\text { Hequency }(\mathrm{Hz}) \\
1.0\end{array}$ & $\begin{array}{l}0.19 \\
0.51\end{array}$ & $\begin{array}{l}2.2 \\
0.7\end{array}$ & $\begin{array}{r}81.2 \\
117.9\end{array}$ \\
\hline 2.5 & $\begin{array}{l}0.42 \\
0.74\end{array}$ & $\begin{array}{l}2.7 \\
1.6\end{array}$ & $\begin{array}{l}48.1 \\
44.1\end{array}$ \\
\hline 5.0 & $\begin{array}{l}0.34 \\
1.01\end{array}$ & $\begin{array}{l}3.6 \\
1.8\end{array}$ & $\begin{array}{l}26.2 \\
19.7\end{array}$ \\
\hline 10.0 & $\begin{array}{l}0.29 \\
0.80\end{array}$ & $\begin{array}{l}2.2 \\
1.4\end{array}$ & $\begin{array}{l}14.7 \\
12.9\end{array}$ \\
\hline 25.0 & $\begin{array}{l}0.35 \\
0.67\end{array}$ & $\begin{array}{l}1.1 \\
0.9\end{array}$ & $\begin{array}{l}6.9 \\
5.7\end{array}$ \\
\hline
\end{tabular}




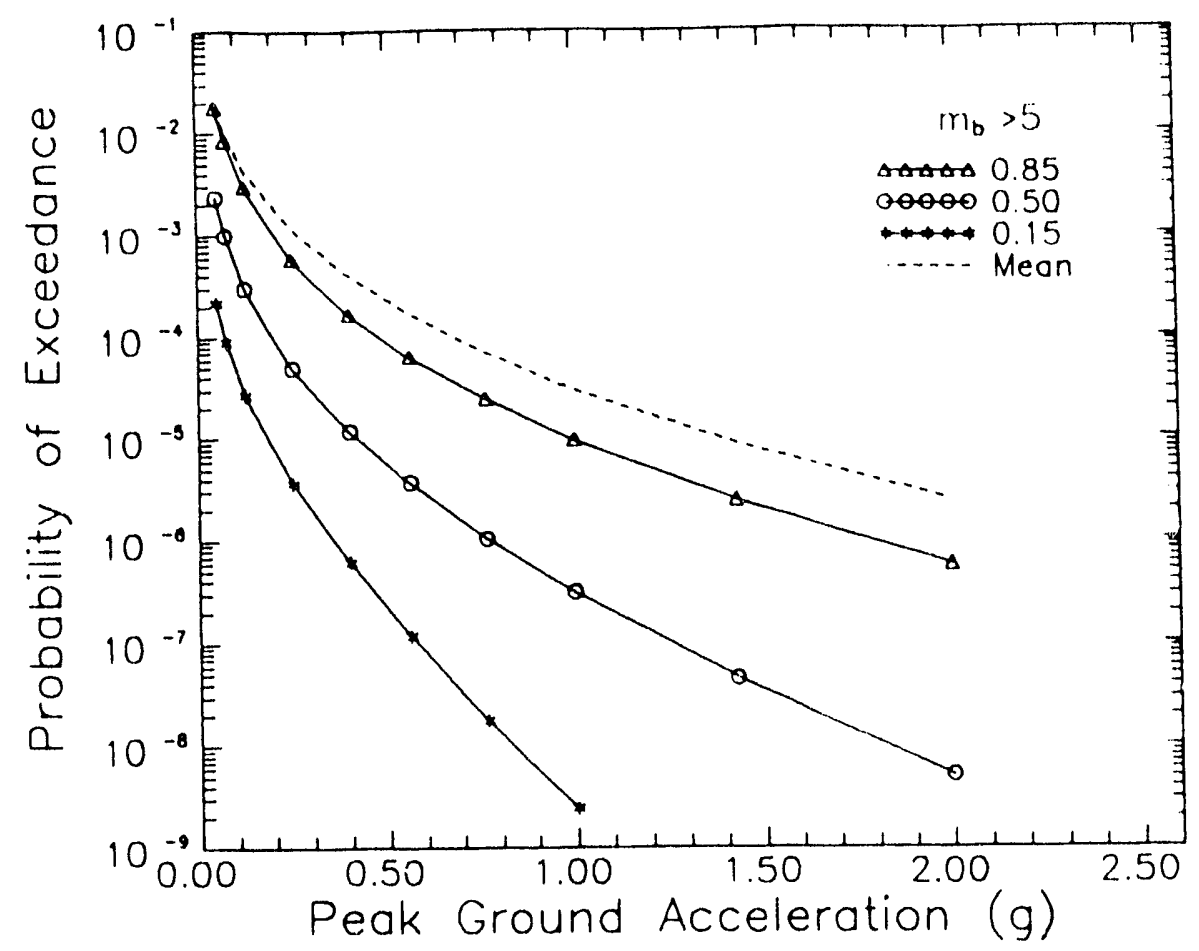

Figure 3-1 LLNL PGA seismic hazard curves for the SRS, 5 GME case.

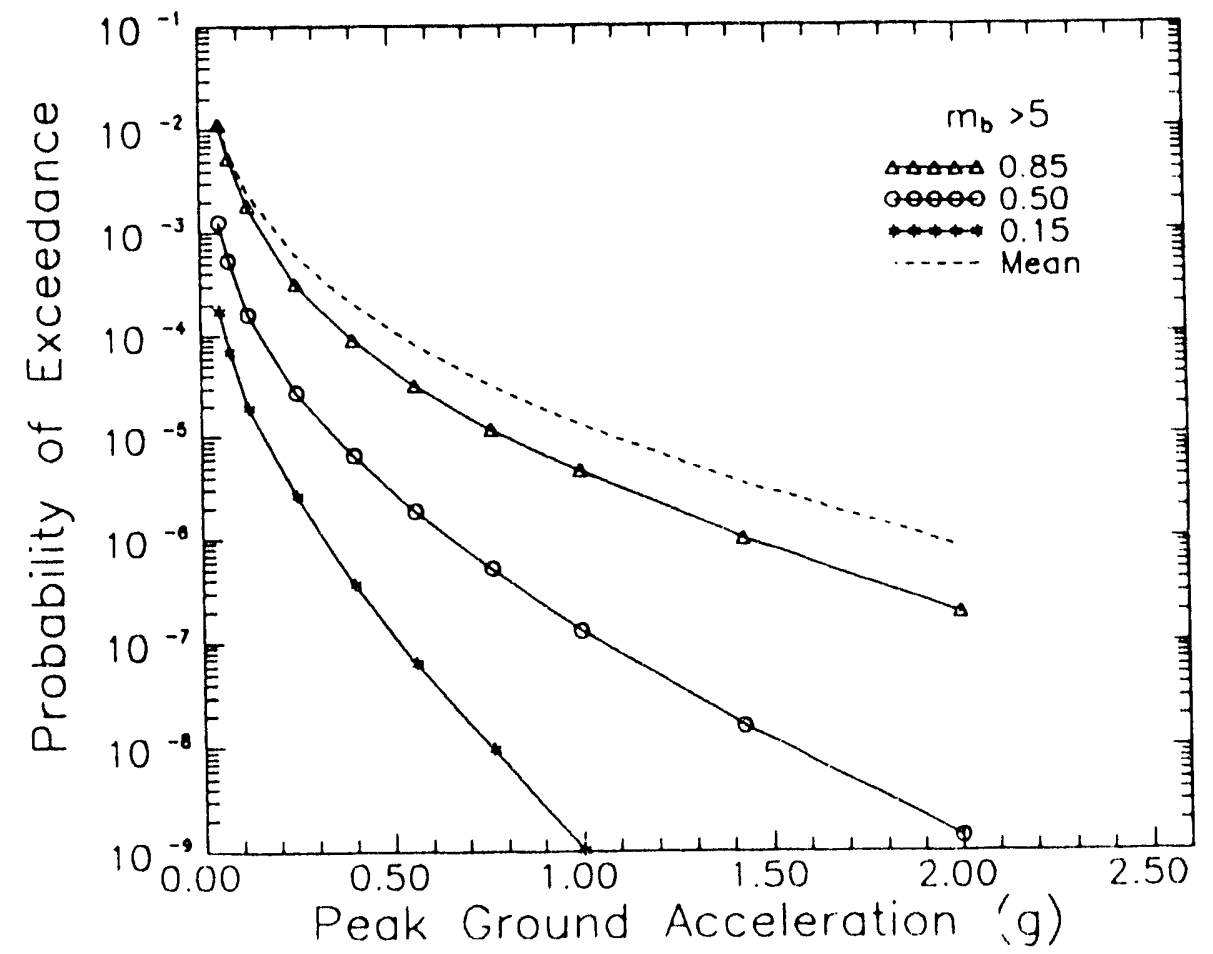

Figure 3-2 LLNL PGA seismic hazard curves for the SRS, 4 GME case. 


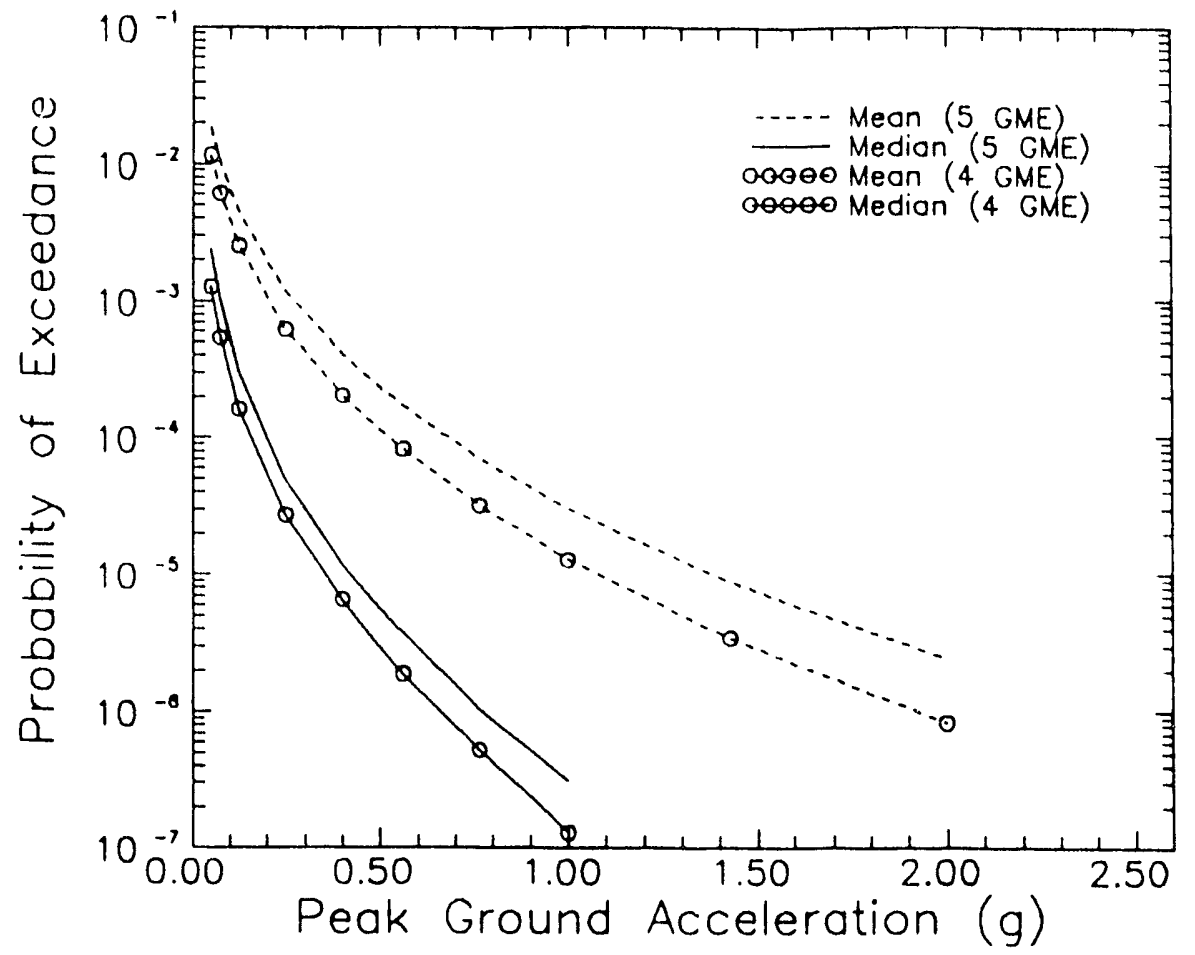

Figure 3-3 Comparison of the LLNL 4 GME and 5 GME median and mean PGA seismic hazard curves. 


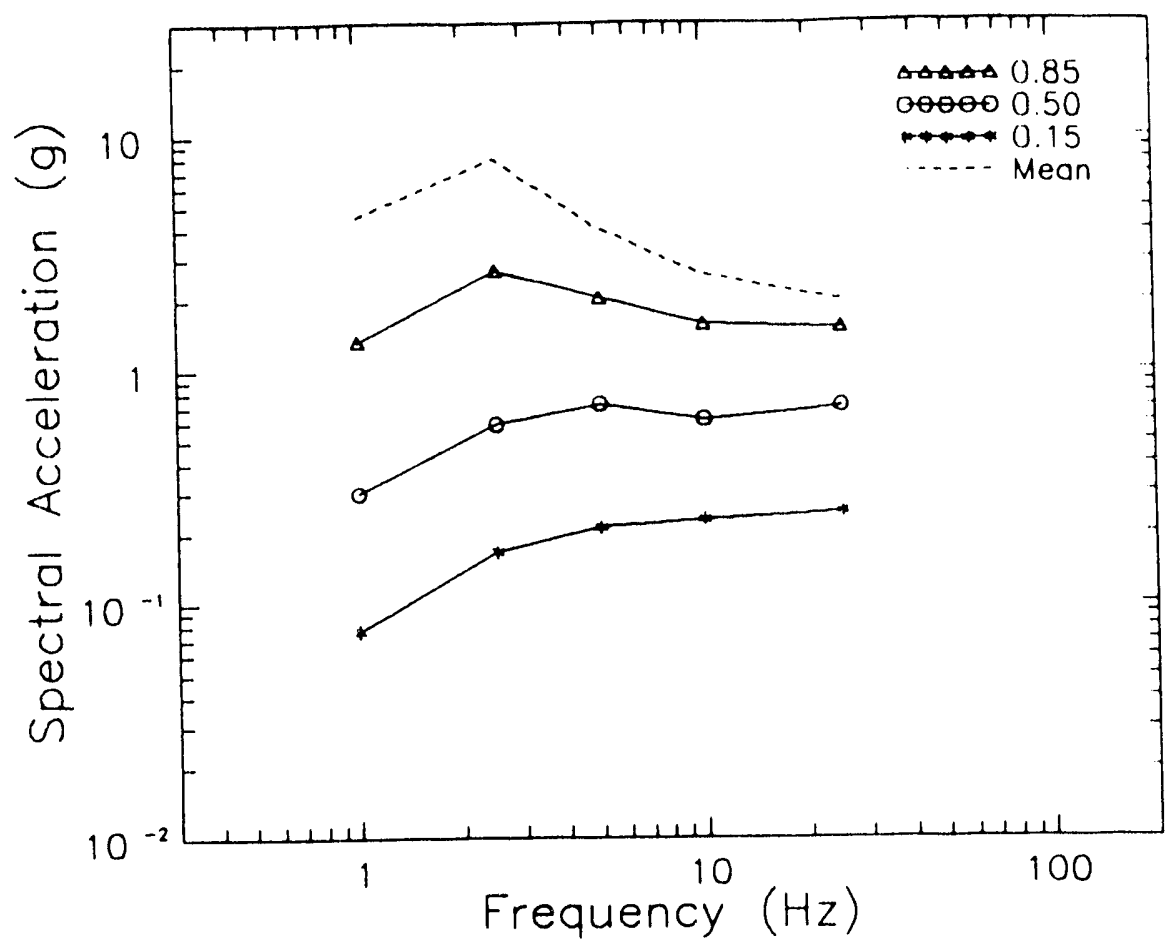

Figure 3-4 LLNL UHS for the SRS for an annual probability of exceedance of $10^{-5}$ for the 5 GME case.

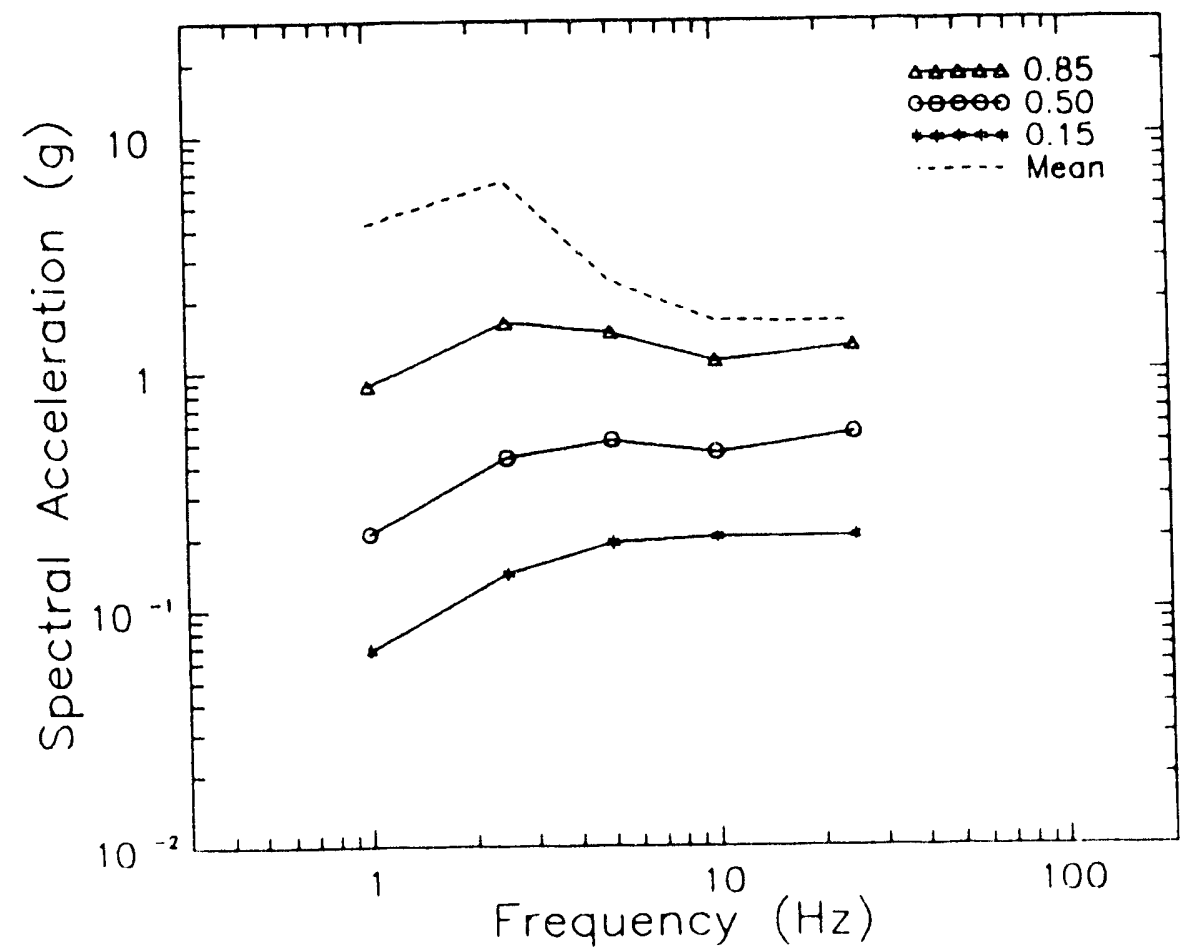

Figure 3-5 LLNL UHS for the SRS for an annual probability of exceedance of $10^{5}$ for the 4 GME case. 


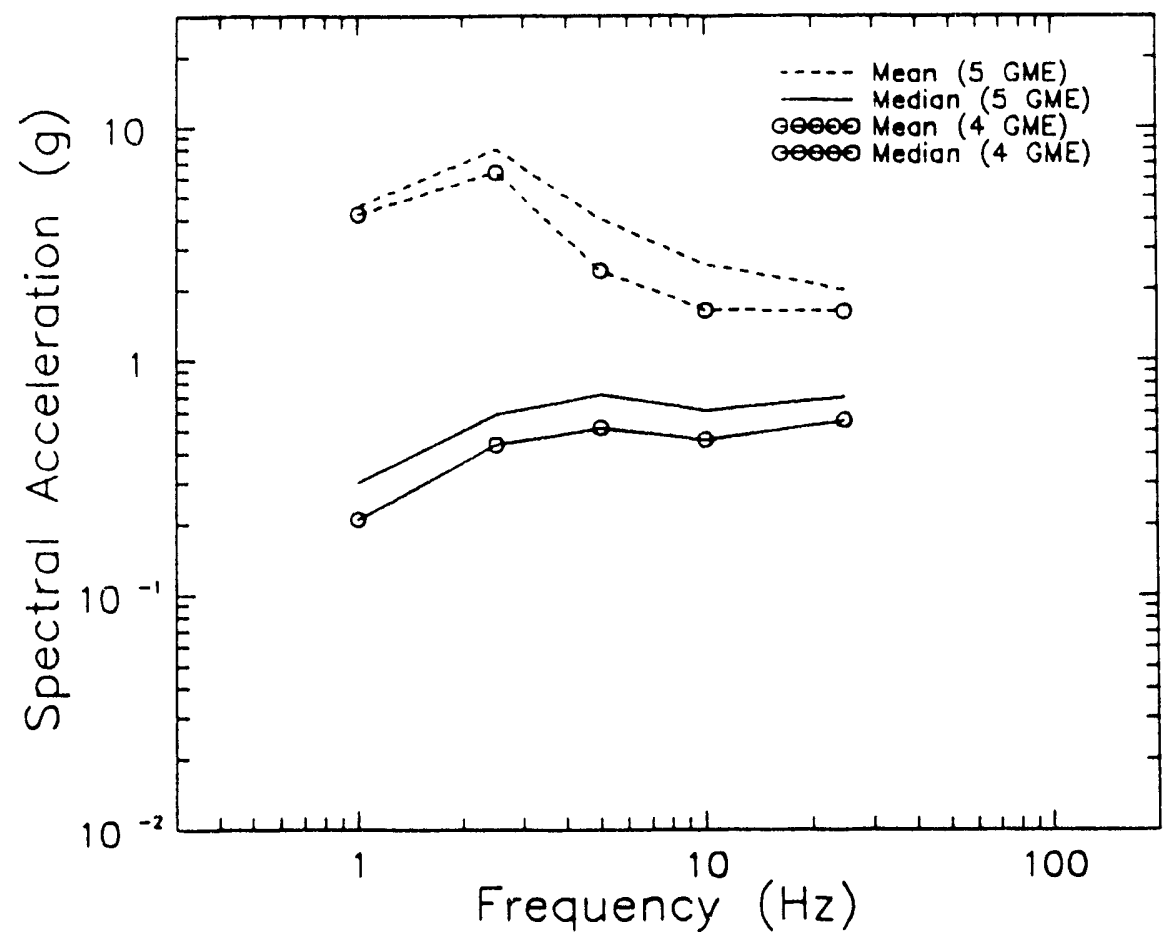

Figure 3-6 Comparison of the LLNL 4 GME and 5 GME median and mean UHS for the SRS. 


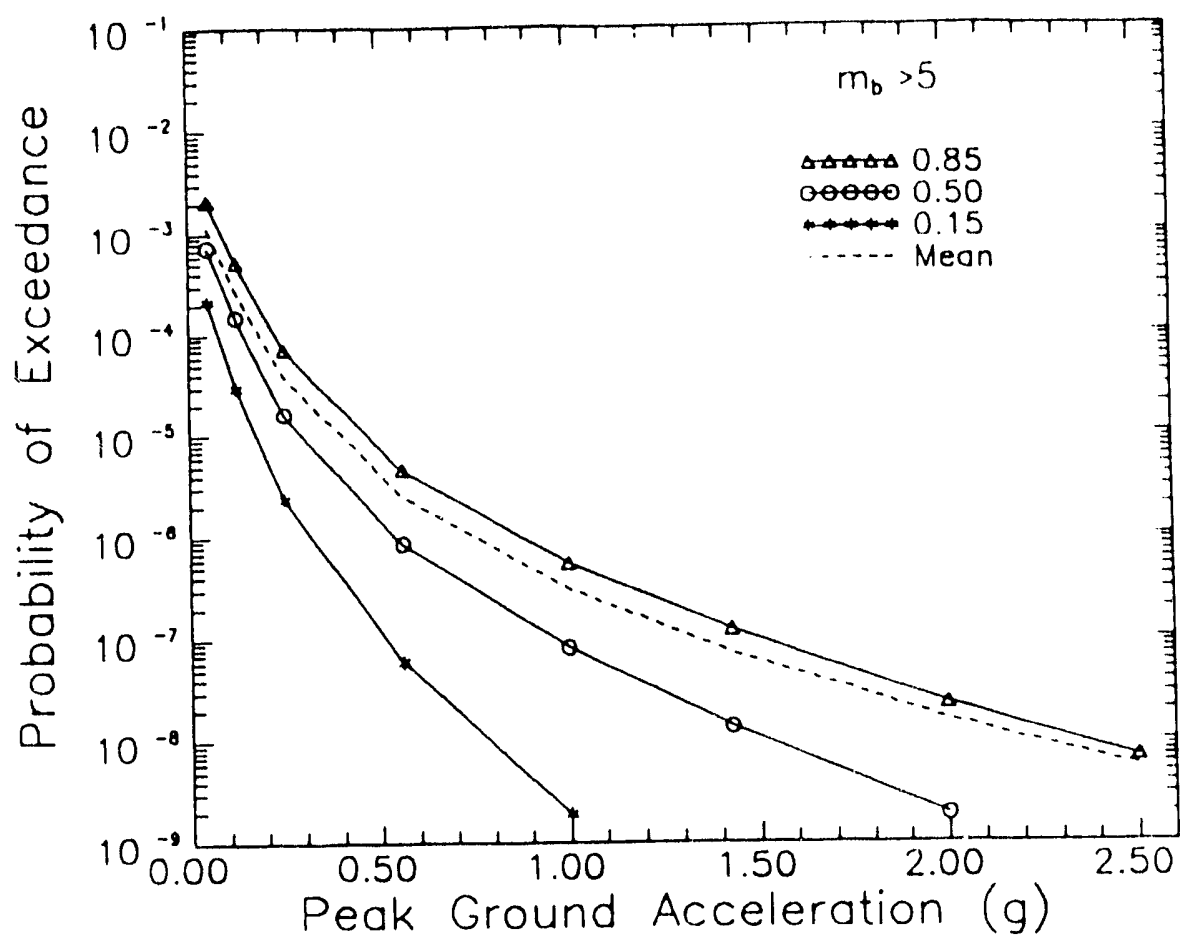

Figure 3-7 EPRI PGA seismic hazard curves for the SRS.

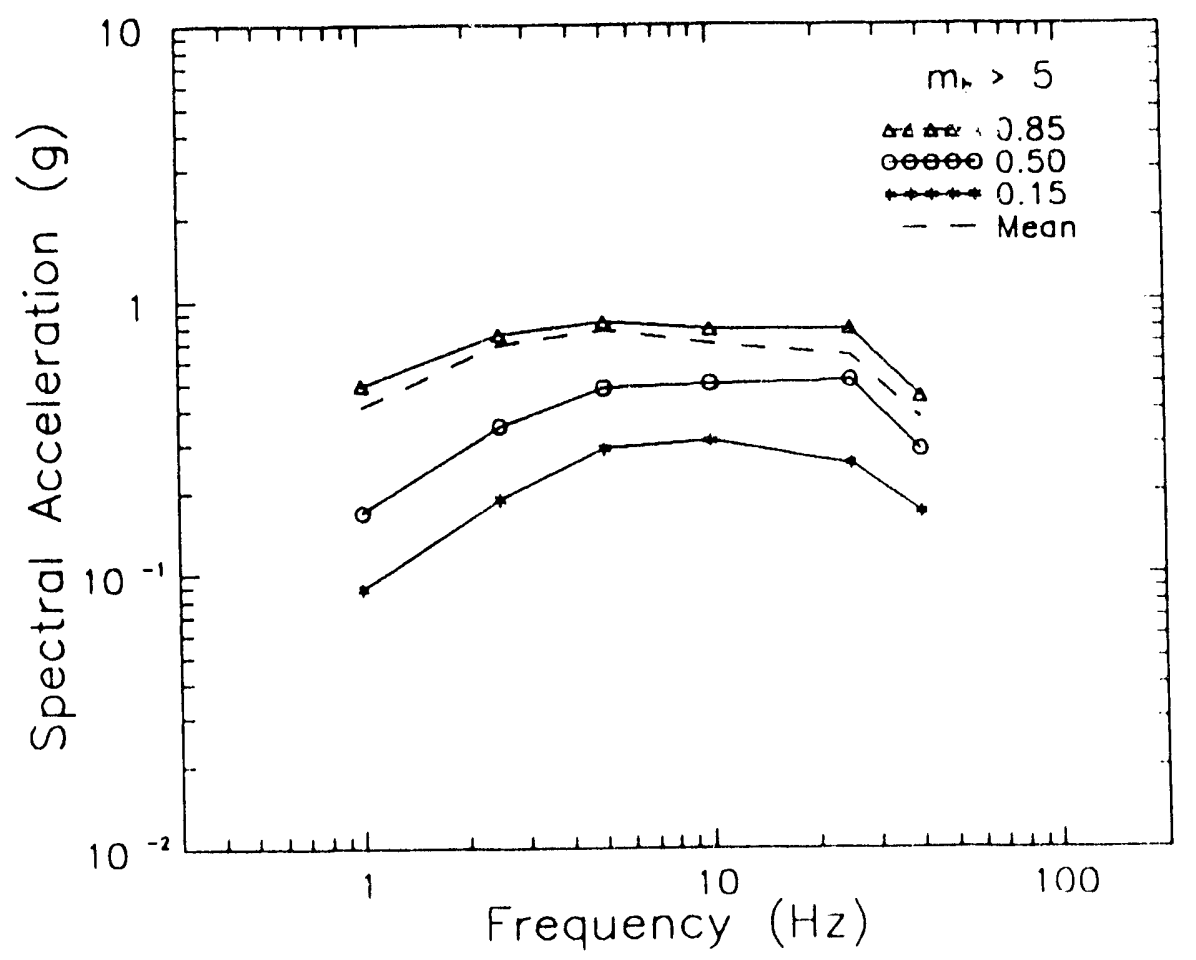

Figure 3-8 EPRI UHS for the SRS for an annual probability of exceedance of $10^{5}$. 


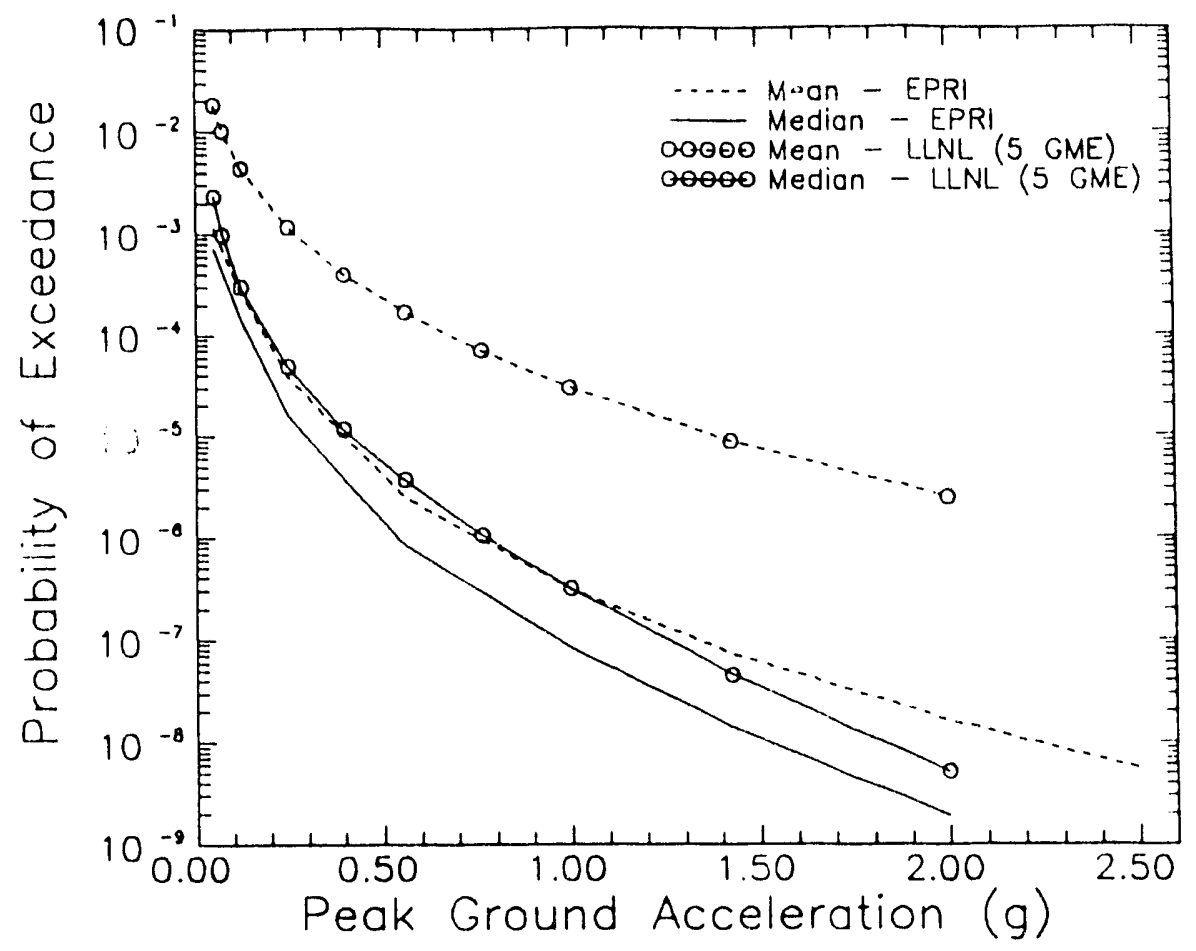

Figure 3-9 Comparison of the LLNL 5 GME case and the EPRI median and mean PGA hazard curves for the SRS.

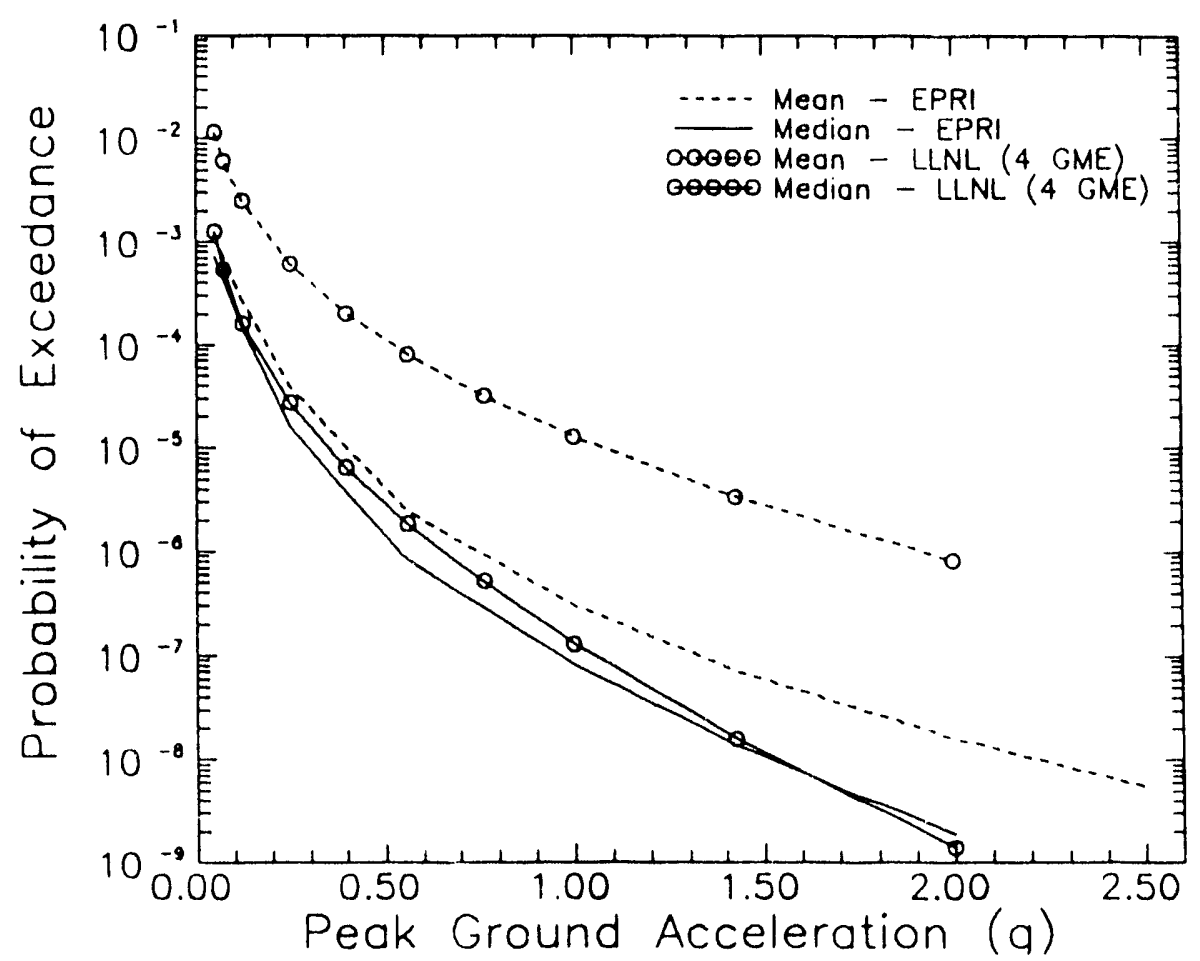

Figure 3-10 Comparison of the LLNL 4 GME case and the EPRI median and mean hazard curves for the SRS. 


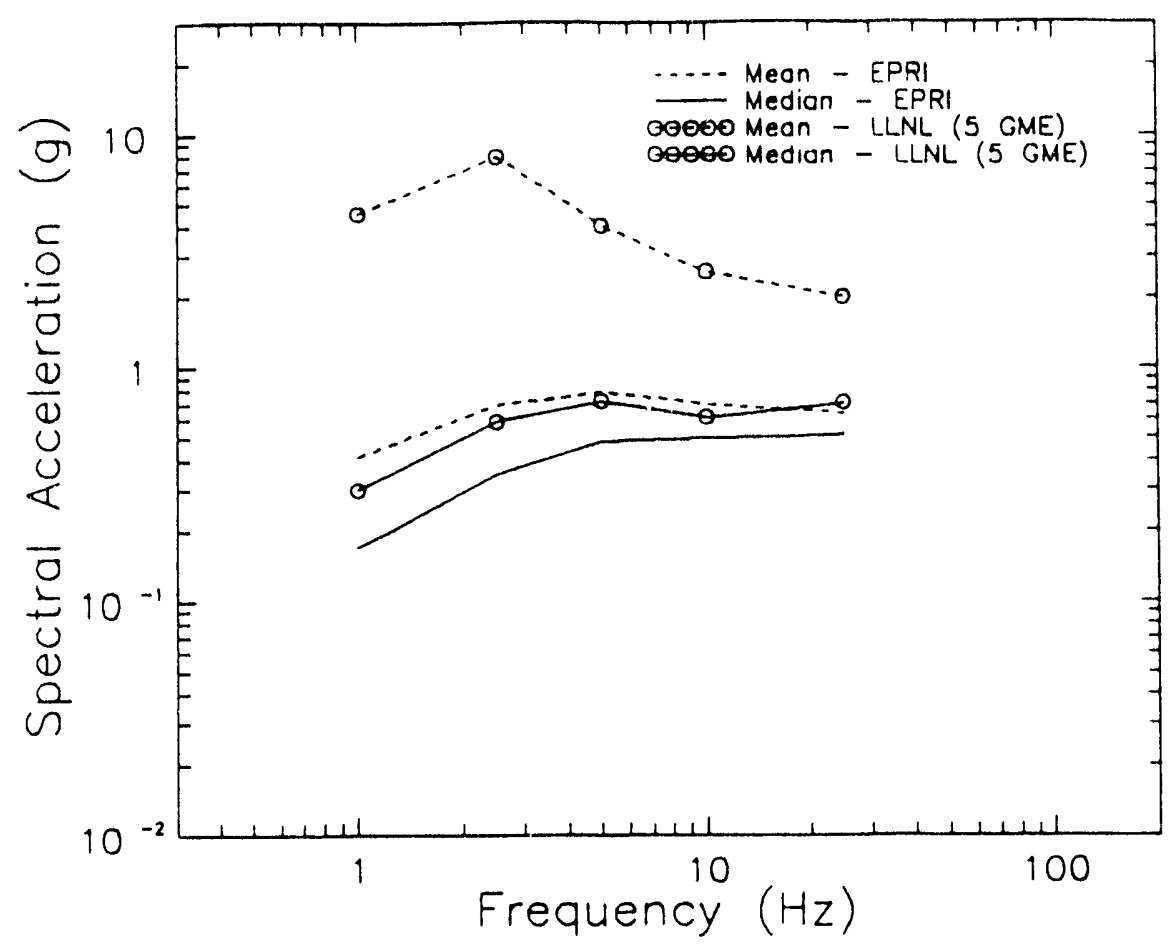

Figure 3-11 Comparison of the EPRI and LLNL 5 GME median and mean UHS for the SRS.

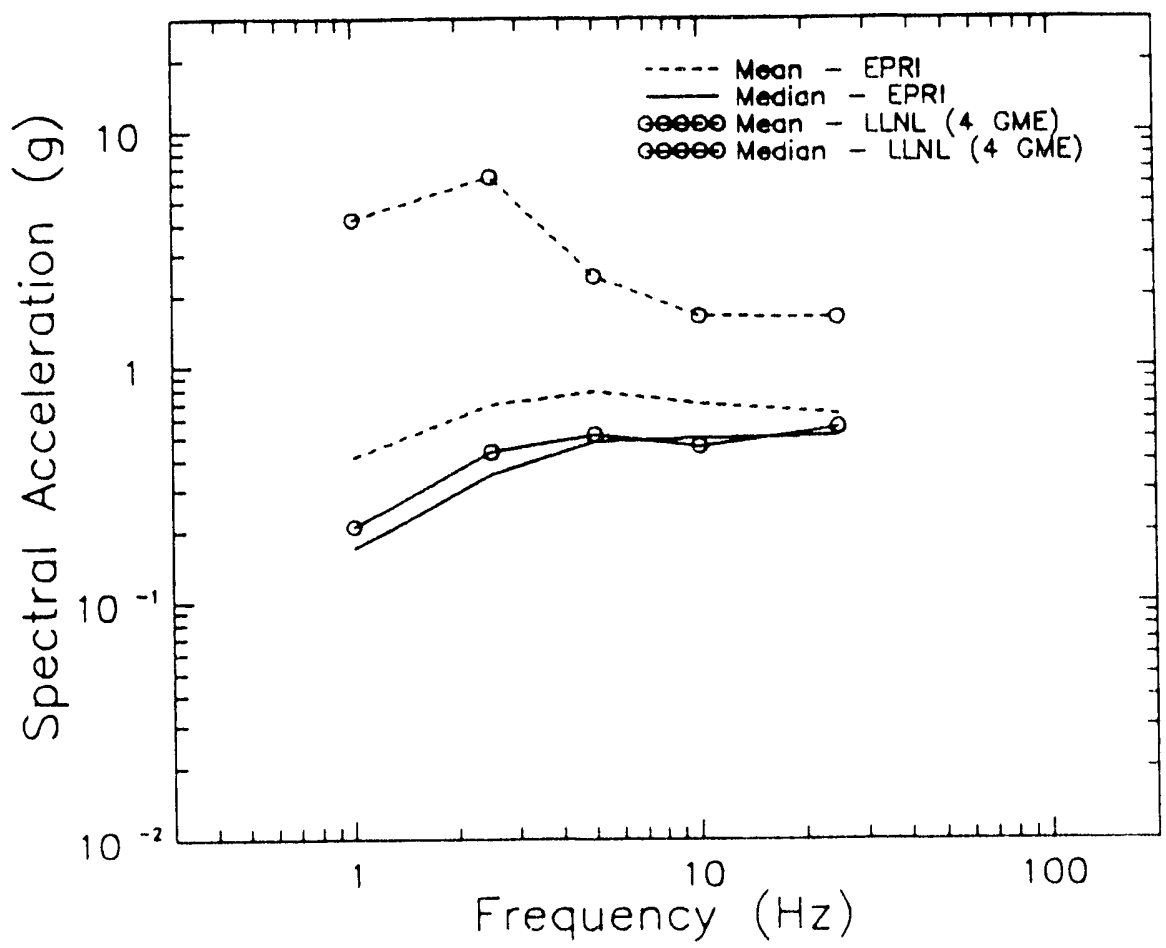

Figure 3-12 Comparison of the EPRI and LLNL 4 GME median and mean UHS for the SRS. 


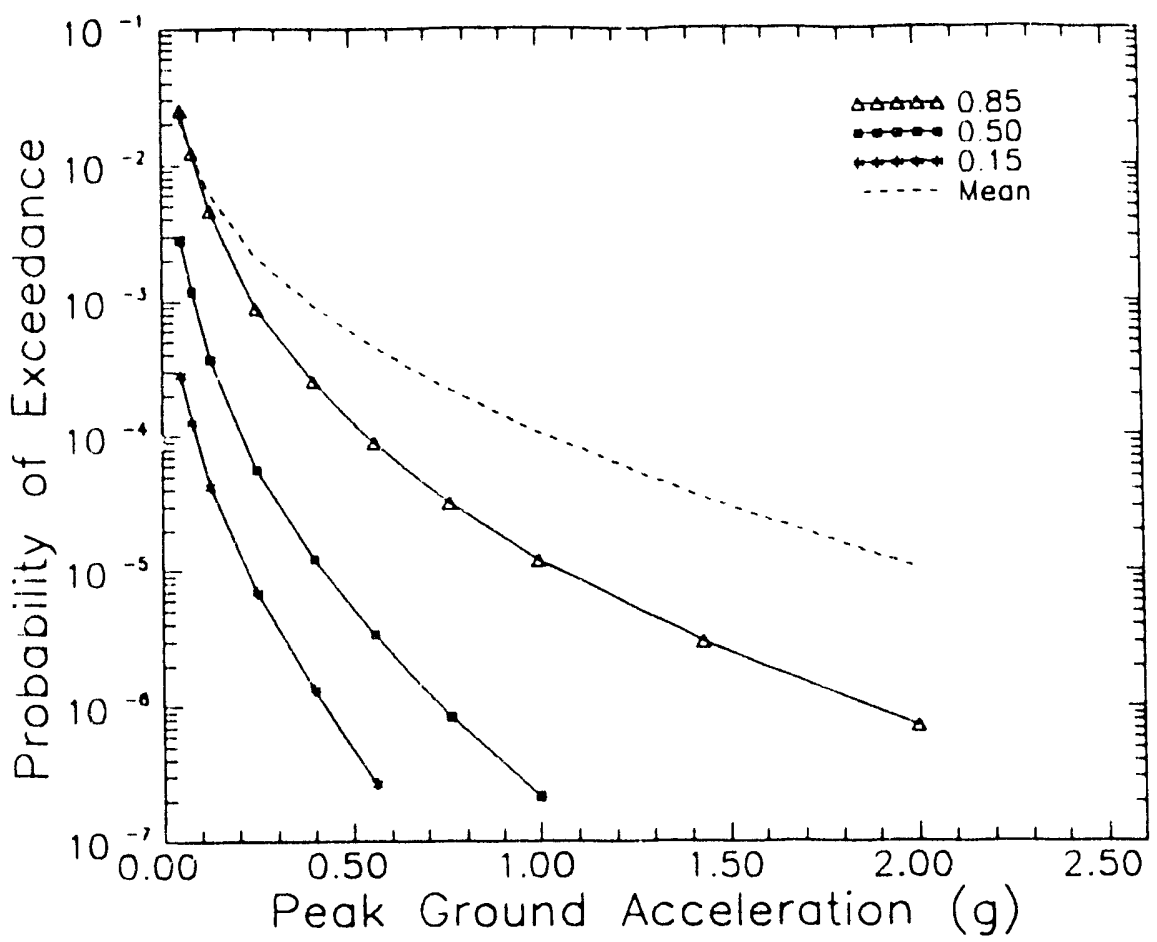

Figure 3-13 LLNL PGA seismic hazard curves for rock-site conditions for the SRS, 5 GME case.

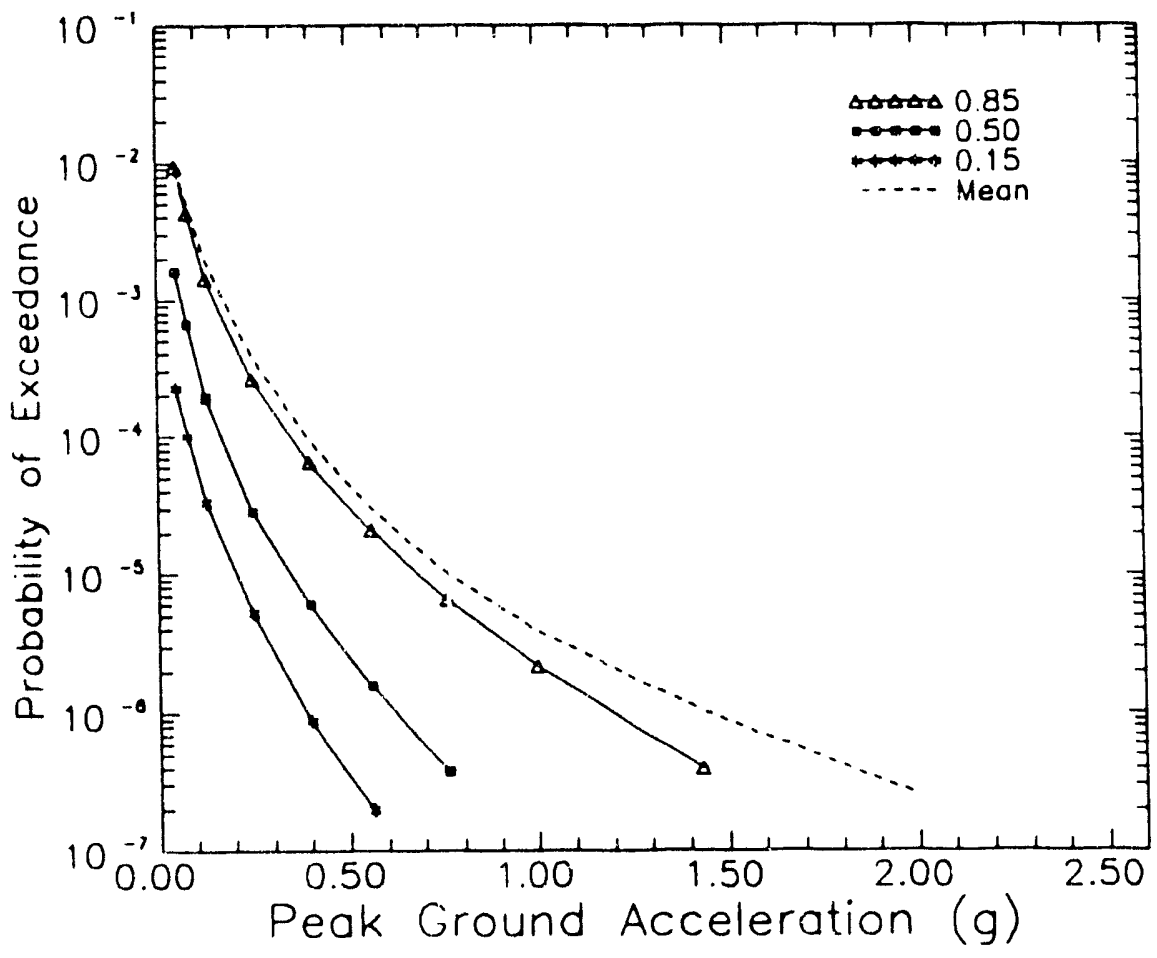

Figure 3-14 LLNL PGA seismic hazard curves for rock-site conditions for the SRS, 4 GME case. 


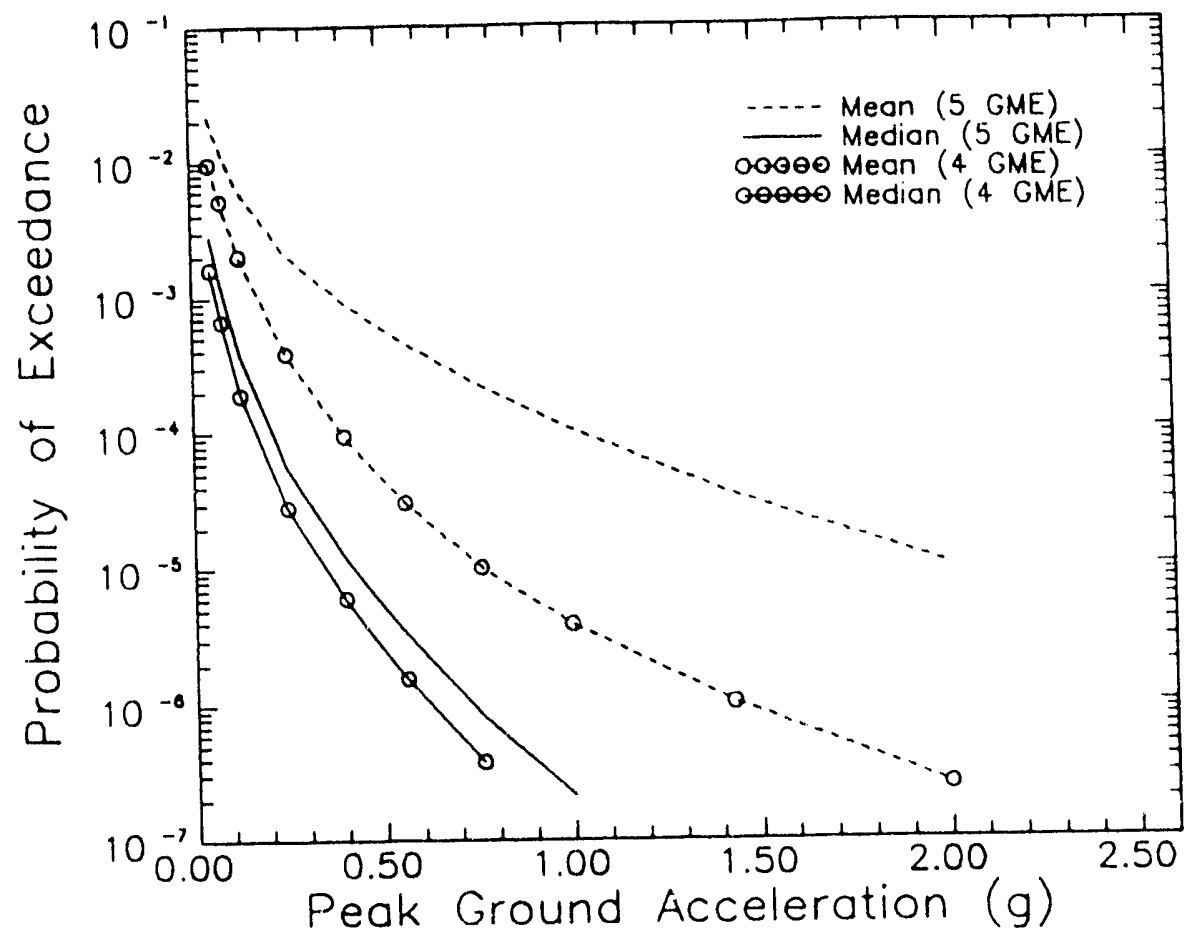

Figure 3-15 Comparison of the LLNL 4 GME and 5 GME median and mean PGA seismic hazard curves for rock-site conditions. 


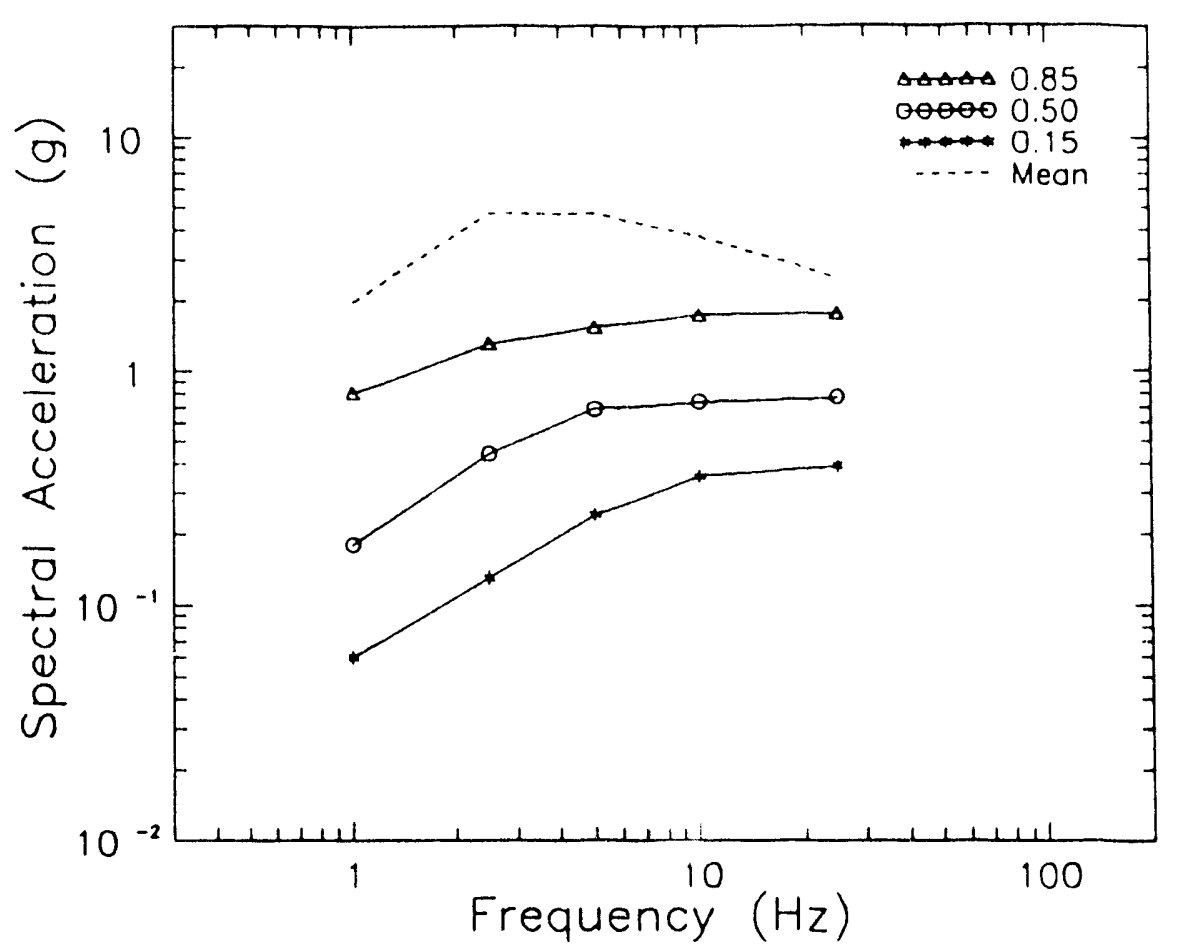

Figure 3-16 LLNL UHS for the SRS for an annual probability of exceedance of $10^{-5}$ for the $5 \mathrm{GME}$ case and rock-site conditions.

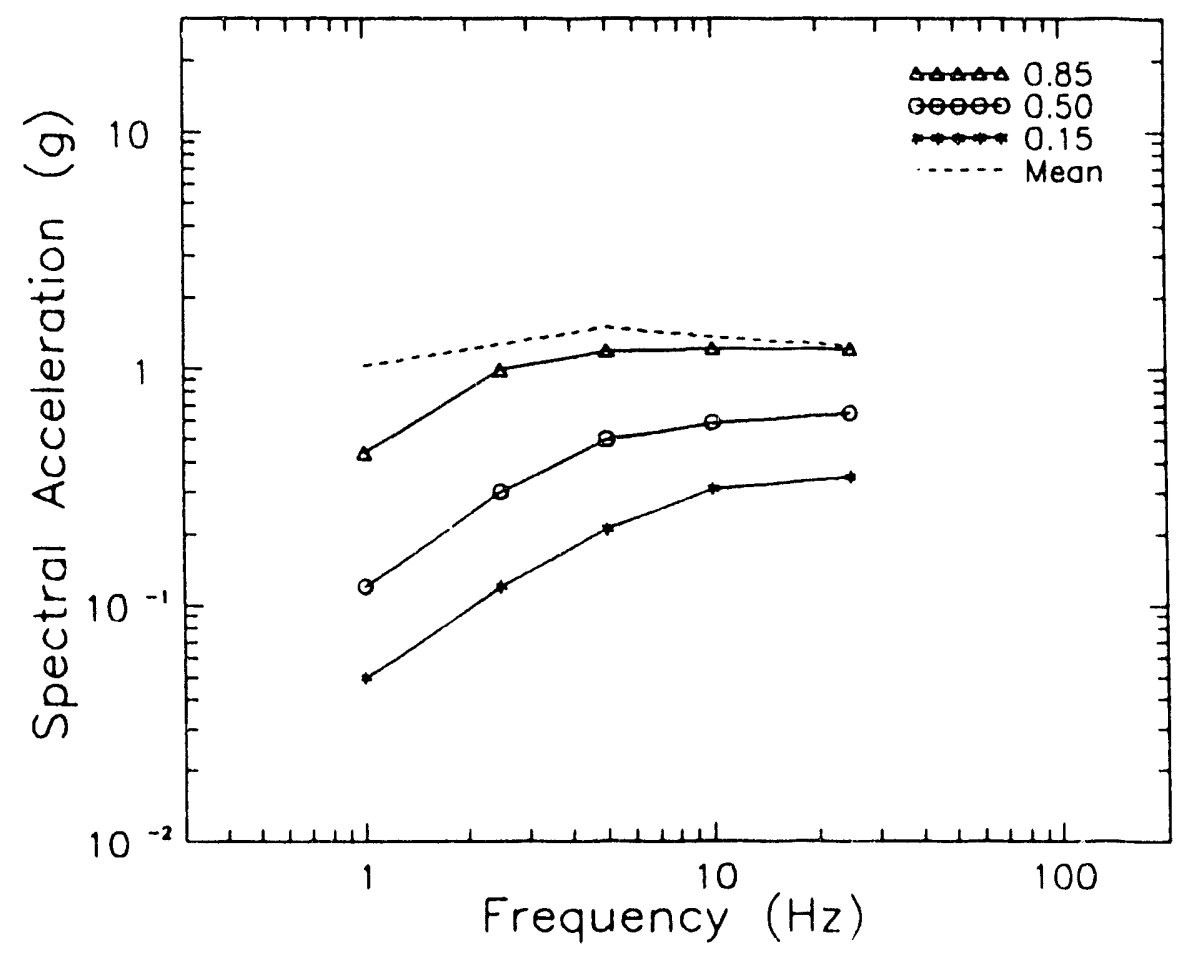

Figure 3-17 LLNL UHS for the SRS for an annual probability of exceedance of $10^{5}$ for the $4 \mathrm{GME}$ case and rock-site conditions. 


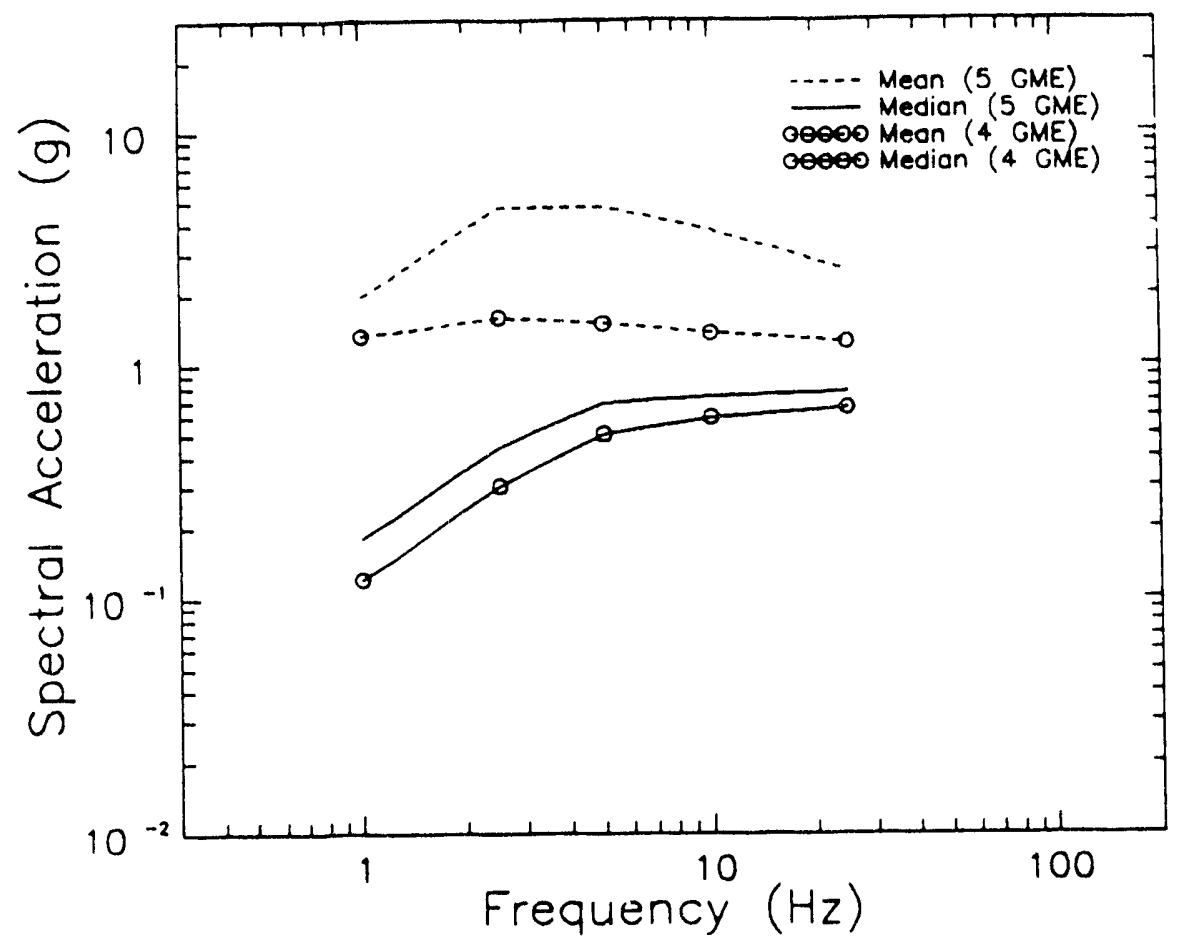

Figure 3-18 Comparison of the LLNL 4 GME and 5 GME median and mean UHS for the SRS for rock-site conditions. 


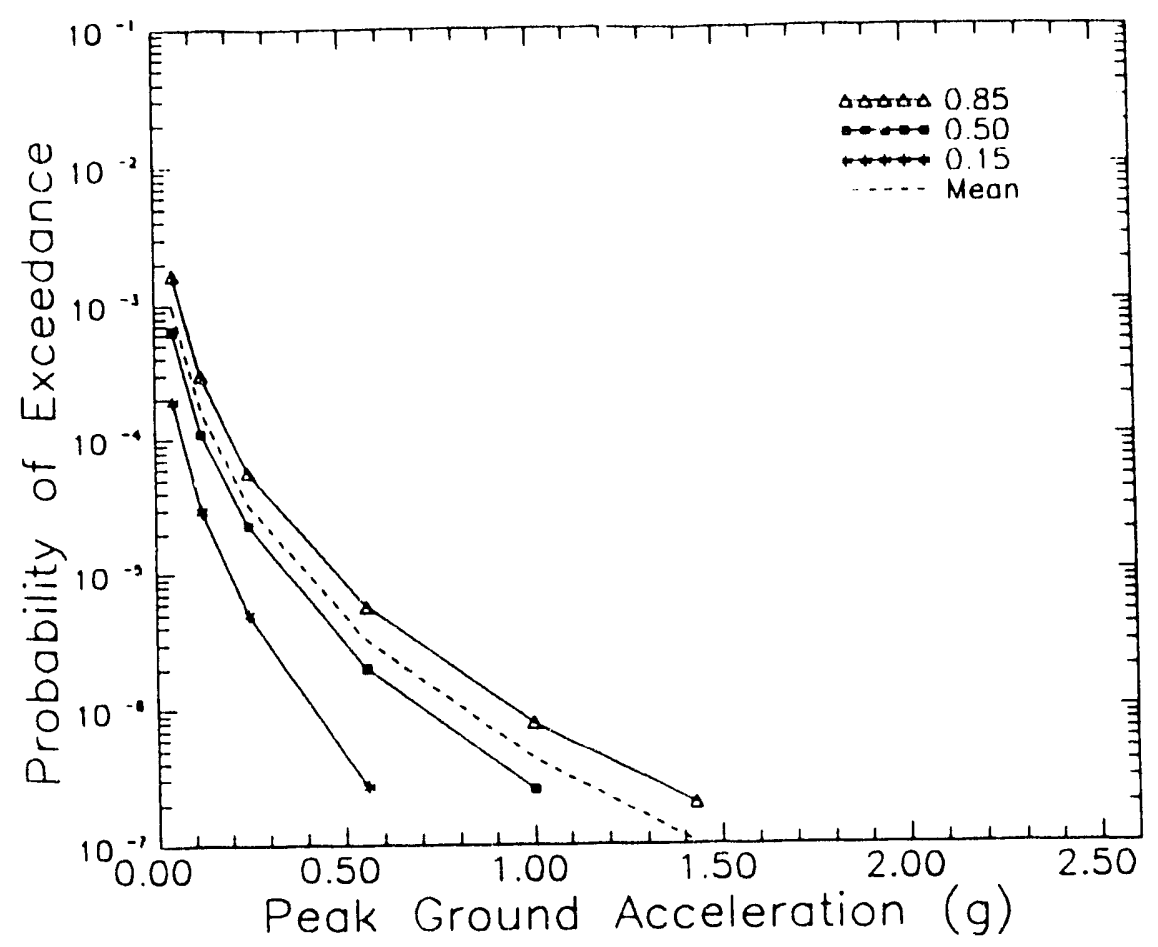

Figure 3-19 EPRI PGA seismic hazard curves for rock-site conditions at the SRS.

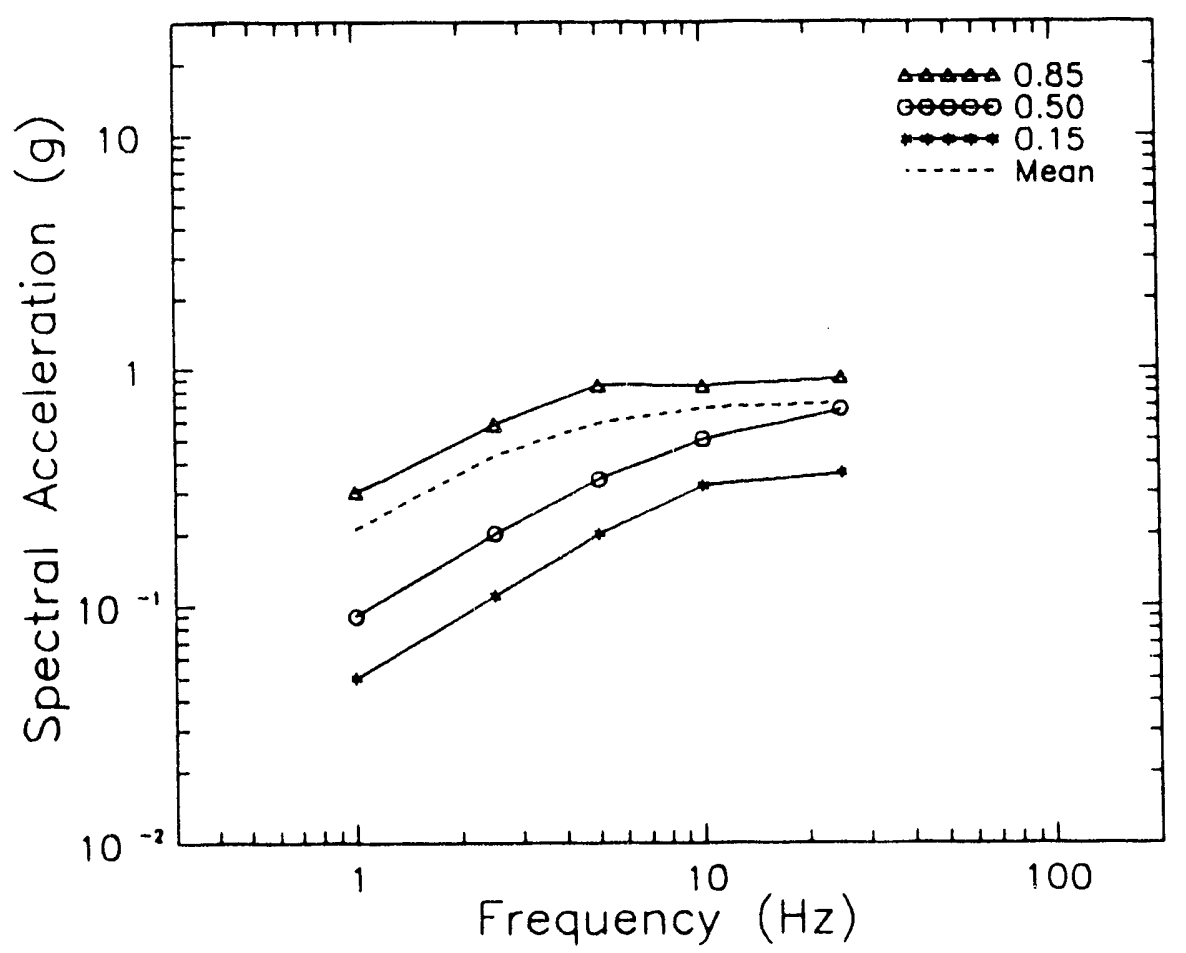

Figure 3-20 EPRI UHS for the SRS for an annual probability of exceedance of $10^{5}$ on rock-site conditions 


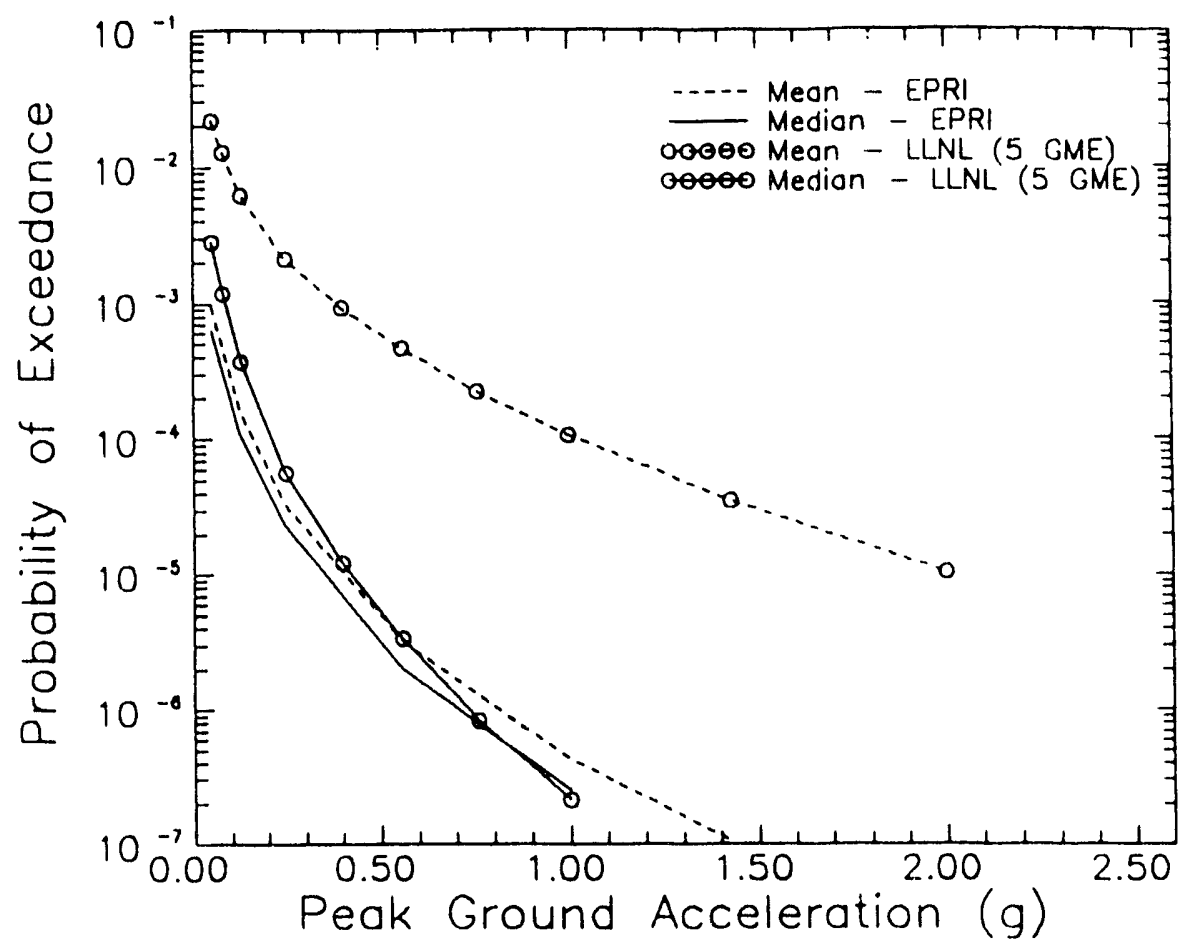

Figure 3-21 Comparison of the LLNL 5 GME case and EPRI median and mean PGA hazard curves for rock-site conditions at the SRS.

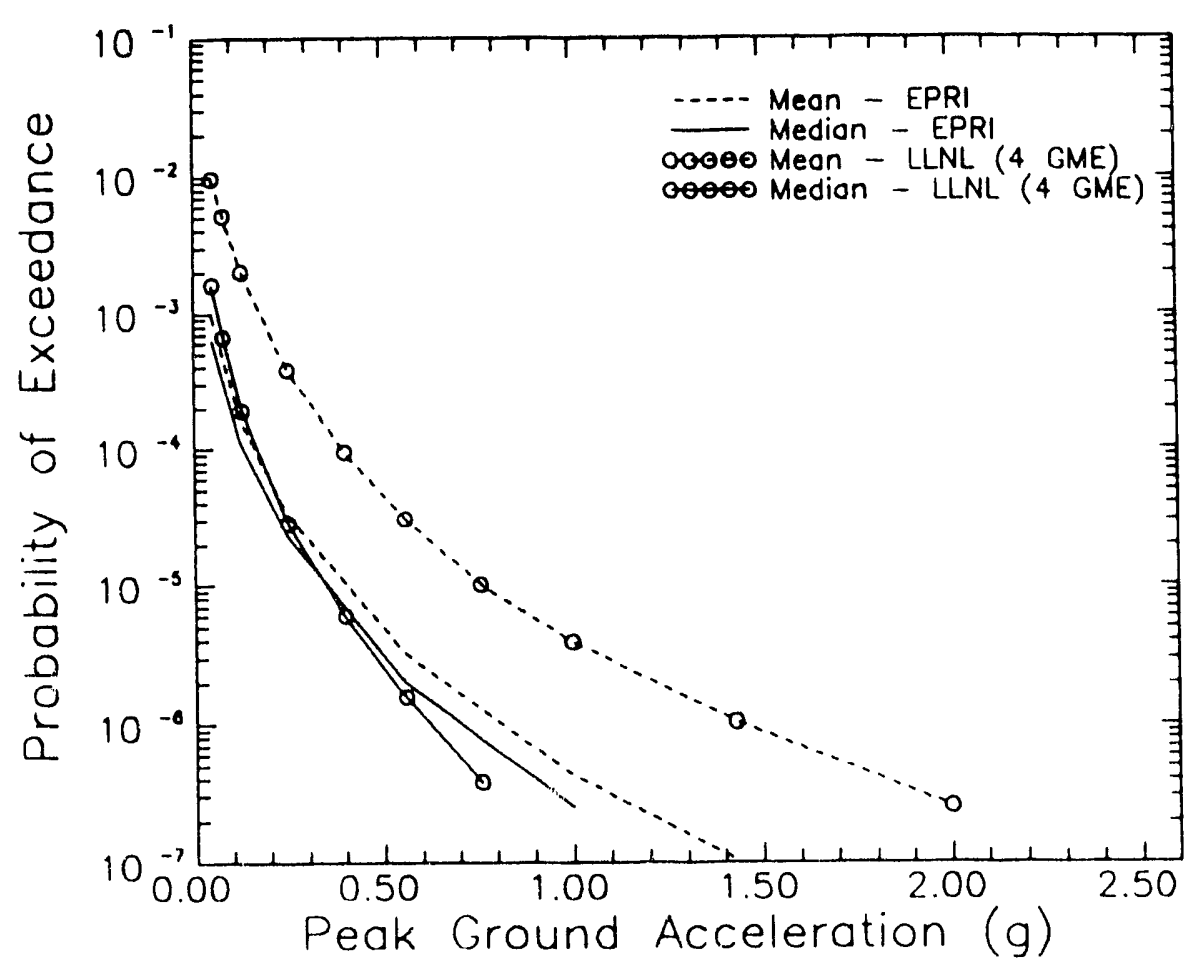

Figure 3-22 Comparison of the LLNL 4 GME case and EPRI median and mean PGA hazard curves for rock-site conditions at the SRS. 


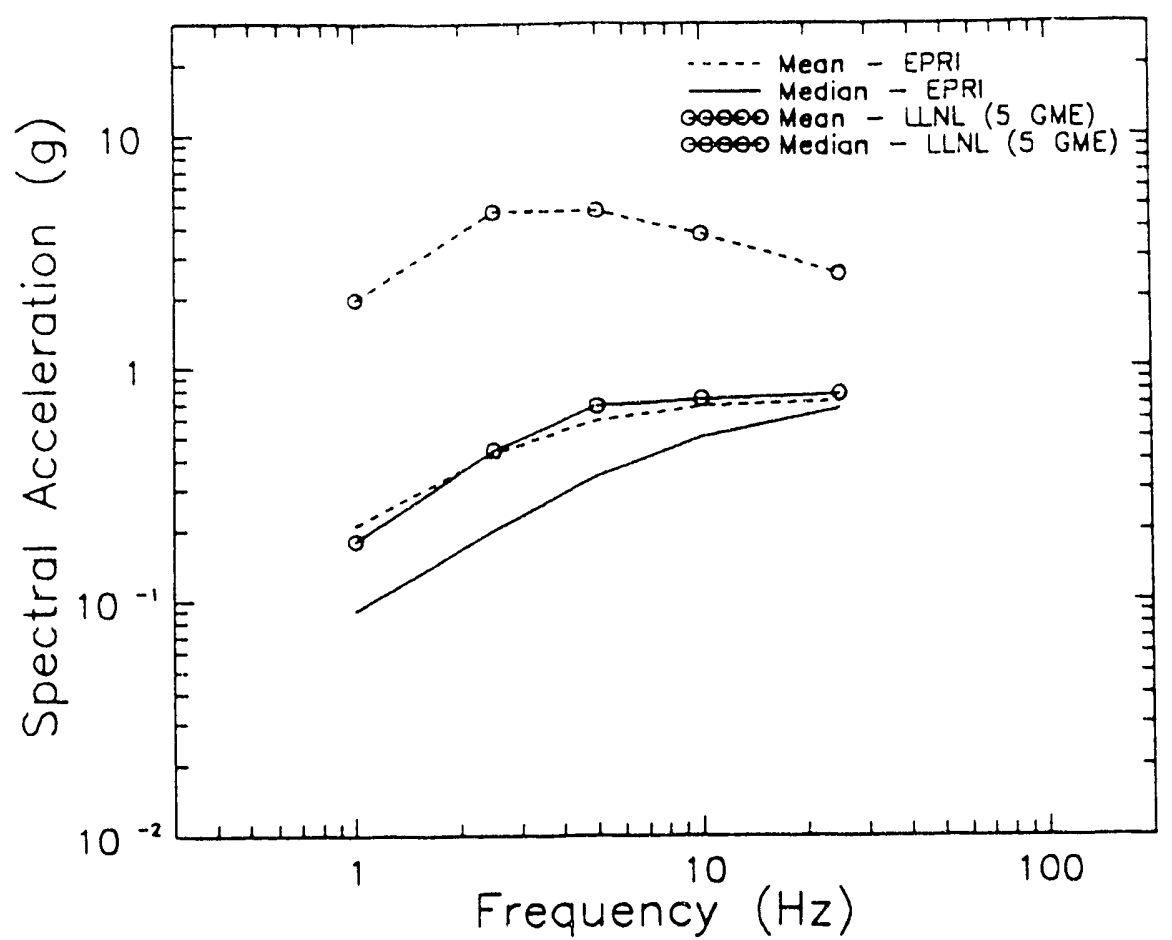

Figure 3-23 Comparison of the EPRI and LLNL 5 GME median and mean UHS for the SRS on rock-site conditions.

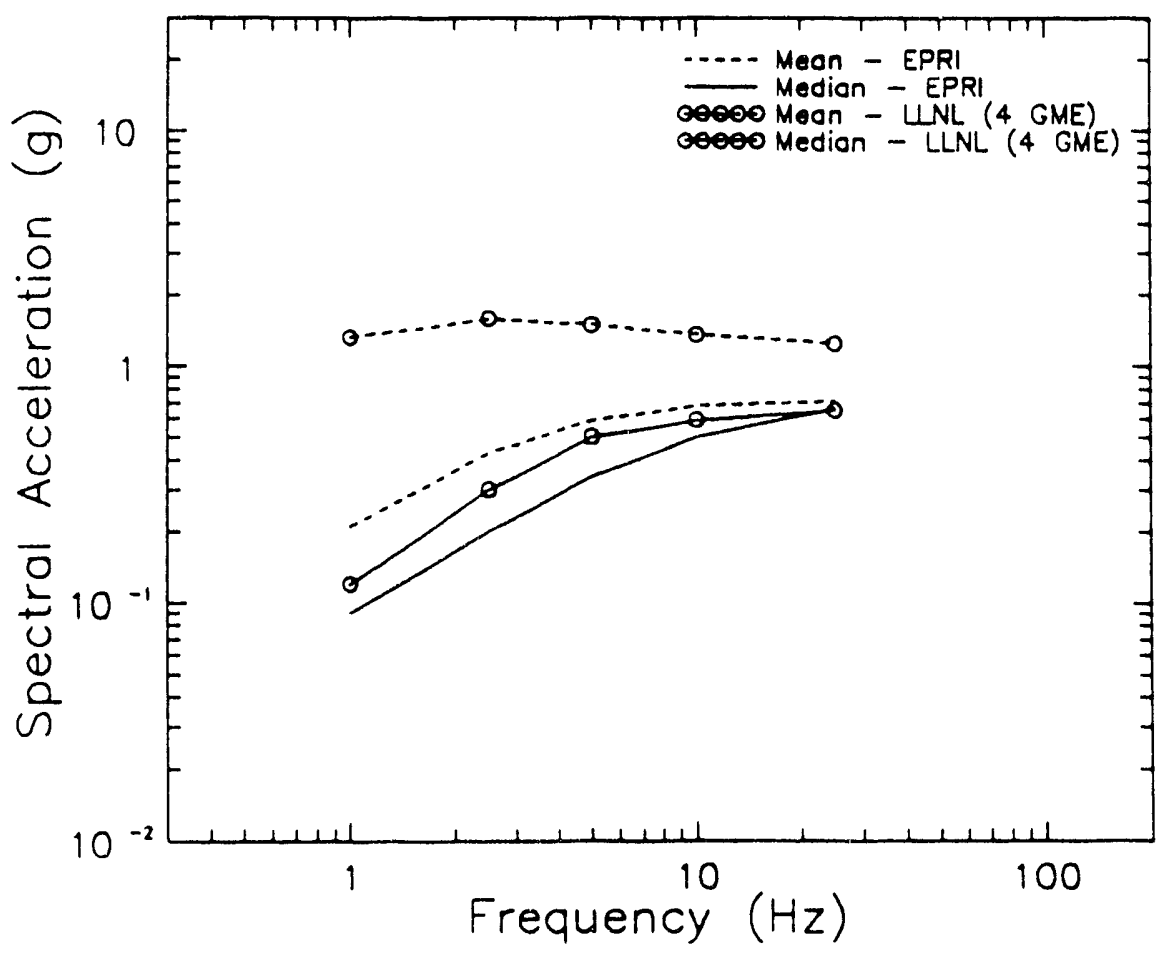

Figure 3-24 Comparison of the EPRI and LLNL 4 GME median and mean UHS for the SRS on rock-site conditions. 


\section{Section 4}

\section{SEISMICITY EVALUATION}

\subsection{Introduction}

As part of the seismic hazard assessment the seismicity experts must model the spatial and temporal distribution of earthquake occurrences. As outlined in Section 2, the seismicity analysis consists of the development of seismic sources that model the possible location of earthquakes and a recurrence relationship which models the size and rate of future events. This section summarizes the principle findings of a comparative evaluation of the EPRI and LLNL study seismicity models. Volume 2 contains a detailed presentation of this aspect of the comparative evaluation.

As part of the evaluation of seismicity in the vicinity of the SRS, there are a number of basic issues the seismicity experts addressed. These included,

- an assessment to determine which tectonic features (e.g., faults) are active (e.g., capable of generating earthquakes),

- assessing the maximum-size earthquake that could occur in a seismic source including the potential that a Charleston-size $\left(m_{b} \geq 6.6\right)$ event could occur anywhere in the EUS $(1,5)$, and

- estimating the SAR for a seismic source and the relative likelihood of different size earthquakes.

Each of these issues was addressed by the seismicity experts in the EPRI and LLNL seismic hazard studies. Potentially, the most critical of these dealt with the possibility of a Charleston-size event occurring near the SRS. The 1886 Charleston earthquake occurred approximately $120 \mathrm{~km}$ from the SRS. 
This section presents the results of a comparative evaluation of the EPRI and LLNL seismicity models. The first issue addressed was the contribution of individual seismic sources to the mean hazard. This assessment provides insights as to whether large-magnitude events generated by the Charleston seismic zone are the primary contributor to the seismic hazard or small- to moderate-size events located near the SRS dominant the seismic hazard. This review will also consider the expert assessment of the geographic dimensions of the Charleston seismic zone.

The second topic addressed was the expert assessment of the rate of earthquake occurrences (of any size above the LBM) in the vicinity of the SRS and the magnitudefrequency distribution. The final parameter reviewed was the maximum magnitude $\left(\mathrm{m}_{\max }\right)$ that can be generated by a seismic source.

In the following subsections, each topic is summarized for the EPRI and LLNL studies and then the findings of the comparative evaluation are presented. Sections 4.2 and 4.3 summarize the EPRI and LLNL seismicity models, respectively. Section 4.4 presents a comparison of the EPRI and LLNL seismicity models. Section 4.5 summarizes the overall findings of the comparative evaluation.

\subsection{EPRI Seismicity Models}

\subsubsection{Seismic Source Contribution}

In the EPRI study six teams of earth scientists developed the seismicity input to the seismic hazard evaluation. Table 4-1 summarizes for each Earth Science Team (EST) the following information:

- number of seismic-source combinations used in the SRS hazard analysis, and the 
- percent contribution of each seismic source to the mean prot ability of exceeding PGA levels of $0.13 \mathrm{~g}, 0.25 \mathrm{~g}$ and $1.00 \mathrm{~g}$.

In the table the Charleston seismic source and the host ${ }^{1}$ source are identified. The results indicate for ground motion levels of $0.25 \mathrm{~g}$ and higher, that the host source is the principle contributor to the mean hazard for all ESTs. The Charleston seismic source makes a moderate contribution to the hazard at low ground motion levels. At PGA levels greater than $0.25 \mathrm{~g}$, the Charleston seismic source makes a limited contribution to the mean hazard. This is attributed to the fact that each of the ESTs defined the Charleston seismic zone, which has a relatively high SAR and the potential for generating moderate-to-large-magnitude earthquakes, as a region which is restricted to the eastern South Carolina area. As a result, seismic events associated with a Charleston seismic zone do not occur at or near the SRS, thus limiting the contribution of this seismic source to the likelihood of low ground motions only.

\subsubsection{Seismic-Activity Rate and Maqnitude Frequency}

A direct measure of the overall level of seismic hazard at a site is quantified by the rate of earthquake occurrences above $m_{0} 5.0$ (the LBM). The SAR sets the level of the hazard curve (e.g., the probability that an earthquake of any size will occur). As indicated in eq. 2-1, the SAR is effectively a scaling factor that anchors the hazard curve to the level of seismicity. Due to the uncertainty in the assessment of seismic sources and seismicity parameters, there is uncertainty in the estimated SAR. Therefore, considering the input from all ESTs, there is a probability distribution that quantifies the uncertainty in the SAR.

Contributions to the seismic hazard can be attributed to sources of seismic activity

'The host seismic source is the source where the site is located. 
within approximately $200 \mathrm{~km}$ of the SRS. For purposes of quantifying the SAR, a rectangular region around the SRS was defined. This region is illustrated in Figure 4-1.

Table 4-2 lists for each EST and for all teams combined the $0.15,0.50$ and 0.85 fractile and the mean estimate of the SAR. Table 4-2 also lists the bounds (lowest and highest estimates) of the SAR for the combined team cumulative distribution function (CDF). Figure 4-2 shows for each EST the SAR CDF in the vicinity of the SRS. Figure 4-3 shows the SAR CDF for all ESTs combined. (Note, in the EPRI study, the seismic hazard results of the individual ESTs are aggregated by assigning equal weight to each team.) The SAR CDFs reported in Table 4-2 and displayed in Figures 4-2 and 4-3 incorporate all sources of uncertainty in the EST seismicity models, including the probability-of-activity of seismic sources, source combinations and estimates of the seismicity parameters.

The full range (low to high) of estimates of the SAR varies over slightly more than one-order of magnitude. The individual EST median values, which is an indication of the central part of the CDF, vary by approximately a factor of 2 about the combined team median value. Two ESTs, Bechtel and Rondout, have relatively narrow distributions, indicating they have estimated very low uncertainty in their assessment of the SAR (see Fig. 4-2). The median for these teams is close to the combined team median results.

A practical perspective on the expert assessments of the SAR can be developed by considering the number of earthquakes that would be required to support these estimates for a time-window equivalent to the period of record. Assuming a period of record of 200 years, Table 4-3 lists the 0.15, 0.50 and 0.85 fractile, the mean and bounds of the SAR for the combined team results and the expected number of earthquakes of $m_{b} \geq 5.0$. The number of events ranges from approximately 1 to 9 . Historically, there have been 3 earthquakes of magnitude 5.0 or greater that occurred in the vicinity of the SRS. (Note, the assessment of seismicity in the EPRI and LLNL studies applies to the occurrence of main events only. 
Foreshocks and aftershocks are not included in the hazard analysis.)

Figure 4-4 shows the EPRI combined team estimate of the frequency of exceedance of earthquake magnitude for the region in Figure 4-1. The frequency of exceedance of an event the size of the 1886 Charleston earthquake or larger $\left(m_{b} \geq 6.6\right)$, occurring anywhere in the SRS vicinity (see Fig. 4-1) has a median frequency of approximately $6.25 \times 10^{-5}$ per year. The mean frequency of exceedance is $1.14 \times 10^{-4}$ per year.

\subsubsection{Maximum Magnitude}

For each seismic source the ESTs must estimate the maximum size event that could be generated. In the EPRI study the uncertainty in $m_{\max }$ was defined in terms of a discreteprobability distribution. Table 4-4 lists the EPRI EST assessment of the maximum magnitude for the Charleston seismic zone. The values range from $m_{b} 6.6$ to 7.5. The majority of the teams have assigned the highest weight to estimates in the range of 6.6 to 7.2. The EPRI earthquake catalog assigns the 1886 Charleston event an $m_{b} 6.6$. In view of the fact that the Charleston seismic source is not a significant contributor to the SRS hazard, the assessment of the maximum magnitude is not a critical parameter in the EPRI analysis.

Table 4-5 lists the EPRI $m_{\max }$ values for the SRS host seismic zone. The EST assessments vary from 5.6 to 7.4. As a result the EST teams have included in their seismicity models, the potential for Charleston-type seismic events to occur at or near the SRS.

\subsection{LLNL Seismicity Models}

\subsubsection{Seismic Source Contribution}

This subsection summarizes the contribution of the LLNL SE seismic sources to the hazard at the SRS. Table 4-6 lists the contribution of the LLNL seismic sources to the PGA 
hazard for $0.13 \mathrm{~g}, 0.25 \mathrm{~g}$, and $1.0 \mathrm{~g}$ for the LLNL 5 GME case. Table $4-6$ is similar in format to Table 4-1. Table 4-7 shows the contribution of each seismic source to the PGA hazard for the LLNL 4 GME case. Of the eleven SEs, two experts defined the Charleston seismic zone such that it extends far enough to the west that it is also the host source for the SRS.

For the 5 GME case, the seismic hazard at the site is dominated by the Charleston seismic source. In the $4 \mathrm{GME}$ case, the results in Table 4-7 indicate that the Charleston seismic zone does not make as great a contribution to the seismic hazard, particularly for PGA $\geq 0.25 \mathrm{~g}$. In this case, the host seismic source is the principle contributor. This is attributed to the fact that the ground motion model selected by GME 5 predicts higher ground motions (higher than the other LLNL models), particularly for events that occur at large distances (greater than about $80 \mathrm{~km}$ ). For cases when the Charleston seismic source is located in eastern South Carolina (at distances greater than about $80 \mathrm{~km}$ ), the model selected by GME 5 estimates ground motion that is considerably higher than the motion predicted by the models selected by the other LLNL GMEs (2). Thus, in the 5 GME case the seismic hazard at the SRS associated with the Charleston seismic source is much higher and has a greater contribution to the site hazard.

\subsubsection{Seismic-Activity Rate and Magnitude Frequency}

Table 4-8 lists for each SE the 0.15, 0.50 and 0.85 fractiles and the mean SAR for the region shown in Figure 4-1. At the bottom of the table the results for all SEs combined are given as are the bounds (upper and lower) of the combined CDF. (In the LLNL study, the SE hazard results are aggregated using weights derived from a self-weighting procedure (2).) For the LLNL SEs the median values vary by approximately a factor of 5 about the combined median. Figure 4-5 shows the SAR CDF for the LLNL SEs for the region in Figure 4-1. Figure 4-6 shows the CDF for all SEs combined. The combined LLNL SARs 
range from a low estimate of $8.11 \times 10^{-5}$ to 29.5 events per year.

Table 4-9 lists the $0.15,0.50$ and 0.85 fractiles and mean SAR values for the combined team results and the number of earthquakes of $m_{b} \geq j .0$ that would be expected to occur in a 200-year time period. For the full range of the CDF the expected number of events varies from approximately 0 to 5900. An examination of the SAR CDF reveals there are 82 estimates that exceed one event per year. In terms of the expected number of earthquakes, there are 82 LLNL estimates that predict 200 or more events in a 200 -year period.

Figure 4-7 shows the LLNL magnitude-frequency distribution based on the input for all SEs for the region near the SRS. The median-frequency of exceedance of a Charleston-size earthquake or greater $\left(m_{b} \geq 6.6\right)$ is $2.09 \times 10^{-4}$ per year. The mean-frequency of exceedance is $1.1 \times 10^{-2}$ per year. The mean-frequency corresponds to an average-recurrence interval of approximately 91 years.

\subsubsection{Maximum Magnitude}

In the LINL study the uncertainty in $m_{\max }$ was defired in terms of a triangular probability density function. To define this distribution, the SE provided a lower bound, upper bound and best estimate for $m_{\max }$. The best estimate corresponds to the mode of the triangular density function and the lower and upper-bounds define the 0.025 and 0.975 probability levels of the distribution function, respectively.

Table 4-10 lists for each SE the lower and upper bounds and the best-estimate $m_{\max }$ values for the Charleston seismic zone. Across all experts, the majority of the $m_{\max }$ values are in the range 6.7 to 7.3 . Whereas the lower- and upper-bound $m_{\max }$ values provided do not establish the limits of the triangular distributions, values beyond these bounds may be 
used in the seismic hazard calculations.

Table 4-11 lists the $m_{\max }$ values for the LLNL SE host seismic sources. For the host, the LLNL experts assign $m_{\max }$ values that range from 5.0 to 7.5. (Recall, for two experts, the Charleston seismic zone is also the host zone.) The best-estimate values range from 5.5 to 7.3 .

\subsection{Comparison of the EPRI and LLNL Seismicity Models}

This subsection summarizes the comparative evaluation of the EPRI and LLNL seismicity assessments for the SRS region. The comparisons presented here are the primary source of differences in the EPRI and LLNL seismic hazard estimates. Volume 2 provides a more detailed discussion of the comparative assessment.

\subsubsection{Seismic Sources}

A critical question associated with the assessment of the SRS seismic hazard concerns the location of the Charleston seismic source relative to the SRS. In the EPRI and LLNL studies, all the experts with two exceptions ( 2 of 17 ), define the Charleston seismic zone as a geographic area located in eastern South Carolina. Thus, there is general agreement not only within each study, but between the two studies in terms of the characterization of the Charleston regional tectonic framework.

\subsubsection{Comparison of EPRI and LLNL Seismicity Models}

This subsection presents a comparative assessment of the EPRI and LLNL seismicity models, focusing on the SAR and the frequency of exceedance of Charleston-type events. In addition, the earthquake recurrence intervals and expected number of events predicted by these data are compared. 
Figure 4-8 provides a comparison of the EPRI and LLNL SAR CDFs for the region near the SRS (see Fig. 4-1). Table 4-12 lists the EPRI and LLNL 0.15, 0.50 and 0.85 fractiles and the mean SAR. Table 4-12 also lists the CDF lower and upper bounds.

The comparisons in Figure 4-8 and Table 4-12 illustrate large differences in the seismicity assessments of the two studies. In terms of the median SAR, the LLNL study estimate is approximately a factor of 3 higher than the EPRI value. This is indicated by the fact that the central part of the LLNL CDF is shifted toward higher values relative to EPRI (see Fig. 4-8). With respect to the mean, the differences are more pronounced. The LLNL mean SAR is approximately a factor of 10 higher.

The differences between the EPRI and LLNL mean SAR values are indicative of the long, upper-tail of the L.LNL CDF (see Fig. 4-8). As noted previously, the top 82 LLNL estimates of the SAR (of 2750 values calculated in the LLNL study) exceed a rate of one event of $m_{b} \geq 5.0$ per year. The differences in the SAR estimates of the two studies is further illustrated by the fact that the upper-bound of the EPRI CDF is less than the LLNL median.

Table 4-13 shows a comparison of the expected number of earthquakes that are estimated by the two studies for a time window comparable to the period of record (e.g., 200 years). The expected number of events can be interpreted as the number of earthquakes that would be required in the historic record in order to support the SAR values reported in Table 4-12. Viewing the assessment of seismicity in terms of the earthquake count provides a tangible perspective to the estimate of occurrence rates.

A final comparison of the SARs is illustrated in Table 4-14 in terms of the average recurrence interval (in years) for events of $m_{b} \geq 5.0$. The table compares the recurrence intervals associated with the median, mean and upper-bound SAR values for the two studies. 
Focusing on the mean value, the EPRI recurrence interval corresponds to one $m_{b} \geq 5.0$ every 56 years. The LLNL mean is 5.3 years which is short, relative to the historic record. This rate suggests that since the SRS has been occupied by the DOE (or its predecessor) since about 1950, approximately 8 events of $m_{b} \geq 5.0$ would be expected to occur. Another interpretation of the data in Table 4-14 suggest that 50 percent of the LLNL estimates of the SAR suggest that events of $m_{b} 5.0$ or greater should occur, on average, once every 20 years or less. Recurrence intervals of this magnitude (many days to less than 20 years) are so short, their validity can be questioned in the context of the historic record in which only 3 events have occurred in a period of approximately 150-200 years.

The task of assessing earthquake-occurrence rates in low-seismic regions is difficult at best. Thus, it is reasonable to expect that expert assessments will reflect a considerable degree of uncertainty, given the available data. At the same time it is reasonable to think that estimates of earthquake occurrence rates have realistic limits, at least in a broad, regional sense. In this context, consideration could be given to regions of higher or comparable rates of seismicity. For example, as a type of 'sanity check' should the assessment of seismic activity in most areas of the EUS exceed the rate of earthquake occurrences in high-seismic regions? This question has practical significance in view of the extreme SARs that are estimated in the LLNL study. For example, there are estimates of the SAR in the LLNL study that rival observed rates in California (if not the entire U.S.).

The assessment of seismicity in a region must balance the information that is available both locally (in the immediate region of interest) and globally, with the need to provide a practical measure of uncertainty. It appears that as part of the LLNL assessment of source seismicity parameters and ultimately in the development of the seismicity models (e.g., the assessment of the temporal and spatial rate of occurrence of earthquakes near a site) there was a failure to address these issues in the process of soliciting expert input. (Note, based on conversations with J.B. Savy of LLNL, this is being addressed as part of the seismic 
hazard evaluation being performed for the DOE New Production Reactor at the SRS (6)).

Whereas the SAR is the anchor point (the scaler) that determines the level of the hazard, if all other factors are equal, the LLNL estimate of the SRS mean seismic hazard could be expected to be a factor of 10 higher.

Recall in Section 3 (see Tables 3-4 and 3-5 that at low-ground motion levels, the EPRI and LLNL mean seismic hazard curves differ by a factor of 12 to 65 (at a PGA $=0.25 \mathrm{~g}$ for rock-site conditions). The range of values are taken from the comparison with the LLNL $4 \mathrm{GX}$ and 5GX cases, respectively. Thus, it could be concluded that a major source of the difference in the seismic hazard results is explained to a large degree, by the difference in the estimate of the SAR.

The difference in the mean estimates of the SAR is the result of the higher median values and the rion-zero weight assigned by the LLNL SEs to extreme estimates (see Table 48, LLNL upper bound). The difference in the median values, which is a more stable parameter, suggests a systematic difference in the two studies. The fact that the LLNL experts have assigned non-zero weight to extreme estimates signals a large deviation of SAR estimates. Based on the review of the two studies, the following factors are believed to contribute to this difference:

- a tendency of the EPRI ESTs to underestimate the uncertainty (see Fig. 4-2), and

- the LLNL process of eliciting seismicity expert assessments did not provide complete feedback to the experts regarding their seismicity rate (and magnitude frequency) predictions. As a result, the experts did not have a composite quantification and probabilistic interpretation of the input they provided.

The later is believed to be the principle source of the differences. 
Figure 4-9 shows a comparison of the EPRI and LLNL median and mean magnitude frequency curves. With respect to magnitude-frequency, as compared to the differences observed between estimates of the SAR, the variance of the magnitude frequency values is even greater, particularly for large-magnitude events. Indicative of the difference between the two studies is the estimate of the frequency of exceedance of Charleston-size events $\left(m_{b}\right.$ $\geq 6.6$ ). The median frequency values are similar, to within a factor of 2 . However, the mean values differ by approximately two orders or magnitude.

Based on historic data, Bollinger, et al., (7) estimate the recurrence interval for $m_{b} \geq$ 6.8 in the Charleston seismic zone of 4000 years with 95 percent confidence bounds of 940 14,300 years. In recent years, paleoseismic studies have been performed in the southeast which extend the historical record of earthquake occurrences. Based on evidence of seismically-induced liquefaction, an recurrence interval of about 1000 years has been estimated for moderate- to large-earthquakes in the Charleston region (8). This suggests a frequency of occurrence of earthquakes of $10^{-3}$ per year. The EPRI and LLNL estimates of the frequency of exceedance of a Charleston-type event brackets this estimate. The EPRI and LLNL medians are $6.25 \times 10^{-5}$ and $2.09 \times 10^{-4}$, respectively. The corresponding mean values are $1.14 \times 10^{-4}$ and $1.10 \times 10^{-2}$, respectively.

A further measure of the extreme difierence in the two magnitude-frequency assessments is given by the following observation. The EPRI mean frequency of exceedance of $\mathrm{m}_{\mathrm{b}} \geq 5.0$ (e.g., the seismic-activity rate) is $1.80 \times 10^{-2}$ events per year, which is within a factor 2 of the LLNL estimated mean frequency of exceedance of $m_{b} \geq 6.6$ (Charleston-size events) which is $1.10 \times 10^{-2}$.

\subsubsection{Maximum Magnitude}

For the most part, the EPRI and LLNL assessments of maximum magnitude for the 
Charleston seismic zone are similar. The best estimate or central $\mathrm{m}_{\mathrm{max}}$ values are consistently in the 6.8 to 7.0 range, with a few higher and lower values. The LLNL expert uncertainty distribution does accommodate slightly higher and lower $m_{n a x}$ estimates. Overall, given that the Charleston seismic source is not a major contributor to the difference in seismic hazard in the EPRI and the LLNL 4 GME case, these differences are considered small.

\subsection{Summary}

To summarize, the differences in the EPRI and LLNL seismic hazard results is attributed to the following:

- a factor of 10 difference in the estimated mean SAR in the vicinity of the SRS,

- location of the Charleston seismic zone relative to the SRS, and

- mean-frequency of exceedance of large magnitude events (e.g., Charleston-type events.

Of these factors, the primary contributor to the difference in the SRS hazard assessment is believed to be the variance in SAR estimates. 
Table 4-1

Contribution (\%) of Seismic Sources for Each EPRI Earth Science Team to the Mean PGA Hazard

\begin{tabular}{|c|c|c|c|c|c|}
\hline \multirow{2}{*}{$\begin{array}{l}\text { Earth Science } \\
\text { Team }\end{array}$} & \multirow{2}{*}{$\begin{array}{l}\text { No. of Source } \\
\text { Combinations }\end{array}$} & \multirow[b]{2}{*}{ Seismic Source ${ }^{2}$} & \multicolumn{3}{|c|}{ Peak Ground Acceleration (g) } \\
\hline & & & 0.13 & 0.25 & 1.00 \\
\hline Weston Geophysical & 9 & $\begin{array}{ll}26 & \text { Host } \\
104 & \\
25 & \text { Charleston }\end{array}$ & $\begin{array}{r}85.0 \\
2.6 \\
8.4\end{array}$ & $\begin{array}{r}93.1 \\
2.1 \\
2.0\end{array}$ & $\begin{array}{r}98.2 \\
0.7 \\
0.1\end{array}$ \\
\hline Dames and Moore & 6 & $\begin{array}{ll}53 & \text { Host } \\
54 & \text { Charleston } \\
52 & \end{array}$ & $\begin{array}{r}46.1 \\
45.0 \\
8.3\end{array}$ & $\begin{array}{r}62.0 \\
27.9 \\
9.9\end{array}$ & $\begin{array}{r}84.7 \\
3.4 \\
11.7\end{array}$ \\
\hline Law Engineering & 20 & $\begin{array}{ll}\text { M39 } \\
22 & \text { Host } \\
\text { C09 } & \text { Host } \\
35 & \text { Charleston }\end{array}$ & $\begin{array}{l}33.9 \\
19.7 \\
11.6 \\
17.5\end{array}$ & $\begin{array}{l}39.1 \\
20.5 \\
13.3 \\
15.4\end{array}$ & $\begin{array}{l}34.1 \\
22.6 \\
19.9\end{array}$ \\
\hline Woodward-Clyde & 4 & $\begin{array}{ll}\text { B32. } & \text { Host } \\
29 & \text { Host } \\
29 B & \text { Host } \\
30 & \text { Charleston }\end{array}$ & $\begin{array}{r}57.3 \\
16.7 \\
8.1 \\
4.2\end{array}$ & $\begin{array}{r}58.3 \\
19.7 \\
9.1 \\
2.4\end{array}$ & $\begin{array}{r}45.2 \\
36.8 \\
12.1 \\
0.2\end{array}$ \\
\hline Bechtel & 9 & $\begin{array}{l}\text { BZ4 Host } \\
\text { BZ5 } \\
\text { F } \\
\text { H } \quad \text { Charleston } \\
\text { N3 }\end{array}$ & $\begin{array}{r}26.6 \\
37.6 \\
12.4 \\
4.5 \\
6.2\end{array}$ & $\begin{array}{r}41.7 \\
31.9 \\
9.4 \\
4.0 \\
4.1\end{array}$ & $\begin{array}{r}89.5 \\
6.5 \\
1.7 \\
0.5 \\
0.2\end{array}$ \\
\hline Rondout & 1 & $\begin{array}{ll}26 & \text { Host } \\
24 & \text { Charleston }\end{array}$ & $\begin{array}{l}86.3 \\
13.7\end{array}$ & $\begin{array}{r}93.4 \\
6.6\end{array}$ & $\begin{array}{r}99.5 \\
0.5\end{array}$ \\
\hline
\end{tabular}

1 Seismic sources that do not contribute at least $2 \%$ to any one of the ground motion levels are not shown.

2 The numbers/symbols in this column correspond to the name of the seismic source as defined by the EST. 
Table 4-2

Summary of the EPRI Earth Science Team Estimates of Seismicity

\begin{tabular}{|c|c|c|c|c|}
\hline \multirow{2}{*}{$\begin{array}{l}\text { Earth Science } \\
\text { Team }\end{array}$} & \multicolumn{4}{|c|}{$\begin{array}{c}\text { Seismic-Activity Rate }\left(\mathrm{m}_{\mathrm{b}} \geq 5\right)^{1} \\
(\text { Events/Year })\end{array}$} \\
\hline & 0.15 & 0.50 & 0.85 & Mean \\
\hline Weston Geophysical & $1.37-2$ & $1.41-2$ & $1.46-2$ & $1.40-2$ \\
\hline Dames and Moore & $6.48-3$ & $8.03-3$ & $1.58-2$ & $1.05-2$ \\
\hline Law Engineering & $6.53-3$ & $1.03-2$ & $1.73-2$ & $1.11-2$ \\
\hline Woodward-Clyde & $1.80-2$ & $2.68-2$ & $3.52-2$ & $2.70-2$ \\
\hline Bechtel & $2.22-2$ & $2.76-2$ & $3.30-2$ & $2.74-2$ \\
\hline Rondout & $1.40-2$ & $1.51-2$ & $1.53-2$ & $1.50-2$ \\
\hline Combined $^{2}$ & $9.60-3$ & $1.51-2$ & $2.80-2$ & $1.80-2$ \\
\hline $\begin{array}{l}\text { CDF Bounds } \\
\text { Lower }\end{array}$ & $3.00-3$ & & & \\
\hline Upper & $4.61-2$ & & & \\
\hline
\end{tabular}

1 Rate corresponds to activity in the area around the SRS shown in Figure 4-1

2 All teams 
Table 4-3

Summary of the EPRI Combined EST Results on the Seismic-Activity Rate and Earthquake Counts

\begin{tabular}{|c||c|c|}
\hline & $\begin{array}{c}\text { Seismic-Activity Rate } \\
\left(\mathbf{m}_{\mathbf{b}} \geq \mathbf{5 . 0}\right) \\
\text { (Events/Year) }\end{array}$ & $\begin{array}{c}\text { Expected Number } \\
\text { of Events }\end{array}$ \\
\hline 0.15 & $9.60-3$ & 1.9 \\
0.50 & $1.51-3$ & 3.0 \\
0.85 & $3.04-2$ & 6.1 \\
Mean & $1.80-2$ & 3.6 \\
Lower & $3.00-3$ & 0.6 \\
Upper & $4.61-2$ & 9.2 \\
\hline
\end{tabular}


Table 4-4

EPRI Earth Science Team Maximum Magnitude Estimates For the Charleston Seismic Zone

\begin{tabular}{|c|c|c|c|}
\hline Earth Science Team & Seismic Source & $\begin{array}{l}\text { Maximum } \\
\text { Magnitude }\end{array}$ & Probability \\
\hline Weston Geophysical & 25 & $\begin{array}{l}6.6 \\
7.2\end{array}$ & $\begin{array}{l}0.90 \\
0.10\end{array}$ \\
\hline Dames and Moore & 54 & $\begin{array}{l}6.6 \\
7.2\end{array}$ & $\begin{array}{l}0.75 \\
0.25\end{array}$ \\
\hline Law Engineering & $\begin{array}{l}22 \\
35\end{array}$ & $\begin{array}{l}6.8 \\
6.8\end{array}$ & $\begin{array}{l}1.00 \\
1.00\end{array}$ \\
\hline Woodward-Clyde & 30 & $\begin{array}{l}6.8 \\
7.3 \\
7.5\end{array}$ & $\begin{array}{l}0.33 \\
0.34 \\
0.33\end{array}$ \\
\hline Bechtel & $\mathrm{H}$ & $\begin{array}{l}6.8 \\
7.1 \\
7.4 \\
\\
6.8 \\
7.1 \\
7.4\end{array}$ & $\begin{array}{l}0.20 \\
0.40 \\
0.40 \\
0.20 \\
0.40 \\
0.40\end{array}$ \\
\hline Rondout & 24 & $\begin{array}{l}6.6 \\
6.8 \\
7.0\end{array}$ & $\begin{array}{l}0.20 \\
0.60 \\
0.20\end{array}$ \\
\hline
\end{tabular}


Table 4-5

EPRI Earth Science Team Maximum Magnitude Estimates For the SRS Host Seismic Zone

\begin{tabular}{|c|c|c|c|}
\hline Earth Science Team & Seismic Source & $\begin{array}{l}\text { Maximum } \\
\text { Magnitude }\end{array}$ & Probability \\
\hline Weston Geophysical & 26 & $\begin{array}{l}6.0 \\
6.6 \\
7.2\end{array}$ & $\begin{array}{l}0.67 \\
0.27 \\
0.06\end{array}$ \\
\hline Dames and Moore & 53 & $\begin{array}{l}5.6 \\
7.2\end{array}$ & $\begin{array}{l}0.80 \\
0.20\end{array}$ \\
\hline I aw Engineering & $\begin{array}{r}22 \\
\mathrm{C} 09\end{array}$ & $\begin{array}{l}6.8 \\
6.8\end{array}$ & $\begin{array}{l}1.00 \\
1.00\end{array}$ \\
\hline Woodward-Clyde & B32 & $\begin{array}{l}5.8 \\
6.2 \\
6.6\end{array}$ & $\begin{array}{l}0.33 \\
0.34 \\
0.33\end{array}$ \\
\hline & $29,29 B$ & $\begin{array}{l}6.7 \\
7.0 \\
7.4\end{array}$ & $\begin{array}{l}0.33 \\
0.34 \\
0.33\end{array}$ \\
\hline Bechtel & $\mathrm{BZA}$ & $\begin{array}{l}6.6 \\
6.8 \\
7.1 \\
7.4\end{array}$ & $\begin{array}{l}0.10 \\
0.10 \\
0.40 \\
0.40\end{array}$ \\
\hline Rondout & 26 & $\begin{array}{l}5.8 \\
6.5 \\
6.8\end{array}$ & $\begin{array}{l}0.15 \\
0.60 \\
0.25\end{array}$ \\
\hline
\end{tabular}


Table 4-6

Contribution (\%) of Seismic Sources for Each LLNL Seismicity Expert to the Mean PGA Hazard - 5 GME Case'

\begin{tabular}{|c|c|c|c|c|c|}
\hline \multirow[b]{2}{*}{$\begin{array}{c}\text { Seismicity } \\
\text { Expert }\end{array}$} & \multirow[b]{2}{*}{$\begin{array}{c}\text { Number of } \\
\text { Maps }\end{array}$} & \multirow[b]{2}{*}{$\begin{array}{l}\text { Seismic } \\
\text { Source }^{2}\end{array}$} & \multicolumn{3}{|c|}{ Peak Ground Acceleration (g) } \\
\hline & & & 0.13 & 0.25 & 1.00 \\
\hline 1 & 30 & $\begin{array}{ll}1 & \text { Host } \\
2 & \text { Charleston } \\
3 & \\
9 \\
26 \mathrm{~A} \\
26 \mathrm{~B}\end{array}$ & $\begin{array}{r}11.5 \\
37.4 \\
6.4 \\
6.9 \\
11.1 \\
17.9\end{array}$ & $\begin{array}{r}12.8 \\
38.0 \\
3.9 \\
4.9 \\
13.3 \\
22.5\end{array}$ & $\begin{array}{r}16.9 \\
20.7 \\
0.8 \\
0.5 \\
18.2 \\
41.7\end{array}$ \\
\hline 2 & 30 & $\begin{array}{l}18 \\
29 \text { Host } \\
30 \text { Charleston } \\
\mathrm{CZ}\end{array}$ & $\begin{array}{r}7.1 \\
13.4 \\
75.9 \\
2.2\end{array}$ & $\begin{array}{r}5.1 \\
10.9 \\
82.1 \\
1.4\end{array}$ & $\begin{array}{r}0.8 \\
6.0 \\
92.4 \\
0.7\end{array}$ \\
\hline 3 & 30 & $\begin{array}{ll}5 & \\
7 & \\
8 & \text { Host } \\
9 & \text { Charleston }\end{array}$ & $\begin{array}{r}7.2 \\
4.5 \\
9.9 \\
75.0\end{array}$ & $\begin{array}{r}2.7 \\
2.2 \\
11.2 \\
82.0\end{array}$ & $\begin{array}{r}0.1 \\
0.2 \\
11.7 \\
87.1\end{array}$ \\
\hline 4 & 30 & $\begin{array}{l}4 \\
9 \\
10 \text { Charleston } \\
25 \text { Host }\end{array}$ & $\begin{array}{r}4.2 \\
5.2 \\
89.8 \\
-0\end{array}$ & $\begin{array}{r}2.4 \\
2.9 \\
94.6 \\
-0\end{array}$ & $\begin{array}{c}0.2 \\
0.4 \\
99.4 \\
\sim 0\end{array}$ \\
\hline
\end{tabular}

Seismic sources which do not contribute at least $2 \%$ to any one of the ground motion levels listed are not shown.

2 The numbers/symbols in this column correspond to the name of the seismic source as defined by the seismicity expert. 
Table 46 (continued)

Contribution (\%) of Seismic Sources for Each LLNL Seismicity Expert to the Mean PGA Hazard - 5 GME Case'

\begin{tabular}{|c|c|c|c|c|c|}
\hline \multirow[b]{2}{*}{$\begin{array}{l}\text { Seismicity } \\
\text { Expert }\end{array}$} & \multirow[b]{2}{*}{$\begin{array}{c}\text { Number of } \\
\text { Maps }\end{array}$} & \multirow[b]{2}{*}{$\begin{array}{l}\text { Seismic } \\
\text { Source }^{2}\end{array}$} & \multicolumn{3}{|c|}{$\begin{array}{l}\text { Peak Ground } \\
\text { Acceleration (g) }\end{array}$} \\
\hline & & & 0.13 & 0.25 & 1.00 \\
\hline 5 & 11 & $\begin{array}{l}1 \\
9 \text { Charleston } \\
10 \text { Host } \\
11\end{array}$ & $\begin{array}{r}3.4 \\
85.3 \\
2.9 \\
6.6\end{array}$ & $\begin{array}{r}2.2 \\
94.4 \\
1.5 \\
1.3\end{array}$ & $\begin{array}{r}1.1 \\
98.5 \\
0.3 \\
0.0\end{array}$ \\
\hline 6 & 3 & $\begin{array}{l}13 \text { Host/Charleston } \\
\mathrm{CZ} \\
10 \\
11\end{array}$ & $\begin{array}{r}55.6 \\
3.8 \\
20.3 \\
18.1\end{array}$ & $\begin{array}{r}59.3 \\
3.1 \\
16.9 \\
16.6\end{array}$ & $\begin{array}{r}74.5 \\
2.5 \\
9.7 \\
13.2\end{array}$ \\
\hline 7 & 1 & $\begin{array}{ll}6 & \\
8 & \text { Host } \\
10 & \text { Charleston }\end{array}$ & $\begin{array}{r}51.9 \\
6.0 \\
40.9\end{array}$ & $\begin{array}{r}47.3 \\
5.5 \\
46.7\end{array}$ & $\begin{array}{r}11.2 \\
4.6 \\
84.1\end{array}$ \\
\hline 10 & 30 & $\begin{array}{l}4 \text { Host } \\
15 \text { Charleston } \\
28\end{array}$ & $\begin{array}{l}44.9 \\
26.7 \\
14.6\end{array}$ & $\begin{array}{r}53.7 \\
28.0 \\
8.3\end{array}$ & $\begin{array}{r}74.2 \\
19.4 \\
1.1\end{array}$ \\
\hline 11 & 30 & $\begin{array}{l}6 \\
7 \\
8 \\
11\end{array}$ Host/Charleston & $\begin{array}{r}2.0 \\
10.3 \\
71.4 \\
14.1\end{array}$ & $\begin{array}{r}0.5 \\
3.7 \\
89.9 \\
5.0\end{array}$ & $\begin{array}{r}0.0 \\
0.1 \\
99.7 \\
0.0\end{array}$ \\
\hline
\end{tabular}


Table 46 (continued)

Contribution (\%) of Seismic Sources for Each LLNL Seismicity Expert to the Mean PGA Hazard - 5 GME Case

\begin{tabular}{|c|c|c|c|c|c|}
\hline \multirow[b]{2}{*}{$\begin{array}{l}\text { Seismicity } \\
\text { Expert }\end{array}$} & \multirow[b]{2}{*}{$\begin{array}{c}\text { Number of } \\
\text { Maps }\end{array}$} & \multirow[b]{2}{*}{$\begin{array}{l}\text { Seismic } \\
\text { Source }^{2}\end{array}$} & \multicolumn{3}{|c|}{ Peak Ground Acceleration (g) } \\
\hline & & & 0.13 & 0.25 & 1.00 \\
\hline 12 & 8 & $\begin{array}{ll}19 & \\
20 & \\
22 & \\
23 A & \text { Charleston } \\
23 & \text { Host } \\
24 & \\
32 & \end{array}$ & $\begin{array}{r}3.7 \\
2.2 \\
2.6 \\
40.0 \\
39.5 \\
2.6 \\
5.5\end{array}$ & $\begin{array}{r}0.9 \\
0.7 \\
1.1 \\
43.7 \\
46.4 \\
1.7 \\
3.8\end{array}$ & $\begin{array}{r}0.0 \\
0.0 \\
0.1 \\
47.6 \\
50.8 \\
0.3 \\
1.2\end{array}$ \\
\hline 13 & 30 & $\begin{array}{l}8 \\
9 \quad \text { Charleston } \\
13 \\
\text { CZ15 } \\
\text { CZ17 Hist }\end{array}$ & $\begin{array}{r}7.5 \\
81.9 \\
1.9 \\
2.3 \\
4.9\end{array}$ & $\begin{array}{r}2.4 \\
88.4 \\
2.1 \\
2.4 \\
4.3\end{array}$ & $\begin{array}{r}0.0 \\
93.6 \\
2.7 \\
2.0 \\
1.7\end{array}$ \\
\hline
\end{tabular}


Table $4-7$

Contribution (\%) of Seismic Sourc for Each LLNL Seismicity Expert to the Mean PGA Hazard - 4 GME Case ${ }^{1}$

\begin{tabular}{|c|c|c|c|c|c|}
\hline \multirow{2}{*}{$\begin{array}{l}\text { Seismicity } \\
\text { Expert }\end{array}$} & \multirow{2}{*}{$\begin{array}{c}\text { Number of } \\
\text { Maps }\end{array}$} & \multirow{2}{*}{$\begin{array}{l}\text { Seismic } \\
\text { Source }^{2}\end{array}$} & \multicolumn{3}{|c|}{ Peak Ground Acceleration (g) } \\
\hline & & & 0.13 & 0.25 & 1.00 \\
\hline 1 & 30 & $\begin{array}{ll}1 & \text { Host } \\
2 & \text { Charleston } \\
3 \\
23 \\
26 \mathrm{~A} \\
26 \mathrm{~B}\end{array}$ & $\begin{array}{r}29.9 \\
13.9 \\
3.4 \\
3.1 \\
12.4 \\
36.1\end{array}$ & $\begin{array}{r}45.7 \\
2.1 \\
0.8 \\
4.5 \\
9.1 \\
37.3\end{array}$ & $\begin{array}{r}75.9 \\
0.0 \\
0.0 \\
3.4 \\
0.8 \\
19.8\end{array}$ \\
\hline 2 & 30 & $\begin{array}{l}29 \text { Host } \\
30 \text { Charleston } \\
\text { CZ }\end{array}$ & $\begin{array}{r}22.1 \\
75.8 \\
2.0\end{array}$ & $\begin{array}{r}31.5 \\
65.7 \\
2.8\end{array}$ & $\begin{array}{l}75.8 \\
13.6 \\
10.6\end{array}$ \\
\hline 3 & 30 & $\begin{array}{ll}7 & \\
8 & \text { Host } \\
9 & \text { Charleston } \\
8 \mathrm{~A} & \end{array}$ & $\begin{array}{r}3.1 \\
20.3 \\
75.1 \\
1.4\end{array}$ & $\begin{array}{r}0.7 \\
38.0 \\
57.7 \\
3.2\end{array}$ & $\begin{array}{r}0.0 \\
83.5 \\
3.6 \\
12.7\end{array}$ \\
\hline 4 & 30 & $\begin{array}{l}9 \\
10 \text { Charleston } \\
25 \text { Host }\end{array}$ & $\begin{array}{c}2.4 \\
97.4 \\
-0\end{array}$ & $\begin{array}{c}0.7 \\
99.1 \\
\sim 0\end{array}$ & $\begin{array}{c}0.0 \\
99.9 \\
\sim 0\end{array}$ \\
\hline 5 & 11 & $\begin{array}{ll}1 & \\
9 & \text { Charleston } \\
10 & \text { Host }\end{array}$ & $\begin{array}{r}6.1 \\
87.5 \\
5.6\end{array}$ & $\begin{array}{r}7.2 \\
86.4 \\
5.8\end{array}$ & $\begin{array}{r}30.6 \\
64.2 \\
4.3\end{array}$ \\
\hline
\end{tabular}

Seismic sources which ( $n$ not contribute at least $2 \%$ to any one of the ground motion levels listed are not shown.

2 The numbers/symbols in this column correspond to the name of the seismic source as defined by the seismicity expert. 
Table $4 \mathbf{7}$ (continued)

Contribution (\%) of Seismic Sources for Each LLNL Seismicity Expert to the Mean PGA Hazard - 4 GME Case ${ }^{1}$

\begin{tabular}{|c|c|c|c|c|c|c|}
\hline \multirow[b]{2}{*}{$\begin{array}{c}\text { Seismicity } \\
\text { Expert }\end{array}$} & \multirow[b]{2}{*}{$\begin{array}{c}\text { Number of } \\
\text { Maps }\end{array}$} & \multirow{2}{*}{\multicolumn{2}{|c|}{$\begin{array}{l}\text { Seismic } \\
\text { Source }^{2}\end{array}$}} & \multicolumn{3}{|c|}{$\begin{array}{l}\text { Peak Ground } \\
\text { Acceleration (g) }\end{array}$} \\
\hline & & & & 0.13 & 0.25 & 1.00 \\
\hline 6 & 3 & $\begin{array}{l}13 \\
\mathrm{CZ} \\
10 \\
11\end{array}$ & $\begin{array}{l}\text { Host/ } \\
\text { Charleston }\end{array}$ & $\begin{array}{r}65.4 \\
3.3 \\
19.9 \\
11.2\end{array}$ & $\begin{array}{r}71.6 \\
\\
3.3 \\
17.6 \\
7.4\end{array}$ & $\begin{array}{r}87.6 \\
3.5 \\
8.2 \\
0.7\end{array}$ \\
\hline 7 & 1 & $\begin{array}{l}8 \\
10\end{array}$ & $\begin{array}{l}\text { Host } \\
\text { Charleston }\end{array}$ & $\begin{array}{l}27.7 \\
71.7\end{array}$ & $\begin{array}{l}45.6 \\
53.9\end{array}$ & $\begin{array}{r}98.1 \\
1.6\end{array}$ \\
\hline 10 & 30 & $\begin{array}{l}4 \\
15 \\
19 \\
28\end{array}$ & $\begin{array}{l}\text { Host } \\
\text { Charleston }\end{array}$ & $\begin{array}{r}62.3 \\
20.4 \\
14.3 \\
3.1\end{array}$ & $\begin{array}{r}73.7 \\
10.9 \\
14.7 \\
0.6\end{array}$ & $\begin{array}{r}96.8 \\
0.1 \\
3.1 \\
0.0\end{array}$ \\
\hline 11 & 30 & $\begin{array}{l}7 \\
8\end{array}$ & $\begin{array}{l}\text { Host/ } \\
\text { Charleston }\end{array}$ & $\begin{array}{r}3.4 \\
95.6\end{array}$ & $\begin{array}{r}0.3 \\
99.1\end{array}$ & $\begin{array}{r}0.0 \\
99.9\end{array}$ \\
\hline 12 & 8 & $\begin{array}{l}23 \mathrm{~A} \\
23\end{array}$ & $\begin{array}{l}\text { Charleston } \\
\text { Host }\end{array}$ & $\begin{array}{l}19.6 \\
76.6\end{array}$ & $\begin{array}{r}5.9 \\
93.5\end{array}$ & $\begin{array}{r}0.0 \\
99.9\end{array}$ \\
\hline 13 & 30 & $\begin{array}{l}9 \\
13 \\
\text { CZ15 } \\
\text { CZ17 }\end{array}$ & Charleston & $\begin{array}{r}89.3 \\
1.7 \\
2.4 \\
6.5\end{array}$ & $\begin{array}{r}82.1 \\
3.2 \\
4.7 \\
10.1\end{array}$ & $\begin{array}{l}21.1 \\
27.8 \\
34.5 \\
16.7\end{array}$ \\
\hline
\end{tabular}


Table 4-8

Summary of The LLNL Seismicity Expert Estimates of Seismic-Activity Rate

\begin{tabular}{|c|c|c|c|c|}
\hline \multirow[b]{2}{*}{ Seismicity Expert } & \multicolumn{4}{|c|}{$\begin{array}{c}\text { Seismic-Activity Rate }\left(m_{b} \geq 5\right)^{1} \\
\text { (Events/Year) }\end{array}$} \\
\hline & 0.15 & 0.50 & 0.85 & Mean \\
\hline 1 & $4.81-2$ & $6.86-2$ & $8.47-2$ & $6.79-2$ \\
\hline 2 & $1.72-2$ & $1.27-1$ & $4.26-1$ & $2.02-1$ \\
\hline 3 & $9.61-3$ & $2.44-2$ & $6.01-2$ & $3.50-2$ \\
\hline 4 & $4.70-2$ & $1.13-1$ & $3.55-1$ & $1.76-1$ \\
\hline 5 & $3.70-2$ & $1.94-1$ & 1.17 & $9.63-1$ \\
\hline 6 & $1.90-2$ & $4.09-2$ & $7.81-2$ & $4.82-2$ \\
\hline 7 & $2.72-2$ & $1.38-1$ & $7.02-1$ & $4.27-1$ \\
\hline 10 & $1.52-2$ & $2.31-2$ & $3.89-2$ & $2.79-2$ \\
\hline 11 & $1.50-2$ & $4.12-2$ & $1.18-1$ & $6.62-2$ \\
\hline 12 & $7.02-3$ & $1.63-2$ & $3.84-2$ & $2.31-2$ \\
\hline 13 & $8.65-3$ & $2.62-2$ & $1.07-1$ & $8.37-2$ \\
\hline Combined $^{2}$ & $1.41-2$ & $4.68-2$ & $1.86-1$ & $1.90-1$ \\
\hline $\begin{array}{l}\text { CDF Bounds: } \\
\text { Lower } \\
\text { Upper }\end{array}$ & $\begin{array}{l}8.11-4 \\
29.5\end{array}$ & & & \\
\hline
\end{tabular}

Rate corresponds to activity in the area around the SRS shown in Figure 4-1 All seismicity experts 


\section{Table 4-9}

Summary of the LLNL Combined Distribution on the Seismic-Activity Rate and the Expected Number of Events

\begin{tabular}{|c|c|c|}
\hline Fractile/Parameter & $\begin{array}{c}\text { Seismic-Activity Rate } \\
\left(\mathbf{m}_{\mathbf{b}} \geq \mathbf{5 . 0}\right) \\
\text { (Events/Year) }\end{array}$ & $\begin{array}{c}\text { Expected Number } \\
\text { of Events }\end{array}$ \\
\hline 0.15 & $1.41-2$ & 2.8 \\
0.50 & $4.68-2$ & 9.4 \\
0.85 & $1.86-1$ & 37.2 \\
Mean & $1.90-1$ & 38.0 \\
Bounds: & & \\
Lower & $8.11-4$ & 5900 \\
Upper & 29.5 & 5.2 \\
\hline
\end{tabular}


Table 4-10

LLNL Seismicity Expert Maximum Magnitude Estimates For the Charleston Seismic Zone

\begin{tabular}{|c|c|c|c|c|}
\hline \multirow[b]{2}{*}{$\begin{array}{l}\text { Seismicity } \\
\text { Expert }\end{array}$} & \multirow[b]{2}{*}{ Seismic Source } & \multicolumn{3}{|c|}{ Maximum Magnitude } \\
\hline & & Lower & Best & Upper \\
\hline 1 & 2 & 6.4 & 6.7 & 6.9 \\
\hline 2 & 30 & 7.0 & 7.5 & 7.8 \\
\hline 3 & 9 & 6.5 & 6.8 & 7.0 \\
\hline 4 & 10 & 6.7 & 6.8 & 7.0 \\
\hline 5 & 9 & 6.8 & 7.3 & 7.8 \\
\hline 6 & 13 & 6.8 & 7.3 & 7.5 \\
\hline 7 & 10 & 6.8 & 7.3 & 7.5 \\
\hline 10 & 15 & 6.8 & 7.0 & 7.3 \\
\hline 11 & 8 & 6.7 & 7.0 & 7.4 \\
\hline 12 & $23 \mathrm{~A}$ & 6.8 & 6.9 & 7.0 \\
\hline 13 & 9 & 6.6 & 6.7 & 6.9 \\
\hline
\end{tabular}


Table 4-11

LLNL Seismicity Expert Maximum Magnitude Estimates For the

SRS Host Seismic Zone

\begin{tabular}{|c|c|c|c|c|}
\hline \multirow[b]{2}{*}{$\begin{array}{l}\text { Seismicity } \\
\text { Expert }\end{array}$} & \multirow[b]{2}{*}{ Seismic Source } & \multicolumn{3}{|c|}{ Maximum Magnitude } \\
\hline & & Lower & Best & Upper \\
\hline 1 & 1 & 6.3 & 6.4 & 6.4 \\
\hline 2 & 29 & 6.0 & 6.5 & 6.8 \\
\hline 3 & 8 & 6.0 & 6.4 & 6.8 \\
\hline 4 & 25 & 5.3 & 5.5 & 5.7 \\
\hline 5 & 10 & 5.3 & 5.8 & 6.3 \\
\hline 6 & 13 & 6.8 & 7.3 & 7.5 \\
\hline 7 & 8 & 5.3 & 6.0 & 6.3 \\
\hline 10 & 4 & 5.8 & 6.0 & 6.8 \\
\hline 11 & 8 & 6.7 & 7.0 & 7.4 \\
\hline 12 & 23 & 5.7 & 6.0 & 6.2 \\
\hline 13 & $\mathrm{CZ} 17$ & 5.0 & 5.8 & 6.1 \\
\hline
\end{tabular}


Table 4-12

Comparison of EPRI and LLNL Seismic-Activity Rates

\begin{tabular}{|c|c|c|}
\hline Fractile/Parameter & EPRI & LLNL \\
\hline \hline 0.15 & $9.60-3$ & $1.41-2$ \\
\hline 0.50 & $1.51-2$ & $4.68-2$ \\
\hline 0.85 & $3.04-2$ & $1.86-1$ \\
\hline Mean & $1.80-2$ & $1.90-1$ \\
\hline $\begin{array}{c}\text { Bounds: } \\
\text { Lower } \\
\text { Upper }\end{array}$ & $3.00-3$ & $8.11-4$ \\
29.5
\end{tabular}

Table 4-13

Comparison of EPRI and LLNL Expected Number of Earthquakes in a 200 Year Period

\begin{tabular}{|c|c|c|}
\hline Fractile/Paraneter & EPRI & LLNL \\
\hline \hline 0.15 & 1.9 & 2.8 \\
\hline 0.50 & 3.0 & 9.4 \\
\hline 0.85 & 6.1 & 37.2 \\
\hline Mean & 3.6 & 38.0 \\
\hline $\begin{array}{c}\text { Bounds: } \\
\text { Lower }\end{array}$ & 0.6 & 0.2 \\
Upper & 9.2 & 5900 \\
\hline
\end{tabular}




\section{Table 4-14}

Comparison of EPRI and LLNL Recurrence Intervals for

$$
m_{b} \geq 5.0 \text { Events }
$$

\begin{tabular}{|c|c|c|}
\hline \multirow{2}{*}{ Parameter $^{1}$} & \multicolumn{2}{|c|}{ Recurrence Interval (Years) } \\
\cline { 2 - 3 } & EPRI & LLNL \\
\hline Median & 66.2 & 21.4 \\
\hline Mean & 55.6 & 5.26 \\
\hline Upper & 21.7 & 0.034 (12.4 days) \\
\hline
\end{tabular}

1 Parameter corresponds to the seismicity-activity rat.: (see Table 4-12) 


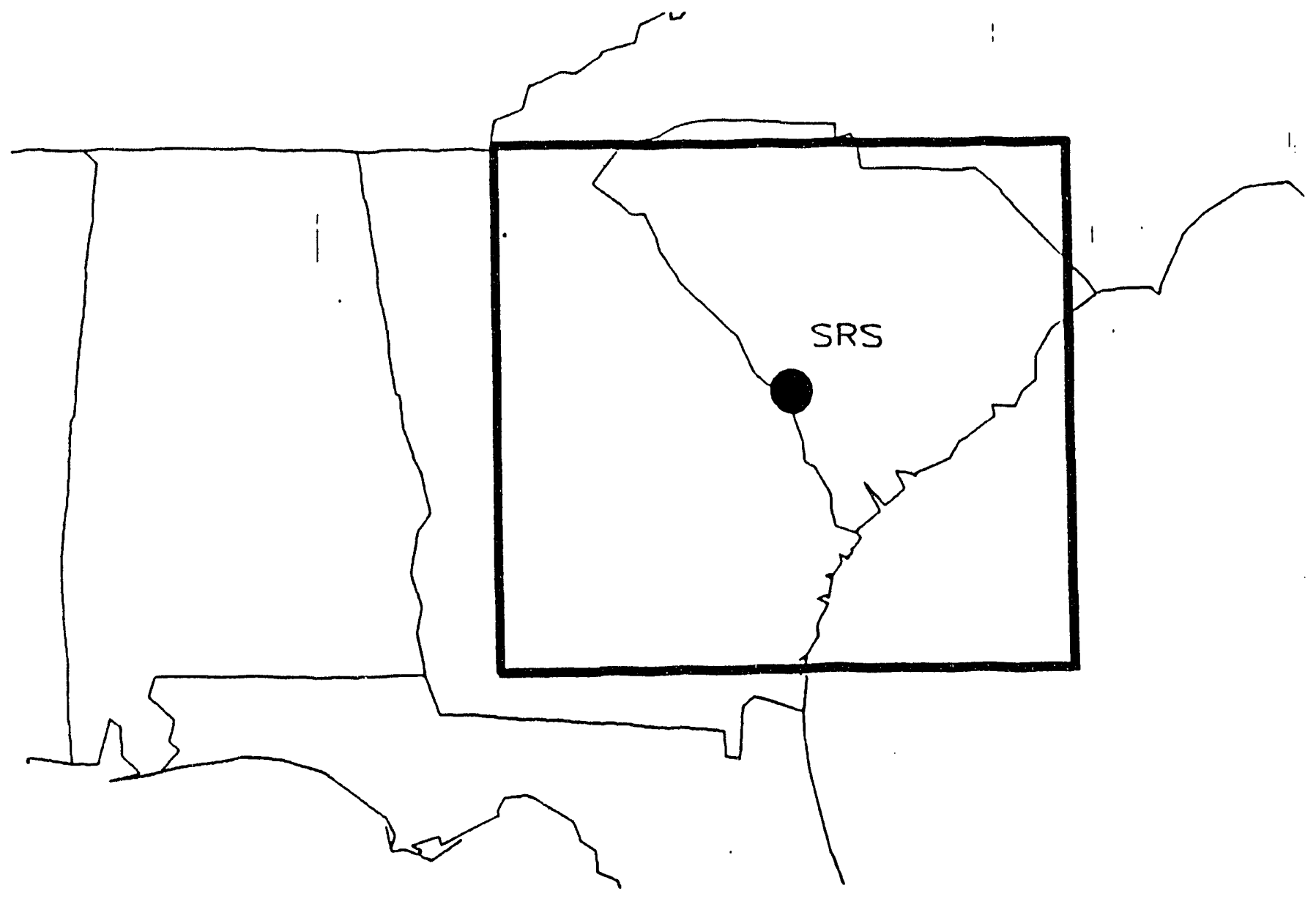

Figure 4-1. Zone around the SRS used to quantify the seismicity expert estimates of the seismic-activity rate in the regional vicinity of the site. 


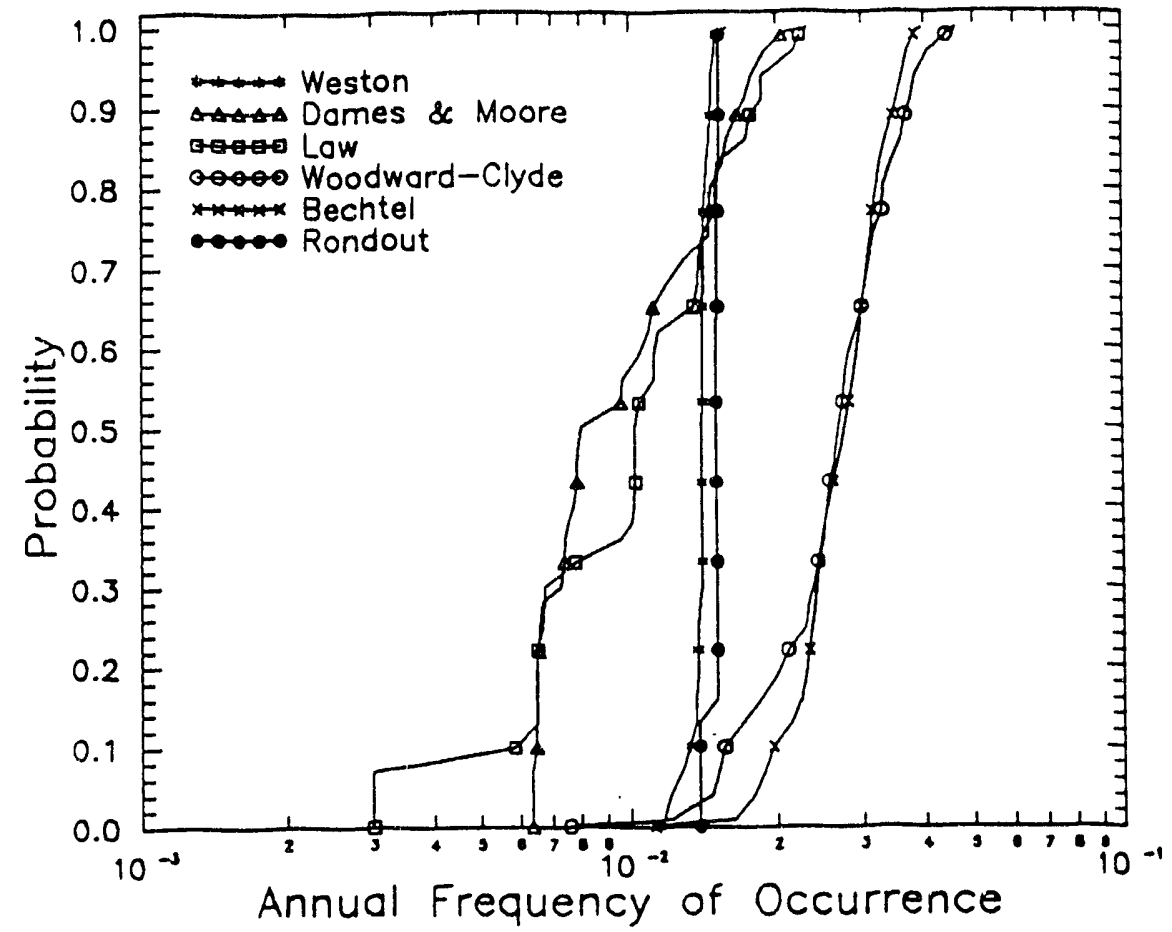

Figure 4-2. Cumulative probability distribution function on the seismic-activity rate $\left(m_{\mathrm{b}} \geq\right.$ 5.0) estimated by the EPRI Earth Science Teams.

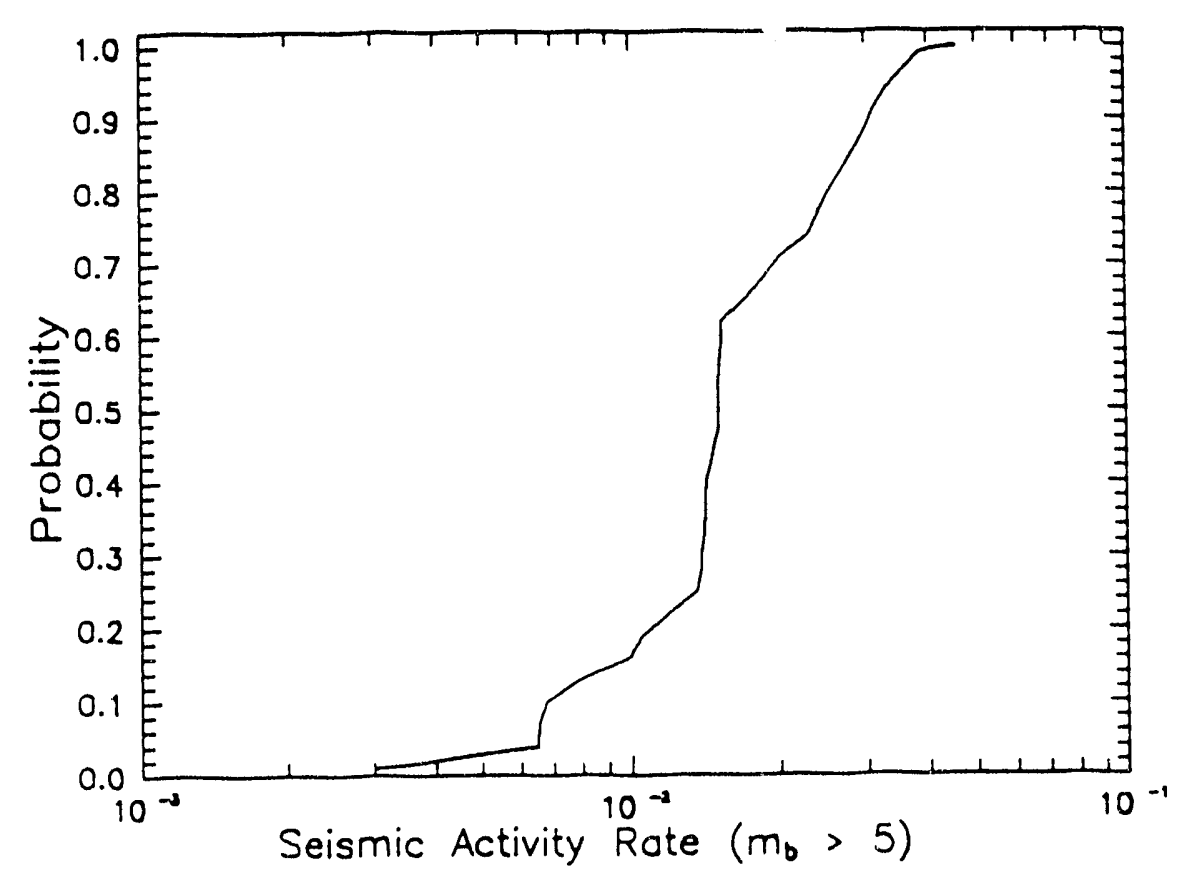

Figure 4-3. Cumulative distribution function on the seismic-activity rate $\left(m_{b} \geq 5.0\right)$ for all the EPRI Earth Science Teams. 


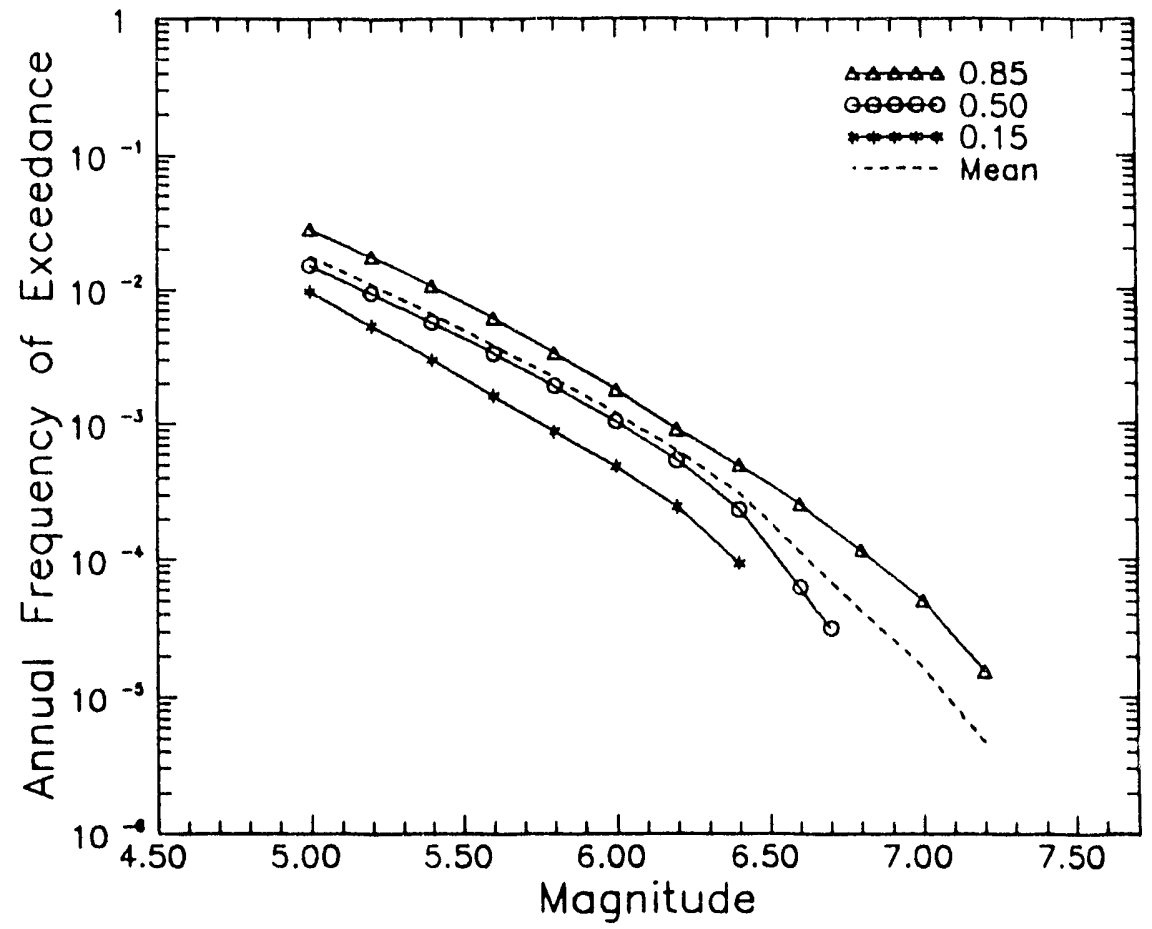

Figure 4-4. EPRI frequency of exceedance of earthquakes in the region near the SRS. 


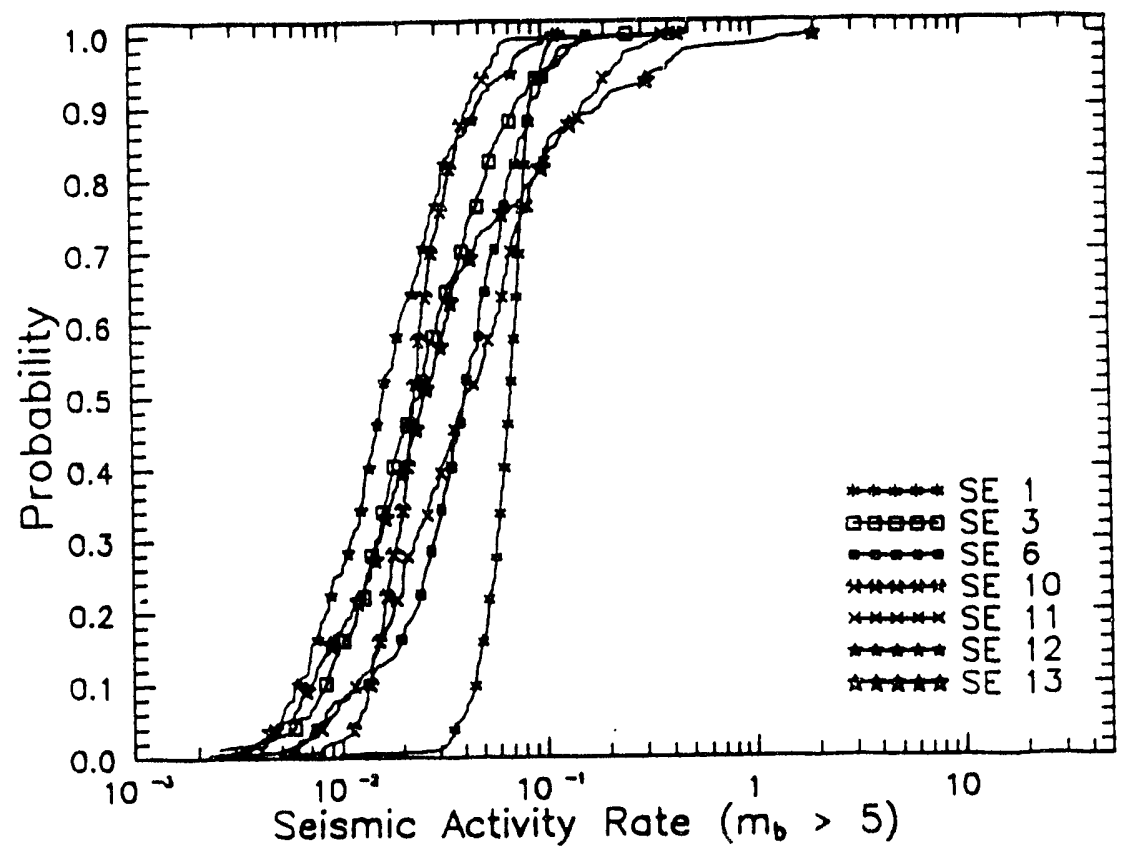

(a)

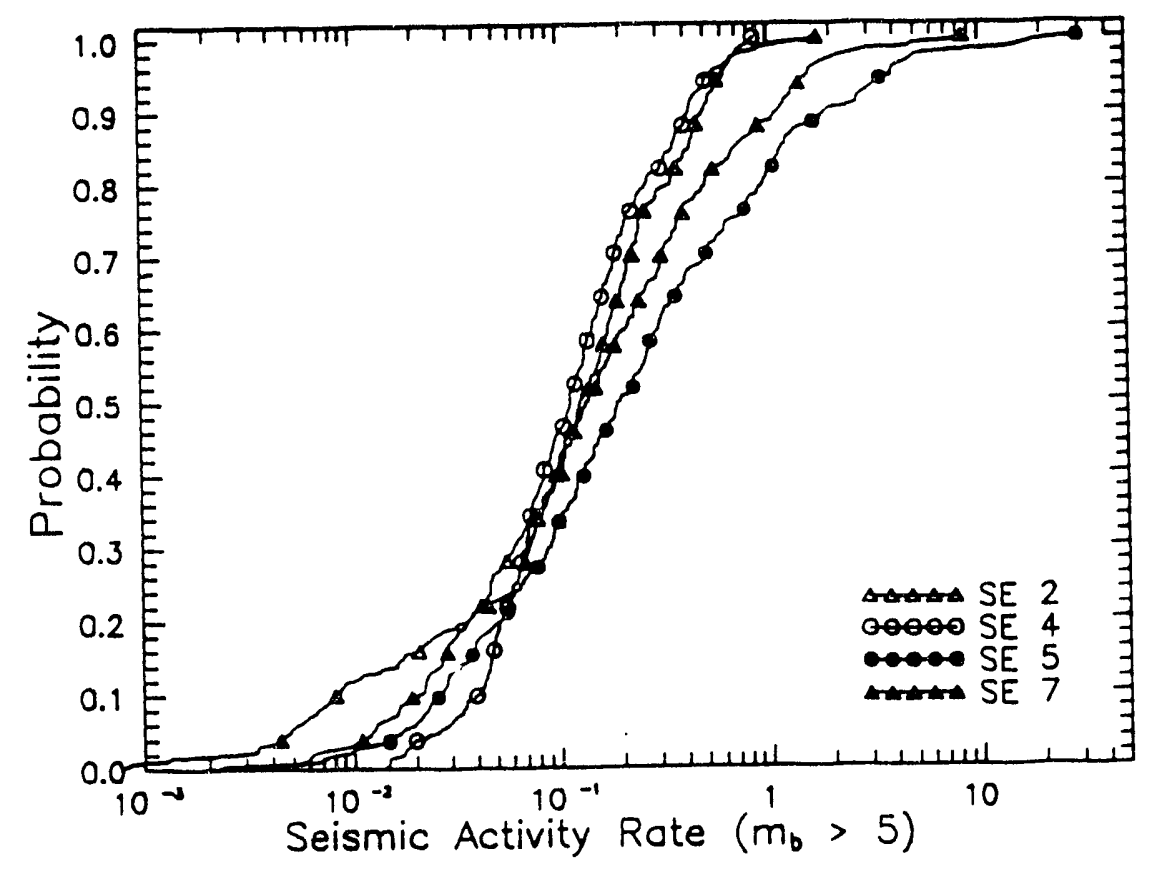

(b)

Figure 4-5. Cumulative probability distribution function on the seismic-activity rate $\left(m_{\mathrm{b}} \geq\right.$ 5.0) for the LLNL seismicity experts. 


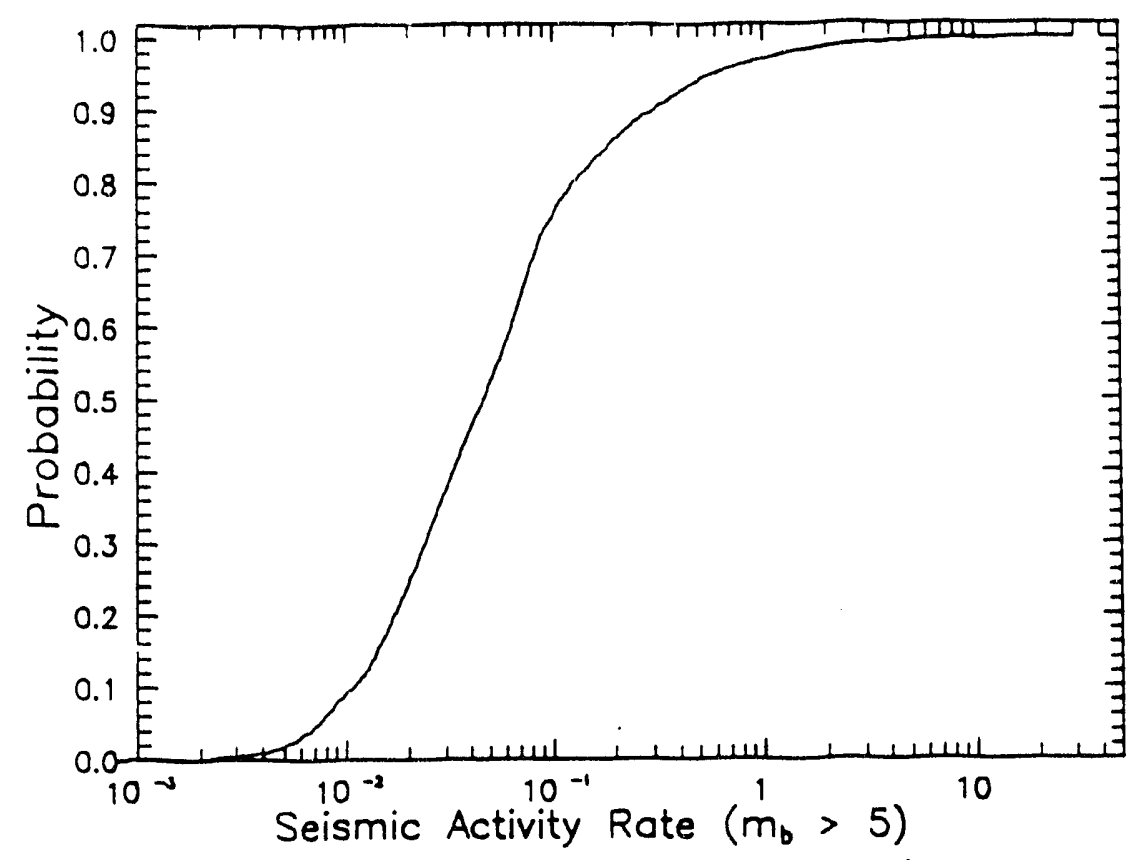

Figure 4-6. Cumulative probability distribution function on the seismic-activity rate $\left(m_{0} \geq\right.$ 5.0 ) for all the LLNL seismicity experts combined for the region near the SRS.

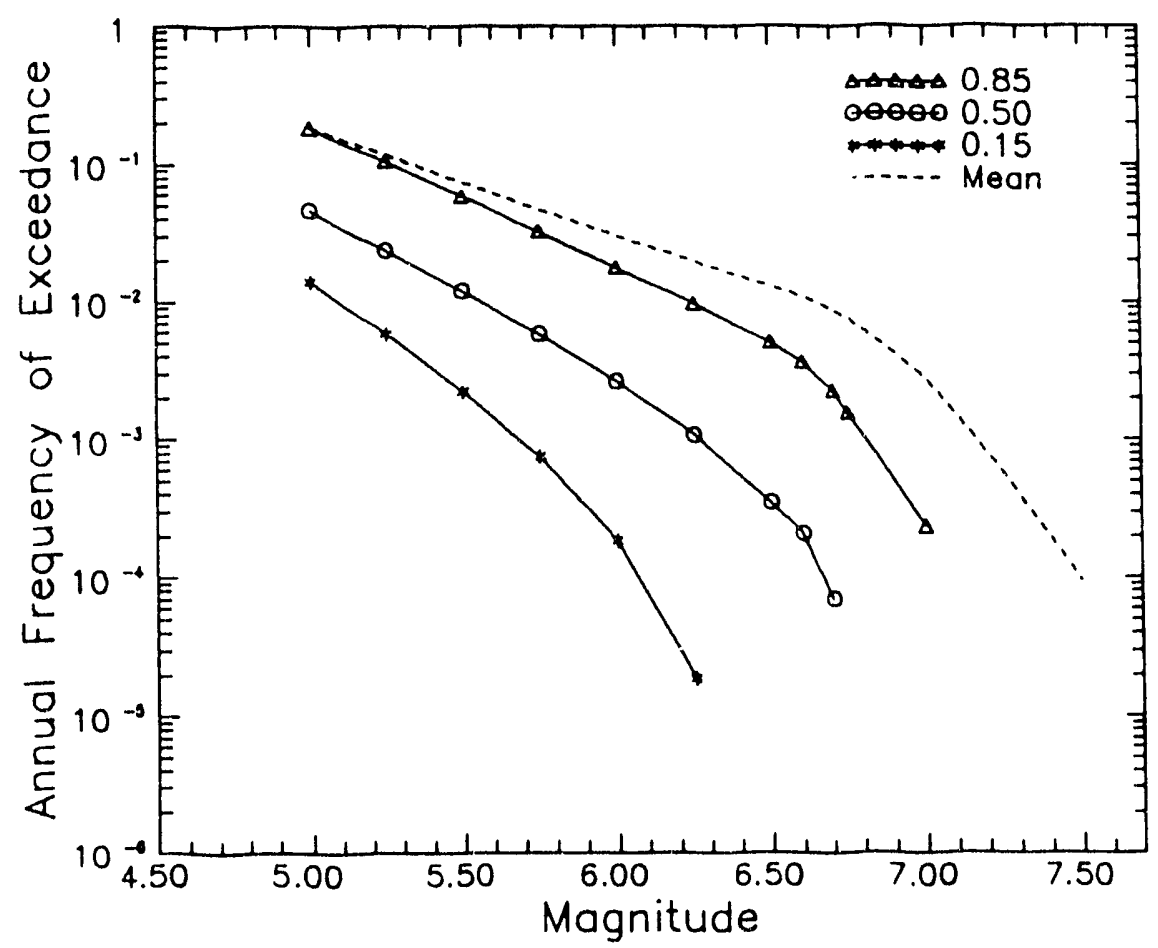

Figure 4-7. LLNL magnitude frequency distribution for all seismicity experts for the region near the SRS. 


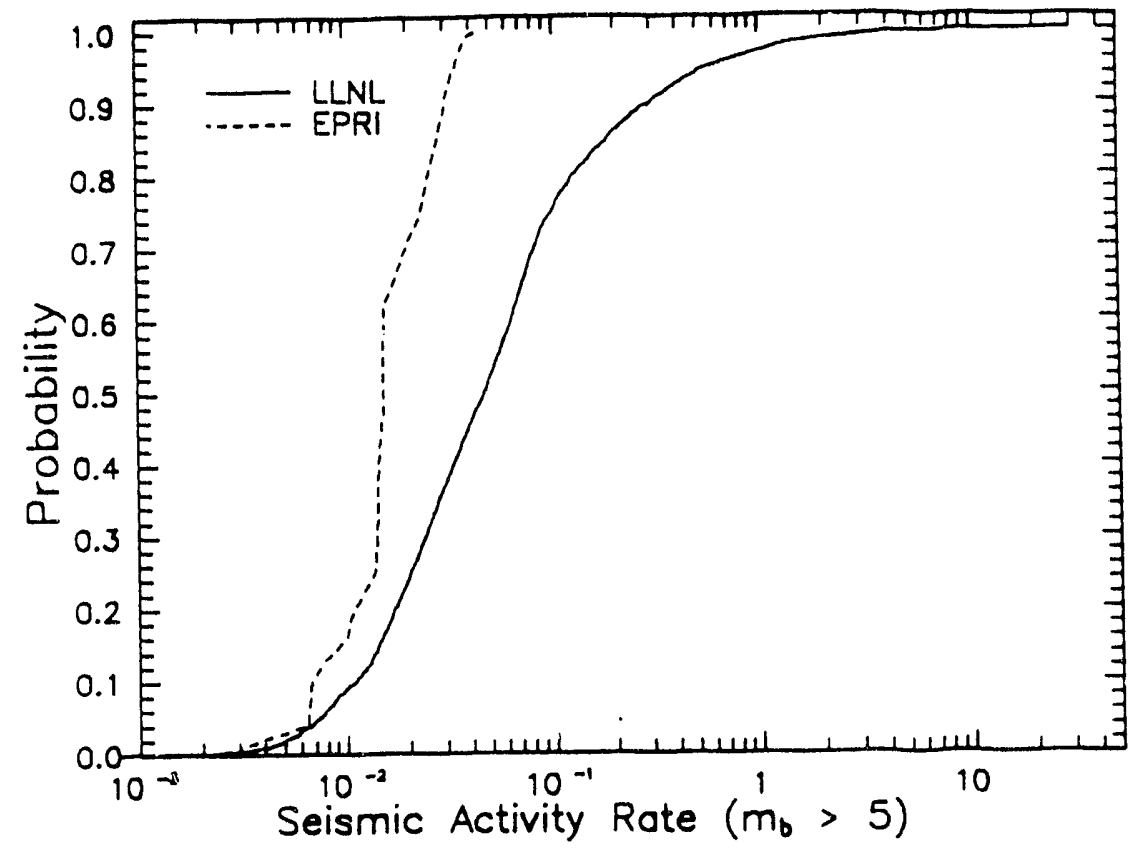

Figure 4-8. Comparison of the EPRI and LLNL cumulative probability distribution functions on the seismic-activity rate for the region near the SRS.

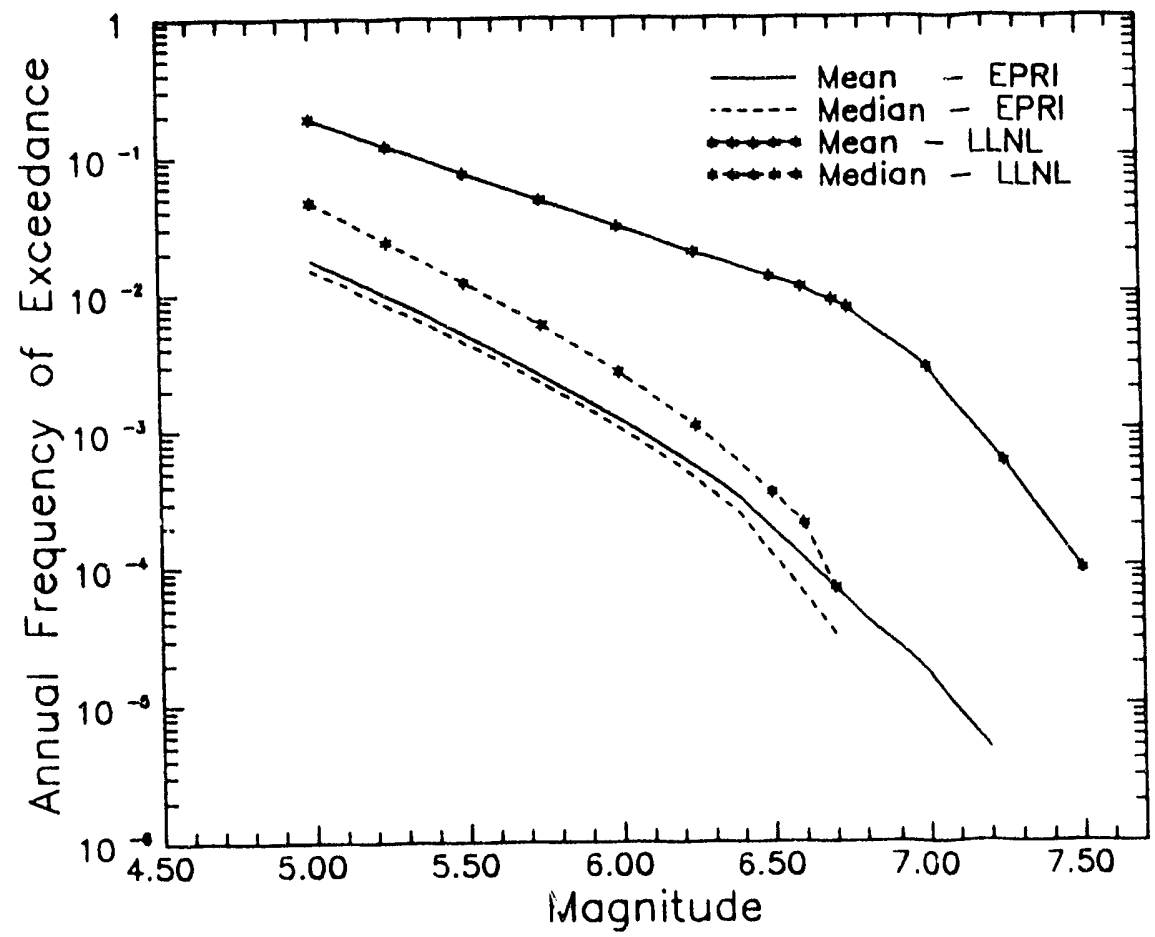

Figure 4-9. Comparison of the EPRI and LLNL median and mean magnitude frequency curves for the region near the SRS. 


\section{Section 5 \\ GROUND MOTION ATTENUATION}

\subsection{Overview}

As a part of the seismic hazard assessment the motion that may occur at a site is modeled by means of a ground motion attenuation relationship. An attenuation relationship estimates the level of shaking as a function of earthquake magnitude and distance from a site. In the EPRI and LLNL seismic hazard studies, ground motion is measured in terms of six parameters. These include PGA and $S_{2}{ }^{1}$ at frequencies of vibration of $1.0,2.5,5.0,10.0$ and $25.0 \mathrm{~Hz}$. In the seismic hazard analysis the likelihood of ground motion for each parameter is estimated independently. Collectively, the set of hazard results for the six ground motion parameters is used to define the UHS (as displayed in Section 3).

This section summarizes the results of a comparative evaluation of the ground motion models used in the EPRI and LLNL studies. As part of the comparison, alternative hazard calculations were performed using the EPRI and LLNL seismicity input. These calculations provide a direct measure of the difference, if any, in the seismic hazard estimated using the EPRI and LLNL attenuation models.

This section summarizes the results of a comparative evaluation of the EPRI and LLNL ground motion modeling. Topics discussed are:

- elements of ground motion modeling,

\footnotetext{
The EPRI and LLNL seismic hazard studies estimate ground response spectra in terms of pseudo-relative response velocity (PSRV). For engineering applications, $S_{\mathbf{a}}$ is preferred. $\mathrm{S}_{\mathbf{a}}$ is determined $2 \Pi \mathrm{f} \cdot \mathrm{PSRV}$, where $\mathrm{f}$ is frequency in $\mathrm{Hz}$.
} 
- uncertainty evaluation,

- comparison of the EPRI and LLNL,

- ground motion attenuation relationships

- estimates of the randomness on ground motion

- ground motion truncation

- comparison of the EPRI and LLNL attenuation models with available strong-motion data,

- differences in seismic hazard estimates using the EPRI and LLNL attenuation models, and

- review of the LLNL GME 5 attenuation models.

Section 5.2 provides an overview of ground motion modeling as applied in the seismic hazard analysis. The following subsection presents a general summary of the EPRI and LLNL approach to modeling ground motion. In Section 5.4 the results of a comparative evaluation of the attenuation models used in the two studies is presented. In the course of the LLNL seismic hazard study, the L.LNL and USNRC staff observed that at many sites the ground motion model selected by LLNL GME 5 has a major impact on the estimate of the mean seismic hazard (see Section 3). Section 5.5 presents the results of a review of the ground motion models selected by GME 5. Section 5.6 summarizes the findings of this review.

A summary of each topic is presented in this report. Volume 2 presents additional supporting data and evaluations.

\subsection{Ground Motion Modeling In Seismic Hazard Assessments}

To model the ground motion that may occur at a site, relationships are used that estimate the level of motion in terms of earthquake magnitude and distance. Due to the 
variation of earthquake source properties (e.g., stress release, fault-rupture characteristics, focal depth, etc.), wave-travel paths and the response of near-surface geologic materials the ground motion that occurs at a site cannot be predicted exactly and in fact is inherently random.

In general terms, ground motion models used in a seismic hazard assessment consist of the following elements:

- a relationship that estimates the median level of motion (for a given ground motion parameter) as a function of earthquake size (i.e., magnitude) and distance,

- a lognormal probability distribution function ${ }^{2}$ that quantifies the randomness in ground motion amplitudes, and a

- truncation level that sets a limit on the motion that can occur.

The ground motion models that were used in the EPRI and LLNL seismic hazard assessments predict motion for rock-site conditions. To estimate the motion at a soil site, both studies developed soil factors for each ground motion parameter that translates the motion at a rock-outcrop to the motion that would be expected to occur at the surface of a soil deposit. Figure 5-1 illustrates the elements of the ground motion model.

The probabilistic model of earthquake ground motion is represented by:

$$
y=g(m, r) * f_{s}^{*} \epsilon \quad y \leq y_{\max }
$$

2The lognormal probability, distribution function is used in the majority of attenuation models, however, in certain cases other probability distribution functions are used to model the randomness in ground motion. 
where,

$$
\begin{aligned}
y= & \text { ground motion parameter (e.g., PGA) } \\
g(m, r)= & \text { relationship that defines the median ground motion level as } \\
& \text { a function of earthquake magnitude, } m \text {, and distance, } r \\
f_{s}= & \text { soil factor that relates the motion at a rock outcrop to the } \\
& \text { motion at the surface of a soil deposit (e.g., } f_{s}=1.0 \text { for } \\
& \text { rock sites) } \\
\epsilon \quad & \text { lognormal random variable with median of } 1.0 \text { and a } \\
& \text { logarithmic-standard deviation, } \sigma_{y} \\
y_{\max }= & \text { limit or truncation level on ground motion }
\end{aligned}
$$

To model the uncertainty in the assessment of ground motion, alternative estimates of $\mathrm{g}(\mathrm{m}, \mathrm{r})$ are specified. Each estimate is assigned a probability weight. This is denoted by the following doublet,

$$
\left\{g(m, r), p_{i}\right\}
$$

where $i$ is the index on the number of attenuation models and $p_{i}$ and is a probability weight that quantifies the relative degree-of-belief assigned to a model. The $p_{i}$ 's sum to 1.0 for the full set of models that are considered.

In the LLNL study a triangular probability density function was used to quantify the uncertainty in $\sigma_{y}$. The density function was defined by a best estimate which corresponds to the mode, and lower- and upper-bounds that define the 0.025 and the 0.975 cumulative probability levels. The uncertainty on $\sigma_{y}$ was not considered in the EPRI study.

In the LLNL study, the GMEs were permitted to specify limits on ground motion. 
Three methods for truncation were considered:

1. Define an absolute limit on the level of ground motion that cannot be exceeded. This limit is independent of earthquake magnitude and distance.

2. The maximum ground motion is defined as a function of earthquake magnitude and distance. In this case the maximum value is specified in terms of the number of standard deviations above the median (or mean $\log$ ) ground motion level.

3. As a third approach, the limiting level on ground motion can be defined as a combination of the first two approaches. In this case the limit on ground motion is defined as the minimum of an absolute limit or a fixed number of standard deviations above the median. This approach defines an envelope of the first two methods.

Figure 5-2 illustrates each of these approaches. Note, the first truncation approach defines a limit that is independent of magnitude and distance, whereas the second approach establishes a limiting curve that parallels the median estimate of ground motion. The third truncation procedure defines an envelope of the first two approaches.

\subsection{Modeling Earthquake Ground Motion: EPRI and LLNL}

This section provides a summary of the EPRI and LLNL approach to modeling ground motion in the seismic hazard assessment. Table 5-1 provides a tabular summary of the basic elements of the EPRI and LLNL approaches. The following summarizes each item listed in the table.

EPRI, in consultation with one consulting firm and review by the USNRC staff, selected the ground motion models used in the hazard analysis. As part of their work, EPRI held an informational workshop to address the issue of modeling strong-ground motion in the EUS (10). To model the uncertainty in ground motion, (PGA and $S_{2}$ ) three models were 
selected and assigned a probability weight. As indicated in Table 5-1 these models are included in the group of models selected by the LLNL experts.

To model the uncertainty in ground motion, LLNL created a panel of five GMEs. Each expert was provided the opportunity to select multiple ground motion models and to specify the uncertainty in $\sigma_{y}$ in terms of a probability density function for each ground motion parameter. Each expert was also given the option to specify a limit or truncation level on ground motion. The uncertainty in ground motion was quantified in terms of:

- a group of GMEs who assigned self-weights to their assessments,

- a set of attenuation models (e.g., alternative functions for $g(m, r)$ ) with corresponding probability weights provided by each GME, and a

- probability density function on $\sigma_{\mathrm{y}}$ provided by each expert.

The use of a group of GMEs provides a broad professional evaluz on of ground motion modeling in the EUS, whereas the models provided by each expert quantifies their individual uncertainty.

\subsection{EPRI and LLNL Ground Motion Models}

\subsubsection{Model Selection}

Table 5-2 lists the EPRI ground motion models for PGA and PSRV ${ }^{3}$ and the probability weight assigned to each model. Figure 5-3 shows the PGA attenuatio:i relationships used in the EPRI study for magnitude 5.0 and 7.0 events. Figure 5-4 shows the S. ground response spectra estimated by the EPRI attenuation models for events of magnitude

${ }^{3}$ The PSRV model coefficients are listed in Table 5-1 for consistency with EPRI published reports. 
5.0 and 7.0 at distances of 20 and $50 \mathrm{~km}$, respectively.

Tables 5-3 and 5-4 list the LLNL PGA and PSRV ground motion models, respectively. Each table lists the experts who selected the model, the expert self weight, the weight assigned to each model by the expert and total model weight (product of the expert selfweight and model weight). The total model weights are reported for the $5 \mathrm{GME}$ case and the 4 GME cases. Figure 5-4 shows the LLNL PGA attenuation models for magnitude 5.0 and 7.0 events. In Figure 5-6 the $S$, ground response spectra for magnitude 5.0 and 7.0 events at 20 and $50 \mathrm{~km}$, respectively are shown.

A comparison of the models used in the two studies suggests the following observations:

- The EPRI PGA and PSRV models are incorporated in the models selected by the LLNL experts.

- With the exception of the models (one each ground motion parameter) selected by GME 5, the EPRI and LLNL models are similar in terms of the range of ground motion levels that are predicted.

- At short distances (less than $10 \mathrm{~km}$ ), LLNL model COMB-1A predicts slightly higher ground motions at large magnitudes than the other models.

- The Nuttli attenuation relationships (used in both studies) predicts higher motions at nearly all distances with the exception of the models selected by LLNL GME 5.

- The ground motion models selected by LLNL GME 5 has a lower rate of attenuation than other models and a larger magnitude coefficient than other relationships. As a result, for magnitude 7 events, the estimated PGA motions are a factor of 1.5 or more higher than the next highest ground motion predictions.

Table 5-5 shows a comparison of the weight assigned by EPRI and ILNL to the PGA 
models used in the two studies. For LLNL, the weights are reported for the $4 \mathrm{GME}$ and 5 GME cases. Overall, the two studies assign comparable weight to the models that are shared. In the $4 \mathrm{GME}$ case, the LLNL experts assign a total weight of 0.90 to the models used in the EPRI study (this includes the Nuttli-SE2 model which is similar to Nuttli-SE1). In the $5 \mathrm{GME}$ case this cumulative weight is 0.72 . Consequently, there is a high degree of similarity in the models that were used in the two studies and the relative weights that were assigned.

\subsubsection{Comparison With Strong Motion Data}

A comparison of the EPRI and LLNL ground motion models with available strongmoticn data was made. Although a comprehensive database of strong-motion recordings is not available for the EUS, it is useful to assess whether the data which are available support the predictions that are made.

In 1988 the Saguenay earthquake occurred in eastern Canada, producing the largest dataset of strong-motion recordings in eastern North America. Since the Saguenay data was not available at the time the EPRI and LLNL studies were performed, this dataset provides a basis for an interesting comparison with model predictions. Volume 2 provides a detailed description of the available database and the comparative evaluations that were performed.

To summarize the comparison of the EPRI and LLNL ground motion models with available strong-motion data, the estimated mean error (bias) in the model predictions was calculated. The assessment was performed for two cases; one using the data available at the time the seismic hazard studies were performed and the second was the same database including the strong-motion data from the Saguenay earthquake. Figure 5-7 shows a plot of the mean, model-to-data ratio for PGA and $S_{a}$ at $1.0,5.0,10.0$ and $25.0 \mathrm{~Hz}$ for the EPRI attenuation models. Two plots are shown in the figure. The first shows the results for the 
EUS strong-motion database recorded at distances of $100 \mathrm{~km}$ or less, excluding the Saguenay earthquake data. The second plot shows the results for the EUS database with the Saguenay data included. Figure 5-8 shows the results for the LLNL attenuation models. The symbol denoted G16-A3/TL corresponds to the model selected by LLNL GME 5.

From the results in Figures 5-7 and 5-8 the following observations are made:

- the EPRI and LLNL ground motion models, in general, tend to overestimate ground motions at all frequencies, with the exception of the Boore-Atkinson model, which is LLNL model RV1,

- overestimates range from just over a factor of 1.0 to about 10. Model underestimates do not exceed about 30 percent.

- for frequencies ranging from 1 to $10 \mathrm{~Hz}$, the models selected by LLNL GME 5 have the highest systematic deviation from the data. At 1 and 5 $\mathrm{Hz}$, ground motion is overestimated by a factor of approximately 10 and 4 , respectively,

- at $25 \mathrm{~Hz}$ the LLNL GME 5 model is generally consistent with the available data, and

- for PGA, the LLNL GME 5 model overestimates ground motion by a factor of about 1.5, which is similar to the results for the Nuttli PGA models (SE1 and SE2).

Since these observations apply to both datasets, it is concluded that the Saguenay earthquake, despite it's unique characteristics, do not significantly affect the conclusions.

To summarize, studies that compare the EPRI and LLNL ground motion models to available strong-motion data conclude that, overall, they are consistent with the data to within a factor of 2 . However, more modeis tend to overestimate, as opposed to underestimate obse:ved ground motions. This conclusion holds as well when the data from the 1988 Saguenay earthquake is considered. With respect to the ground motion models selected by 
LLNL GME 5, the following observations are made:

- for spectral accelerations of 1.0 and $5.0 \mathrm{~Hz}$ the bias in the model predictions exceeds a factor of 4 and is as high as a factor of approximately 10 .

- at large distances, $40 \mathrm{~km}$ and greater, these models tend to overestimate ground motions at most frequencies (the exception being $25 \mathrm{~Hz}$ ).

These empirical evaluations suggest that available strong-motion data does not support the ground motion models selected by LLNL GME 5.

\subsubsection{Comparative Seismic Hazard Evaluations}

To provide a direct measure of the differences between the EPRI and LLNL ground motion models, a series of bazard calculations for PGA are performed. As demonstrated in Section 3, the attenuation: model selected by LLNL GME 5 has a significant impact on the estimated mean hazard, ( $\mathrm{fC} i$ rock-site conditions). For these comparative evaluations, the EPRI and the LLNL 4 GME case attenuation relationships are used.

To assess the potential differences in the seismic hazard using the two sets of attenuation relationships, SRS seismic hazard calculations were performed using the EPRI and LLNL seismicity models (e.g., seismic sources, seismicity parameters). A total of four hazard calculations were performed for alternative pairings of seismicity models and attenuation relatiorisiips. For example, the LLNL seismicity models were paired with the EPRI attenuation models, and so on. In these calculations the LLNL attenuation models are used with the GME best-estimate for the logarithmic-standard deviation, $\sigma_{y}$.

Table 5-6 summarizes the results of these calculations in terms of the ratio of the mean hazard values at $0.25,0.55$ and $1.0 \mathrm{~g}$ PGA. Two sets of comparisons are reported; the ratio of the hazard using the EPRI seismicity models paired with the EPRI and the LLNL ground 
motion models and the ratio of the hazard estimates using the LLNL seismicity models paired with the LLNL and EPRI ground motion models. The alternative pairing of the two sets of ground motion and seismicity models accounts for possible interactions, such as differences that may exist in the EPRI and LLNL seismicity models (e.g., seismic source locations relative to the $S R S$, differences in $m_{\max }$, etc.).

The first case listed in Table 5-6 pairs the EPRI seismicity models with the two sets of attenuation models. The results indicate that the EPRI attenuation models consistently estimate higher hazard by 13 to 18 percent at all ground motion levels.

In the second case the LLNL seismicity models were paired with each set of attenuation models. In this case the hazard based on the LLNL attenuation predicts consistently higher hazard by a factor of 2.4 to 2.8 . From these two sets of comparisons the following observations are made:

- EPRI and LLNL 4 GME case ground motion models produce generally hazard results that are consistent, to within a factor of 3 or less, and

- differences between the LLNL and EPRI seismicity models, emphasizes small differences in the two sets of attenuation models.

The observation that the LLNL attenuation models predict higher hazard than the EPRI attenuation, when paired with the LLNL seismicity data, is believed to be indicative of the differences in the two sets of seismicity models. As noted in Section 4, two of the LLNL seismicity experts have defined the Charleston seismic source such that it is also the host source for the SRS. In this case, larger seismic events have a relatively higher likelihood of occurring closer to the site than predicted in the EPRI study. As a consequence, differences in the attenuation models for large magnitudes and short distances may impact the hazard assessment. As noted earlier in this section, at short distances, less than about $10 \mathrm{~km}$, certain LLNL attenuation models predict slightly higher motions, particularly for moderate- 
to large-magnitude events. As a result, the LLNL attenuation models produce mean hazard results that are higher by a factor of 2 to 3 .

\subsubsection{Randomness of Ground Motions}

In their hazard study, EPRI did not consider the logarithmic-standard deviation on attenuation, $\sigma_{y}$, as an uncertain parameter in the hazard analysis. A single value of 0.50 was used for all ground motion models and ground motion parameters i.e., PGA, PSRV).

In the LLNL study, the GMEs were given the opportunity to provide an estimate of $\sigma_{y}$ that would be used in conjunction with the ground motion models they provided. In addition, each GME could specify the uncert: ikiy on $\sigma_{y}$ by a triangular-probability density function. Table 5-7 lists the best-estimate value and the lower- and upper-bound values on $\sigma_{y}$ for PGA and PSRV. Also listed in the table is the average (for all GMEs) best-estimate value. These values are 0.52 and 0.50 , for PGA and PSRV respectively, which compare with the EPRI value of 0.50 .

With one exception, all LLNL GMEs used a lognormal probability distribution to define the variability on ground motion. GME 5 provided a ground motion model for PSRV that incorporated the distribution on ground motion.

The fact that the LLNL study considered $\sigma_{y}$ an uncertain parameter in the hazard analysis is a difference that exists with the EPRI approach. To assess the impact that the uncertainty on the logarithmic-standard deviation on attenuation may have, a series of hazard calculations were performed. Hazard estimates were obtained for the LLNL ground motion models were combined with the LLNL and EPRI seismicity data. Table 5-8 illustrates the various hazard calculations that were considered. For the calculations using the LLNL and EPRI seismicity data, two sets of hazard evaluations were performed. When calculations 
were performed using the LLNL seismicity data two assessments were made; one in which the uncertainty in $\sigma_{y}$ was considered and a second with $\sigma_{y}=0.50$. When the LLNL attenuation models were run with the EPRI seismicity data, similar assessments were made. however in the second case the GME best-estimate $\sigma_{y}$ values were used. The results, using the LLNL and EPRI seismicity data, indicate that the uncertainty on $\sigma_{y}$ has a small impact on the overall uncertainty in the hazard assessment.

\subsubsection{Truncation}

The lognormal probability distribution function that quantifies the randomness in ground motion is theoretically unbounded. Engineers and seismologists generally agree there are limits on the motion that may be transmitted to the ground surface, particularly at soil sites. If limits on ground motion can be defined, the lognormal distribution can be truncated to rein : "nis.

In the LLNL study the ground motion experts were given the option to specify limits on ground motion using any of the three methods outlined in Section 5.2. EPRI did not include a truncation parameter in their study.

In the LLNL study the experts either did not specify a truncation level or selected a level that is beyond the ground motions of engineering interest (e.g., 2.5g PGA). For PGA and PSRV, 3 of the GMEs did not specify a truncation. As a result it is concluded that the truncation parameter is not a source of differences in seismic hazard assessments between the two studies.

\subsection{LLNL Ground Motion Expert 5 Attenuation Models}

As noted previously in this section, reviews of the LLNL seismic hazard study have observed the relative impact of the ground motion models selected by LLNL GME 5 on the 
assessment of seismic hazard in the EUS. At many sites the $85^{\text {th }}$ percentile and the mean seismic hazard are strongly affected by these models. As part of the USNRC IPEEE program, a review and grouping of the seismic hazard at ccmmercial nuclear power plant sites was carried out using both the EPRI and LLNL 5 GME and 4 GME case hazard results as independent estimates of seismic hazard (18). This approach reflects a general concern the part of the USNRC staff that the LLNL 5 GME results adversely impact the estimated hazard at certain sites, even in a relative sense.

This section presents a summary of information and the results of recent work ine ground motion models selected by LLNL GME 5. Recall, in Sectiun 5.4.2 the EPRI and LLNL ground motion models were compared to the available strong-motion data. The results of the comparative evaluation indicated the attenuation models selected by GME 5 consistently overestimate ground motions, except at $25.0 \mathrm{~Hz}$. In addition, the following topics are discussed in this subsection relative to the attenuation models selected by GME 5:

- procedure used to derive the attenuation models,

- seismic hazard estimates obtained using GME 5's models, and

- LLNL seismic hazard assessment for the New Production Reactor (NPR) at the SRS.

In the remainder of this subsection a summary of these topics is presented.

Model Estimation - The ground motion attenuation models (for PGA and PSRV) selected by LLNL GME 5 were derived through a series of parameter transformations. The steps involved a conversion of the Modified Mercalli Intensity at a site, $I_{2}$, to instrumental ground motion (e.g., PGA or PSRV), epicentral intensity, $I_{o}$, to $I_{1}$ and $I_{0}$ to $m_{b}$. In the past, the process of estimating ground motion through the use of such transformations was popular only when limited instrumental data were available to empirically derive magnitude-distance 
attenuation motion models. However, as a number of studies have pointed out (19-21) there are difficulties associated with such procedures, which, if not properly addressed can lead to results that are biased and unrealistic from the perspective of the physical process being modeled.

In a recent study the issue of model estimation as used by LLNL expert 5 was examined in detail (22). The findings of this study were:

- the assumption that intensities ( $I_{0}$ and $I_{3}$ ) in California and the EUS are similar is not substantiated,

- intensity data are biased since it does not represent average conditions,

- the transformation (or substitution) procedure used by LLNL GME 5 results in ground motion models that are biased (even given unbiased data), and

- differences in the spectral shape of ground motions in the western and eastern U.S. were not accounted for.

The drawbacks in the development of the models used by LLNL GME 5 reflect fundamental concerns with the basic data and the process used to derive the model parameters. These concerns reflect a weak technical foundation for these attenuation models.

Seismic Hazard Assessments Based On GME 5 Models - As discussed in Section 2 the assessment of seismic hazard involves the calculation of many thousands of hazard curves.

When the hazard results are presented in terms of percentile curves and the mean, the individual hazard values that comprise the distribution are not apparent. To provide insights to the hazard estimates in the LLNL study and in particular to those associated with the ground motion model selected by GME 5, an accounting of the individual hazard results was made. Table 5-9 lists the 30 highest PGA hazard results at $0.13 \mathrm{~g}$ in the LLNL 5 GME case (rock-site conditions). The table contains the following information: 
- ground motion expert and seismicity expert numbers that provided the input to the hazard calculation,

- discrete probability weight associated with the hazard estimate,

- the cumulative probability level,

- the contribution (in percent) of the hazard value to the mean probability of exceedance,

- the cumulative contribution (in percent) of the top hazard values to the mean probability of exceedance,

- the hazard value, and the

- cumulative mean hazard.

A review of the data in Table 5-9 and the complete cumulative distribution function illustrates the range and skewness of the LLNL uncertainty assessment. The following observations are made:

- fifty percent of the mean hazard is produced by the top 27 (of a total of 2750) hazard values whose cumulative probability weight is $9.0 \times 10^{-3}$,

- the annual probability of exceedance values for the top 27 hazard estimates range from $1.17 \times 10^{-1}$ to $9.58 \times 10^{-1}$, and

- of the top 100 estimates of the probability of exceedance, 80 are produced by the ground motion model selected by GME 5 .

The hazard results in Table 5-9 demonstrate the fact that as part of the LLNL hazard assessment, there are a number of extreme estimates of the likelihood of ground motions of engineering interest. Although low probability weight is assigned to each hazard result, as indicated in the table, extreme estimates of seismic hazard have a substantial impact on the mean value. 
An interpretation of the extreme estimates of seismic hazard is provided by considering the average-recurrence intervals that are predicted. For example, the top 27 hazard curves that contribute to 50 percent of the mean probability of exceedance correspond to averagerecurrence intervals that range from 1 to 8.5 years. Recurrence intervals of this magnitude suggest that during the period of DOE operations at the SRS (e.g., 1950-1991), ground motions of $0.13 \mathrm{~g}$ PGA or greater could be expected, on average, to have occurred approximately 5 to 40 times. Hazard estimates of this magnitude are extreme and intuitively can be chalienged on the basis they are inconsistent with the historic record. As part of the LLNL seismic hazard study this type of information was not available to the hazard analysts (LLNL staff) or the ground motion or seismicity experts. Consequently, an explicit consideration of the hazard results that were derived from the expert inputs was not made.

LLNL NPR Seismic Hazard Assessment - Based on discussions with Dr. J.B. Savy of LLNL, it is our understanding that the ground motion models selected by GME 5 in the USNRC sponsored project are not being used in the seismic hazard study being performed for the NPR at the SRS (6). From this, it is reasonable to conclude that the credibility (as reflected by approximately a 0.20 weight) assigned to GME 5's models is no longer valid.

\subsection{Summary}

A comparison of the EPRI and LLNL ground motion models indicates a considerable level of agreement between the two studies. All of the EPRI ground motion models are included in the LLNL study and are assigned relatively high weight by the GMEs.

The primary difference between the two studies, with respect to modeling ground motion, are the models selected by GME 5. As illustrated in Section 3, these models are a major source of the differences between the EPRI and LLNL estimate of seismic hazard at the SRS. 
As demonstrated in this section the models selected by GME 5 are unique in many respects and represent an outlying approach to estimating ground motion in the EUS. The following summarizes the findings regarding the models selected by GME 5:

- the EnRI study and the other 4 LLNL GMEs have assigned zero weight to the models selected by GME 5 ,

- GME 5 has assigned zero weight to all other models suggesting this expert has no uncertainty in the assessment of ground motion,

- the data and procedure used by GME 5 to derive the attenuation models are believed to have technical drawbacks,

- hazard results based on GME 5's model for PGA predicts seismic hazard levels (e.g., recurrence intervals, probability of exceedance) that are inconsistent with the historic record, and

- compared to available strong-motion data, the ground motion models selected by GME 5 overestimate the data at all frequencies, except 25 $\mathrm{Hz}$, by as much as a factor of 10 .

These aspects of the models selected by GME 5 raise questions regarding their scientific and engineering credibility and validity to estimate ground motions in the EUS.

Differences in the EPRI and LLNL modeling of the variability in ground mution (e.g., $\sigma_{y}$ ) and estimating limits on ground motion are not considered a source of differences between the two studies. 
Table 5-1

EPRI-LLNL Ground Motion Modeling Summary

\begin{tabular}{|l|c|c|}
\hline \multicolumn{1}{|c|}{ Item } & EPRI & LLNL \\
\hline \hline Ground Motion Models & & \\
1. Number of GME & $1^{1}$ & 5 \\
2. Number of Models & 3 & 9 \\
3. Vary by Region & No & Yes \\
4. Number of Common & Models & All 3 EPRI \\
Randomness on GM 9 LLNL & & \\
1. Probability Distribution & Lognormai & Lognormal \\
2. Logarithmic-Standard \\
$\begin{array}{l}\text { Deviation (Best-Estimate } \\
\text { Value) }\end{array}$
\end{tabular}

EPRI performed research in this area and conducted a workshop on ground motion, including EPRI and LLNL experts and others. Weights on the EPRI ground motion models were assigned by one consulting firm.

2 LLNL allowed the GMEs to specify the models that would be used in different regions of the EUS.

3 For PSRV, one expert did not use a lognormal model. 
Table 5-2

EPRI Ground Motion Attenuation Models

\begin{tabular}{|c|c|c|c|c|c|c|}
\hline \multirow{2}{*}{ Model } & \multicolumn{6}{|c|}{$\ln (Y)=a+b m_{b}+c \ln (R)+d R$} \\
\hline & Weight & $\mathbf{Y}^{1}$ & $\mathbf{a}$ & b & c & d \\
\hline McGuire et al. (10) & 0.50 & $\begin{array}{r}\operatorname{PRSV}(1 \mathrm{~Hz}) \\
\operatorname{PRSV}(2.5 \mathrm{~Hz}) \\
\operatorname{PRSV}(5 \mathrm{~Hz}) \\
\operatorname{PRSV}(10 \mathrm{~Hz}) \\
\operatorname{PRSV}(25 \mathrm{~Hz}) \\
\operatorname{PGA}\end{array}$ & $\begin{array}{r}-7.95 \\
-3.82 \\
-2.11 \\
-1.55 \\
-1.63 \\
2.55\end{array}$ & $\begin{array}{l}2.14 \\
1.49 \\
1.20 \\
1.05 \\
0.98 \\
1.00\end{array}$ & $\begin{array}{l}-1.00 \\
-1.00 \\
-1.00 \\
-1.00 \\
-1.00 \\
-1.00\end{array}$ & $\begin{array}{l}-0.0018 \\
-0.0024 \\
-0.0031 \\
-0.0039 \\
-0.0053 \\
-0.0046\end{array}$ \\
\hline Boore and Atkinson (11) & 0.25 & \multicolumn{5}{|c|}{ Complex functional form see (1i). } \\
\hline $\begin{array}{l}\text { Nuttli (12) and } \\
\text { Newmark-Hall (13) } \\
\text { Amplification Factors }\end{array}$ & 0.25 & $\begin{array}{r}\operatorname{PRSV}(1 \mathrm{~Hz}) \\
\operatorname{PRSV}(2.5 \mathrm{~Hz}) \\
\operatorname{PRSV}(5 \mathrm{~Hz}) \\
\operatorname{PRSV}(10 \mathrm{~Hz}) \\
\operatorname{PRSV}(25 \mathrm{~Hz}) \\
\text { PGA }\end{array}$ & $\begin{array}{r}0.29 \\
-0.62 \\
-1.32 \\
-2.13 \\
-3.53 \\
1.28\end{array}$ & $\begin{array}{l}1.15 \\
1.15 \\
1.15 \\
1.15 \\
1.15 \\
1.15\end{array}$ & $\begin{array}{l}-0.83 \\
-0.83 \\
-0.83 \\
-0.83 \\
-0.83 \\
-0.83\end{array}$ & $\begin{array}{l}-0.0028 \\
-0.0028 \\
-0.0028 \\
-0.0028 \\
-0.0028 \\
-0.0028\end{array}$ \\
\hline
\end{tabular}

$$
\begin{gathered}
\text { PRSV }-\mathrm{cm} / \mathrm{sec} \\
\text { PGA }-\mathrm{cm} / \mathrm{sec}^{2} \\
\mathrm{R}-\mathrm{km}
\end{gathered}
$$

2 For a given $m_{b}$ and $R, \ln (Y)$ is the smaller of $a+b m_{b}+\operatorname{cln}(R)+d R$ and $-8.3+2.3 m_{b}-$ $0.83 \ln (R)-0.0012 R$ 


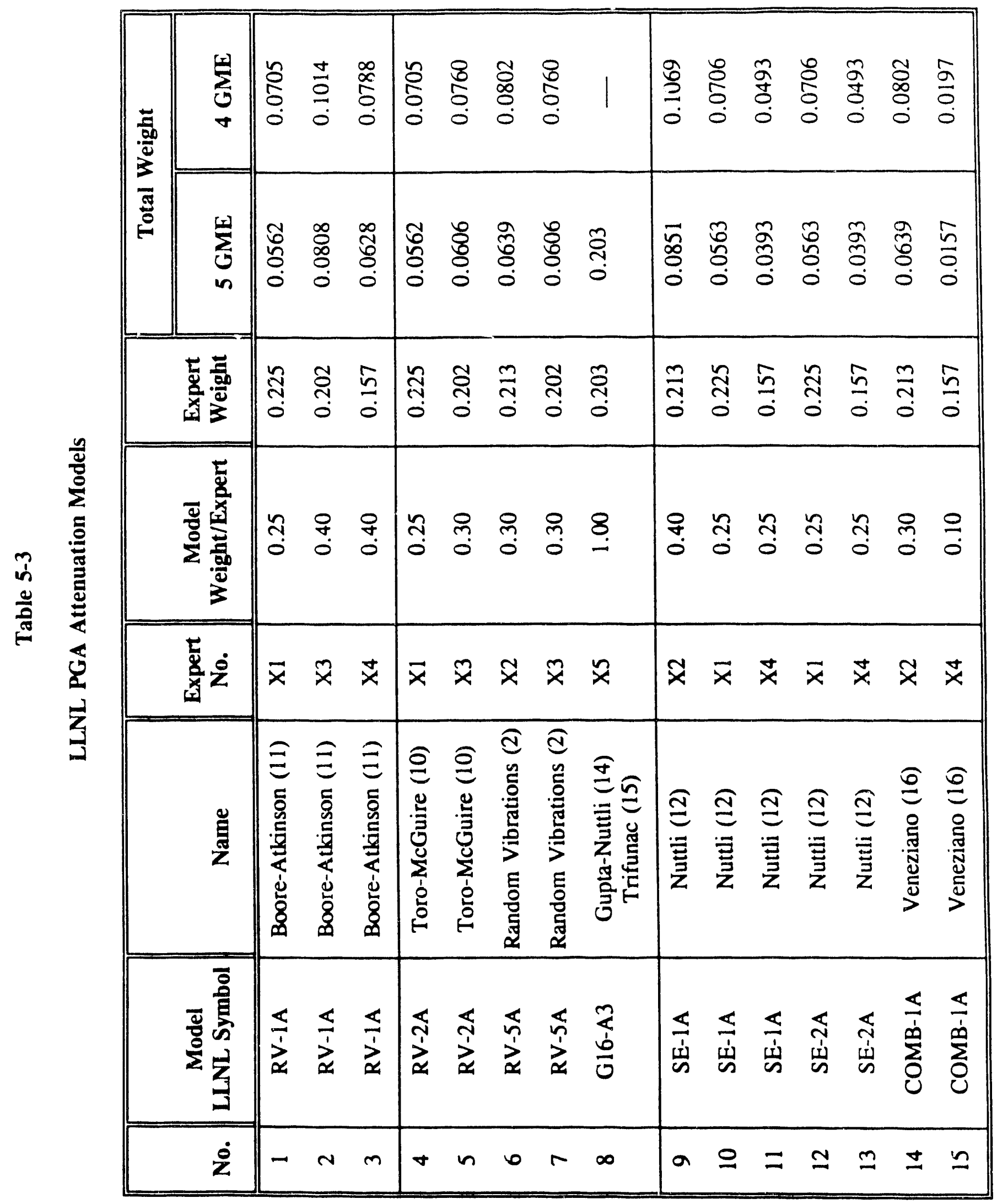




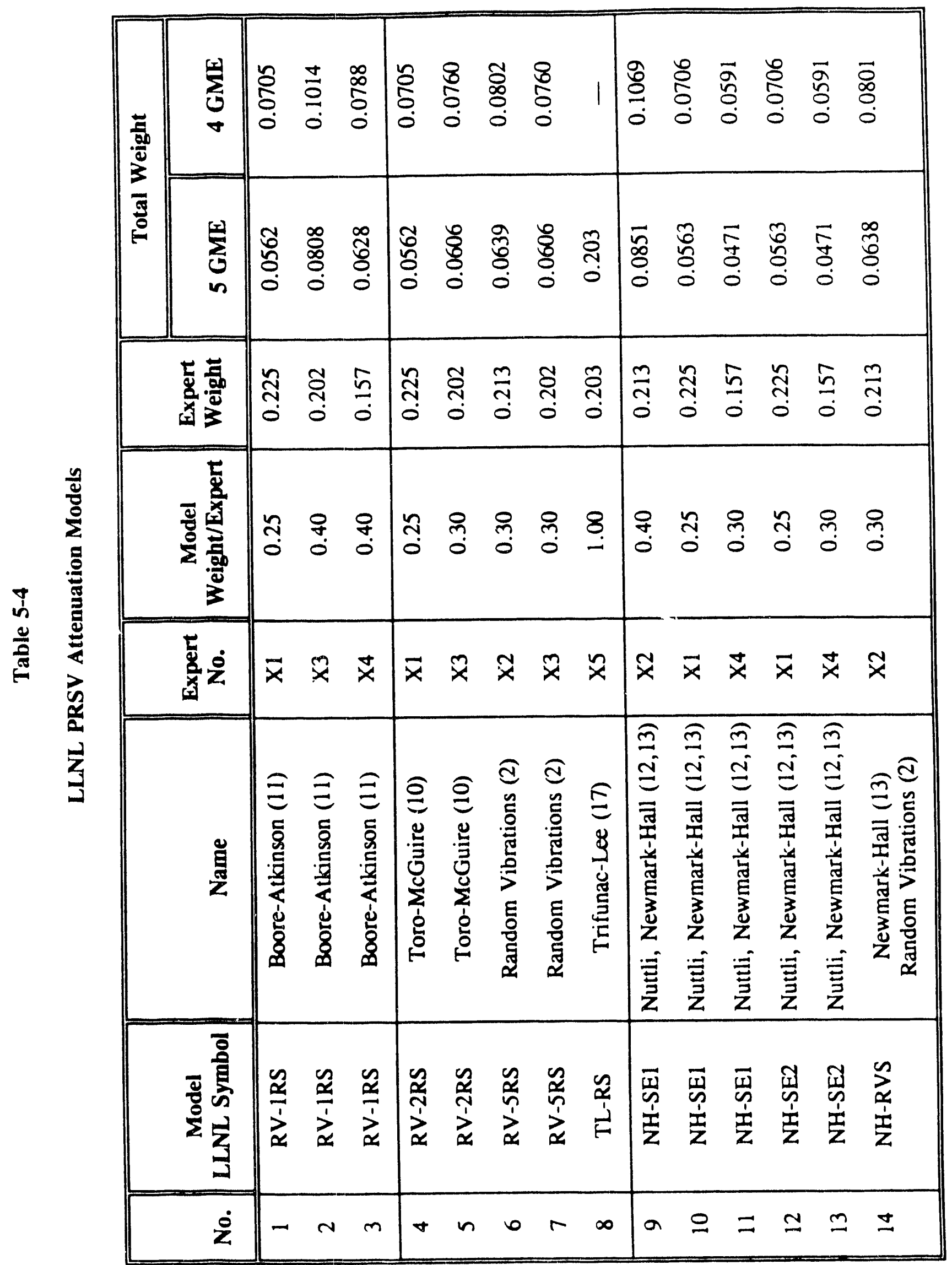


Table 5-5

Comparison of EPRI and LLNL Ground Motion Models Weights

\begin{tabular}{|c|c|c|c|}
\hline \multirow[b]{3}{*}{ Model } & \multicolumn{3}{|c|}{ Weight } \\
\hline & \multirow[b]{2}{*}{ EPRI } & \multicolumn{2}{|c|}{ LLNL } \\
\hline & & 4 GME & $5 \mathrm{GME}$ \\
\hline Toro-McGuire/RV-2 & 0.50 & 0.3027 & 0.2413 \\
\hline Boore-Atkinson/RV-1 & 0.25 & 0.2507 & 0.1995 \\
\hline Nuttli - SEl & 0.25 & 0.2266 & 0.1807 \\
\hline Nuttli - SE2 & 0 & 0.1199 & 0.0956 \\
\hline COMB- $1 \mathrm{~A}$ & 0 & 0.0999 & 0.0796 \\
\hline G16-A3 & 0 & 0 & 0.2030 \\
\hline
\end{tabular}


Table 5-6

Results of EPRI and LLNL Seismic Hazard Comparisons

\begin{tabular}{|c|c|c|c|c|c|c|c|}
\hline \multirow[b]{3}{*}{ Case } & \multicolumn{2}{|c|}{$\mathbf{A}$} & \multicolumn{2}{|c|}{ B } & \multicolumn{3}{|c|}{$\begin{array}{c}\text { Ratio (A/B) Mean Hazard } \\
\text { Results }\end{array}$} \\
\hline & \multirow[b]{2}{*}{$\begin{array}{l}\text { Seismicity } \\
\text { Input }\end{array}$} & \multirow[b]{2}{*}{$\begin{array}{l}\text { Ground } \\
\text { Motion }\end{array}$} & \multirow[b]{2}{*}{$\begin{array}{l}\text { Seismicity } \\
\text { Input }\end{array}$} & \multirow[b]{2}{*}{$\begin{array}{l}\text { Ground } \\
\text { Motion }\end{array}$} & \multicolumn{3}{|c|}{ PGA (g) } \\
\hline & & & & & 0.25 & 0.55 & 1.0 \\
\hline 1 & EPRI & EPRI & EPRI & LLNL $^{\prime}$ & 1.13 & 1.16 & 1.18 \\
\hline 2 & LLNL & LLNL & LLNL & EPRI & 2.8 & 2.4 & 2.5 \\
\hline
\end{tabular}

1 LLNL - 4 GME case 
Table 5-7

LLNL GME Logarithmic Standard Deviation Values

\begin{tabular}{|c|c|c|c|c|c|c|c|}
\hline \multirow[b]{3}{*}{ GME } & \multirow[b]{3}{*}{$\begin{array}{c}\text { GME } \\
\text { Self } \\
\text { Weight }\end{array}$} & \multicolumn{3}{|c|}{ PGA } & \multicolumn{3}{|c|}{ PSRV } \\
\hline & & \multirow[b]{2}{*}{$\begin{array}{c}\text { Best } \\
\text { Estimate }\end{array}$} & \multicolumn{2}{|c|}{ Bounds } & \multirow[b]{2}{*}{$\begin{array}{c}\text { Best } \\
\text { Estimate }\end{array}$} & \multicolumn{2}{|c|}{ Bounds } \\
\hline & & & Lower & Upper & & Lower & Upper \\
\hline 1 & 0.2247 & 0.35 & 0.30 & 0.40 & 0.35 & 0.30 & 0.40 \\
\hline 2 & 0.2135 & 0.55 & 0.40 & 0.70 & 0.55 & 0.40 & 0.70 \\
\hline 3 & 0.2022 & 0.50 & 0.40 & 0.70 & 0.60 & 0.40 & 0.80 \\
\hline 4 & 0.1575 & 0.50 & 0.35 & 0.65 & 0.50 & 0.35 & 0.65 \\
\hline 5 & 0.2022 & 0.70 & 0.70 & 0.90 & (1) & & \\
\hline & Average & 0.52 & & & 0.50 & & \\
\hline
\end{tabular}

GME 5 spectral model is not lognormal 
Table 5-8

Summary of the PGA Seismic Hazard Calculations to Test Sensitivity to the Uncertainty in the Logarithmic-Standard Deviation

\begin{tabular}{|c|c|c|}
\hline \multirow[b]{2}{*}{$\begin{array}{c}\text { Logarithmic Standard } \\
\text { Deviation }\end{array}$} & \multicolumn{2}{|c|}{ Seismicity Input } \\
\hline & LLNL & EPRI \\
\hline 1. GME Distribution & $\mathrm{X}$ & $\mathrm{X}$ \\
\hline 2. GME Best Estimate & & $X$ \\
\hline 3. $\sigma_{y}=0.50$ & $X$ & \\
\hline
\end{tabular}


Table 5-9

Summary of the LLNL Seismic Hazard For PGA of $0.13 \mathrm{~g}$ For the SRS

Mean Probability of Exceedance $=6.20 \times 10^{-3}$

\begin{tabular}{|c|c|c|c|c|c|c|c|c|}
\hline \multirow[b]{2}{*}{ Rank } & \multirow{2}{*}{$\begin{array}{l}\text { Ground } \\
\text { Motion } \\
\text { Expert }\end{array}$} & \multirow{2}{*}{$\begin{array}{l}\text { Seismicity } \\
\text { Expert }\end{array}$} & \multirow{2}{*}{$\begin{array}{c}\text { Hazard Curve } \\
\text { Probability } \\
\text { Weight }\end{array}$} & \multirow[b]{2}{*}{ CDF $^{\prime}$} & \multicolumn{2}{|c|}{$\begin{array}{l}\text { Contribution to the } \\
\text { Mean Hezard (percent) }\end{array}$} & \multirow[b]{2}{*}{$\begin{array}{l}\text { Probability of } \\
\text { Exceedence }\end{array}$} & \multirow{2}{*}{$\begin{array}{l}\text { Cumulative } \\
\text { Meen } \\
\text { Probebility of } \\
\text { Exceedance }\end{array}$} \\
\hline & & & & & Individual & Cumulative & & \\
\hline 1 & 5 & 5 & $4.024 E-04$ & $1.00 \mathrm{Co}$ & 6.22 & 6.22 & $9.584 E-01$ & $3.856 E-04$ \\
\hline 2 & 5 & 5 & $4.024 E-04$ & .9996 & 6.17 & 12.38 & $9.508 E-01$ & $7.682 E-04$ \\
\hline 3 & 5 & 7 & $3.141 E-04$ & .9992 & 3.58 & 15.97 & $7.079 E-01$ & $9.906 E-04$ \\
\hline 4 & 4 & 5 & $3.129 E-04$ & .9989 & 2.98 & 18.95 & $5.909 E-01$ & $1.17 \overline{E E}-03$ \\
\hline 5 & 5 & 5 & $4.024 E-04$ & .9986 & 3.56 & 22.50 & $5.484 E-01$ & $1.396 E-03$ \\
\hline 6 & 5 & 7 & $3.141 E-04$ & .9982 & 1.85 & 24.36 & $3.663 F-01$ & $1.511 E \cdot 03$ \\
\hline 7 & 5 & 5 & $4.024 E-04$ & .9979 & 2.30 & 26.65 & $3.542 E-01$ & $1.654 E-03$ \\
\hline 8 & 5 & 5 & $4.024 E-04$ & .9976 & 2.14 & 28.79 & $3.299 E-01$ & $1.786 E-03$ \\
\hline 9 & 5 & 5 & $4.024 E-04$ & .9970 & 2.10 & 30.89 & $3.235 E-01$ & $1.917 \mathrm{E}-03$ \\
\hline 10 & 5 & 7 & $3.141 E-04$ & .9966 & 1.58 & 32.48 & $3.127 \mathrm{E}-01$ & $2.015 E-03$ \\
\hline 11 & $j$ & 5 & $4.024 E-04$ & .9963 & 1.96 & 34.43 & $3.020 E-01$ & $2.136 E-03$ \\
\hline 12 & 5 & 7 & $3.141 E-04$ & .9959 & 1.15 & 35.59 & $2.279 E-01$ & $2.208 E-03$ \\
\hline 13 & 1 & 5 & $4.469 E-04$ & .9956 & 9.61 & 37.19 & $2.230 E-01$ & $2.308 E-03$ \\
\hline 14 & 4 & 5 & $3.129 E-04$ & .9952 & 1.10 & 38.30 & $2.187 \mathrm{E}-01$ & $2.376 E-03$ \\
\hline 15 & 5 & 5 & $4.024 \bar{\varepsilon}-04$ & .9949 & 1.39 & 39.69 & $2.144 E-01$ & $2.462 E-03$ \\
\hline 16 & 4 & 5 & $3.129 E-04$ & .9945 & 1.02 & 40.71 & $2.026 E-01$ & $2.526 E-03$ \\
\hline 17 & 5 & 5 & $4.024 E-04$ & .9941 & 1.29 & 42.00 & $1.990 E-01$ & $2.606 E-03$ \\
\hline 18 & 1 & 5 & $4.469 E-04$ & .9937 & 1.39 & 43.39 & $1.934 E-01$ & $2.692 E-03$ \\
\hline 19 & 4 & 5 & $3.129 E-04$ & .9933 & .83 & 44.22 & $1.636 E-01$ & $2.743 E-03$ \\
\hline 20 & 5 & 2 & $2.769 E-04$ & .9930 & .72 & 44.93 & $1.604 E-01$ & $2.788 E-03$ \\
\hline 21 & 5 & 7 & $3.141 E-04$ & .9927 & .79 & 45.72 & $1.558 E-01$ & $2.837 \mathrm{TE}-03$ \\
\hline 22 & 5 & 7 & $3.161 E-04$ & .9924 & .74 & 46.46 & $1.462 E-01$ & $2.883 E \cdot 03$ \\
\hline 23 & 5 & 5 & $4.024 E \cdot 04$ & .9921 & .92 & 47.39 & $1.424 E-01$ & $2.940 E-03$ \\
\hline 26 & 5 & 4 & $2.75 T E \cdot 04$ & .9917 & .56 & 47.94 & $1.252 E-01$ & $2.974 E-03$ \\
\hline 25 & 5 & 7 & $3.141 E-04$ & .9916 & .62 & 48.57 & $1.232 E-01$ & $3.013 E-03$ \\
\hline 26 & 5 & 5 & $4.024 E-04$ & .9911 & .80 & 49.37 & $1.231 E-01$ & $3.063 E-03$ \\
\hline 27 & 2 & 5 & $4.2466-04$ & .9907 & .80 & 50.17 & $1.173 E-01$ & $3.112 E-03$ \\
\hline 28 & 5 & 5 & $4.024 E-04$ & .9903 & .73 & 50.90 & $1.121 E-09$ & $3.158 E-03$ \\
\hline 29 & 5 & 5 & $4.024 E-06$ & .9899 & .72 & 51.61 & $1.105 E-01$ & $3.202 E-03$ \\
\hline 30 & 5 & 2 & $2.769 E-06$ & .9894 & .49 & 52.10 & $1.101 E-01$ & $3.232 E-03$ \\
\hline
\end{tabular}

$\overline{\mathrm{CDF}}=$ cumulative prohability distribution function 


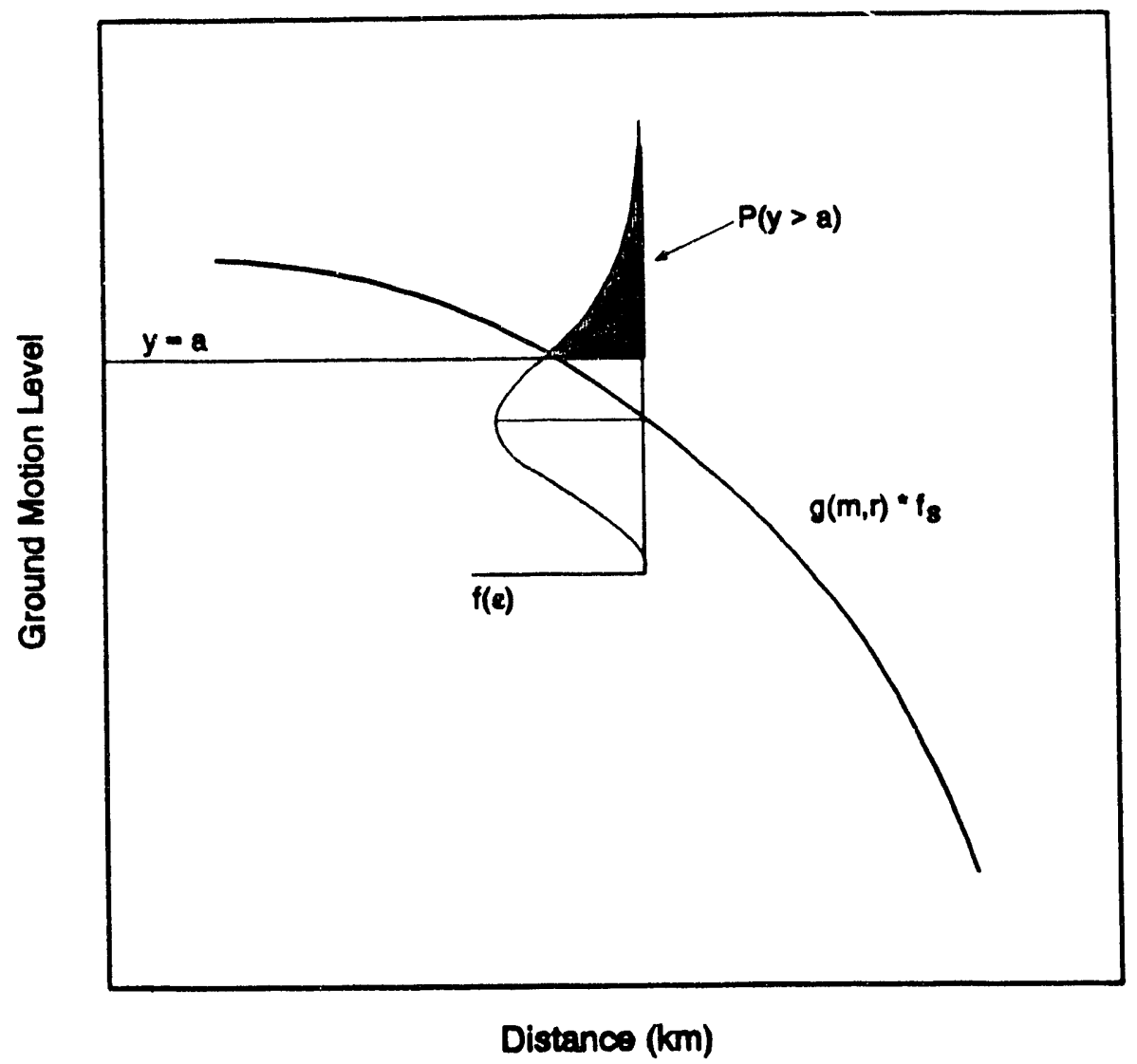

Figure 5-1 Illustration of the elements of the ground motion attenuation model. 


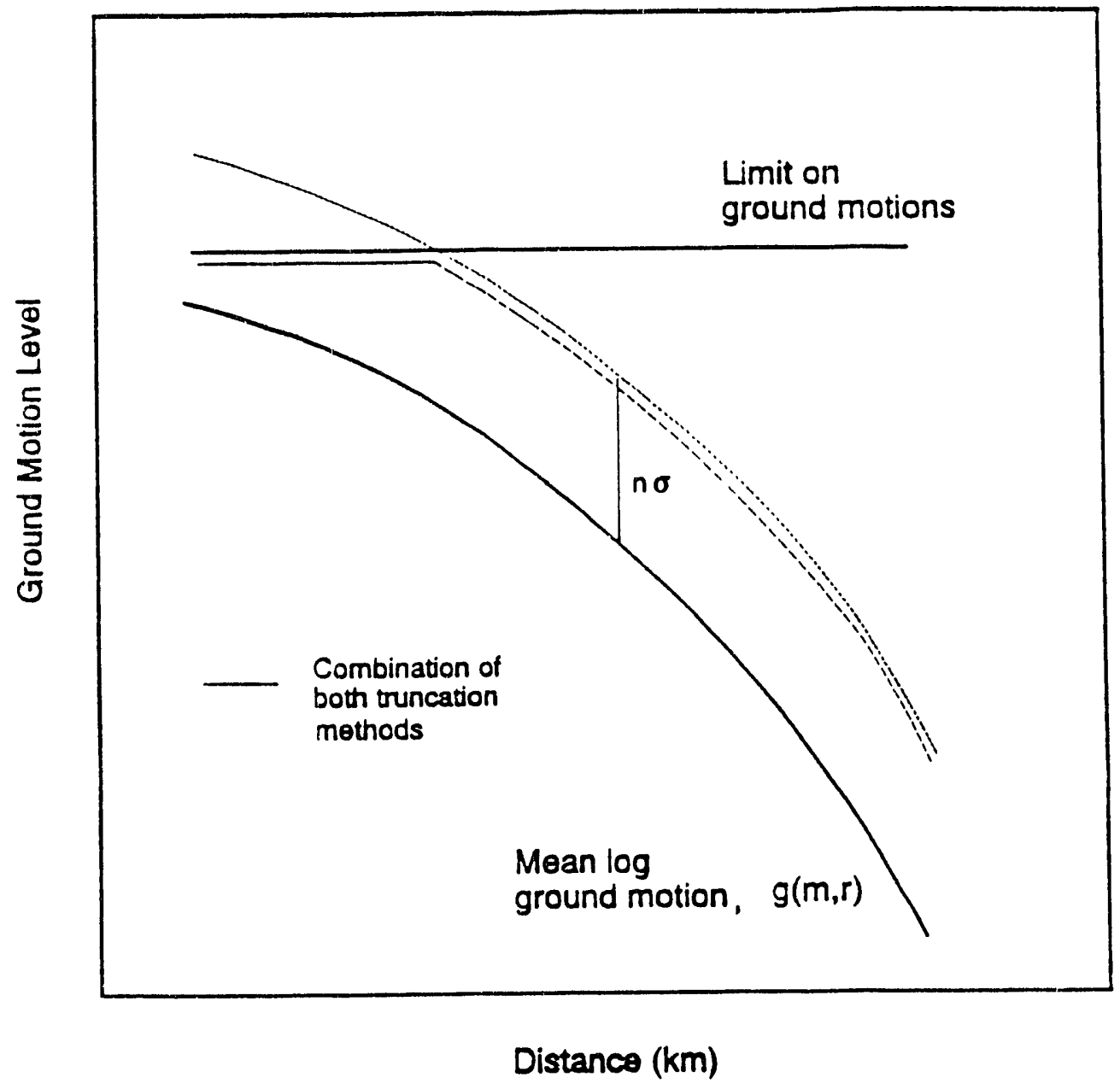

Figure 5-2 Illustration of methods for truncating ground motion. 


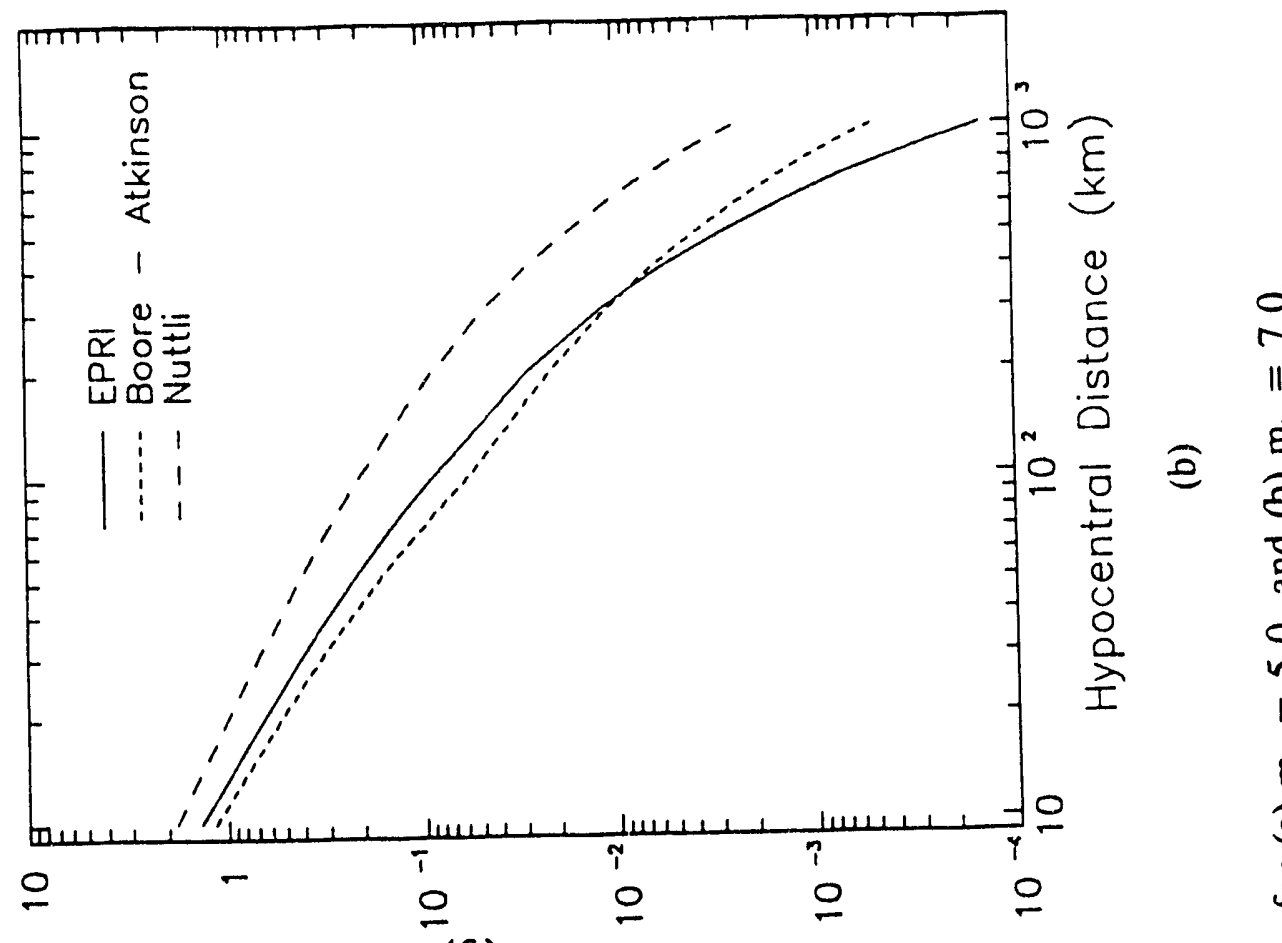

(6) $\forall D_{d}$

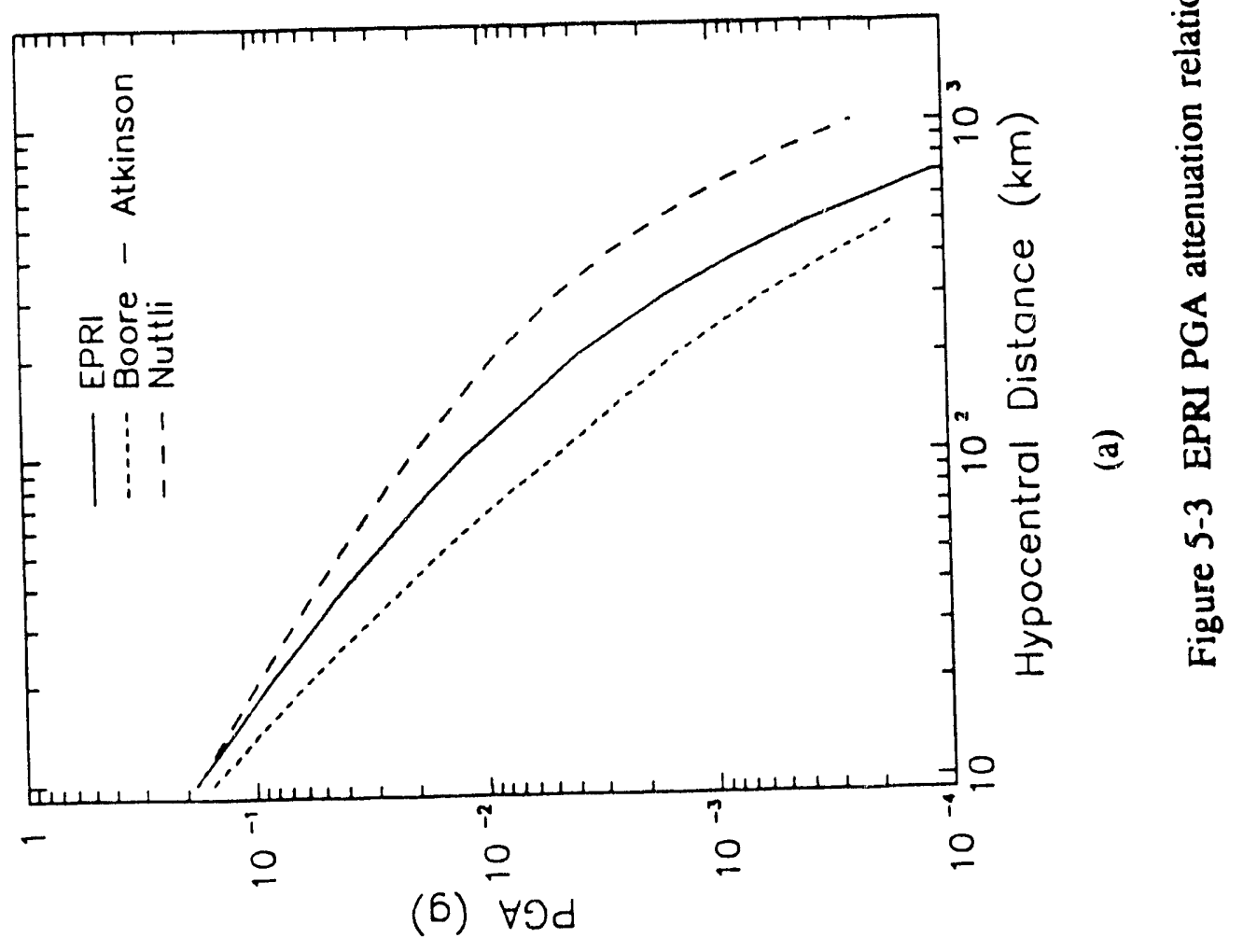



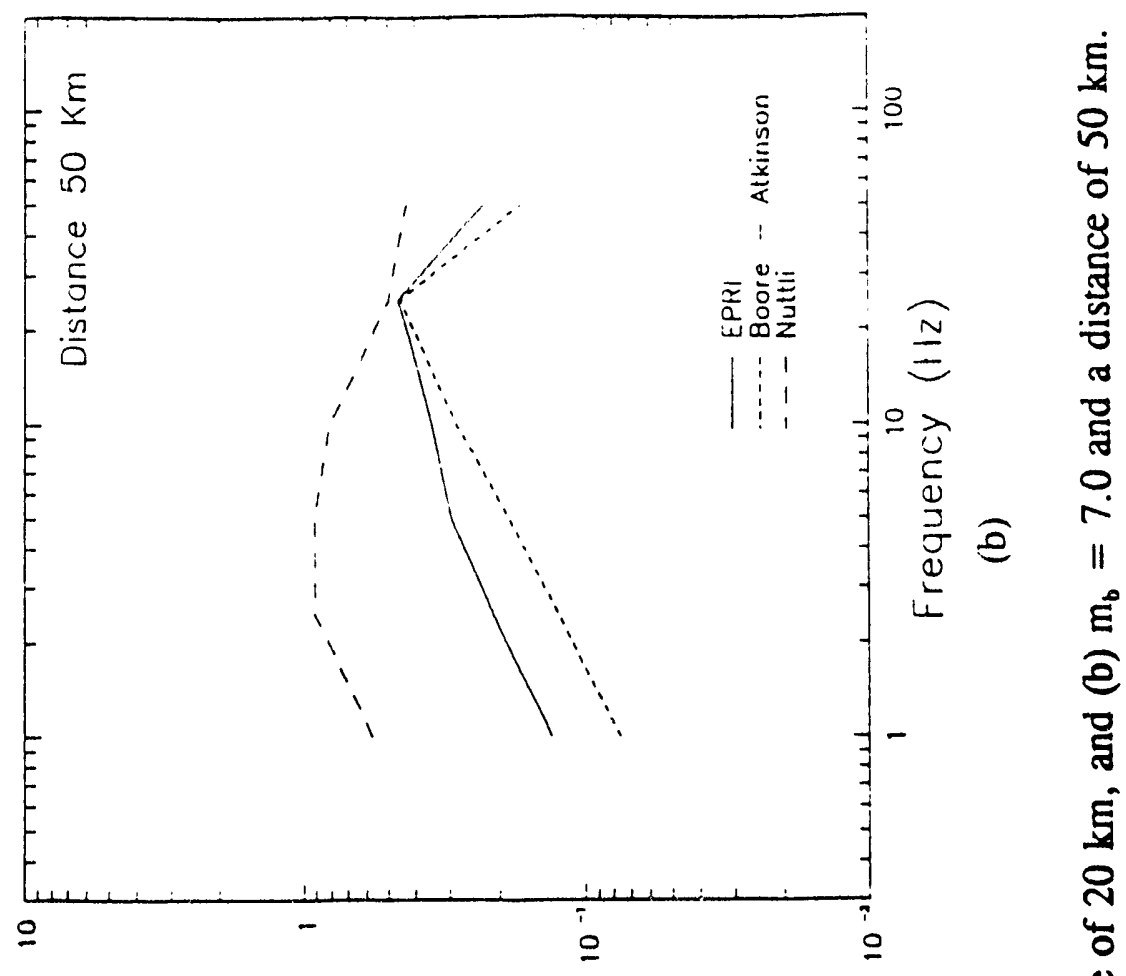

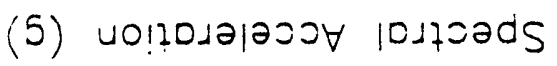

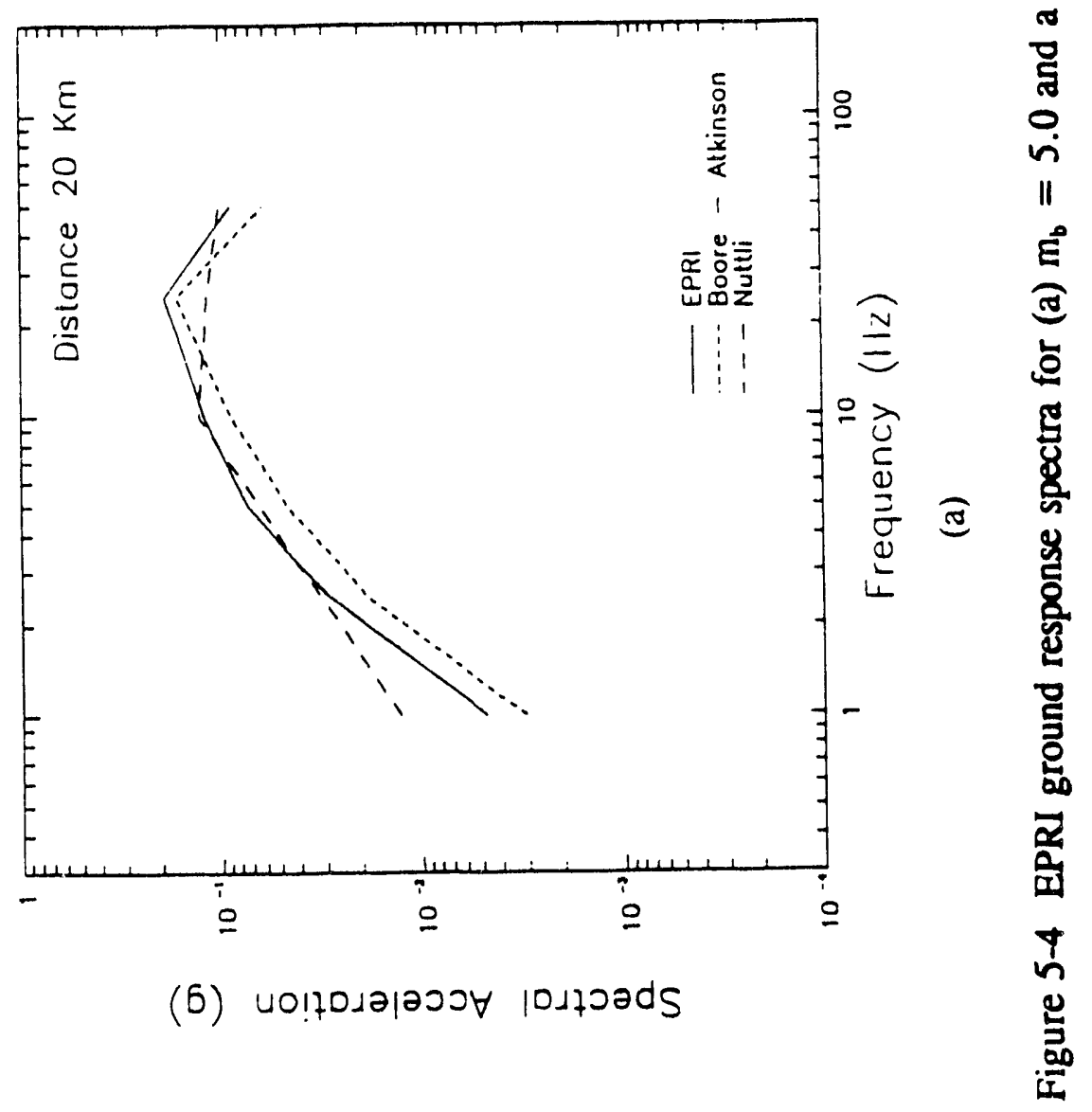



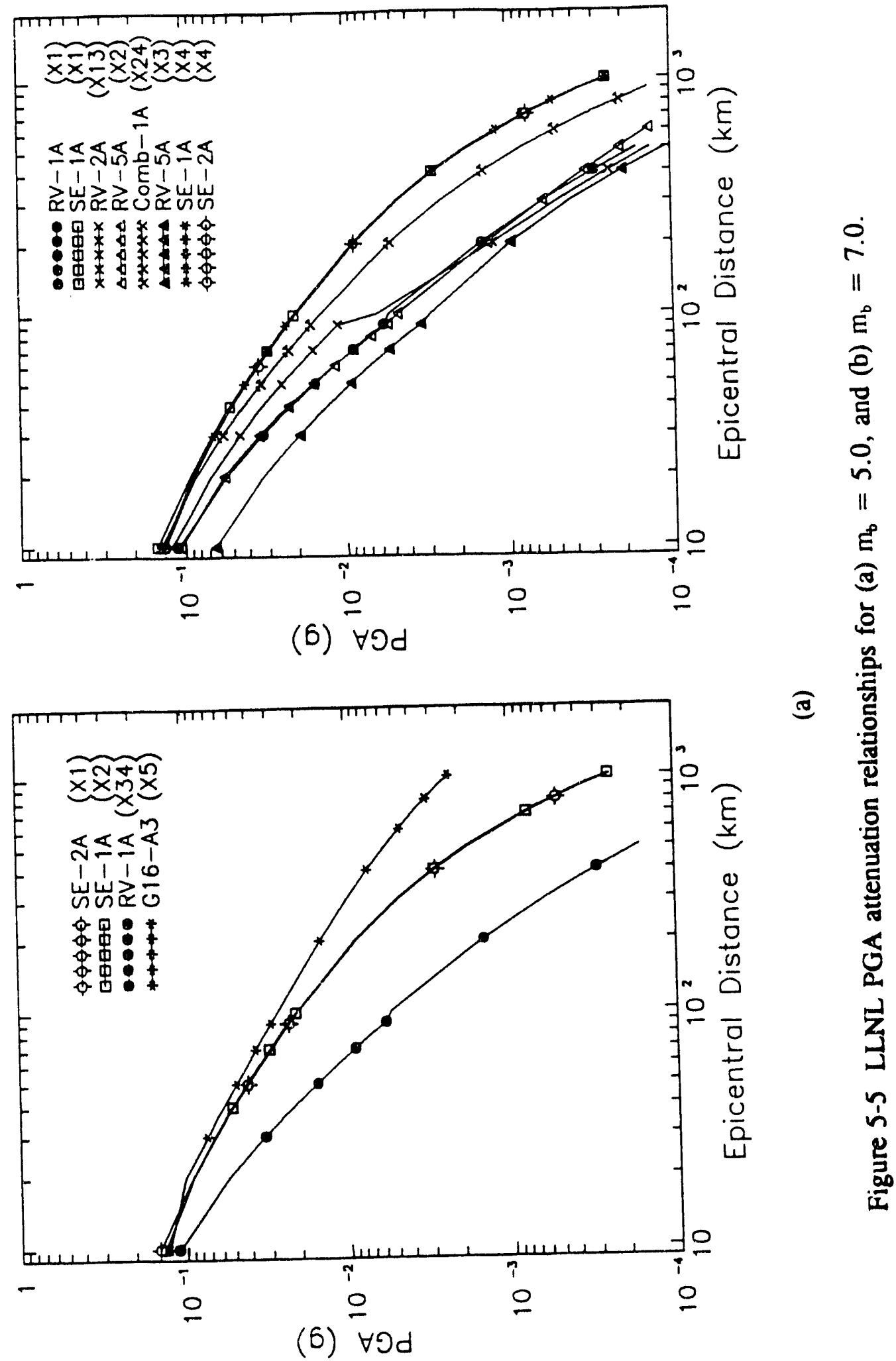

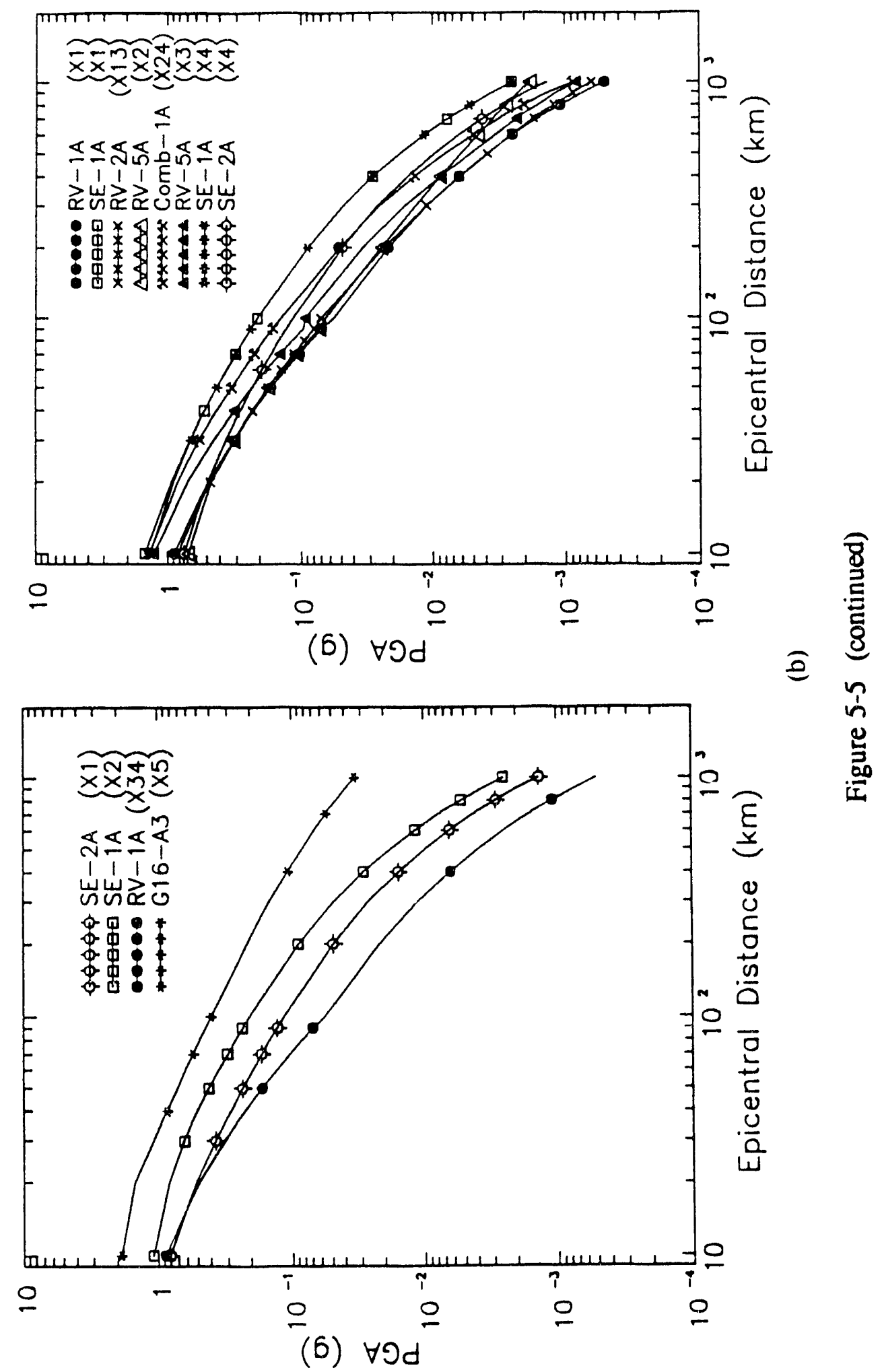


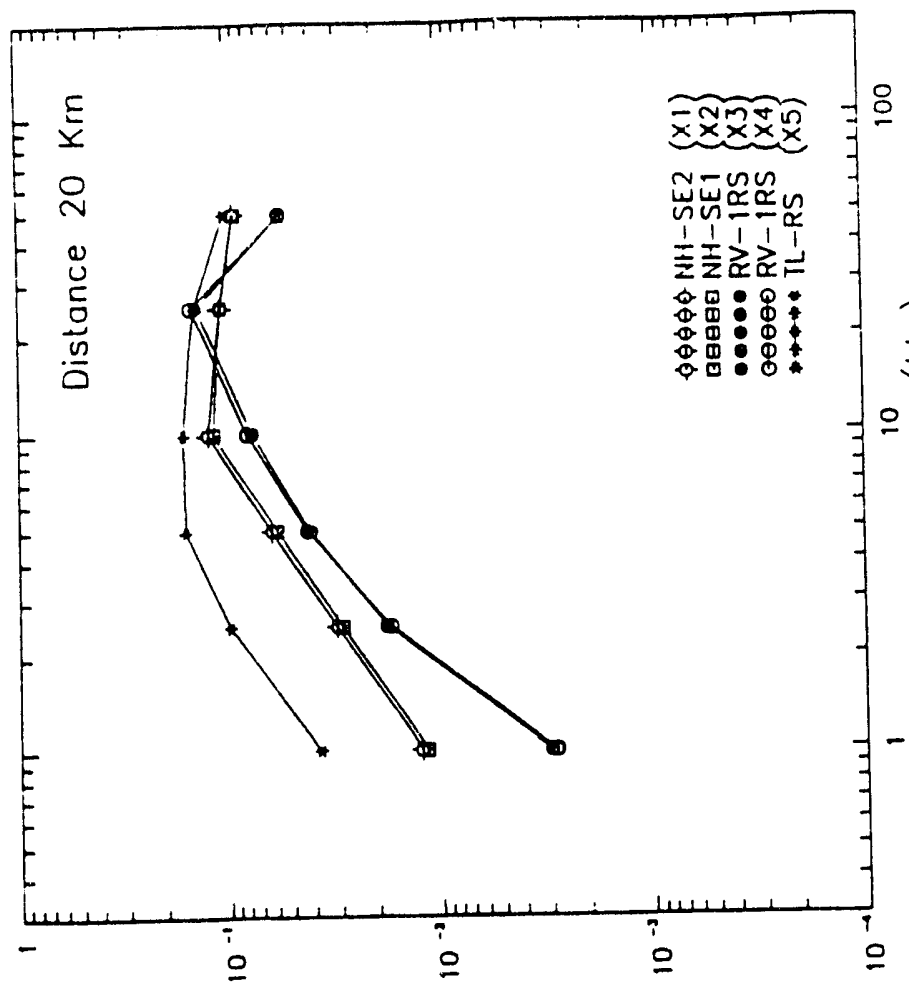

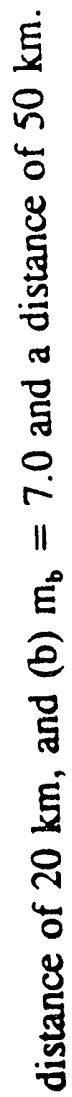

(6) vo!foja!joวt joj7כads

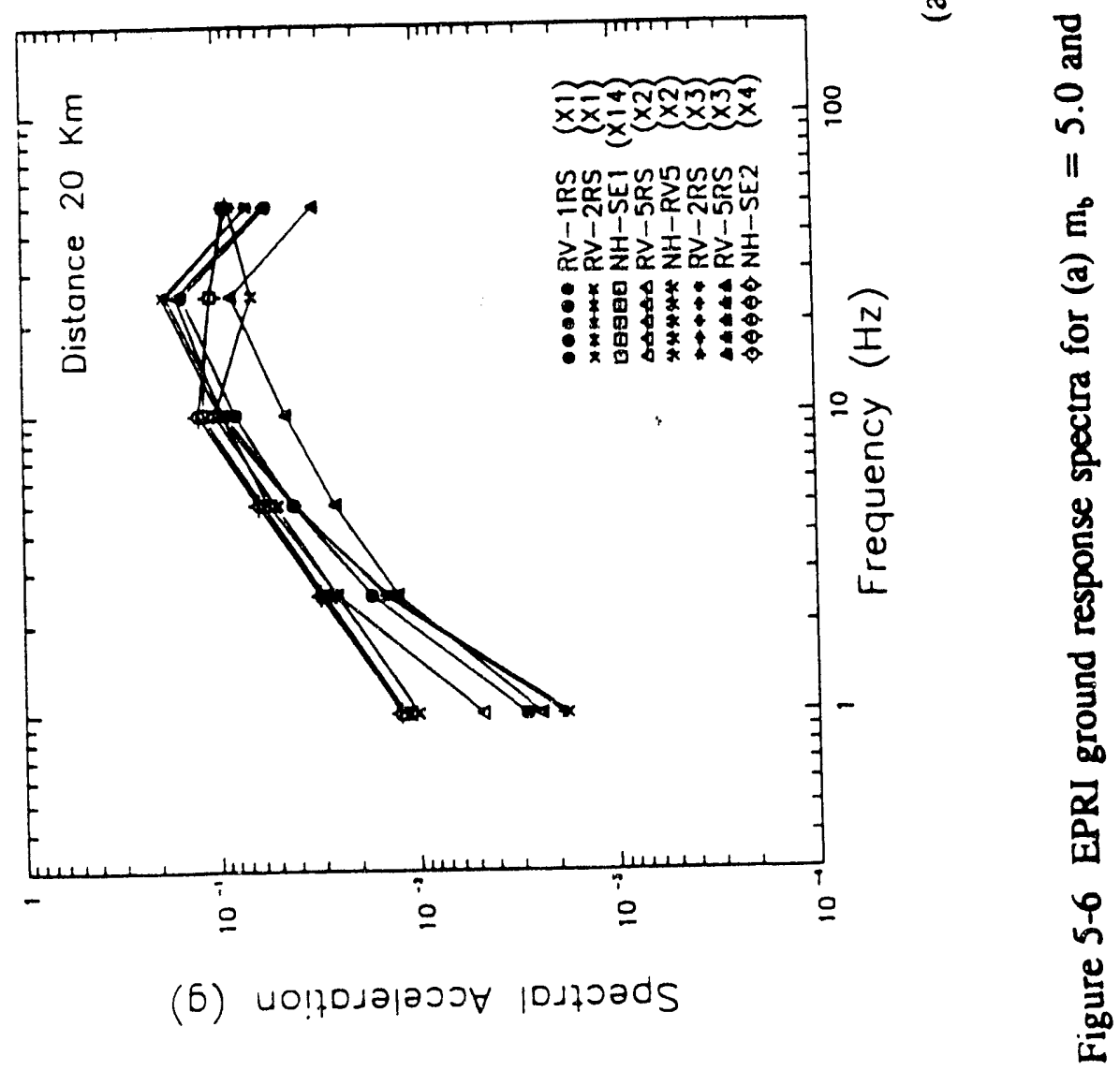




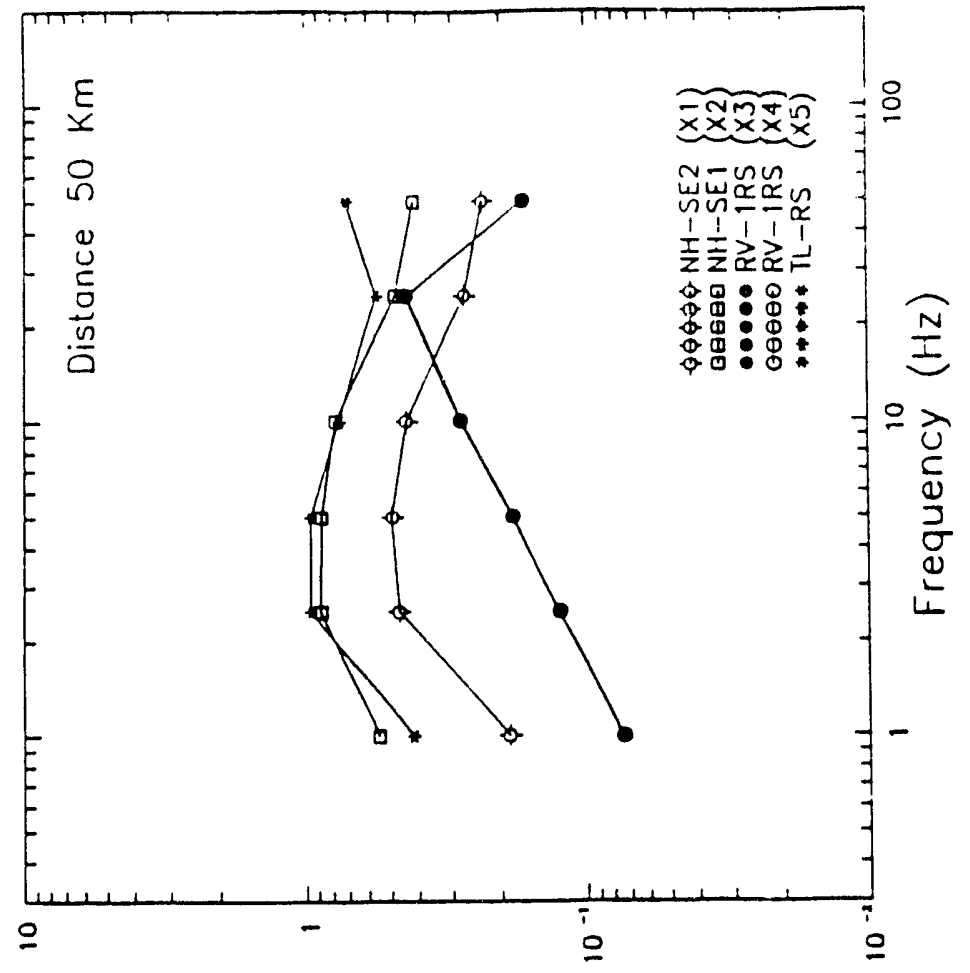

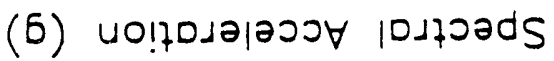

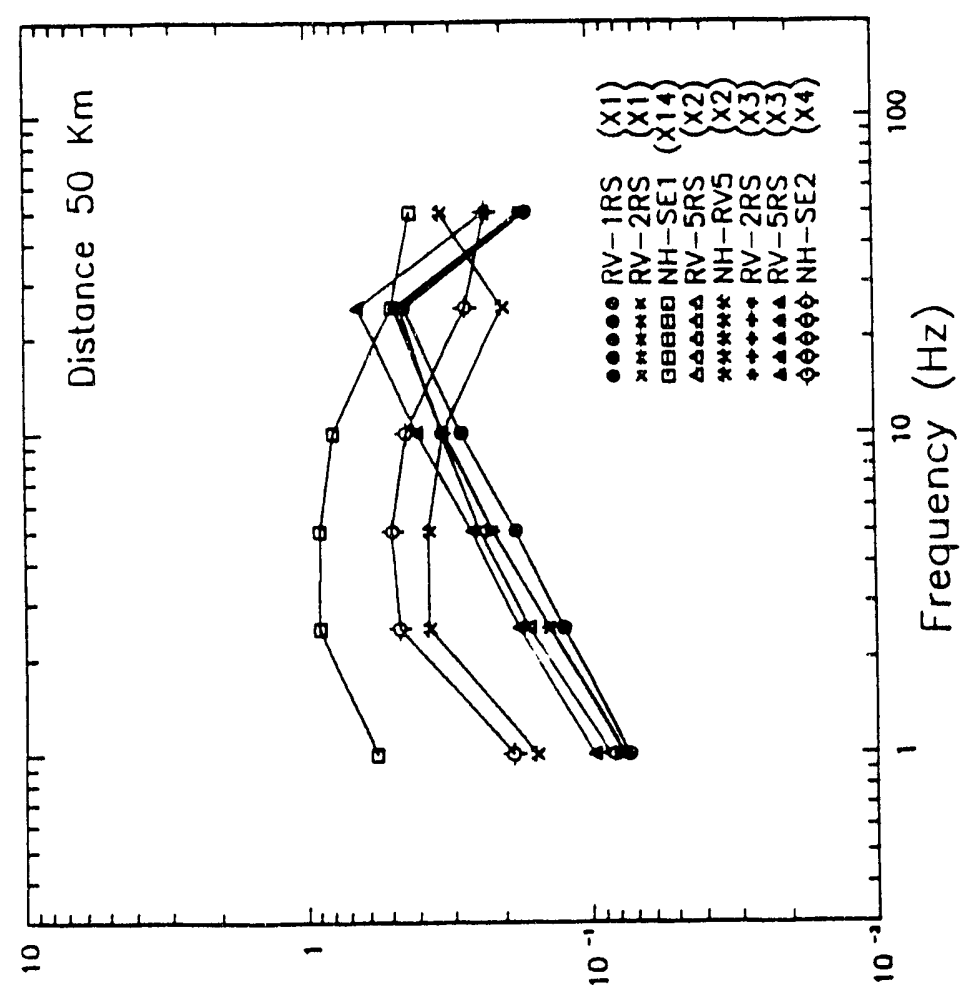

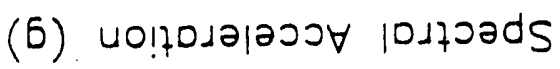




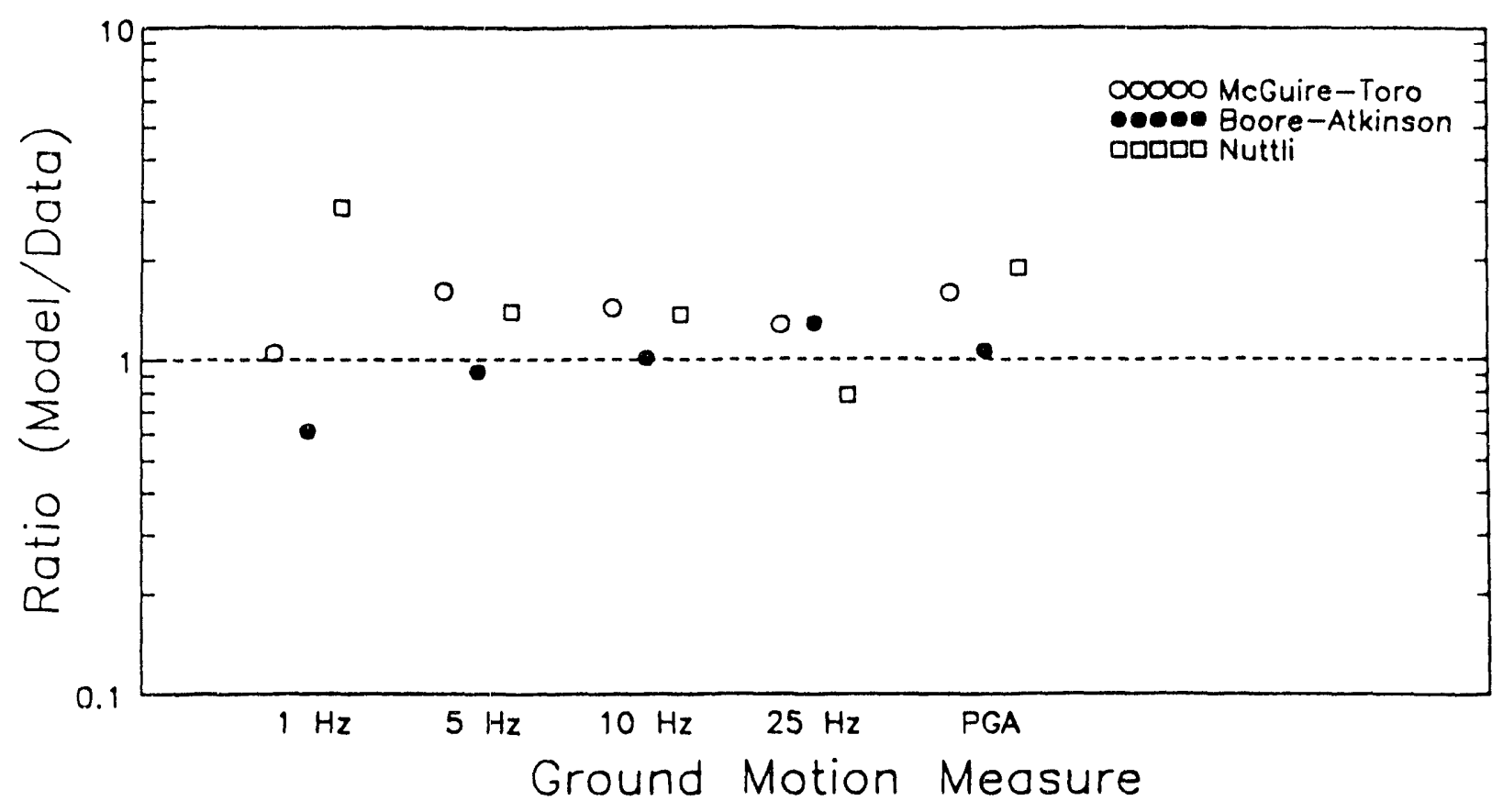

(a)

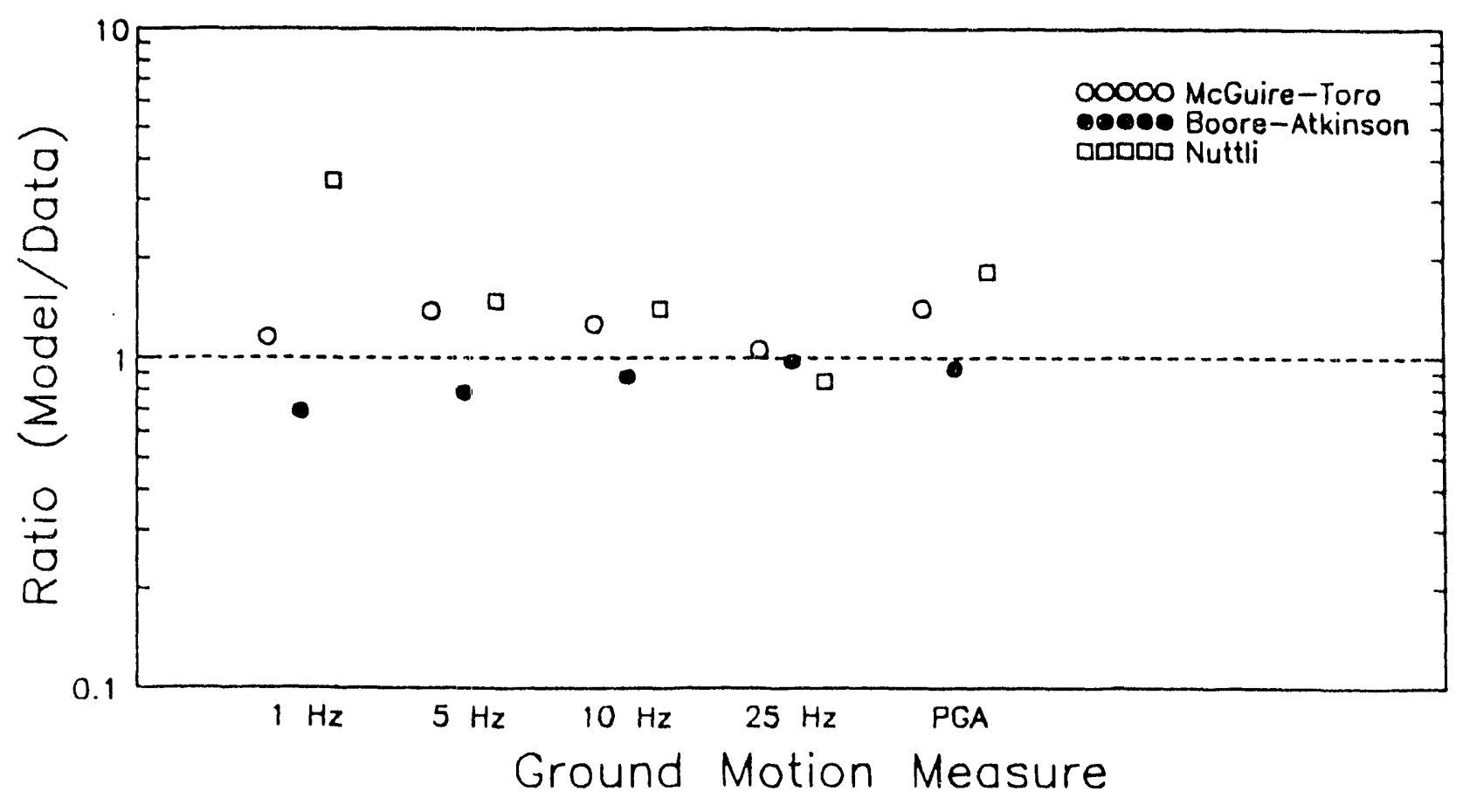

(b)

Figure 5-7 Plot of the mean, model-to-data ratio comparing the EPRI ground motion models to EUS strong-motion data recorded at distances less than $100 \mathrm{~km}$ (a) without and (b) with, the Saguenay data. 

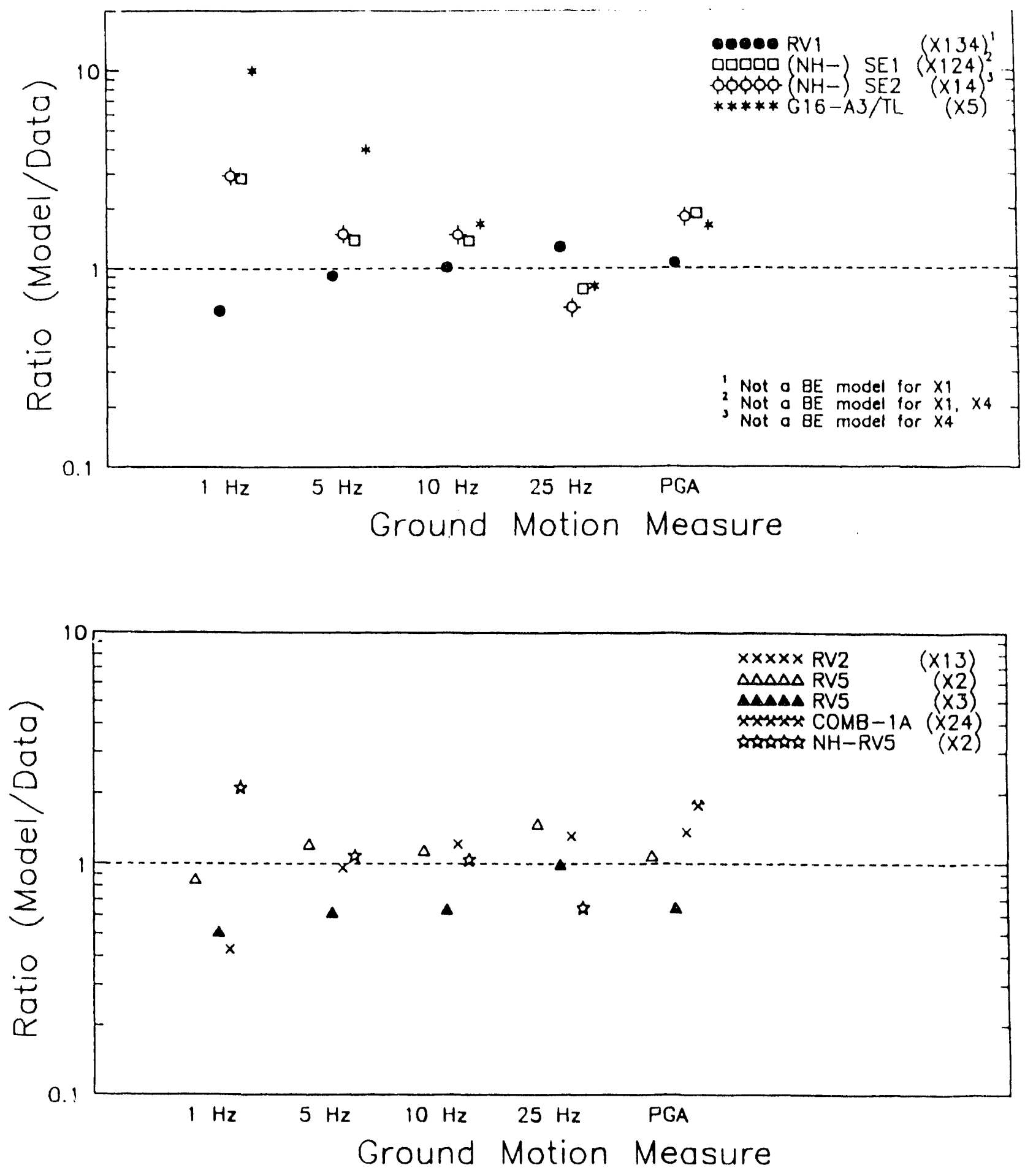

(a)

Figure 5-8 Plot of the mean, model-to-data ratio comparing the LLNL ground motion models to EUS strong-motion data recorded at distances less than $100 \mathrm{~km}$ (a) without and (b) with, the Saguenay data. 

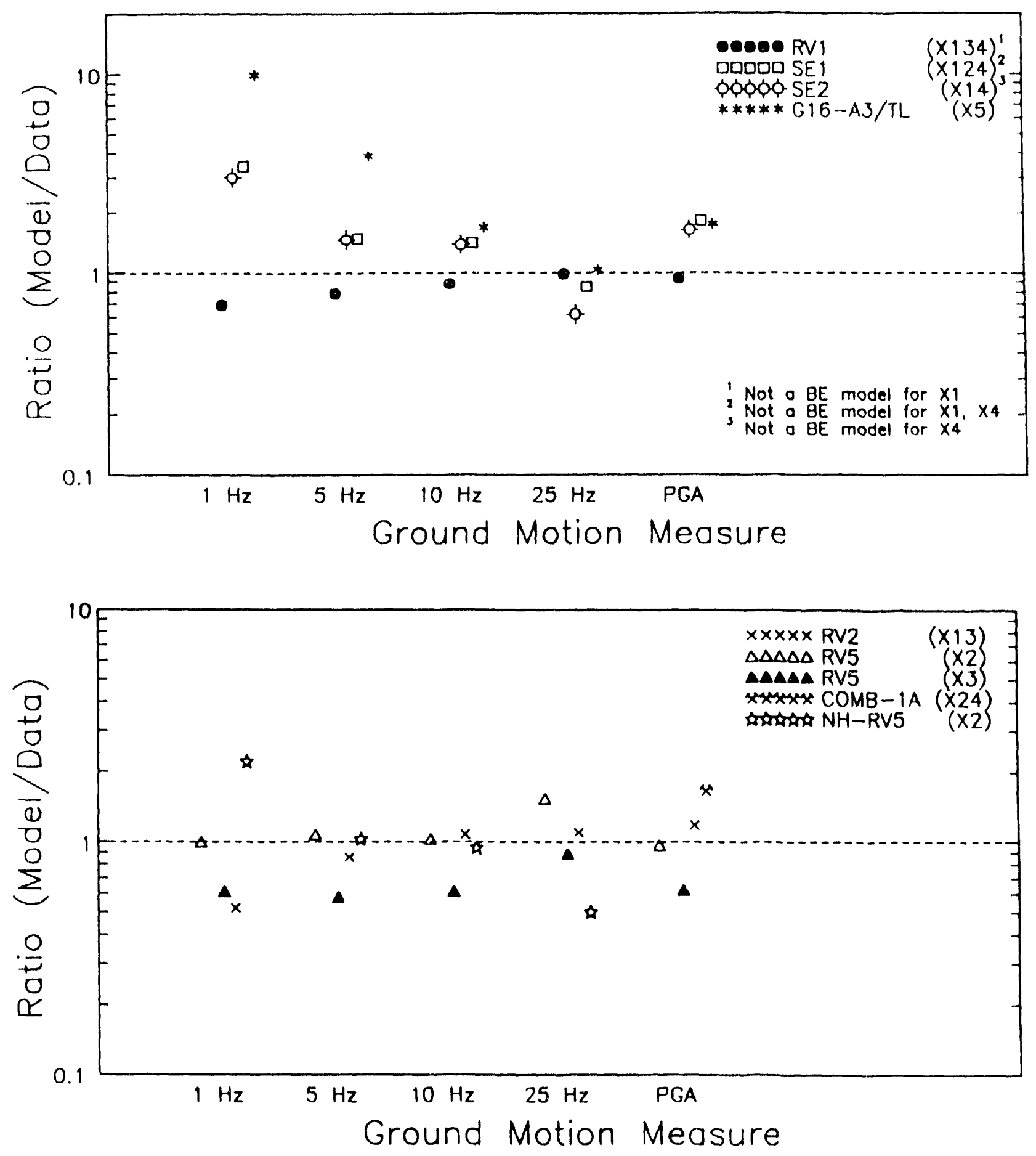

(b)

Figure 5-8 (continued) 


\section{Section 6 \\ SRS SEISMIC HAZARD EVALUATION}

\subsection{Review}

Based on comparative evaluation of the EPRI and LLNL seismicity and ground motion models it was determined there are two primary factors that are the source of differences between the two seismic hazard evaluations for the SRS. They were the assessment of the rate of seismic activity $\left(m_{b} \geq 5.0\right)$ in the vicinity of the SRS and the ground motion models (one for each ground motion parameter) selected by LLNL GME 5. In Section 4 it was demonstrated that the mean SAR estimated in the two studies differs by a factor of 10 . Furthermore it was shown that many of the SAR values estimated in the LLNL study are not consistent with the historic record. In Section 5 it was concluded that the ground motion models provided by GME 5 (for PGA and PSRV) are another source of the differences between the two studies. These models represent an outlying measure of ground motion and have a weak technical foundation. This section recommends the basis for developing the SRS seismic hazard.

\subsection{Recommendation}

The basic purpose of this study was to determine a single measure of the SRS hazard as derived from the EPRI and LLNL studies. Based on the results of the comparative evaluation, a procedure is recommended to determine the SRS seismic hazard. The procedure is based on: the elimination of extreme estimates of seismic hazard that are not supported by historic data and assessments that represent outlying estimates in both studies. To determine the SRS seismic hazard the following recommendations are made:

1. Use the EPRI and LLNL 4 GME case (for rock-site conditions) as basic input data. The LLNL seismic hazard results based on 
the GME best-estimate $\sigma_{y}$ values shall be used.

2. Use a statistical-screening evaluation (e.g., hypothesis test) to identify estimates of the SAR and/or ground motion hazard that are not supported by the historic record.

3. Eliminate estimates of seismic hazard identified in Step 2.

4. Aggregate the hazard results from the two studies that survive the screening in Step 3.

Figure 6-1 illustrates the steps in this procedure. The key step is the screening evaluation on the SAR and the estimates of the ground motion hazard. The procedure is carried out for each ground motion parameter in the hazard analysis.

In both the EPRI and LLNL studies the seismicity experts relied principally on the earthquake catalog to estimate the rate of earthquake occurrences. One difficulty in relying on the historic record is the fact that it is relatively short in comparison to the recurrence interval of moderate- to large-magnitude earthquakes. This fact implies a statistical uncertainty associated with estimating earthquake occurrence rates.

In both the EPRI and LLNL studies, a formal evaluation was not performed to provide the seismicity experts or the seismic hazard analysts (involved in the final hazard quantification), with information to test the consistency of the SAR or ground motion hazard results with the historic record. While some information was provided to the experts in this regard, it was usually performed for individual seismic sources and not to any level of detail (i.e., see Tables 4-8, 4-9 and 5-9).

To evaluate the consistency of individual seismic hazard estimates with the historic record, a two-step screening procedure was developed. The purpose of the scriening procedure is to identify extreme estimates of seismic hazard that are not statistically 
supported by the historic record. The procedure is set up to test specific parameters in the analysis whose estimate by the experts is closely tied to the historic record. For example, the overall rate of earthquake occurrences with $m_{b} \geq 5.0$ is a key parameter in the analysis that is derived from the earthquake catalog. Thus, a statistical test is developed to assess whether there are extreme estimates of the SAR that are not supported by the historic record.

There is uncertainty in the estimate of specific parameters from the earthquake catalog. Due to the length of the historic record, there is a range of values that a parameter may take. with a specified level of confidence, that are consistent with the available data.

The statistical-screening procedure is developed to examine the following parameters:

- seismic-activity rate $\left(m_{b} \geq 5.0\right)$, and

- probability of exceedance of low-level ground motions (e.g., for PGA of $0.13 \mathrm{~g}$ ).

The screening evaluation on the SAR assesses the expert seismicity mujels (only), whereas the screening of the hazard resuits includes all elements of the hazard analysis (e.g., seismic sources, seismicity parameters, ground motion models). The screening assessment on estimates of seismic hazard is performed at low-ground levels of enginering interest. For example, for PGA the $0.13 \mathrm{~g}$ level is used. This corresponds to a level of motion whose probability of excee' 'nce is closely tied to the overall SAR and yet is high enough that it is of engineering interest.

\subsection{Screening Analysis - Approach}

The screening evaluation was performed by developing statistical-confidence intervais on each parameter (e.g., SAR, probability of exceedance of ground motion). For each parameter, a statistical, non-parametric distribution was derived. From this distribution, the 
bounds for a specified level of confidence are found and used to identify extreme estimates of each parameter that are not supported by the historic record. To develop the statistical distribution, a simulation procedure was used. The bounds for each parameter (e.g., SAR, probability of exceedance of ground motion) are set at the 99 percent confidence level. Given the limits of the confidence interval, each estimate of a parameter is examined to determine whether it passes the hypothesis test (i.e., falls within the specified intervai). If it does not, that estir dte of seismic hazard is rejected on the basis that it is not supported by the historic record. The statistical screening is performed first for the SAR and then for the probability of exceedance of ground motion (see Fig. 6-1). The second screening is performed only on the estimates of seismic hazard that survive the first screen. As illustrated in Figure 6-1, the EPRI and LLNL hazard results are evaluated in parallel. Once ihe statistical screening assessment was performed, the surviving hazard results from the two studies were aggregated to define the SRS seismic hazard.

To estimate the statistical uncertainty in the SAR and probability of exceedance of giound mcion at the SRS, a bootstrap simulation on the earthquake catalog was performed. This method is $₹$ robist statistical technique to estimate the uncertainty in parameters derived from a limited database (23). The bootstrap simulation is particularly useful in cases where the uncertainty distribution is not known or cannot be assumed beforehand. In this application, the simulation procedure creates a set of random earthquake catalogs (i.e., 1,000 simulations). From each catalog, an estimate of the SAR and the probability of exceeding a specified ground motion level (given a particular ground motion model) using an historicseismicity analysis procedure (24) was determined.

The simulated results (1,000 estimates of each parameter) are used to define a nonparametric distribution for the SAR and the probability of exceedance of ground motion. This distribution is used to define the bounds of the 99 percent confidence intervals. These bounds establish the statistical screen for each parameter. Volume 2 provides a detailed 
description of the bootstrap method and the development of the statistical screens.

A drawback of the earthquake catalog is the fact that it covers a relatively short-time period, approximately 300 years. Other shortcomings include the problem of incompleteness, uniformity of reporting earthquake size and errors in the reported location and magnitude of earthquakes $(1,2)$. In this evaluation the EPRI earthquake catalog and probabilities of detection were used to address some of these issues.

\subsection{Seismic-Activity Rate Screen}

As part of the seismic hazard assessment the seismicity experts must model the spatial and temporal rate of occurrence of earthquakes in the vicinity of a site. The model of seismicity developed by an expert consists of the seismic sources and corresponding seismicity parameters (a- and b-values and maximum magnitude estimates). Due to the uncertainty in the assessment of these parameters, there is a complex combination of seismic sources and seismicity parameters that produces the expert probability distribution on the rate of occurrence of earthquakes near a site.

In Section 4 the estimate of the SAR for each seismicity expert was reported. The SARs were determined for a specified region around the site and are based on the complete assessment of the uncertainty of seismic sources, source combinations and seismicity parameters and thus represent an expert's complete assessment of the probability distribution on the rate of occurrence of earthquakes. The bootstrap simulation on the earthquake catalog was performed for the same region.

Figure 6-2 shows the statistical distribution on the SAR for the SRS region derived from the bootstrap simulation. The screening values are selected from the statistical distribution which specify the bounds of the 99 percent confidence interval. The 99 percent 
confidence interval range is 0.00 to $5.42 \times 10^{-2}$ events $\left(m_{b} \geq 5.0\right)$ per year. Historically, there have been three magnitude 5 or greater events in the SRS region in a period of over 300 years. Based on the bounds of the statistical-confidence interval for the SAR, an estimate can be made of the range on the number of earthquakes that would be expected to occur over the period of record. In this case, the expected number of events of magnitude 5.0 or greater ranges from 0 to 8 .

Figure 6-3 provides a comparison of the EPRI and LLNL combined expert CDFs on the SAR with the historic distribution. The comparisons demonstrate that the EPRI assessment of SAR is in general agreement with the historic data. However, the EPRI CDF is not as broad at the lower and upper tails, as the historic distribution. The LLNL CDF on the other hand, differs significantly from the historic distribution. In particular, a large fraction of the LLNL CDF extends well beyond the upper-bound of the historic distribution.

Each EPRI and LLNL estimates of the SAR were screened to identify the hazard results that are not supported by the historic record. Based on the screening analysis, all EPRI estimates of the SAR passed the hypothesis test. For LLNL, a total of 1036 estimates of the SAR failed the hypothesis test. The cumulative weight of the hazard results that failed the hypothesis test was approximately 0.32 . Figure 6-4 shows the revised LLNL SAR distribution (after being renormalized) and the original CDF. As compared to the original $\mathrm{CDF}$, the revised estimate is shifted, such that the median has been reduced by about a factor of 2 .

Figure 6-5 shows the revised LLNL magnitude-frequency distribution. Recall, that hazard results which do not survive the screening, are rejected. As a result, a number of extreme estimates of the frequency of earthquake occurrences were removed from the distribution. Figure 6-6 shows the comparison of the revised and original LLNL median and mean magnitude-frequency curves. The median magnitude-frequency distribution has been 
reduced by a factor of 2 to 4 . However, the mean is lower by a lactor of 10 or more for moderate- to large-magnitude events.

\subsection{Evaluation of Historic Seismic Hazard}

For each ground motion parameter (e.g., PGA, PSRV) and ground motion attenuation model used in the EPRI and LLNL seismic hazard studies, an historic seismic hazard analysis was performed for each earthquake catalog generated in the bootstrap simulation (see Fig. 6-1). The purpose of the historic seismic hazard assessment was to estimate, based on the historic record, the probability that levels of ground motion have occurred at a site. Based on the group of simulated earthquake catalogs, the result is a statistical distribution on the probability of exceedance of a specified ground motion level (i.e., PGA $=0.13 \mathrm{~g}$ ) at the SRS. Table 6-1 lists the ground motion levels used in the screening evaluation for each ground motion parameter. Figure 6-7 shows an example of the statistical distribution on the frequency of exceedance of $0.13 \mathrm{~g}$ PGA at the SRS. The distribution has a bimodal shape that is attributed to the occurrence or nonoccurrence of the 1886 Charleston earthquake in a simulated catalog. The lower mode of the distribution corresponds to random catalogs that do not include the 1886 Charleston event. As a result, the frequency of exceeding $0.13 \mathrm{~g}$ at the site is low. The upper mode of the distribution corresponds to earthquake catalogs in which the 1886 Charleston event occurs at least once. Volume 2 contains a complete description of the bootstrap analysis and discussion of the results. A statistical distribution similar to the one shown in Figure 6-7 was derived for each ground motion parameter and attenuation model used in the two hazard studies.

As compared to the screening that was performed for the SAR, few extreme estimates of seismic hazard fail the second hypothesis test. This is indicative of the fact that the SAR was a dominant contributor to the extreme hazard values that were calculated. In this second part of the screening evaluation, all the EPRI estimates of seismic hazard passed the 
hypothesis test. For LLNL, Table 6-2 summarizes for each ground motion parameter the number of hazard results that failed the hypothesis test and the total number of hazard curves that survived the two-step screening.

Figure 6-8 shows the revised LLNL PGA seismic hazard results (rock-site conditions for the SRS). Figure 6-9 shows the revised LLNL median and mean PGA hazard curves with the original 4 and 5 GME results which correspond to the starting point for this evaluation. As illustrated in the figure, there has been a small change in the median hazard curve. However, the mean hazard curve has been reduced significantly. A large part of this reduction is due to the elimination of GME 5. The remaining reduction is attributed to the screening evaluation.

Figure 6-10 shows the EPRI and the revised LLNL median and mean PGA hazard curves. Following the screening evaluation, the results are in close agreement. The LLNL median value is lower than the EPRI result by about a factor of $2-3$ beyond $0.40 \mathrm{~g}$. Conversely, the LLNL mean hazard curve is higher, but in close agreement with the EPRI result. At PGA levels beyond about $0.80 \mathrm{~g}$, the LLNL mean curve is about a factor of 2 higher than EPRI.

\subsection{Final Aggregation}

To determine the SRS seismic hazard (see Fig. 6-1), the EPRI and LLNL assessments that satisfied the screening evaluation are aggregated. To perform the final aggregation (for all ground motion parameters) it is recommended that equal weight be assigned to each study. Within each study, the same weights are assigned to each Earth Science Team and seismicity expert and to the ground motion models. Figure 6-11 shows the final SRS PGA seismic hazard curves, for rock-site conditions. Figure 6-12 shows the $10^{5}$ uniform hazard response spectra. 
Table 6-1

Ground Motion Levels Used in the Screening Assessment

\begin{tabular}{|c|c|}
\hline Parameter & Level \\
\hline \hline PGA & $0.13 \mathrm{~g}$ \\
PSRV $(1.0 \mathrm{~Hz})$ & $18.9 \mathrm{~cm} / \mathrm{sec}$ \\
PRSV $(2.5 \mathrm{~Hz})$ & $16.6 \mathrm{~cm} / \mathrm{sec}$ \\
PRSV $(5.0 \mathrm{~Hz})$ & $8.3 \mathrm{~cm} / \mathrm{sec}$ \\
PRSV $(10.0 \mathrm{~Hz})$ & $3.7 \mathrm{~cm} / \mathrm{sec}$ \\
PRSV $(25.0 \mathrm{~Hz})$ & $0.90 \mathrm{~cm} / \mathrm{sec}$ \\
\hline
\end{tabular}


Table 6-2

Summary of LLNL Seismic Hazard Screening

\begin{tabular}{|c|c|c|c|}
\hline \multirow[b]{2}{*}{ Parameter } & \multicolumn{2}{|c|}{$\begin{array}{c}\text { Number of Haxard Results Failing } \\
\text { Each Hypothesis Test }\end{array}$} & \multirow[b]{2}{*}{$\begin{array}{l}\text { Final Number of } \\
\text { Hazard Results }\end{array}$} \\
\hline & $\mathbf{S A R}^{1}$ & $\begin{array}{l}\text { Probability of } \\
\text { Exceedance }\end{array}$ & \\
\hline PGA & 1036 & 166 & 998 \\
\hline $\operatorname{PSRV}(1.0 \mathrm{~Hz})$ & 1036 & 20 & 1144 \\
\hline PRSV $(2.5 \mathrm{~Hz})$ & 1036 & 18 & 1146 \\
\hline PRSV $(5.0 \mathrm{~Hz})$ & 1036 & 49 & 1115 \\
\hline PRSV $(10.0 \mathrm{~Hz})$ & 1036 & 97 & 1067 \\
\hline PRSV $(25.0 \mathrm{~Hz})$ & 1036 & 43 & 1121 \\
\hline
\end{tabular}

1 Same number for all ground motion parameters

2 Total number of hazard results initially was $\mathbf{2 2 0 0}$ 


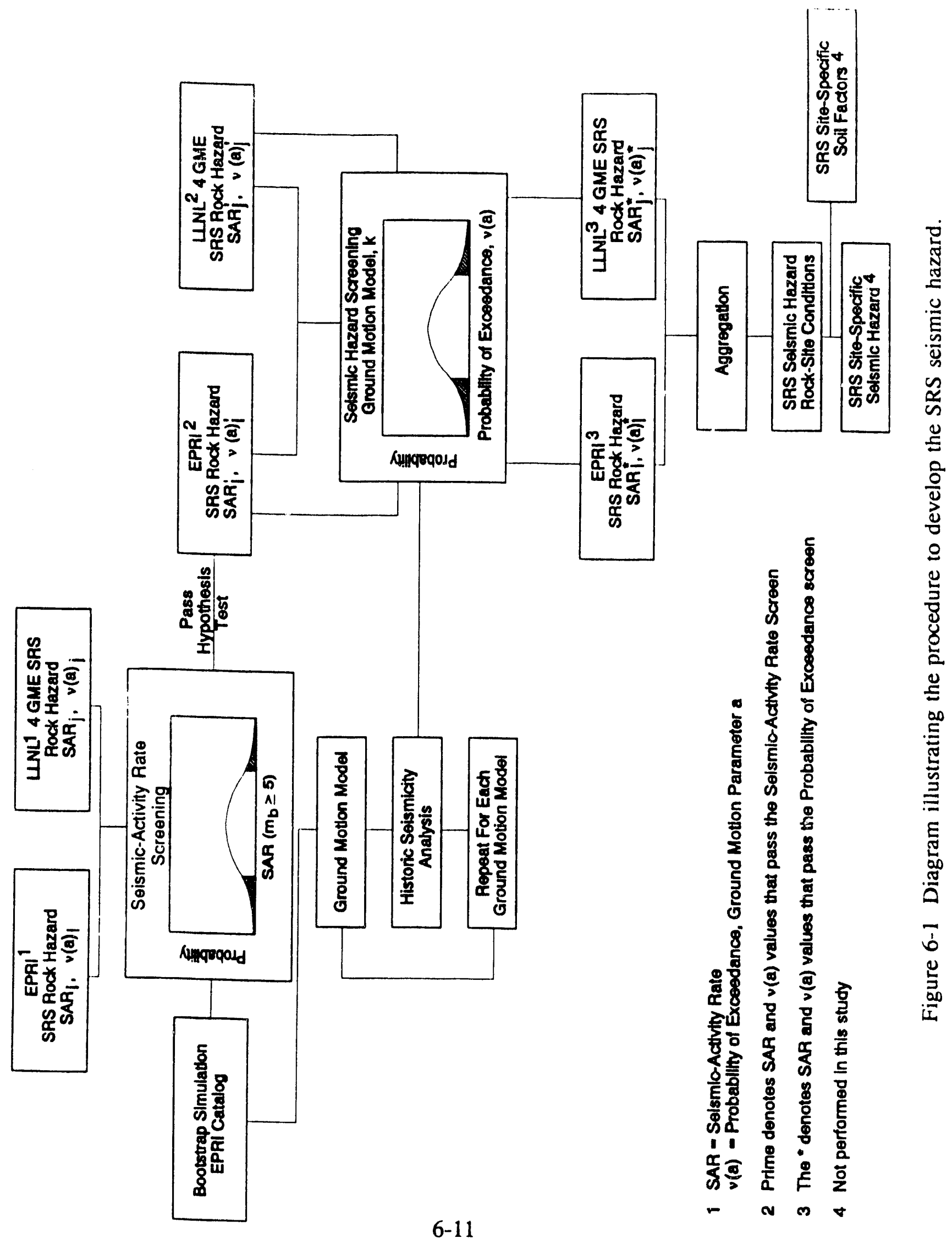




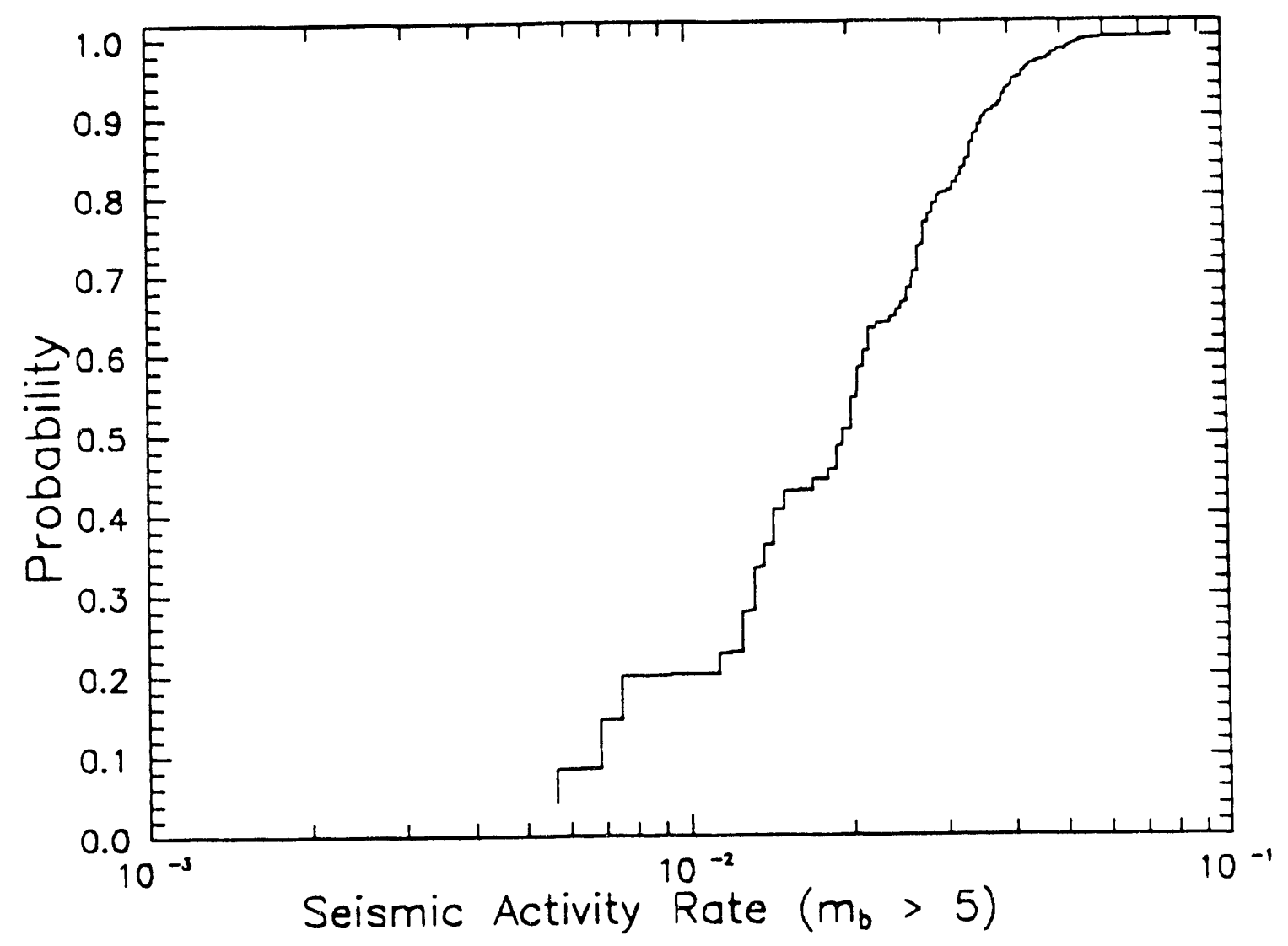

Figure 6-2 Non-parametric cumulative distribution function on the seismic-activity rate for the SRS region derived from the historic record. 


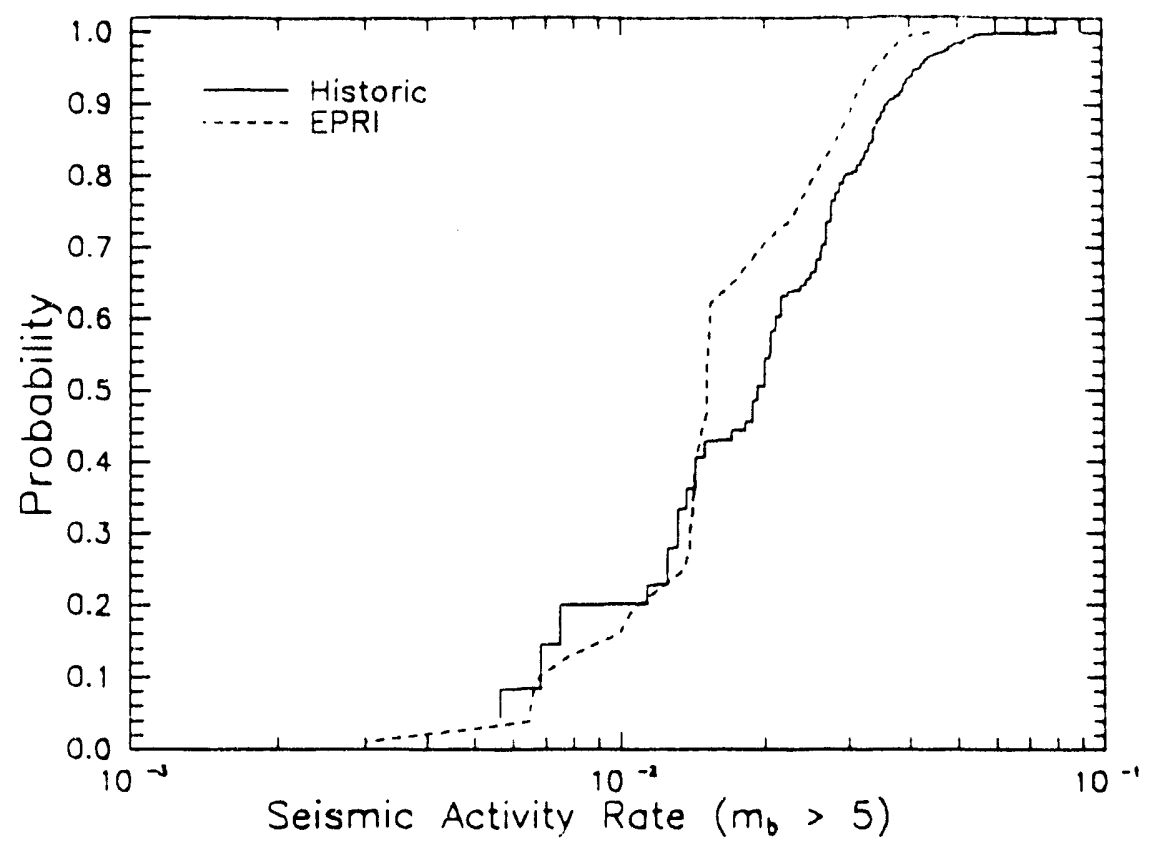

(a)

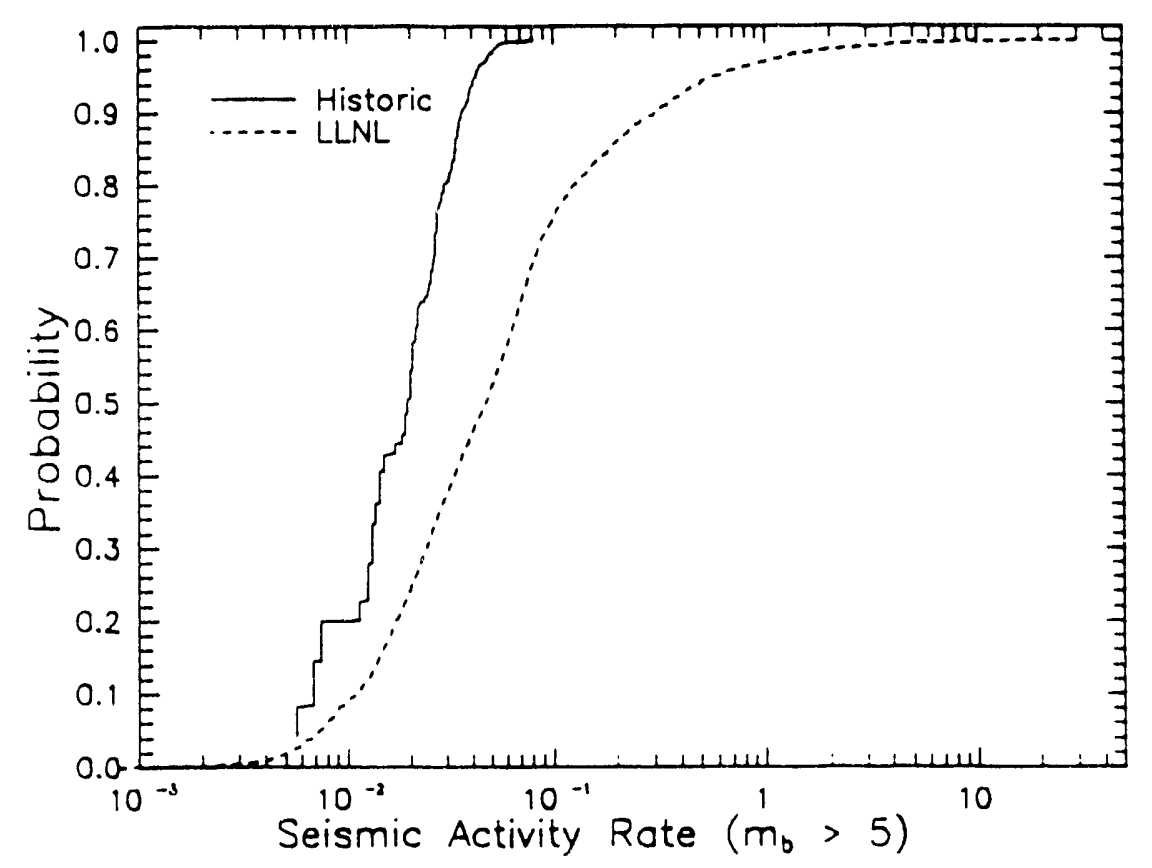

(b)

Figure 6-3 Comparison of the cumulative distribution function on the historic seismicactivity rate and the (a) EPRI and (b) LLNL results. 


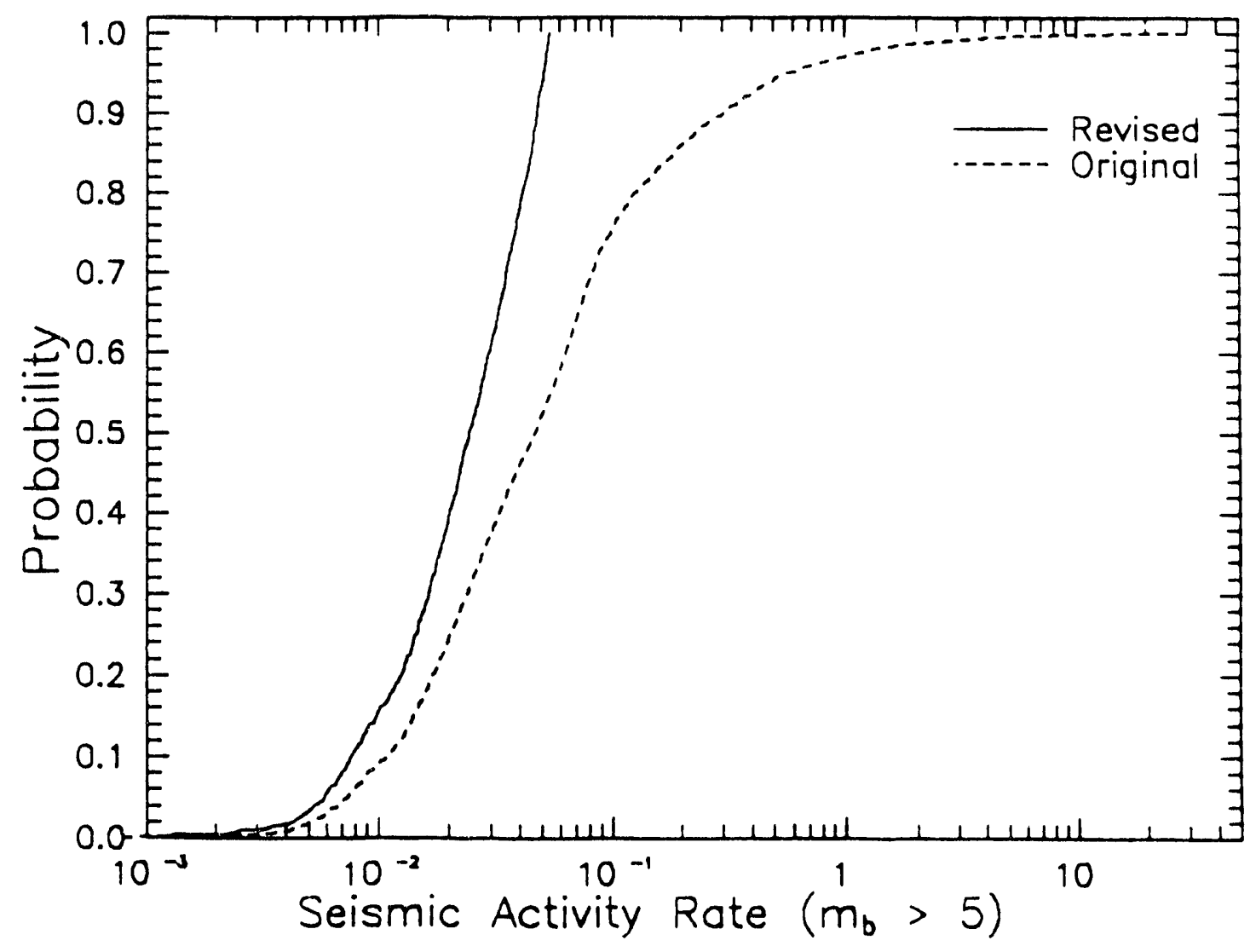

Figure 6-4 Comparison of the LLNL original and revised (after screening) distribution function on the seismic-activity rate. 


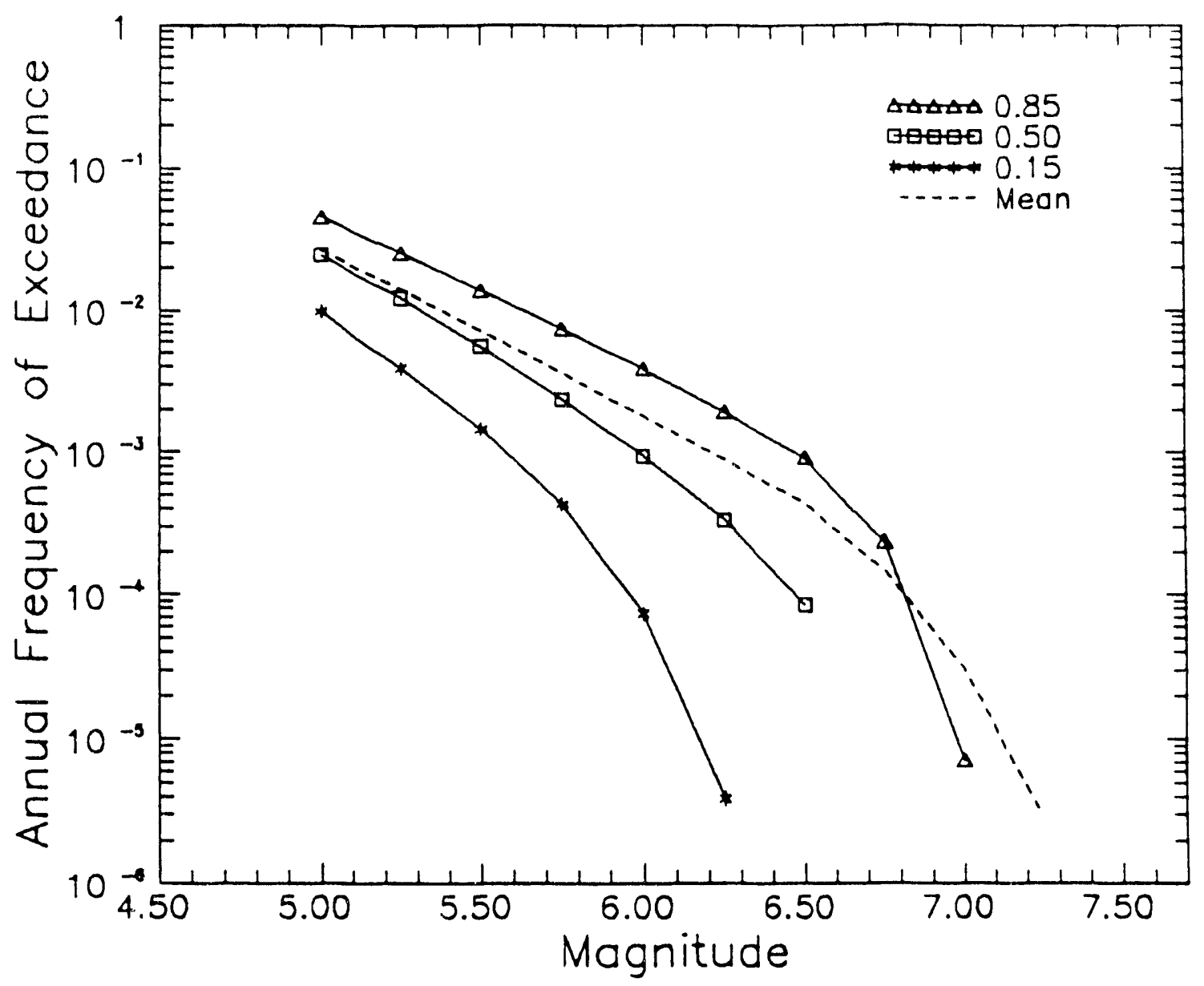

Figure 6-5. LLNL revised magnitude-frequency distribution. 


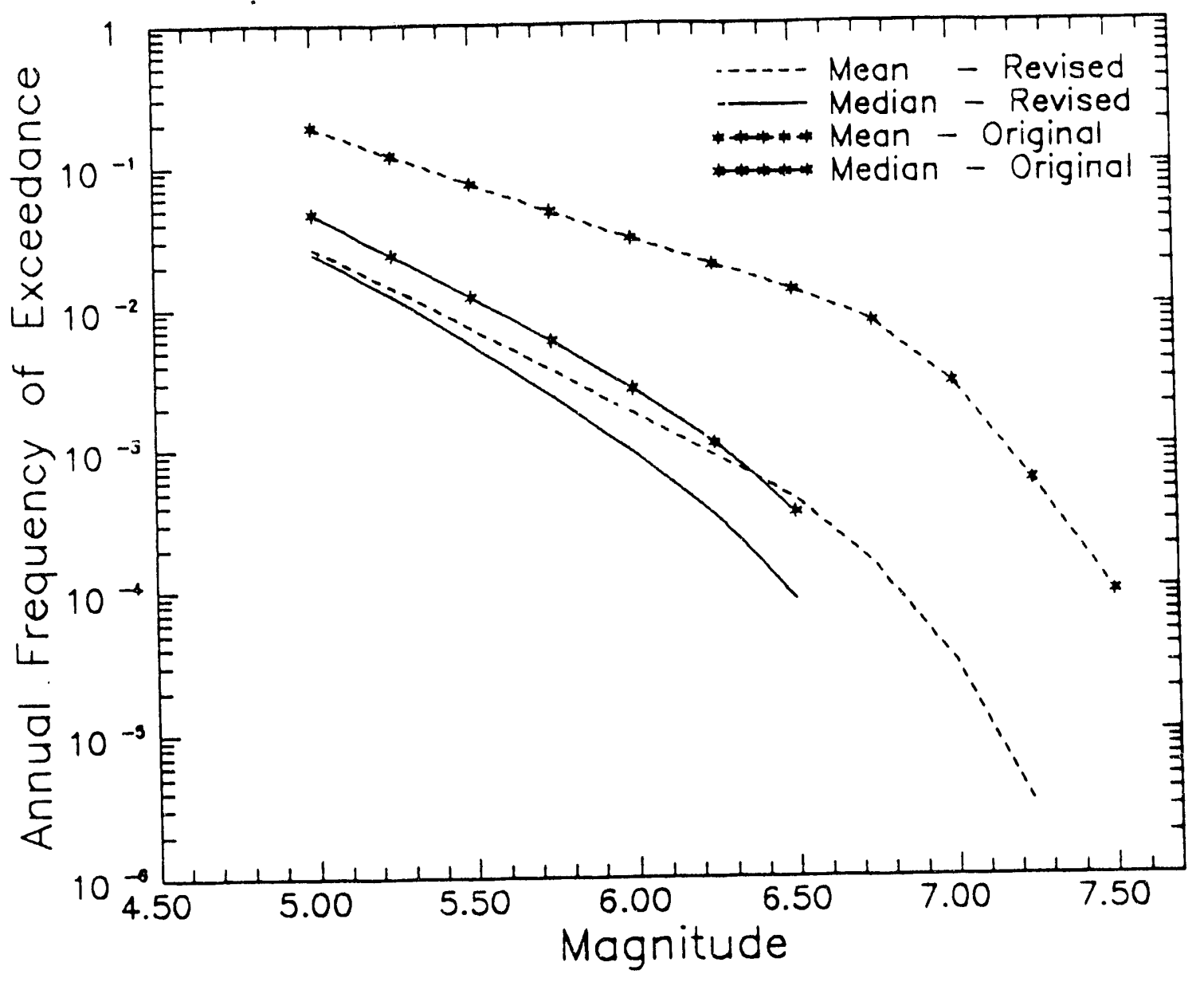

Figure 6-6 Comparison of the LLNL original and revised, median and mean magnitude-frequency curves. 


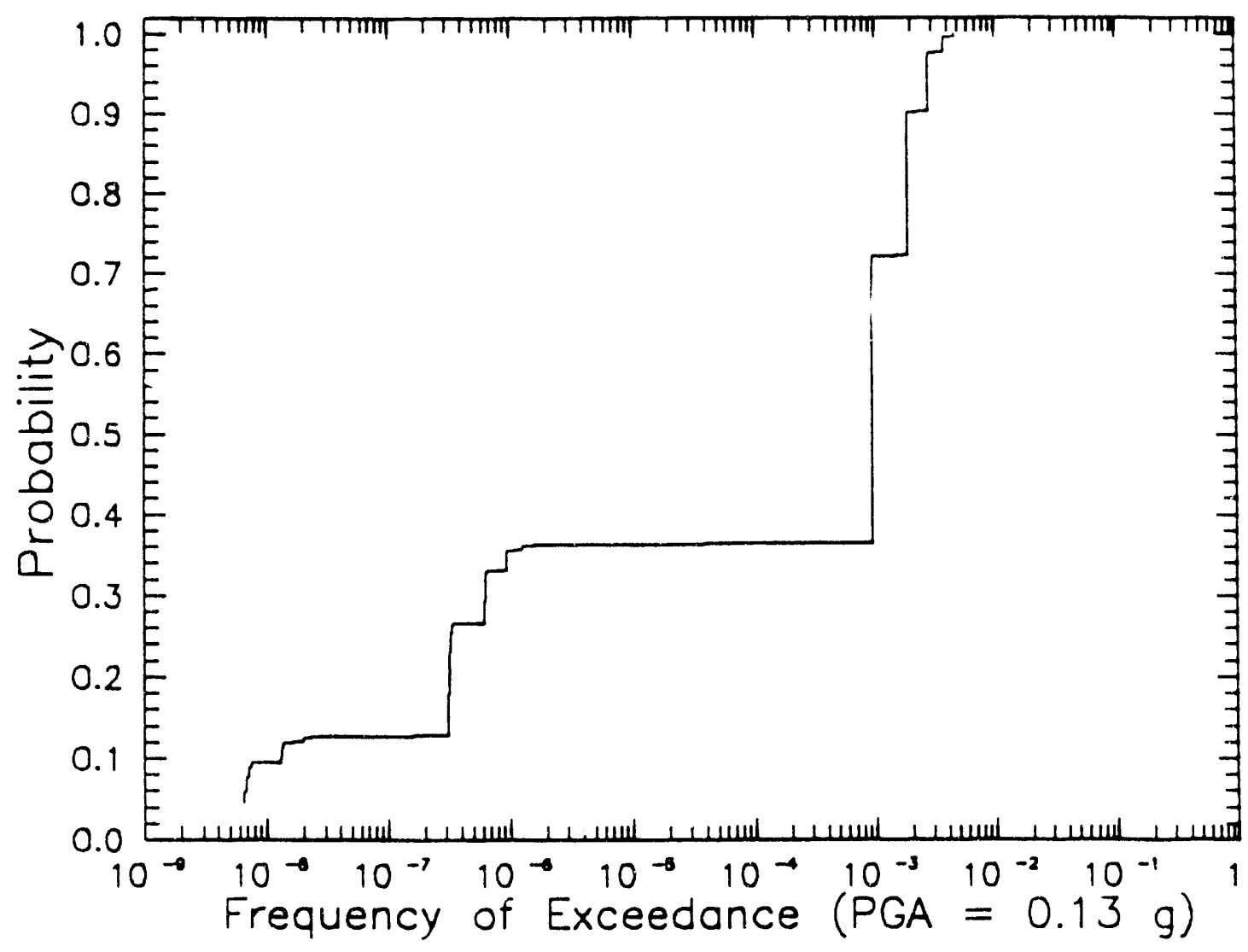

Figure 6-7 Historic cumulative distribution function on the probability of exceedance for the Nuttli attenuation model (LLNL model SEl) for PGA = $0.13 \mathrm{~g}$ for the SRS. 


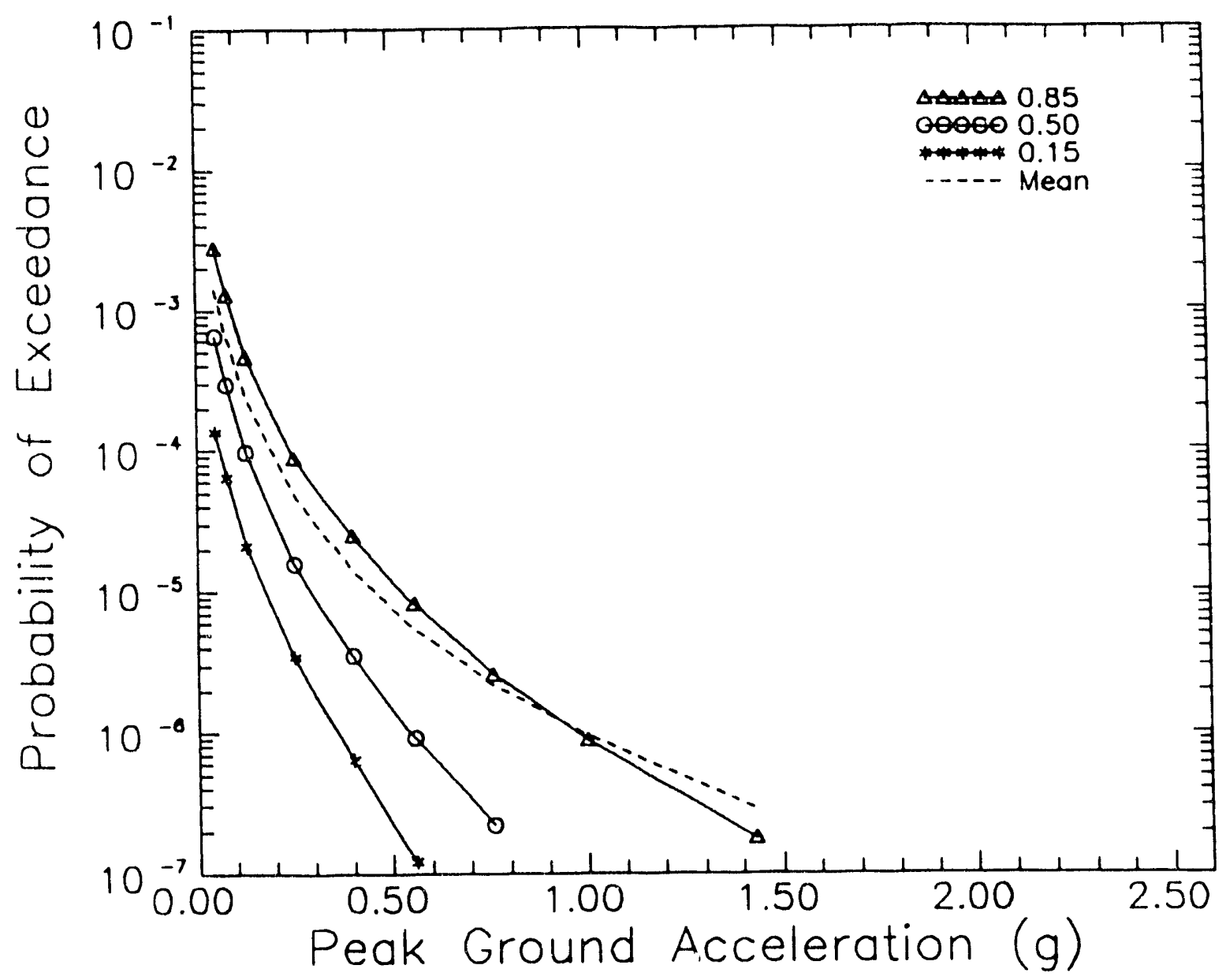

Figure 6-8 Resulting LLNL $0.15,0.50$ and 0.85 fractile and mean seismic hazard curves for PGA following the screening evaluation on the seismic-activity rate and probability of exceedance of $0.13 \mathrm{~g}$ PGA (rock-site conditions). 


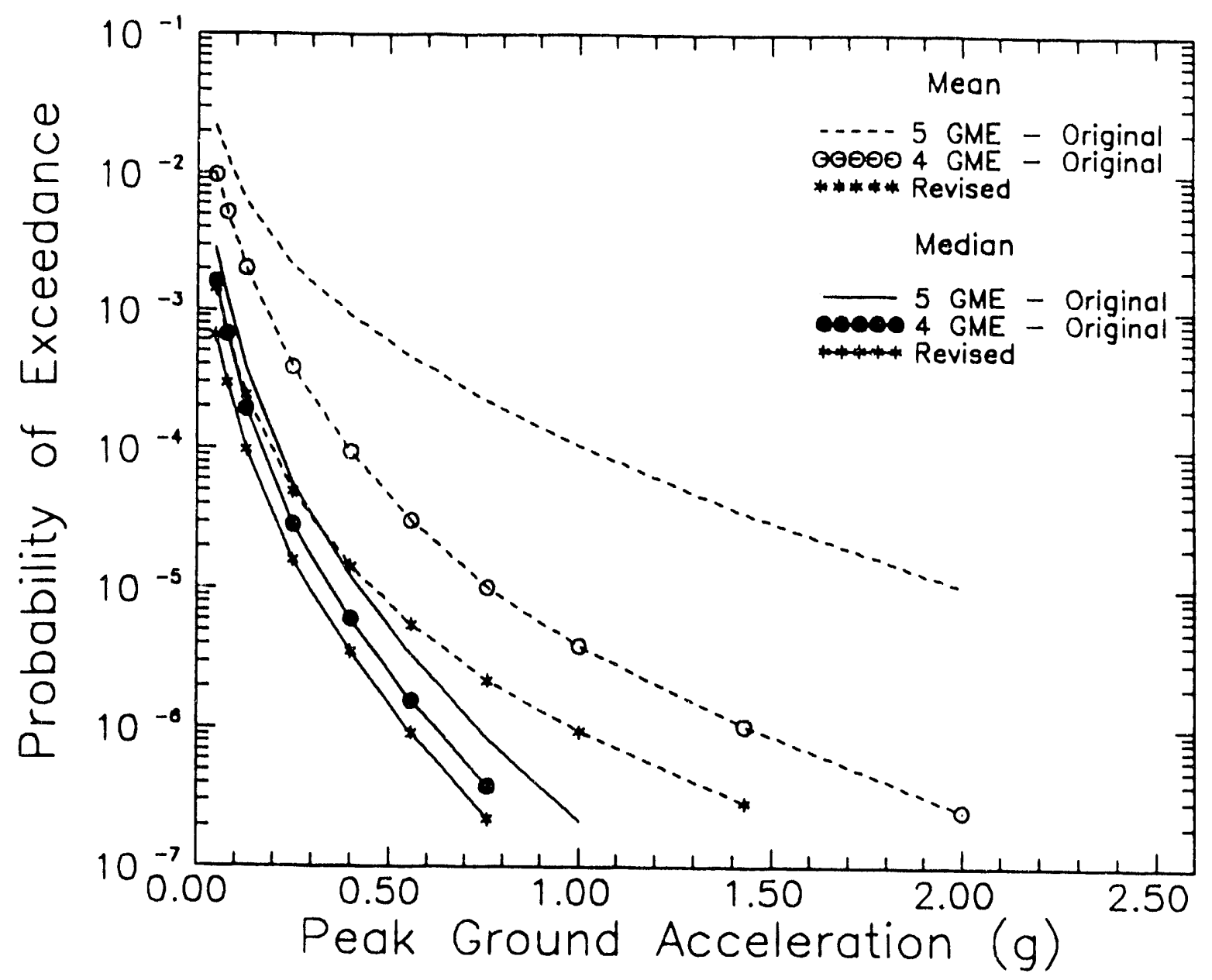

Figure 6-9 Comparison of the revised LLNL and original 4 and 5 GME case median and mean hazard curves for PGA (rock-site conditions). 


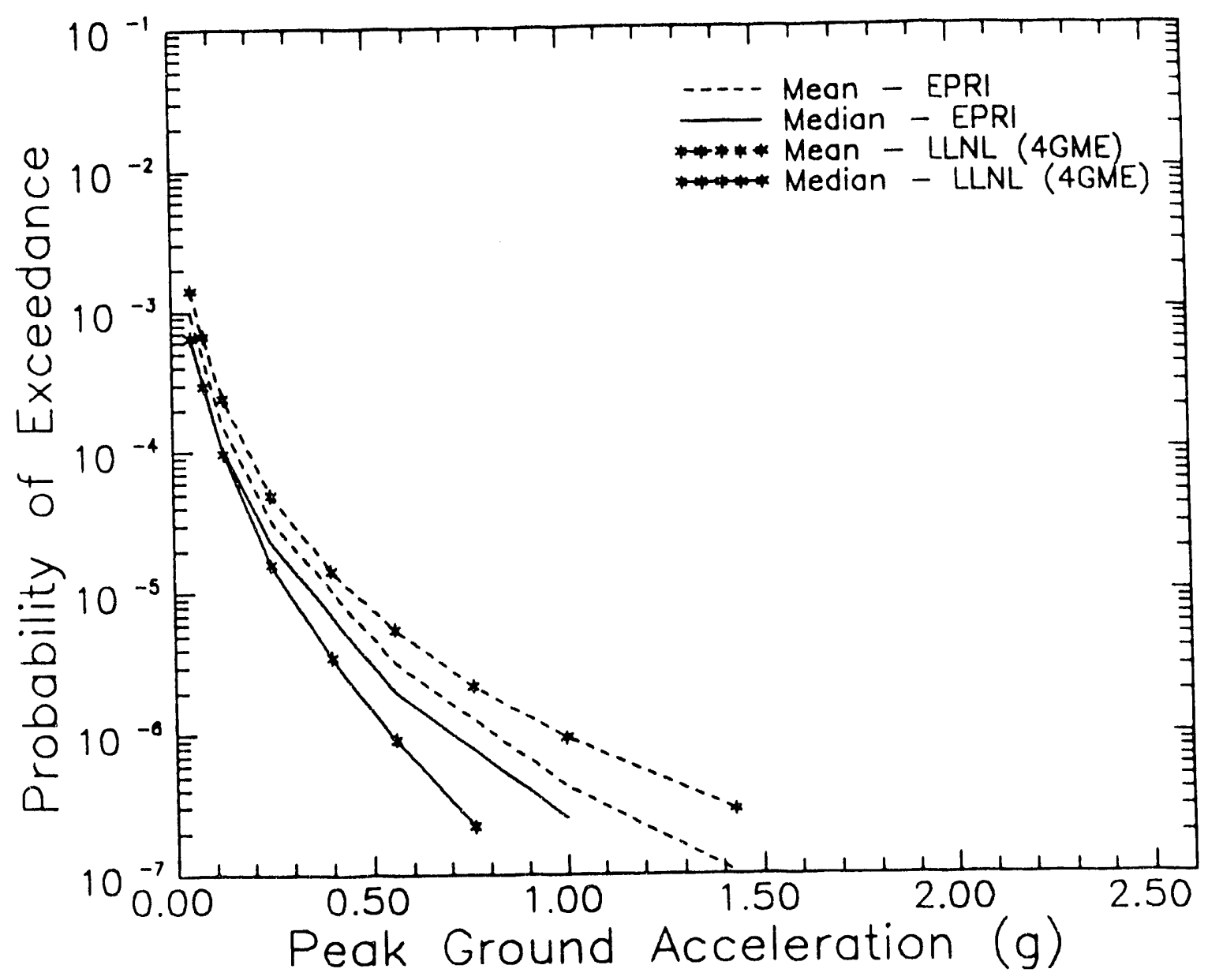

Figure 6-10 Comparison of the EPRI and the revised LLNL median and mean seismic hazard curves for PGA (rock-site conditions). 


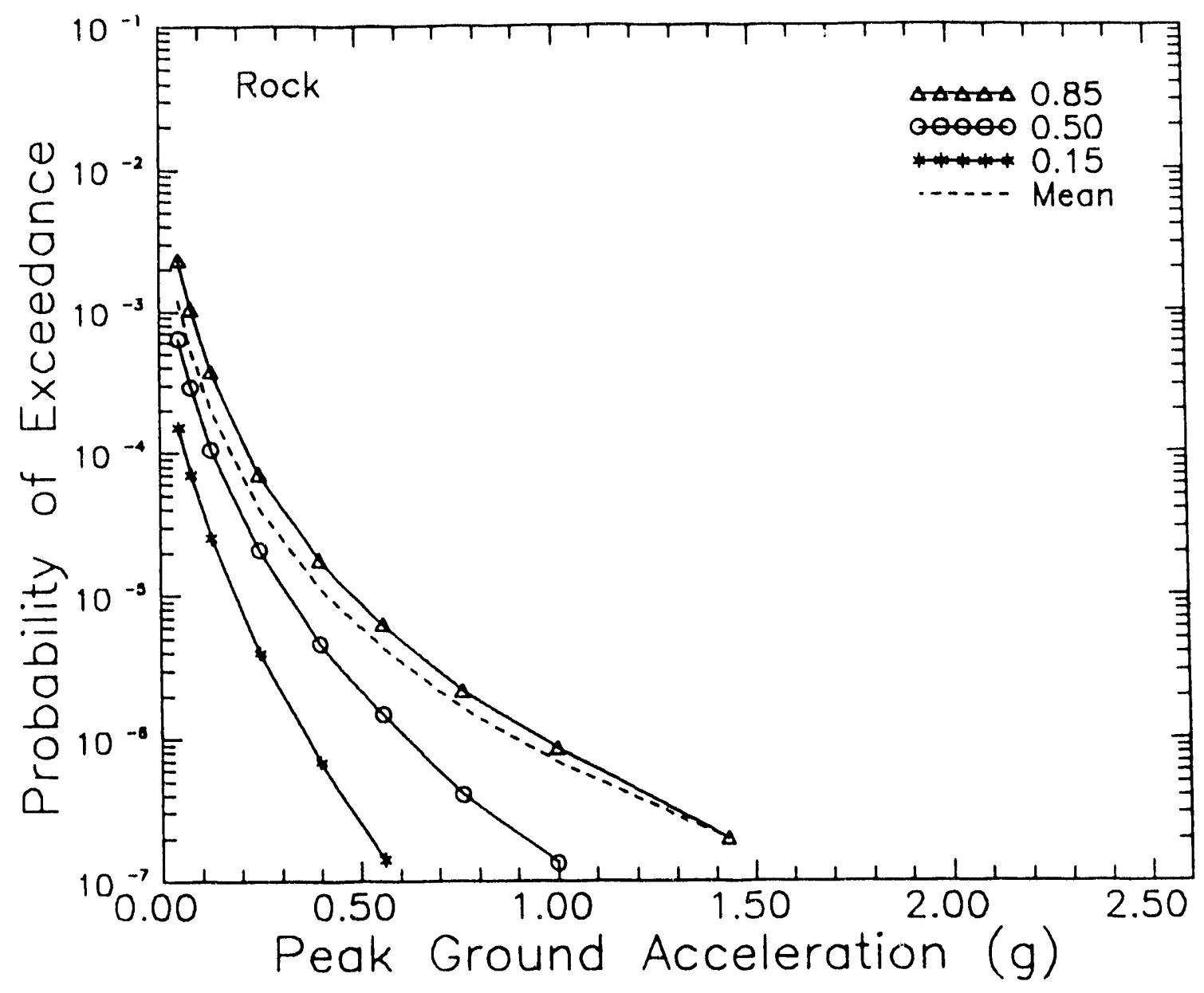

Figure 6-11 SRS PGA seismic hazard curves, rock-site conditions. 


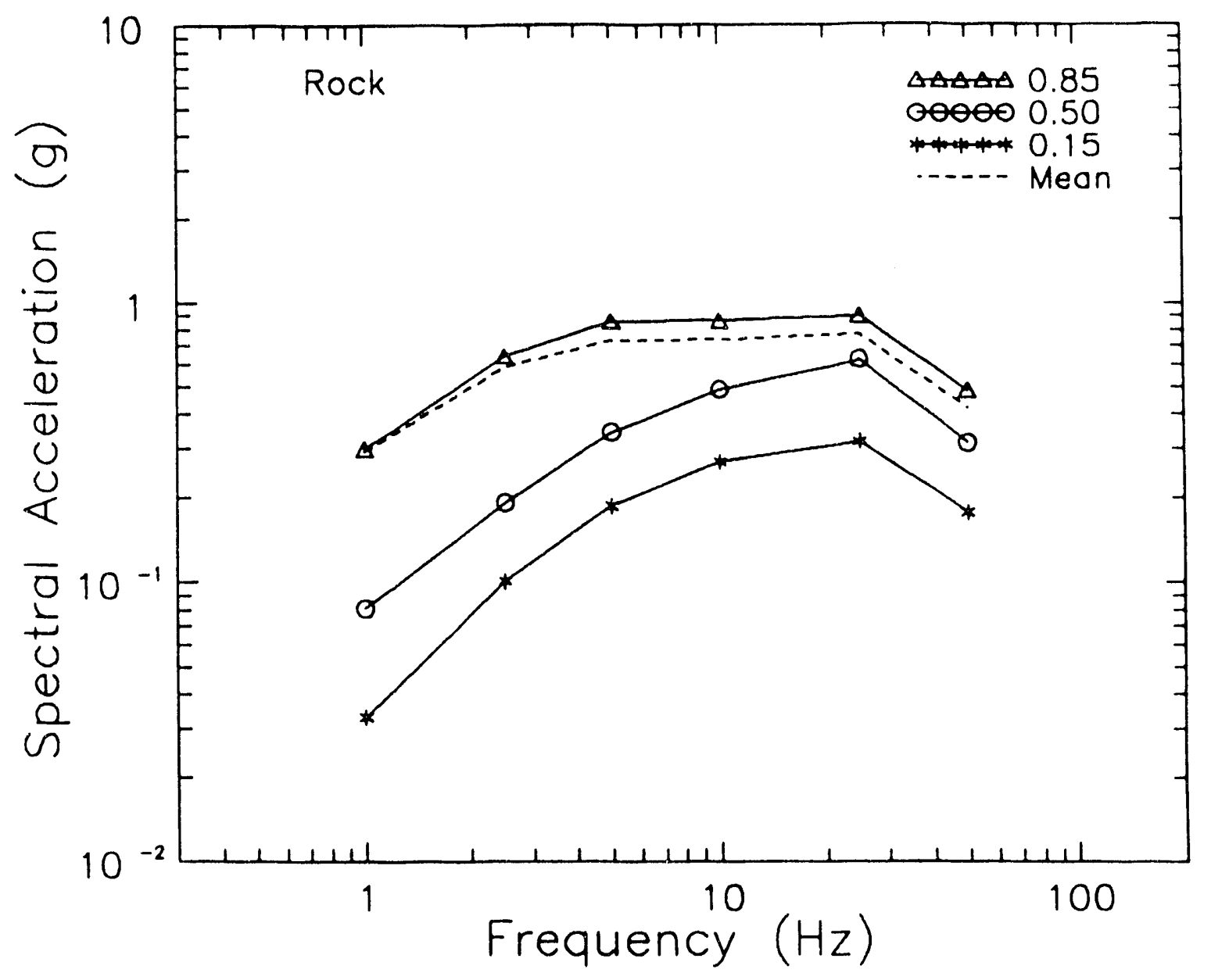

Figure 6-12 SRS $10^{-5}$ uniform hazard response spectra, rock-site conditions. 


\section{Section 7}

\section{CONCLUSIONS}

This report presents the results of a comparative evaluation of the EPRI and LLNL seismic hazard assessments for the SRS and a recommendation for the development of a single measure of the site hazard based on these studies. The final recommended SRS seismic hazard is based on a reconciliation of the ground motion models used in the two studies and elimination of extreme estimates of the SAR for events of $m_{b} \geq 5.0$ and extreme estimates of the probability of exceedance of ground motion.

The comparative evaluation of the SRS seismic hazard studies identified two major factors that contributed to the differences in the estimate of the probability of exceedance of ground motion. The first factor was the estimate of the SAR for earthquakes of magnitude 5.0 and greater in the vicinity of the SRS. Two important findings were made in the comparative evaluation of the EPRI and LLNL SARs: the mean SAR values in the two studies differed by approximately a factor of 10 and there were a number of extreme estimates of the SAR in the LLNL study that were inconsistent with the historic record.

The second contributor to the differences in the SRS seismic hazard were the ground motion models selected by LLNL GME 5 . The comparative evaluation of the ground motion models indicated that the group of models used in each study (EPRI and the LLNL 4 GME case), were comparable and produced similar estimates (to within a factor of 3) of the SRS mean hazard. However, the ground motion models selected by LLNL GME 5 represent an outlying assessment of attenuation in the EUS that was not assigned any credibility by the other LLNL GMEs or the EPRI study. In addition, the technical basis for the models selected by GME 5 was questioned, from the perspective of the data and the numerical

procedure that was used to derive them. Lastly, estimates of the probability of exceedance 
based on the LLNL GME 5 attenuation models are not consistent with the historic record at the SRS.

To determine the SRS seismic hazard, a procedure was recommended that addresses the primary factors that are a source of the differences in the two studies. The procedure is based on the idea that the SRS hazard should be consistent with (or not inconsistent with) the historic record and that it represent a consensus of the EPRI and LLNL studies. With this approach, it was recommended that extreme estimates of the SAR and probability of exceedance of ground motion that are not consistent with the historic record be rejected as credible estimates of the rate of earthquake occurrences in the region and that the ground motion models selected by LLNL GME 5 not be used in the assessment of the seismic hazard at the SRS.

The procedure to determine the SRS seismic hazard was applied and the hazard curves for rock-site conditions were determined. The assessment of the SRS seismic hazard, incorporating the effect of local-soil conditions, must be performed following the completion of the site-specific soils evaiuation. 


\section{Section 8}

\section{REFERENCES}

1. Electric Power Research Institute, "Seismic Hazard Methodology for the Central and Eastern United States," Vols. 1-11, NP-4726A, Palo Alto, CA 1988.

2. Bernreuter, D.L., J.B. Savy, R.W. Mensing, and J.C. Chen, "Seismic Hazard Characterization of 69 Plant Sites East of the Rocky Mountains," NUREG/CR-5250, UCID-21517, Prepared by Lawrence Livermore National Laboratory for the U.S. Nuclear Regulatory Commission, Washington, D.C. 1989.

3. Savy, J.B. "Seismic Hazard Characterization of the Savannah River Plant (SRP)," UCD-21596, Prepared by Lawrence Livermore National Laborator's for E.I. duPont de Nemours Company, November 1988.

4. Westinghouse Savannah River Company, "SRS PRA of Reactor Operation Level 1 External Events," WSRC-RP-89-733, Aiken, South Carolina, June 1990.

5. Devine, J., "Clarification of the USGS Position on the Seismic Potential of Certain Regions in the Eastern United States," U.S. Geological Survey letter to R. Jackson, U.S. Nuclear Regulatory Commission, November 1982.

6. Savy, J.B., Personal Communication with M.W. McCann, Jr., 1991

7. Bollinger, G.A., Davinson, F.C., Jr., Sibol, M.S., and Birch, J.B., "Magnitude Recurrence Relations for the Southeastern United States and its Subdivisions," Journal of Geophysical Research, Vol. 94, No. B3, p. 2857-2873, 1989.

8. Amick, D., et al., "Paleoliquefaction Features Along the Atlantic Seaboard," NUREG/CR-5613, Prepared by Ebasco Services Incorporated, Prepared for the U.S. Nuclear Regulatory Commission, Washington, D.C., October 1990.

9. Electric Power Research Institute, "Proceedings: Earthquake Ground-Motion Estimation in Eastern North America," NP-5857, Palo Alto, California, August, 1988. 
10. Toro, G.R. and R.K. McGuire. "An Investigation into Earthquake Ground Motion Characteristics in Eastem North America," Bulletin of the Seismological Society of America, Vol. 77, No. 2, pp. 468-489, April 1987.

11. Boore, D.M. and G.M. Atkinson. "Stochastic Prediction of Ground Motion and Spectral Response Parameters at Hard-Rock Sites in Eastern North America," Bulletin of the Seismological Society of America, Vol. 77, No. 2 , pp. 440-467, 1987.

12. Nuttli, O.W. Letter dated September 19, 1986 to J.B. Savy. Reproduced in: D.L. Bernreuter, J.B. Savy, R.W. Mensing, J.C. Chen, and B. Davis. "Seismic Hazard Characterization of 69 Nuclear Plant Sites East of the Rocky Mountains: Questionnaires," NUREG/CR-5250, UCID-21517, prepared by the Lawrence Livermore National Laboratory for the U.S. Nuclear Regulatory Commission, Volume 7, 1989.

13. Newmark, N.M. and W.J. Hall. Earthquake Spectra and Design. Earthquake Engineering Research Institute, Berkeley, CA, 1982.

14. Gupta, I.N., and Nuttli, O.W., "Spatial Attenuation of Intensities for Central U.S.," Bulletin of the Seismological Society of America, Vol. 66, pp. 743-751, 1976.

15. Trifunac, M.D., "A Note on the Range of Peak Amplitudes of Recorded Accelerations, Velocities and Displacements with Respect to the Modified Mercalli Intensity," Earthquake Notes 47, p. 9-24, 1976.

16. Veneziano, D., "The Use of Intensity Data In Ground Motion Estimation," Proceedings," Workshop on Estimation of Ground Motion in the Eastern United States," EPRI Report NP-5875, Electric Power Research Institute, Palo Alto, California, 1987.

17. Trifunac, M.D. and V.W. Lee. "Frequency-Dependent Attenuation of Strong Earthquake Ground Motion," Technical Report 86-02, University of Southern Califomia, Department of Civil Engineering, 1986.

18. U.S. Nuclear Regulatory Commission, "Procedural and Submittal Guidance for the Individual Plant Examination of External Events (IPEEE) for Severe Accident Vulnerabilities," Office of Nuclear Regulatory Research, Washington, D.C., 1991. 
19. Cornell C.A., H. Banon, and A.F. Shakal. "Seismic Motion and Response Prediction Alternatives," Earthquake Engineering and Structural Dynamics, Vol. 7, pp. 295-315, 1979.

20. Veneziano, D. and M. Heidari, "Statistical Analysis of Attenuation in the Eastern United States," In, "Methods for Estimating Ground-Motion Prediction for the Eastern United States," EPRI Project RP2556-16, Electric Power Research Institute, Palo Alto, California, 1986.

21. Veneziano, D., Letter dated December 24, 1986 to D.L. Bernreuter. In, Bernreuter D.L., J.B. Savy, R.W. Mensing, and J.C. Chen, "Seismic Hazard Characterization of 69 Plant Sites East of the Rocky Mountains," NUREG/CR-5250, UCID-21517, Prepared by Lawrence Livermore National Laboratory for the U.S. Nuclear Regulatory Commission, Washington, D.C. 1989.

22. Risk Engineering, Inc. "Assessment of the 1988 Saguenay Earthquake-Implications On Attenuation Functions For Seismic Hazard Analysis," Revised Draft Report, Prepared for Pickard, Lowe and Garrick, Inc., 1991.

23. Efron, B., "The Jackknife, the Bootstrap and Other Resampling Plans," Society for Industrial and Applied Mathematics, Philadelphia, Pennsylvania, 1982.

24. Veneziano, D., C.A. Cornell, and T. O'Hara, "Historical Method of Seismic Hazard Analysis," Electric Power Research Institute, Palo Alto, California, NP3438, 1984. 
Distribution List

EXTERNAL

1) David Ward, North Augusta

2) Herbert Kouts, Brookhaven National Laboratory

3) Carl J. Constantino, Brookhaven National Laboratory

4) Carl Fleming, Pickard Lowe \& Garrick, Inc

5) John D. Stevenson, Stevenson \& Associates, Inc., 9217 Midwest Ave, Cleveland, Ohio

6) Blake Putney, SAIC, Palo Alto

7) DNFSB, Washington, D. C.

8) Jim Holderness, SAIC

9) Goutam Bagghi , NRC

10) Bob Rothman, NRC

11) Andrew Murphy, NRC

12) R. J. Budnitz, --Future Resources Inc.

13) M. P. Bohn, Sandia National Laboratory

14) Kevin J. Coppersmith, Geomatrix Corp, One Market Plaza, Spear Street Tower, Suite 717, San Francisco, Calif. 94105

15) Dr. Pardeep Talwani, University of South Carolina, Columbia

16) Dr. Gil Bollinger, University of Virginia

17) Dr. Joe Fletcher, USGS, Denver Col

18) Dr. Zoback, Stanford University, Calif 
19) Dr. Allin Comell, Stanford University, ('alif

20) Peter Davis, Senior Review Panel

21) Harry Reilly, INEL,

22) David Okrent, Senior Review Panel

23) Jeff Kimball, US DOE DP-621

24) Maurice Pitts, US DOE DP-621

25) Jim Hill , U. S. DOE

26) Kamiar Jamali, U S. DOE

27) Martin McCann, Jack R. Benjamin \& Assoc

28) George Flanagan, Martin Marietta, Oak Ridge, Tenn

29) James Beavers, Martin Marietta, Oak Ridge, Tenn.

30) Thomas Matteson, Senior Review panel

31) Norman Rasmussen, Senior Review Panel

32) Elmer Schwartz, University of South Carolina

33) Ken Varick, Westinghouse Energy Center

34) Mike Zentner, Westinghouse Hanford Company

35) Jean Savy, Lawrence Livermore National Laboratory

36) D. L. Bernreuter, Lawrence Livermore National Laboratory

37) Bob Murray, Lawrence Livermore National Laboratory

38) Carl Stepp, Electric Power Research Institute 


\section{INTERNAL}

39) Fred Beranek, 707-C

40) Tam Tran, DOE SRS

41) M. W. Barlow, 707-49B

42) M. E. Maryak, 703-25C

43) W. N. Kennedy, 707-49B

44) G. A. Antaki, 707-35B

45) T. H. Monahon, 707-C

46) D. E. Stephenson, 735-11A

47) Richard Lee, 735-11A

48) M. J. Hitchler, $992 \mathrm{~W}-1$

49) D. A. Sharp, 992W-1

50) K. R. O’Kula, 992W-1

51) H. Elwyn Wingo, 992W-1

52) PRA Risk Assessment File

53) SRL Records 

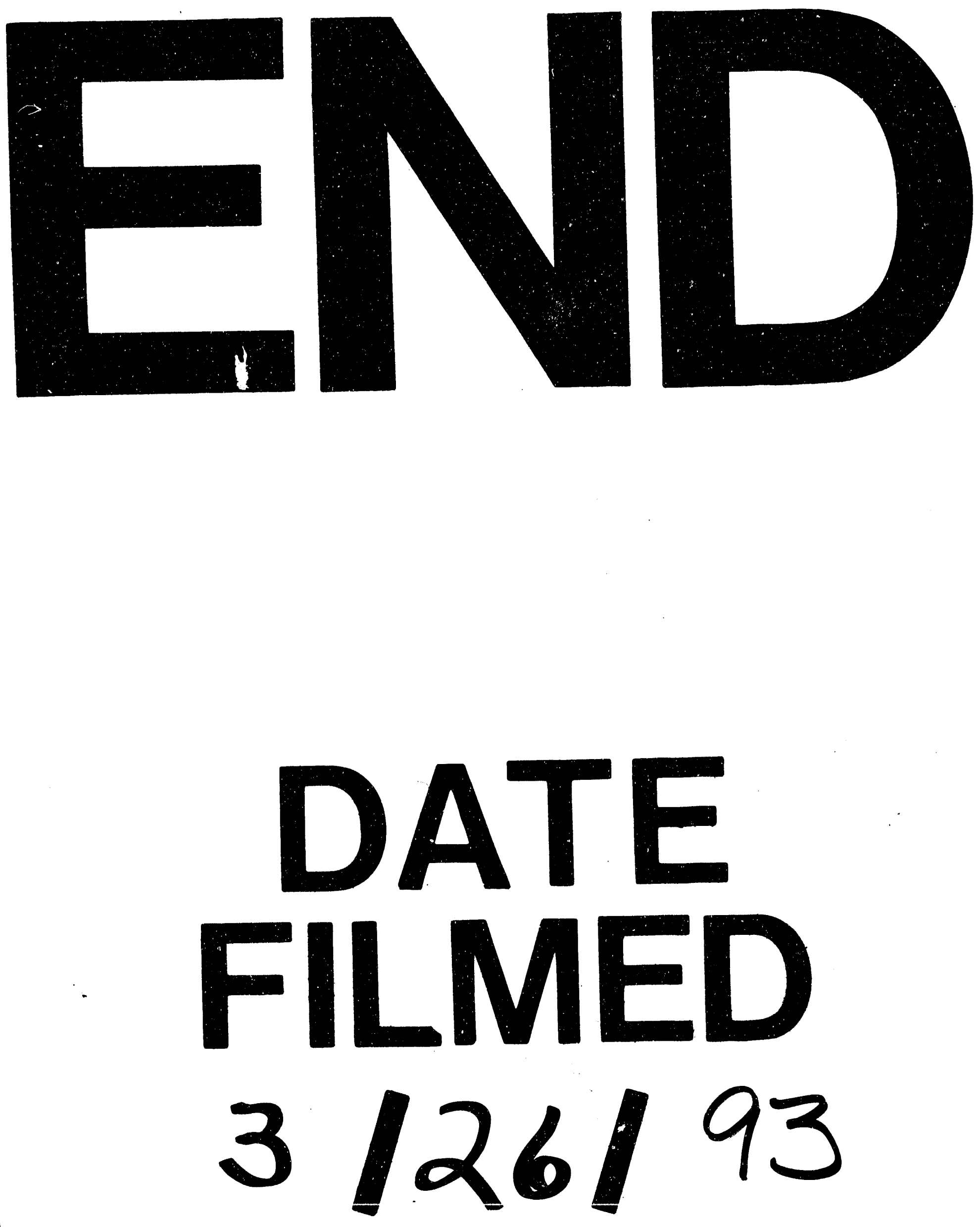

I 
